University of Louisville ThinkIR: The University of Louisville's Institutional Repository

Electronic Theses and Dissertations

$5-2016$

\title{
To my betas, endless chocolate frogs! : exploring the intersections of emotion, the body, and literacy in online fanfiction.
}

Brittany Kelley

University of Louisville

Follow this and additional works at: https://ir.library.louisville.edu/etd

Part of the Rhetoric and Composition Commons

\section{Recommended Citation}

Kelley, Brittany, "To my betas, endless chocolate frogs! : exploring the intersections of emotion, the body, and literacy in online fanfiction." (2016). Electronic Theses and Dissertations. Paper 2474.

https://doi.org/10.18297/etd/2474

This Doctoral Dissertation is brought to you for free and open access by ThinkIR: The University of Louisville's Institutional Repository. It has been accepted for inclusion in Electronic Theses and Dissertations by an authorized administrator of ThinkIR: The University of Louisville's Institutional Repository. This title appears here courtesy of the author, who has retained all other copyrights. For more information, please contact

thinkir@louisville.edu. 
TO MY BETAS, ENDLESS CHOCOLATE FROGS!: EXPLORING THE

INTERSECTIONS OF EMOTION, THE BODY, AND LITERACY IN ONLINE

FANFICTION

By

Brittany Kelley

B.A., Boston University, 2008

M.A., University of New Mexico, 2011

\begin{abstract}
A Dissertation
Submitted to the Faculty of the

College of Arts and Sciences of the University of Louisville

in Partial Fulfillment of the Requirements

for the Degree of
\end{abstract}

Doctor of Philosophy

in English/Rhetoric and Composition

Department of English

University of Louisville

Louisville, KY

May 2016 

TO MY BETAS, ENDLESS CHOCOLATE FROGS!: EXPLORING THE INTERSECTIONS OF EMOTION, THE BODY, AND LITERACY IN ONLINE FANFICTION

\author{
By \\ Brittany Kelley \\ B.A., Boston University, 2008 \\ M.A., University of New Mexico, 2011 \\ A Dissertation Approved on \\ December 11, 2015 \\ by the following Dissertation Committee:
}

Bronwyn T. Williams, Director

Mary P. Sheridan

Karen Kopelson

Susan Ryan

Dawn Heinecken 


\section{DEDICATION}

This dissertation is dedicated first to my parents

Pamela and Murray Kelley

because of their fierce belief in the importance of education, and their unflagging confidence in my abilities

and to my sister

Emma Kelley

because she never fails to remind me of the kind of world I want to live in - where women are always proud of who they are and what they can do. 


\section{ACKNOWLEDGEMENTS}

I would like to thank my director, advisor, and friend, Bronwyn T. Williams, for so generously welcoming me into the program at the University of Louisville, and for all of the guidance, comments, and patience throughout my five years here, and certainly during my dissertation. I would also like to thank Mary P. Sheridan for her unflagging enthusiasm in my project, as well as her astute comments on my theories and methods. I thank my committee members Karen Kopelson and Susan Ryan for their thoughtful and astute comments on my ideas and my writing over these past couple of years. And I would like to thank my committee member, Dawn Heinecken, not only for introducing me to fan studies and Slayage, but for her support as I first began a version of this project in her Gender and Sci Fi course. Finally, I'd like to thank my colleagues, comrades, and friends, Stephanie Weaver, Benjamin Wetherbee, Kathryn Perry, and Jessica Winck for their years of positive feedback, intellectual stimulation, and constant support. 


\begin{abstract}
TO MY BETAS, ENDLESS CHOCOLATE FROGS!: EXPLORING THE INTERSECTIONS OF EMOTION, THE BODY, AND LITERACY IN ONLINE FANFICTION Brittany Kelley
\end{abstract}

May 14, 2016

My dissertation, To My Betas, Endless Chocolate Frogs!: Exploring the Intersections of Emotion, the Body, and Literacy in Online Fanfiction, examines the complex intersections of identity, including gender, sexuality, and social class, in the literacy practices of online fanfiction. Previous scholarship has focused solely on the gender and/or pedagogical implications of fanfiction communities, and my project engages and extends these conversations by analyzing how fanfiction practices provide a distinctive space to explore how we understand identity, digital technologies, and fannish participation. I conducted textual analysis of stories, authors' notes, "how-to" guides, and questionnaires and interviews. A close inspection of fanfiction practices provide insight into how digital technologies and literacy practices interact within exchange economies.

My dissertation is divided into five chapters. Chapters 1 and 2 include a review of the literature as well as a theoretical approach to the project and its methods. Chapters 3 and 4 address the functions of online fanfiction by looking at fan websites, fan stories, and how-to fan documents, as well as questionnaires and interviews. Finally, Chapter 5 develops a theory of online fanfiction literacy practices, and the ways in which these 
practices are shaped by power structures, identity construction, community norms, and material circumstances. I focus, in particular, on developing a theory of emotion in terms of literacy practices_-what I come to call “emotioned literacy” (borrowing from Micciche).

The investigation of online fanfiction spaces is especially valuable for rhetoric and composition because it highlights how writing is a deeply embodied and emotional, life-long (learning) process. In addition, this project highlights the importance of a network of dedicated participants with knowledge(s) in different areas. Finally, this project highlights the importance of paying closer attention to the ethics of our online research methodologies. 


\section{TABLE OF CONTENTS}

ACKNOWLEDGMENTS ...........................................................

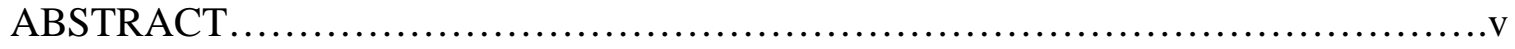

INTRODUCTION: Coming to Fandom and Why Fanfiction Really Matters.............1

CHAPTER1: Intersectionality in Fanfiction Practices: A Review of the Literature......12

CHAPTER 2: Never "Power sans Risk": Towards a Goodwill Ethics of Online Research

Methods.........................................................60

CHAPTER 3: The Emotion Economies of Online Fanfiction........................101

CHAPTER 4: Response, Originality, and Expression: Three Case Studies of Fanwriter

Realities.......................................................... 162

CHAPTER 5: Towards Emotioned Literacy Practices............................212

CONCLUSION: Let's Bring Emotion Back....................................248

REFERENCES.........................................................258

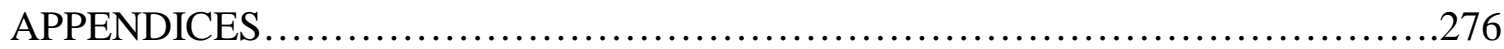

Appendix I: The Participants and Methods of Gathering Data................276

Appendix II: The Questionnaire......................................280

Appendix III: The Interview.......................................285

CURRICULUM VITA....................................................286 


\section{INTRODUCTION}

\section{COMING TO FANDOM AND WHY FANFICTION REALLY MATTERS}

It was the fall of 2007. The seventh and last Harry Potter installment had come out that summer, along with the fifth film, and I was a senior in college. I was feeling bored, bereft, and underwhelmed by my choice of major (Linguistics). I really needed a moment to re-evaluate. So, of course, I lay on my little college cot in my closet-sized room in my Easy-Live apartment [TM], and I searched the internet for anything and everything Harry Potter-related. It was then that I discovered my first fanfic. In it, Ron and Harry share an undying (and undeniably steamy) romance, while Hermione ever so magnanimously does everything she can to protect their love. I remember neither the title nor the author's penname- only that four months, hundreds of “shipper” fics, and countless hours later, I started my own fanfic_-a romance featuring Severus Snape, a young woman fighting a revolution, and a Time Turner. My colleague in the mail roomwe'll call her D—was gracious enough to be enthusiastic about my story. It's still incomplete, and I doubt I'll ever return to it.

Flash forward 3.5 years. I’ve just moved to Louisville, Kentucky and started a PhD program. My grandmother had recently loaned me a "fabulous book!” that turned out to be a romance novel—Sara Donati's Into the Wilderness. In it, a textual version of Daniel Day Lewis (from Last of the Mohicans) seduces a school teacher almost turned old maid. Sexual explicitness and intrigue ensue. I am embarrassed to say that I read the entire 876-page tome in one week. My grandmother had pointed me, especially, to the 
author information page: "Sara Donati lives with her husband and daughter in the Pacific Northwest, where she teaches creative writing and linguistics at the university level." That's me someday, apparently. But, what does any of this have to do with anything? When I stumbled upon that online novella celebrating Ron and Harry's deep affection for each other, I entered into a different kind of space than I had experienced before. Something different from but similar to Into the Wilderness (even if Daniel Day Lewis does seem eerily present in the text). Something different from but similar to that report I wrote on Japanese Phonetics my junior year (after completing my own primary research — transcribing even four hours of audio is a truly unique experience) and to that other report I wrote the same year on college-age, English-speaking learners of French (a particularly ineffective pilot study I stumbled my way through). Something entirely different from but similar to asking students to do group work on Tuesday afternoon is definitely happening. Maybe. There is text, yes. This text is based in a shared body of semiotic resources (and system of knowing/knowledge), yes. But, more so, these writers are involved in some sort of affective exchange. Their texts are multivoiced because of their editing practices (which are almost exclusively collaborative). It certainly was a turning point for me in terms of the path I would choose in life. It reinvigorated my somewhat "lost" love of writing — of craft. It inspired me to find a new direction outside of the field of Linguistics. It reminded me of all of those years of storytelling that I had somehow lost sight of. And, the more that I investigated the complex, sophisticated, and deeply political economies of fanfiction practices, the more I saw similar stories of rediscovering self-expression, rediscovering joy in storytelling, and rediscovering a 
dedication to craft. In short, I found vibrant writing communities where the relationships among writers and readers are just as important as the writing itself.

My dissertation, To My Betas, Endless Chocolate Frogs!: Exploring the Intersections of Emotion, the Body, and Literacy in Online Fanfiction, has been a real labor of love. In that final year of my undergraduate program, I found a writing community—the first real writing community I had ever encountered—that left me feeling refreshed, excited, and invigorated. It made me want to write. And even after I submitted my first chapter to Sycophant Hex in February 2008, only to have it rejected the very next day because of a slew of punctuation errors (I had forgotten all about punctuating dialogue, it seems), I was still determined to continue. I felt more determined to post this "silly" little fanfic than I had in the past year about all of my linguistics courses combined. There was something about this writing space that was special, and this only became more and more obvious the more I learned about rhetoric and composition, and literacy studies, and teaching. I knew I had to go back into this space and explore what made it so special, so magical to me in my senior year of college. I had to share this magic with my colleagues and my students if I could. So that's really where this project started. It started from love, and continued with love as I developed my research questions, my research methods, and my analytical frames.

Fanfiction is by no means a new practice. Its magic has intrigued writers and academics for decades now, starting with the work of Constance Penley, Henry Jenkins, and Camille Bacon-Smith. They too were fans who wanted to share the magic of fan practices with colleagues and students. With everyone who hadn't had the pleasure, really. They argued that fan activities were worth academic study. That these activities 
were sophisticated, resistive, and deeply important to the fans and even to popular culture at large. Since these studies, which were conducted in the mid to late-1980s and published in the early 1990s, fan studies has become a substantial field of study, and it has explored fandom from a range of perspectives, from fandom as a cultural practice, to fandom as sets of literacy practices, to the ways in which fandom might be used in the classroom. While the word "fan" may still technically be a shortened version of the word "fanatic," in academia fandom is coming to be seen as legitimate—in terms of personal and community growth, in terms of emotional engagement, and in terms of the potential for transformative effects. For me, "fan" has always been a positive word, and fandom has always been a safe space to explore and expand my sense of self, not to mention my writerly craft. And as I will come to discuss later, it is these elements of fandom that most fans focus on when they discuss their experiences.

My project examines the intersections of identity, including gender, sexuality, and social class, in the literacy practices of online fanfiction. Previous scholarship has focused only on gender and/or the pedagogical implications of fanfiction communities. My project extends these conversations by analyzing fanfiction practices as distinctive spaces for understanding identity, digital technologies, and fannish participation. My analysis demonstrates the ways in which identity features are coded and performed into readings of both source texts and fan texts. For example, while some fanwriters try to undermine binary genders by writing a female "Harriet” Potter, they often still rely upon these same binaries in their performance of Harry as a woman. Furthermore, fanfiction practices provide insight into how digital technologies and literacy practices interact within exchange economies, which include the relationships among the capitalist market, 
material conditions, and circulation of stories and friendship. Investigating these kinds of online spaces highlights quite a bit about how learning and writing function in our lives.

Since Shirley Brice Heath zoomed back and forth among her teaching duties and two working class communities in de-segregation era North Carolina, literacy and education scholars have sought to understand how it is that we learn and practice literacy. Heath's study (Ways with Words) showed that upbringing and community interact with schooling, which interacts with income and material circumstances (at least). Those whose community values and material resources fall more in line with dominant expectations will encounter more success in dominant-leaning school systems. Since then, literacy studies has exploded, showing that reading and writing is always shaped by and shaping culture, politics, history, ideologies, and material resources. Literacy learning is life-long, non-linear, and always situated. We've learned a lot in the past 30odd years, but the main question remains the same: How is it that we come to learn and use literacy in different spaces? In fanfiction, we find a space where writing is enabled and nurtured through shared interests and friendly support. But we also find writing spaces with a limited field of possibilities based on those "shared interests," or, better put, similar habituses and, therefore, taste profiles. We see writing and reading that could not exist without open-access circulation. And we find an approach to writing that absolutely could not work without fans' goodwill dedication to reading, commenting on, and praising other fans' work. We can really see the ways in which educational and administrative concerns such as (student) “engagement” and "retention” and "development” are achieved through love, respect for ideas, and enthusiasm. And love, here, is on the side of both writers—love for their chosen fandom/content—and readers, 
who also love the fandom content as well as finding others like themselves—-kindred spirits.

As so much of our lives has become digital and digitized in the past two decades, literacy and education scholars have begun to ask what roles the digital and the internet play in literacy learning and practices. The sheer (growing) volume of online fanfiction suggests one very clear answer to the difference the digital makes: access. This includes access to tools and information about how to use those tools; access to source texts; access to fan texts and fellow fans. It includes access to circulation so much wider and so much quicker than was at all imaginable to the fans Jenkins studied in the late 1980s (see Textual Poachers). But, looking closely at online fanfiction also makes it clear that access is still limited by dominant ideologies and power structures. Digital "bodies” are still read, judged, and policed in these spaces. However, these are also spaces where love, goodwill, embodiment, and emotion are integral features. In that sense, online fanfiction is just one site to begin exploring how embodiment and emotion interact with literacy learning and practices, as well as how these interact with the digital. Finally, the structure and uses of these fanfiction spaces extend scholarly conversations about our ethical responsibilities as researchers in these still embodied yet often more anonymous internet spaces.

I conducted this project from an ethnographic perspective, which means that I did my best to both study and reflect fanfiction practices in the way that fans might talk about them. Since I openly identified as a fan both at the beginning and throughout the process of researching and writing this dissertation, in a way, I have also been a participantobserver. But I was not a participant-observer in the strictest sense: first, I mostly read 
stories rather than writing them, and I did not act as a beta reader at any point during my research; second, I read stories and talked with writers in fandoms I otherwise do not participate in. Throughout the course of 1.5 years, I conducted textual analysis of fanfiction stories, authors' notes, authors’ profiles, fan community pages, and administrator "how-to" guides. In addition, I conducted questionnaires and interviews with 7 fanwriters, and I conducted case studies with 3 participants. The majority of these writers identified as women between the ages of 18 and 40, and the majority of these writers were from outside of the United States. I will discuss my methods in more detail in Chapter 2, and my case studies in much more detail in Chapter 4. But I would like to state here that that my main concern as I was conducting this research was not only to represent fans in the ways they might represent themselves, but to approach all research from the very fannish notion of goodwill. I learned this notion of goodwill throughout my years as a (mostly lurking) fan in Harry Potter fandom, and certainly during my time researching different fandoms, namely Harry Potter, The X-Files, and WWE Raw. This notion consists, ideally, of open-minded and enthusiastic reading, kind and critical support, and always a clear sense of the IRL (in real life) person behind the words (or video, or art) on the screen.

In particular, it was this notion of goodwill that came to inform every aspect of my project: from my methods, to my analyses, to my findings. It became even clearer to me, the more fans I talked to, that fanfiction could not exist and positively affect so many lives without goodwill—without the welcoming spaces it provides for writers to love their work, and to write characters and worlds that are so difficult to find in so much of mainstream media. Fanfiction provides a safe space particularly for less dominantly 
privileged writers, such as women, people of color (especially women of color) and members of the LGBTQIA+ community. Of course, the notion of goodwill is an ideal, and fanfiction communities do include elements of gatekeeping, and certainly the very content of fanfiction stories, not to mention discussions about them, often reflect dominant ideologies of heteronormativity, misogyny, and racism. Nonetheless, it is this notion of goodwill that I have come to believe is the key to why fanfiction is not only so interesting to study, but to why it works so well for those who practice fandom. While this project started from a position of, shall we say, very selfish "love,” it came to be, ultimately, about love. Fan practices provide insight into the question: What happens with literacy when love and excitement are taken as givens?

In order to address this very large question, the dissertation moves from the more theoretical in scope within my literature review and methods chapters, to particular textual and primary research analysis in my fansite data and case study chapters, to the theoretical again in my final chapter addressing women, writing ,and emotion theory. In Chapter 1, “Intersectionality in Fanfiction Practices: A Review of the Literature,” I address rhetoric and composition, literacy studies, fan scholarship, and digital-new media studies. In it, I argue for a more in-depth look at the intersections of identity construction and performance, literacy practices, and material circumstances in scholarship on fan work. I am particularly concerned, in this chapter, in conducting an intersectional approach to fan studies that includes considerations of class, material circumstances, and economies. Class plays a complex role in fanfiction practices: it plays a role in limiting (prospective) participants' material circumstances in terms of financial capital as well as cultural capital—limiting access to leisure time, technology, and college-level literacy, 
for example. More importantly, as I come to find in Chapter 3 (see below), class is always in conversation with the alternative "goodwill" economies of operation that occur within online fanfiction. Ultimately, in this chapter, I am concerned with establishing a foundation of scholarship as well as terms upon which to build as I engage with the primary texts (fan stories, forum comments, "how to" guides, questionnaire and interview answers, etc.) of the fandoms I study.

I move from the literature review into a hybrid of methods and theory in Chapter 2, “Never 'Power sans Risk': Towards a Goodwill Ethics of Online Research Methods.” In this chapter, I outline my study design (which I have discussed above), as well as the benefits and challenges of this design. I am particularly concerned here with tracing what a "goodwill” approach to online research methods might look like. I come to argue that this approach must include the values of respect, reciprocity, transparency, and vulnerability. I show that vulnerability is especially key to "goodwill" research methods in working with online fanfiction participants, because it requires the researcher to constantly revisit and rethink her/his positionality, goals, and values with respect to those of her/his participants'. Importantly we can best change our online research methods through what I call “doing vulnerability,” where a researcher is open and honest about her/his position and remains open to the full input of study participants.

In Chapter 3, “The Emotion Economies of Online Fanfiction,” I conduct in-depth textual analysis of the fan practices within the Harry Potter, The X-Files, and the WWE Raw fandoms. In this chapter, I discuss how elements of identity are performed in these fanfiction communities, paying special attention to gender, sexuality, and social class in the specific spaces I've chosen to explore. I investigate these elements of gender, 
sexuality, class etc. as I move through different genres / practices, looking at fan stories and educational/instructional texts written by website administrators / community moderators. I connect these textual analyses to the differing economies of fanfiction communities. These economies exist within and therefore are always in conversation with the larger, fast capitalist economy, but they also highlight the importance of emotion in literacy practices.

I build on this foundation of goodwill, emotion economies by exploring how they interact with fans' material realities and their writerly identities in Chapter 4, "Response, Originality, and Expression: Three Case Studies of Fanwriter Realities.” I conduct case studies of major participants in the three different fandoms in my project whom I have interviewed. With these fanwriters' informed consent, I discuss the following in this chapter: how s/he first became involved in her/his chosen fandom; her/his interactions with other fanwriters (publicly posted); her/his fanfiction-related posts; her/his answers to a questionnaire covering basic demographics such as age, gender, etc.; in-depth data from my interview; and other material s/he is willing to provide that demonstrates the writing/revision process with her/his closest beta readers. I link all of this activity to what I was able to find of the writing economies in the previous data chapter.

Finally, I discuss why fan studies is still a relevant field of study, in addition to beginning to develop what I will call emotion theory in Chapter 5, “Towards Emotioned Literacy Practices.” This chapter builds upon the two data chapters, and it acts as a binding theory chapter for my findings. I assert a theory of online fanfiction literacy practices, and the ways in which these practices are shaped by power structures, identity construction, community norms, and material circumstances. While it is true that a great 
deal of fanfiction practices provide spaces for women writers to write themselves and their desires into the world, and while fanfiction is certainly still feminized in many dominant views, fanfiction spaces can urge us to go beyond a binary gender system, beyond compulsory heterosexuality, beyond normative monogamy. It can rehabilitate denigrated, feminized writing practices that are viewed as "too subjective," or "too touchy-feely," or "too self-centered." Fanfiction urges us to see the central role that embodiment and emotion play in all learning and literacy practices. As I conclude this chapter, I focus in particular on developing a theory of emotion in terms of literacy practices—what I come to call “emotioned literacy” (borrowing from Micciche). Emotioned literacy are practices that do something in the world for the practitioners, that are shaped by embodied-emotional life, and that are done in complex exchange economies.

While this project began from a deeply personal feeling of love for fanfiction communities, and Harry-Draco romance stories, and Severus redemption stories, and Hermione defeats Voldemort stories (to name just a few), I began to realize that how I view myself as a writer, as well as how many fanwriters have come to view their own writerly identities, has been deeply informed by the goodwill of the fan community, and writing fic "for the love of it.” The investigation of online fanfiction spaces is especially valuable for rhetoric and composition because it highlights how writing is a deeply embodied and emotional, life-long (learning) process. In addition, this project highlights the importance of a network of dedicated participants with knowledge(s) in different areas. Finally, this project highlights the importance of paying closer attention to the ethics of our online research methodologies. 


\section{CHAPTER 1}

\section{INTERSECTIONALITY IN FANFICTION PRACTICES: A REVIEW OF THE}

\section{LITERATURE}

"Randy Orton watched in amusement as 30 or so little kids ran towards him. His arms opened for hugs and autographs. They jumped up and down and squealed. He chuckled and looked over at his friend, John Cena, who was also being swarmed. He winked at Randy and opened his arms as well. When each child came up to him, Randy made sure that he had a short conversation and a hug with all of them. Children's homes were something that really touched his heart. They were denied the innocence of their childhood and all they wanted was someone to love, and Randy was going to give it to them."

Somebody to Love | harleysjoy In WWE Fanfiction World | Fanfiction.net

\footnotetext{
Above are the words of a highly-rated fanfiction from the WWE Fanfiction World community at Fanfiction.net. In it, Randy Orton retains his fame and bulking size; but he also shares a fond friendship with his frequent WWE-opponent, John Cena. In this story, Randy is allowed to show more than strangleholds and body slams. He shows easy intimacy with his "best friend” (and sometime overnight guest) John Cena. He shows a vulnerable and wondering fatherly love toward an adopted daughter. His masculinity only an afterthought of blind protectiveness towards his adopted ward. Randy Orton is a famous WWE Raw wrestler, who, according to IMDB and the answers.com/WWE Wiki
} 
often plays an "evil" character in the popular wrestling series. The series is a true spectacle of hyper-masculinity—where men exchange strangleholds rather than hugs, and where the women are a side-spectacle all their own.

Fanfiction lets people cheer on their favorite wrestlers as they fight epic battles on the TV screen. And then, later, fans can ask - But, really, what would Randy Orton be like off-screen? Do he and John Cena hang out? Does he always have to be the "heel ${ }^{1 \text { ”? }}$ Fanfiction allows fans to answer those questions, and to fill the empty spaces of their wondering. In some ways, fanfiction allows a space for the fan to take a loved universe/artifact/object, and expand the space for this loving engagement by talking back to the source text.

Fanfiction is a literacy practice whereby a fan takes the plot features, characters, and settings from a favored text (for example, Harry Potter or WWE Raw wrestling), and s/he uses those features to write her/his own stories about that text. Sometimes, those stories fill gaps readers and/or viewers were not able to see: e.g., what was Hermione and Ron's dating life like before they married? Other times, these stories imagine completely different scenarios for the characters: e.g., what would happen if Harry Potter died and Voldemort won? And, at other times, writers sometimes imagine aspects of the actors' lives beyond their roles in their major TV shows or films: e.g., what would Randy Orton, a "bad guy" from the WWE Raw wrestling series, be like off stage? Fanfiction activities are complex practices. They express and explore deeply-felt emotional attachments to popular culture texts—-the love the fan has for different books, films, TV shows, sports

\footnotetext{
${ }^{1}$ According to the Answers.com WWE wiki, a "heel" is an evil character on the WWE Raw wrestling series. Interestingly, according to the Oxford English Dictionary Online, "heel" is a slang word that first originated in the United States around the turn of the century (first seen in print around 1914), used to mean "a double-crosser, a sneak-thief; more generally: a dishonorable or untrustworthy person.”
} 
teams, music, etc. In addition, this love gets combined with a certain questioning: wouldn't it be great if/what would happen if this event had taken place instead? And, sometimes, fanfiction practices even delve into political resistance: so, why aren't there any LGBTQA+ relationships in the Harry Potter books beyond the passing reference of Dumbledore and Grindelwald's youth ${ }^{2}$ ?

Fanfiction practices provide a distinctive space for us to explore how we understand identity, digital technologies, fannish participation, and online research methodologies. First, a close inspection of fanfiction practices can demonstrate quite insightfully the complex ways in which identity features are coded and performed into readings of "source texts," and certainly fan texts such as stories, author's notes, reader reviews, discussion forum comments, and even user profiles (as we will come to see in Chapters 3 and 4). In addition, digital technologies have changed the ways in which fans participate in their favored fandoms, and certainly in their fanwriting activities, so fanfiction practices can provide us with an insight into how digital technologies interact with literacy practices_-especially in terms of how these technologies change the ways in which texts are produced, circulated, and received, not to mention how networks of fans overlap and connect.

Furthermore, as many recent fan scholars have argued, especially in relation to digital fandoms (see especially Matt Hills’ Fan Cultures), current fan work must take us beyond a simple resistance/complicity dichotomy—fan engagement is always both resistant and complicit with dominant structures at the same time. Finally, engaging with online research of fanfiction can provide us with important ways to reconsider our work as researchers in rhetoric and composition, as well as the humanities and social sciences

\footnotetext{
${ }^{2}$ This "passing reference," in fact, is only just a hint at a love affair, not an actual confirmation.
} 
more generally. In this chapter, I develop a theoretical foundation for addressing fanfiction practices by putting the fields of fan studies, new literacy studies, and digitalnew media studies into conversation with each other. I address elements of fanwriting, fan community practices, and identities, focusing especially on gender, sexuality, and class. I focus particularly on how identity features, literacy, the digital, and economies interact in complex ways to create the specific context(s) in which fanfiction can and does operate. Ultimately, in this chapter, I establish a foundation for exploring identities, economies, and material circumstances in the complex sets of practices that make up fanfiction.

\section{Fandom Enters Academe: Spaces for Fans as Sophisticated, Critical, and Resistant}

As I stated in my introduction, fan activities are certainly not new phenomena. Within a North-American context (see especially Camille Bacon-Smith’s Enterprising Women, and Henry Jenkin’s Textual Poachers), traditions of fan engagement are often traced back to the increasing popularity of "speculative science” "pulp” magazines such as Amazing Stories. In the late 1920s, in concert with the development of these science fiction pulps, “fan conventions” also began to develop. Just a couple of decades later, with the widespread popularization of J.R.R. Tolkien's classic Lord of the Rings series, and the cult status of science fiction television shows like Star Trek (1966-1969), the United States saw the development of a number of now very familiar fan activities: scifi/fantasy games ${ }^{3}$, fanart, fan music, fanfiction, etc. It has been argued by several fan studies scholars that women's engagement with fan activities, especially in the 1950s and 1960s began to change the shape of these activities, particularly of the science fiction

\footnotetext{
${ }^{3}$ For example, the popular role-playing game, Dungeons and Dragons, was developed by Gary Gygax and Dave Arneson in 1974 as both homage to and extension of the complex, fantasy universe created by Tolkien in his Lord of the Rings trilogy, The Hobbit, and The Silmarillion.
} 
stories, leading to the development of a genre often depicted as largely "female" - "soft science fiction" or science fiction stories that focus more so on the interpersonal relationships in a futuristic setting, rather than on the technology itself (see especially Bacon-Smith, Science Fiction Culture 105). In other words, fan culture has a long and rich history that I argue raises some important questions and concerns for literacy and education scholars.

However, fan culture has very often been connected to ideas of the mundane, the everyday, the "trivial," and, certainly, the popular. In The Cult of the Amateur: How Today's Internet is Killing Our Culture, Andrew Keen asserts that, "Instead of creating masterpieces, these millions and millions of exuberant monkeys—many with no more talent in the creative arts than our primate cousins-are creating an endless digital forest of mediocrity" (2-3). In this view of fanfiction, intense engagement with popular culture texts is reduced as "merely" emotional and acritical. Furthermore, in this view, an individual who engages fervently with these texts is seen as duped by inherently troubling dominant ideologies, and that s/he is therefore incapable of remarking upon, let alone critiquing dominant structures. Bronwyn Williams remarks upon this "panic over popular culture" (188) in Shimmering Literacies: Popular Culture and Reading and Writing Online, saying that while students participate in a vast array of engaged, sophisticated, and deeply critical interpretive practices when they discuss their daily, online pop culture fix, "Popular culture, in the eyes of many teachers, does not involve thinking and learning, is not real reading and writing, and should not be part of literacy education” (187-8). This “popular culture bad/high culture good” dichotomy is a relatively prevalent truism not only in academia but in dominant media. 
Even more troubling, this view depicts fans not only as grasping sycophants, but as aimless individuals seeking an escape from the "real” world. This view, however, is highly misinformed, and is largely predicated upon privileged biases, particularly class biases. Work in the past two decades, especially in the field of cultural studies, has demonstrated that fanfiction can be and often is critical work. In my dissertation, I focus mainly on fanfiction writing, and the online communities in which it is taking place, but I want to stress that I see fanwriting as a part of (and certainly deeply conversant with) fan activities more generally: conventions, discussion forums, email lists, and even activities like Fantasy Football. All of these activities share a similar kind of dedicated and sometimes very intense engagement that calls into question arguments that being a "fan" of a TV show, book series, sport, etc. is a "passive" and "anti-social” state. Importantly, fan studies scholarship has shown that fan practices are very complex. I argue, similarly to major fan scholars Henry Jenkins, Camille Bacon-Smith, and Christine Scodari, that fan practices: are emotional as well as critical; maintain and even celebrate dominant structures even as they might call them into question; work within a capitalist economy even as they might provide an alternative economy; and certainly reflect dominant structures of identity (gender, sexuality, race, class, nationality, etc.) even as they resist some of these same structures.

Fans Are Worthy of Study Because They Resist Dominant Ideologies through Fannish Practices

Cultural studies scholars Camille Bacon-Smith and Henry Jenkins spearheaded the development of fan studies, which has demonstrated not only that fan activities are critical, but that they are worthy of scholarly attention. In Textual Poachers: Television 
Fans and Participatory Culture, Jenkins argues that media fans (which he defines as fans of television shows and movies) are not escaping from everyday life through their fan activities, nor are they endlessly reliving their affective experiences of watching their favorite films or TV shows when they create fanart, fan music, and fanfiction, but rather that they are engaging in a sophisticated, interpretive community, in which they "rewrite" the source text in order to comment upon the social and political limitations of both its world and the larger, contemporary world that it reflects. Similarly, Bacon-Smith argues that, rather than being, "just pornography" or "just" desire-fulfilling, derivative, insubstantial texts, female fanwriters find important communities within which to nurture and practice writing, editing, and other creative skills. Moreover, fanwriting creates a place for validation of more "feminized" writing practices, such as collaboration, friendly support, and an unapologetic focus on romantic themes.

Much of this early and, in truth, enduring work on fan practices in cultural studies has focused on the resistant aspects of fan practices. In many ways, fan practices were legitimated within academia through arguments demonstrating fan practices' resistant, political engagement. Scholars such as Jenkins, Bacon-Smith, Scodari, and Constance Penley, especially, strove to show that fan work was not just a "nothing" activity, but rather that it was a space for fans to engage with their real-life worlds as well as their preferred popular culture worlds in ways that could address gaps and redress injustices. In fact, Bacon-Smith, when describing the Star Trek fan group she studied in depth, makes a point to introduce that group to readers by showing their resistant disposition. Female fanwriters, as Bacon-Smith found, tend to view themselves as "rebels in the cause of women's art/communication" (Enterprising 3), a "'terrorist society'" (Enterprising 4), as 
one fan gleefully referred to it in the opening of Bacon-Smith's foundational ethnography of fanzines, appropriately entitled "The Crime." Bacon-Smith locates this "rebellion," these "terrorist" activities within copyright debates; these women's activities are subversive because they inhabit that fine line between "fair use" and copyright infringement. Moreover, Bacon-Smith argues that these women's activities are subversive because they provide a space to not only air "feminine" writing practices, but to celebrate them. This introduction to fan work is particularly telling and evocative for readers: it suggests that fan work is worthy of scholarly attention because it is political in ways that we can easily approve of in academia.

What we see building here, then, is that fanwriting is generally seen as occupying a position of resistance. In fact, this is often the taken-for-granted view held by many scholars who work with fanwriting. In cultural studies, certainly, scholars have tended to focus on fanwriting's resistance to limiting ideologies of gender and sexuality. In “The Final Frontier is Queer: Aberrancy, Archetype and Audience Generated Folklore in K/S Slashfiction,” Paul Falzone investigates fanwriting on romantic and sexual relationships between Star Trek characters Captain Kirk and Mr. Spock—“K/S slash fiction”-as a practice that is not only resistant but transformative: "K/S represents a fan folklore in which an aberrant reading of a genre-specific narrative has had the power to transcend issues of genre, gender, sexuality, medium, time, as well as the retirements of the primary narrative source” (243, my emphasis). Falzone comes to argue that by writing Kirk and Spock into homoerotic pairings (whether explicitly sexual or not), the largely female writers create a space wherein they can "transcend" heteronormative structures of gender characteristics and roles, and of acceptable sexuality. 
Similarly, fan culture researcher and feminist scholar, Constance Penley, examines the ways in which fanwriting, especially within the "slash" genre ${ }^{4}$, provides writers with powerful, subversive spaces that are, in many ways, transformative, at least insofar as they work against dominant, heteronormative and patriarchal ideologies. According to Penley, these fanwriters develop cachet for themselves through their work's association with pornography (148). Most compelling, however, is her argument that, "The women Star Trek fans, especially the slash fans, have defined technology in a way that includes the technologies of the body, the mind, and everyday life" (118). In other words, women's fanwriting is subversive because it troubles the "hard science fiction"/"soft science fiction" dichotomy (addressed also by Bacon-Smith), and because it reimagines accepted understandings of technology, human relationships, and "good" writing.

Scholars tend to agree, then, that fan activities more generally and fanwriting specifically provides spaces wherein individuals might reproduce but also respond to or subvert dominant ideologies. However, these joint functions of conservation and subversion are not without tension—-they are best explained through struggle. A Bakhtinian perspective helps to make this clearer. Within this perspective, we can understand fan activities such as fanwriting as heteroglossic and dialogic. In Mikhail Bakhtin's Discourse in the Novel, he sees language as a living entity always already imbued with the social, political, and historical: "We are taking language not as a system of abstract grammatical categories, but rather language conceived as ideologically

\footnotetext{
${ }^{4}$ Fanfiction stories dealing primarily with homosexual relationships. Some will argue that "slash" refers only to gay stories, or man-man homosexuality, and they will only refer to stories focusing on lesbian pairings as "femme slash." Others will use the term "slash" more generally to refer to stories that include lesbian, gay, and/or bisexual pairings (or threesomes).
} 
saturated, language as a world view, even as a concrete opinion, insuring a maximum of mutual understanding in all spheres of ideological life” (271). Within this larger “ideological life,” there exist dominant, "unitary” structures or what Bakhtin calls “centripetal forces of language,” which are unifying and centralizing (270-2). Importantly for fanwriting, we cannot see the centripetal forces of unitary language as a single, monolithic entity. Rather, we have to acknowledge multiple levels of centralization: larger society as unified around certain dominant ideologies of race, class, and, especially, gender and sexuality; source texts as “canon”; and commonly accepted interpretations of the source texts and their limits within individual fan communities. Furthermore, these “unitary languages” intersect, converge, and struggle against each other in unique ways.

While terms such as "unitary,” "centralizing," and "force” certainly tend to have negative connotations precisely because of their conservative functions, it is impossible to imagine any community, and certainly any literacy practice existing without them. As Bakhtin makes clear, "For the prose writer... [the heteroglot] voices create the background necessary for his own voice, outside of which his artistic prose nuances cannot be perceived, and without which they 'do not sound'” (278). In other words, it is impossible for fanwriters' work to have any meaning at all, let alone any subversive functions without structuring and structured "verbal-ideological worlds" (272) shared in common with other readers and writers. The work of fanwriters, then, can be said to take dominant ideologies in larger society, the unitary features of the source text, and dominant interpretations of individual fan communities and reproduce as well as stratify them. This is where the centrifugal or "stratifying forces" (272) of language take shape. 
According to Bakhtin, centripetal and centrifugal forces cannot exist without each other: "Alongside the centripetal forces, the centrifugal forces of language carry on their uninterrupted work; alongside verbal-ideological centralization and unification, the uninterrupted processes of decentralization and disunification go forward” (271-2). We can say, then, that any instance of writing includes a dynamic, dialogized relationship between centripetal and centrifugal forces of language, in which a fanwriter establishes her/his position of authority and credibility through responding to currently unitary ideologies, thereby creating a new pathway, a new "particular way of viewing the world, one that strives for social significance” (Bakhtin 333).

From a similar perspective, Henry Jenkins, in Textual Poachers argues that media fans are not escaping from everyday life through their fan activities, nor are they endlessly reliving their affective experiences of watching their favorite films or TV shows when they create fanart, fan music, and fanfiction, but rather that they are engaging in a sophisticated, interpretive community, in which they "rewrite" the source text in order to comment upon the social and political limitations of both its world (universe) and the larger, contemporary world that it reflects (i.e. Star Trek fanwriters, for instance, not only "rewrite" Star Trek to address issues of gender inequality in the "Trek universe," but also to address similar issues as they existed in the 1960s and 1970s, and, in fact, as they continue to exist today). From a Bakhtinian perspective, fanwriting is deeply heteroglossic, in that it is defined by a struggle between centripetal and centrifugal forces of language, where individual stories by fanwriters might include both forces in their reimaginings of the worlds of source texts. 
Building upon Jenkins’ work in Textual Poachers, and engaging with Jenkins’ later work in Convergence Culture, Williams argues of fan forums that they "display the multivocal and heteroglossic landscape that Bakhtin (1981) imagines as the voices of participants compete, overlap, and offer new discursive resources for the interpretation of texts" (42). Williams goes on to argue that these spaces are "explicit in the dialogic dynamic of writer and audience" (42). Just as Bakhtin argued that the heteroglossia within the novel is necessarily "a special type of double-voiced discourse" (324), wherein the "two voices are dialogically interrelated...it is as if they actually hold a conversation with each other” (324), Williams argues that online fan forums are more obviously dialogic. He extends the Bakhtinian understanding of dialogism, however, to include what he calls "collective intelligence," a term he has borrowed from scholar Pierre Levy: Collective intelligence is the phenomenon where members of a community, even a temporary online community, are able to pool their information and experiences in ways that create new knowledge available to the entire group. It is not a matter of everyone knowing all the information all the time but more a matter of individuals being able to contribute what they have to the collective in order to answer questions and make meaning. (43, my emphasis) “Collective intelligence,” then, reflects, I would argue, not only the dialogic, multivocal features of Bakhtin's theory of discourse, but also the feature of struggle, where we understand struggle as generative (and potentially transformative).

According to Bakhtin:

Internally persuasive discourse—as opposed to one that is externally authoritative—is, as it is affirmed through assimilation, tightly interwoven 
with 'one's own word.' In the everyday rounds of our consciousness, the internally persuasive word is half-ours and half-someone else's. Its creativity and productiveness consist precisely in the fact that such a word awakens new and independent words, that it organizes masses of our words from within, and does not remain in an isolated and static condition. ... More than that, it enters into an intense interaction, a struggle with other internally persuasive discourses. Our ideological development is just such an intense struggle within us for hegemony among various available verbal and ideological points of view, approaches, directions and values. (345-6)

Here, "internally persuasive discourse" might be seen as the simultaneously conservative and subversive features of each new fan discussion or fanfiction. I would argue, building upon Williams' view of fan forums, that fanfiction webpages are similarly dialogic and conversational: they include not only the dialogic features of any discourse within the confines of the individual stories, but they include, also, dialogue between and among fanwriters and fanreaders in authors' notes, reader reviews and author responses, and, to a lesser extent perhaps, users’ ratings of stories.

As I've been trying to demonstrate to this point, I agree that there are sophisticated and critical, even resistant aspects to fanfiction practices. However, I also argue that not all fan practices are equally resistant. In fact, many fan practices, perhaps like the one above with Randy Orton turned from WWE "heel” to intimate, male companion and adoring adoptive father, is perhaps better understood as an action of the love of a fan, taken almost entirely within the confines of a patriarchal, heteronormative, individualistic American ideology, rather than as a rewriting or questioning of any of 
these constraints. Fan scholar, Matt Hills, would refer to this resistant fan/complicit fan dichotomy as a “moral dualism” (see especially Fan Cultures), born, in scholarship at least, out of a desire to legitimate both our sites of study and our appropriately distanced, critical, and cognitive “academic subjectivities.” Throughout Fan Cultures, Hills traces certain "moral dualisms" that appear in academic work on fandom: 1) pitting the fan against the academic (i.e., the "bad" fan who is too subjective, and the "good" academic who is resistant and informed); and 2) pitting the passionate fan against the mindless consumer. Hills argues that, while the moral dualism of "fan" v. "consumer" does seem to be at work in how fans describe their own alliances and communities, in fact, fans are working within two worlds simultaneously: they are both complicit within capitalist economies (consumerism) and resistant to this same structure. As Hills states:

On the one hand, we are presented with a view of fans as (specialist) consumers, whose fandom is expressed through keeping up with new releases of books, comics, and videos. On the other hand, we are told that fans whose practices are 'clearly linked with' dominant capitalist society (e.g. they may be trying to sell videos recorded off-air) are likely to be censured within the fan cultures concerned. This is not simply a theoretical contradiction; it is an inescapable contradiction which fans live out. (29)

In other words, Hills is getting at how academics have tended (and perhaps some fans themselves) to pit fans as totally resistant to the capitalist, consumerist economy in which we live. But this "resistant" positioning is, in many ways, a result of turning fans into "mini academics." Hills argues, and I would agree, that these fan v. academic categories 
are much more liminal and much more blurred than they have often been represented within scholarship 5 .

Furthermore, Hills argues for the importance of acknowledging the place of "affect" and even emotion in fan practices, and, by extension, in scholarship on fan practices. He argues compellingly that:

Fandom, I would suggest, deserves to be represented more on its own terms (in which the limits of this 'limited factual basis' are explored and made explicit) rather than being used to form part of a moral dualism. The task which confronts cultural studies at this moment (and it is a task which is relevant given the historical state of the field, and not as a matter of theoretical dogma) is to theorise the media cult and its fandoms through a primary allegiance to the role of 'fan' and a secondary allegiance to 'academia'. (9-10)

Hills does acknowledge that scholars who have positioned fan activities within these "resistant” and, therefore, "good” spaces were in large part responding to very real institutional constraints that scandalized the study of fandom—of anything that seemed too touchy-feely. However, as Hills argues, and as I argue in my dissertation, we need a more thorough exploration of fandom. This exploration of fan practices must include emotion. It must acknowledge that fan practices include hierarchical communities, where some are "in" and others are "out." And this exploration must acknowledge that fanfiction, in particular, is not always, and does not always need to be doing resistant work. I argue in my dissertation that fan practices are always both resistant and complicit,

\footnotetext{
${ }^{5}$ I will not address the tension between "academic" and "fan" here, but I will address these tensions in much more depth as I discuss my research methodologies in the next chapter, and throughout the chapters in which I explore fan activities within multiple sites, as well as when I discuss the case studies of particular fanwriters.
} 
and that an important part of theorizing these little subversions and conservations is a willingness to contend with the highly complex intersections of gender, race, sexuality, nationality, language, and social class. This argument will necessarily both “‘[look up]’ to more abstract theory...to glimpse the constellation of social forces, differences and mechanisms of control” (Burnett et al. 11) and “'[look down]’ into the complexities and interconnections of situated activity” (Burnett et al. 11). It will include ideological structures, “mind,” and "body"."

Apprenticeship in Fandom: Online Fanficcers as Literacy Guild?

Fan scholars have not only argued that fandom is worth study because of its resistant nature, but because fan practices can demonstrate how people engage with popular culture texts, their worlds, and each other. In other words, a close exploration of fan practices can demonstrate aspects of learning that we might not be able to see within, say, a classroom space. In Enterprising Women, Bacon-Smith focuses particularly on the learning that happens in fanfiction communities, describing a complex process of “initiation” that occurs over time, and that depends highly upon mutual respect and friendship among fans (82). What Bacon-Smith describes of the apprenticeship model of fanwriting is reminiscent, particularly, of Lave and Wenger's theory of “community of practice," something which has been marshaled by rhetoric and composition scholars to understand workplace communities as well as business and technical writing. In fact, digital-new media scholar James Paul Gee takes up the theory of “community of practice” and adds to it the concept of “affinity space,” which are spaces where people join together and “identify” into positions related to each other through shared interest,

\footnotetext{
${ }^{6}$ See also Leander and Boldt’s “Rereading 'A Pedagogy of Multiliteracies’: Bodies, Texts, and Emergence."
} 
rather than through demographics. The concept of "affinity space” recognizes the importance of both an apprentice-ship-like relationship ${ }^{7}$ and friendship. Ito et al. also describe, in detail, the importance of "peer-based learning" in online spaces, arguing that, "A growing body of ethnographic work documents how learning happens in informal settings, as a side effect of everyday life and social activity, rather than in an explicit instructional agenda” (21). In other words, Bacon-Smith’s work invites us not only to see fanfiction as a legitimate(/ing) practice, but also as one that can, with close study, demonstrate the complexities of learning in "informal spaces." Other notable fan scholars Christine Scodari and Rhiannon Bury also take up a dual focus on the subversive nature of fanwriting, and what it teaches us about learning and interacting.

Because of the complexities of fan practices, I argue that fanwriting is of interest not only because of its fascinating (and often political) engagement with sets of source texts, but perhaps even more so because of what it can tell us about what it means to be literate in different spheres. Fanfiction practices are never passive. Fans make source texts their own by discussing and rewriting them. Importantly, fanfiction is not just a blind repetition of the text, nor only a solipsistic writing of self into the text, but rather it is a resistance to the text and its imagined and invoked systems of power. Fanfiction writing is writing, not blind mimicry. What fan scholarship has done, to this point, is to closely investigate the intersections of fans as full people, whose positions are certainly shaped by features of race, class, gender, sexuality, and (in the case of Bury's argument at least) even nationality. Moreover, fan studies has shown that these fans have complex ideas about the popular culture texts that they enjoy, but they are also implicated within a

\footnotetext{
${ }^{7}$ As Gee states in Situated Language and Learning: "Newbies and masters and everyone else share a common space” (85).
} 
powerful system of white, middle class, male, and heteronormative ideologies, even as they might try to resist this system. What's more, they are implicated and operate within a powerful, "fast capitalist” economy, even while their work provides some potential for resisting this economy.

Most fan scholars have tended to focus solely on gender, or rather, to assume that fanfiction is not only feminine and feminized, but also inarguably middle class (see especially Jenkins; Bacon-Smith). Certainly, Bury points out that most fan scholarship has focused on fan activity within the United States, and has assumed all other fan activity to follow the same model of participation, as well as production, circulation, and reception, but she nonetheless focuses largely on fanfiction as a uniquely "feminine" practice. Many fan scholars have looked closely at issues of audience, genre, and writing processes, especially among adolescents (Black; Booth; Buckingham \& Willett; Chandler-Olcott \& Mahar), but many of these scholars tend to focus more on the possibilities of the technology itself (see also Hellekson \& Busse), rather than the ways in which composition using these technologies is implicated within and influenced by systems of power and privileged ideologies of gender, sexuality, race and ethnicity, nationality, and class. Finally, some fan scholars have also considered the issue of “intellectual property” and copyright (see especially Rebecca Tushnet), but this focus avoids entirely any investigation of gender, sexuality, race and ethnicity, nationality, or class. So, while fan studies scholars have certainly demonstrated that fan activities are worth scholarly attention, and they have tended to pull out important features of identity in their studies, there is a lot that we still do not know about the complexities of reading and writing in fanfiction spaces. In this dissertation, I intend to build upon previous 
research by focusing on the effects the intersections of technology, literacy practices, and intersectionality in identity might have on reading and writing practices, as well as community engagement.

\section{New Literacy and Digital-New Media Studies: “Literacy” as Practices in a Political World}

Putting fan studies into conversation with new literacy and digital-new media studies can deepen our scholarly understanding of the work that fans do. New literacy studies has foundations in the revolutionary work of social anthropologists Shirley Brice Heath and Brian Street. Heath's examination of the cultural, communicative, and literacy practices of three communities in the Piedmont Carolinas laid the foundation for considering and researching how the ways in which individuals both lived and learned outside of school had a huge impact on how an individual would learn inside a school setting. In Literacy in Theory and Practice, Street disrupts the dichotomies upon which the "autonomous model of literacy” rests by establishing an "ideological model” of literacy, which “concentrate[s] on the specific social practices of reading and writing” (2). Importantly, while an autonomous model of literacy has been used to make ethnocentric arguments which naturalize a conflation between literacy technologies and societal development, the ideological model focuses on the specific ways social groups interact, as well as the power relations inherent in these interactions. Importantly, Heath and Street lay two theoretical foundations for researching literacy and learning: 1) that “literacy” is not one kind of thing always, but, rather, exists differently in different contexts - there are literacies: 2) that literacies are always already shaped by/shaping the larger, ideological, political, and social worlds in which they are used. 
Of particular interest to my research on fanwriting practices is the work of Deborah Brandt and James Paul Gee. Brandt's work in Literacy in American Lives and Literacy and Learning: Reflections on Writing, Reading, and Society investigates the intersections of gender, class, race, and geographic region (both larger areas within the United States and the more generalized sense of distinguishing the urban from the rural) on the development of literacy practices in everyday, American lives. Brandt's focus on the changing world economy and sponsorship are particularly important in my own investigation of fanfiction practices. Brandt argues that we cannot understand histories of literacy practices without understanding larger shifts in the economy. I agree with Brandt, and I argue that, in my own investigation of fanfiction practices and their relationship to our understanding of "literacies," the practices of any particular fan website are developed within a world where there is a premium on one's ability to receive, interpret, add to, and distribute information widely. Furthermore, in all of the cases that Brandt investigates, literacy cannot be developed without “sponsorship”:

Sponsors, as I have come to think of them, are any agents, local or distant, concrete or abstract, who enable, support, teach, model, as well as recruit, regulate, suppress, or withhold literacy—and gain advantage by it in some way....Although the interests of the sponsor and the sponsored do not have to converge (and, in fact, may conflict) sponsors nevertheless set the terms for access to literacy and wield powerful incentives for compliance and loyalty. (Literacy and Learning 25)

This concept of "sponsorship" seems especially relevant to fanfiction practices, which are often reliant, on the one hand, upon acceptance into any fan community by other, more 
"senior" community members, and, certainly, upon the nurturing fanwriters receive from their editors or "beta readers.” On the other hand, any fanwriter’s practices are particularly influenced by the policing they might encounter by website administrators who may or may not allow their stories to be posted. In Gee's terms, we might see "sponsorship" in online, fanfiction websites as made possible by "affinity."

In a similar way to Brandt's focus on the changing economic and political climate in the United States in the $20^{\text {th }}$ century, Gee argues that:

In the old capitalism, it was dangerous to treat individuals as social beings with collective interests or to allow them to be so, because that might have further encouraged unionisation and collective organisation. Cultures were dangerous, too, because their specific ways and mores could stand in the way of the standard procedures and norms needed for large, secular, modern, rational, universal (that is, culturally transcendent) businesses. (“The New Literacy Studies” 184-5) This argument, in particular, highlights the ways in which class appears to act as a particularly troublesome/troubling category in digital-new media studies, as any feature of what me might see as "identity" (especially in relation to larger structures of power)— namely, class, race, gender, sexuality, and nationality—can get picked up in and reified in traditional terms (on a completely individual, consumer basis) by the "fast capitalist" system of exchange in which online literacy practices, fanfiction absolutely included, is so much a part. However, Gee’s work with online literacy practices, especially gaming, also highlights the importance of what Gee refers to as "affinity spaces," which focuses on the learning that happens in these spaces through shared interest and friendship. 
What new literacy studies (and the related area of digital-new media scholarship) brings to the conversation of fanfiction practices is the central, structuring influence of systems of power on fans' work. Structures of gender, sexuality, race, nationality, and class can be read in fans' practices as well as their material conditions. What's more, these features can be reimagined, shifted, and even obscured by fans’ engagement in supportive friendship relationships, as well as reading and writing practices that allow them to respond to and even talk back to dominant ideologies. Put another way, literacy studies provides a heuristic through which to closely consider the full context of fans' lifeworlds—-"the ways of living, eating, sleeping, worshiping, using space, and filling time which surrounded these language learners would have to be accounted for as part of the milieu in which the processes of language learning took place” (Heath 3).

\section{The Role of Class in Exploring Online Fanfiction Practices}

Before I move on, I would like to take some time to define class, seeing as it plays a complex role in the intersectionality of fan identities-in terms of how they choose texts, engage with texts, and how/when/where they choose to write (as we will see to some degree in Chapters 3 and 4). However, class also plays an important and complex role in understanding the fans' writerly identities as well as the economies of circulation that fans operate within. Finally, much of the work within fan studies has focused more so on gender and sexuality rather than class, and so I intend to begin including more on class in my own work here. For the purposes of my project, I would like to start with a relatively "simple" definition of class, and to place it in opposition to the term "socioeconomic status." "Socio-economic status" refers more explicitly to financial income and the material circumstances that this financial income allows: in general, the larger one's 
financial income, the more expensive products one can own, and, likely, the more leisure time one can "afford" to have. Perhaps more importantly, within this model, the more financial income one has access to, the more control one can exert over one's conditions of labor, education, etc. Within the United States, we tend to use terms like "working class" and "middle class" (primarily) when we are referring to socio-economic status. However, despite the blurriness of these terms, socio-economic status, while related to class, can only provide a limited view of what is involved in class.

Class always includes much more than financial income and material circumstances. It is also comprised of a complex nexus of dispositions: towards education, literacy practices, popular culture engagements, gender roles, sexuality, even clothing. These dispositions are complex and varying, depending highly upon the current, larger ideological moment, and upon the particular combinations of gender, sexuality, race, nationality, language, and class identifications a person might both live and enact. While I do not believe that class dispositions are easily mapped (if they can be usefully mapped at all), I do believe that we tend to represent class dispositions as mappable. In other words, as scholars, we can map the ways in which social class dispositions seem to affect our expectations, interpretations, and judgments of texts and practices. Importantly, while social class and socio-economic status are not interchangeable terms, they are related to each other. As I discussed above, the concept of socio-economic status is often only interpreted through financial capital; and the idea is that the more financial capitalmoney—one has, the more materials one can afford to buy: food, housing, educational resources, technological resources, and certainly entertainment. In that way, then, I would argue that class and socio-economic status meet; one's material circumstances, especially 
those one encounters early in one's life, and certainly the material circumstances of one's parents, create certain limitations on what it is possible for someone to encounter and do in the world.

For example, in terms of fanfiction practices, if someone does not have a home computer (desktop or laptop), a tablet, or even, say, a smart phone, s/he will not have ready access to fanfiction websites in the first place, and may never even have the occasion to hear of them. It is most likely that s/he would only have access to a computer and the internet at a public or school library, and s/he would only likely be able to find and peruse fanfiction websites there. Given this person's limited access to digital and internet technology, her/his engagement with fanfiction, even just reading, would be highly limited as well. One could imagine, also, that in this case, as an adult, this person would be working long hours in order to pay for housing and food, and would, therefore, have little time to read and certainly to write fanfiction. These chances might increase if s/he had a smart phone. But, even then, this person would be highly limited by her/his data plan. Moreover, this person's access to source texts would be limited as well, and so s/he might have a difficult time engaging in fandom, or her/his choices of fandom might be much more limited to, say, what appears regularly on the basic cable television channels that can be picked up through a digital antenna. In any case, this particular fan could not only be said to have a very different socio-economic status from other fans but, likely, also a different class disposition than some fans.

From an academic/schooling perspective, one good example of how to understand this is Donna Dunbar-Odom's story about her development of literacy practices. In her work, Defying the Odds: Class and the Pursuit of Higher Literacy, Dunbar-Odom tells a 
story of growing up in a working-class household where her parents "had jobs, not careers” (49), and where the main reading material was not books, but rather newspapers and Reader's Digest (49), which seemed not to get read. She explains that though her mother remembers reading to her a lot when she was young, Dunbar-Odom's mother refused to teach her to read until the first grade, so that she would not be seen as different from the other students (3). Dunbar-Odom reflects, in contextualizing her study within her own working-class upbringing, that, "I have to wonder where my intense desire to read and study increasingly complex texts comes from because it was not significantly encouraged in my early years” (3).

This story points both to Bourdieu's theory of habitus and field, demonstrating habitus as impacted by the practices of the communities we engage in, and that we can, to a certain degree, choose how we will perform certain features of habitus in any given community at any given moment.

Habitus and field are limited:

It is always forgotten that the universe of products offered by each field of production tends in fact to limit the universe of the forms of experience (aesthetic, ethical, political, etc.) that are objectively possible at any given moment. It follows from this, among other things, that the distinction recognized in all dominant classes and in all their properties takes different forms depending on the state of the distinctive signs of 'class' that are effectively available. (Bourdieu, Distinction 231)

In the case of Dunbar-Odom above, then, we might say that her desire to read and study was highly limited by the material circumstances of her childhood home, but also, I 
would argue, the possible field of choices for reading and study were opened up, very likely, by her introduction to a school environment, especially as Dunbar-Odom continued into higher levels of education. She would have been introduced to different possibilities for identification and dispositions.

It is possible to say something similar about the case of the materially-limited fan, as well. If this fan were to come into contact with another fan or a fan space with access to other source and fan-texts, the field of possibilities for this fan to do fannish work would shift and change. What I mean by this is that it is possible for a fan of lesser means to come into contact with fan work that may perform and express different class dispositions, and she or he may come to identify with this set of fan work or s/he may not. Another way to put this might be to reference Gee’s theory of “affinity space.” The "affinity space" in an online environment is a place wherein individuals can come to form communities based on shared interests rather than other physical or social features, such as class, race, gender, sexuality, etc. However, even if it is true that fans can come together across certain ideological boundaries of power, these fans do not leave their habitus behind, as it were.

Class, as with any identity marker, is a tricky concept to define. It is a concept, I argue, that combines features of what we might view as "personal” identification, something which arises out of years of socialization within particular ideological circumstances, and out of choice via affinity with certain groups and/or values. It is a particularly tricky concept to define within a contemporary American context, because we often represent ourselves as living within a classless society in the United States. In an American context, class is something that is always present, yet always carries with it a 
sense of transcendence: it is a situation that happens to us (we are born within a certain financial and educational family status), but that we can change through our sheer force of will (we can rise from a "lower class status" to a "higher class status" through "hard work," education, and the accumulation of more financial capital).

Bourdieu’s theories of capital, "habitus,” and “field” are particularly useful in understanding class in the way that I approach it in my dissertation. Bourdieu defines habitus as "not only a structuring structure, which organizes practices and the perception of practices, but also a structured structure: the principle of division into logical classes which organizes the perception of the social world is itself the product of internalization of the division into social classes” (Distinction 170). As can be seen with his arguments from The Logic of Practice, Bourdieu clearly sees theory and practice as constantly in dual action—as theory-practice or praxis. More importantly, Bourdieu clearly sees what we might refer to as "identity," here habitus, not as some "original” and "natural” state of being (within each individual) that can only be seen through that individual's actions on any given day, but, rather, as sets, perhaps, of limited choices (by) in the social sphere. Upon first glance, the concept of habitus might seem particularly determined and determining — or, in other words, as a space we get assigned to and stuck in. And it can certainly seem this way because, while habitus is not “original,” “natural,” or "preexisting,” it is something that has been shaped by life-long socialization; socialization starting so early for all of thus that we hardly remember it. But while this socialization is early, strong, and certainly pervasive, that does not suggest that there is no choice involved in the concept of habitus. 
Another highly important feature of Bourdieu's theory for my work is the field. Bourdieu argues that, "There are thus as many fields of preferences as there are fields of stylistic possibles” (Distinction 226). In other words, a "field" is a space where people engage in certain practices depending upon their positioning within this field (their habitus within this field). As Claire Kramsch puts it, “According to Bourdieu’s theory, my habitus was in a dialectical relationship with the field of educational practice as I encountered it in school. The educational field...is a relational, multidimensional space of activity where agents - that is, students, teachers, and administrators—-take up and occupy positions according to how much capital they have” (39). Within fanfiction, as Scodari and Felder describe of $X$-Files fans in “Creating a Pocket Universe: 'Shippers,' Fan Fiction, and the $X$-Files Online,” we might see $X$-Files fandom as a generalized “field,” where certain agents (from different though likely similar backgrounds) come together to discuss what they see as "acceptable" interpretations of the $X$-Files.

Bourdieu's theory of field relies upon acknowledging the social struggle between the powerful or privileged and those with less power and privilege. What we see going on in the examples of Scodari and Felder's article are, to a large degree, fields in the Bourdieuian sense because they rely upon a struggle among "more privileged" and "less privileged” communities of $X$-Files fans. As Bourdieu argues of the highly privileged "liseurs" of religious texts, "Hence the incessant revisions, reinterpretations and rediscoveries which the learned of all religions of the book perform on their canonical texts: since the levels of 'reading' designate hierarchies of readers, it is necessary and sufficient to change the hierarchy of readings in order to overturn the hierarchy of 
readers" (Distinction 229) ${ }^{8}$. We can see this same kind of shifting power dynamics and struggle in the examples Scodari and Felder examine between two major camps of " $\mathrm{X}$ Philes.”

In the case that Scodari and Felder describe, there appear to be two opposed groups within the larger field of $X$-Files fans: “shippers,” or fans who are dedicated to exploring the possibilities of certain romantic pairings in the show, particularly that of Agents Fox Mulder and Dana Scully, and “NoRomos” who see this romantic pairing as an adulteration of the show’s original intent: “[Shippers'] anti-essentialist feminist endeavors to reclaim the concept of romance rather than rejecting it out of hand because of its patriarchal misappropriation. While the Mary Sue ${ }^{9}$ dynamic operates for Shippers insofar as they identify with one agent as the romantic interest of the other, the relationship itself, in light of its political dynamics, is their primary object of devotion” (244). What we see in this example, then, is a larger "field" $-X$-Files fandom, and a smaller "sub-field” of "Shipper” $X$-Files fans who resist the dominant, "platonic romance” (Scodari and Felder 249) narrative of both the show's author, Chris Carter, and other fans. These fields are certainly aware of and conversant with each other, and they are certainly implicated within dominant, heteronormative structures of power in American society. In other words, these fans operate within systems of ideas that are

\footnotetext{
${ }^{8}$ I'd like to point out that, in much of fan studies, and among fans themselves, the use of “religious-like" language - a language of devotion, faith, revelation, and even of cults - is used frequently as an analogy to the experience of the media fan. Fan scholar Matt Hills addresses this in depth in Fan Cultures.

${ }^{9}$ Within fanfiction, "Mary Sue" is a term for a story in which the main character is all-knowing and allpowerful. It is typically assumed by fanwriters that the "Mary Sue” story (or, in the case of a male writer and/or male character, the "Gary Stu") is only written by new and inexperienced fanwriters. In a way then, while the "Mary Sue" story is reviled within fanfiction communities, it is also accepted as an important step in the development of a fanwriter. Fan scholar Camille Bacon-Smith has argued that the term, "Mary Sue” originates from a well-known Star Trek fanfiction, in which the main character, named Mary Sue, was written as an infallible character who not only single-handedly saves the Starship Enterprise, but gains the romantic attention of Captain Kirk. For more information see Bacon-Smith and Enterprising Women. (I address the concept of the Mary Sue in more depth in Chapters 4 and 5.)
} 
circulated to them. They take up these ideas, they modify them, and they re-circulate alternative ideas.

I'd like to take a moment to discuss some limitations of Bourdieu's theory for my project. While I think that this theories of "habitus," "field,” and different types of capital are useful in terms of understanding some tricky aspects of ways in which lived experiences meet material circumstances meet dispositions and expectations, I also think that this theory can, at times, seem far too rigid. In a similar fashion, fan scholar Matt Hills argues in Fan Cultures that fan scholars' uses of Bourdieu:

Bourdieu's work is rooted in a central and guiding metaphor. Bourdieu supposes that cultural life can be modelled by taking an 'economistic approach.' This treats all social relations as if they are economic; people invest in knowledge (reading the right books), in social contracts (networking and knowing the right people) and in culture (having knowledge of appropriate cultural works and how to respond to them). Bourdieu argues that different types of capital as well as 'economic capital' (money) are unequally distributed across society. (47)

In other words, as I was trying to stress by saying that while socio-economic status and class are related, they are not interchangeable terms, Bourdieu's "economistic metaphor" cannot be too strictly applied. In addition, I would like to stress that financial capital and cultural capital are certainly not the only types of capital that get exchanged, or even that are valued, in any community. As Hills argues in Fan Cultures: "I have suggested in this section that cultural capital has been overly emphasised in later accounts, while other types of capital (social and symbolic) have been underplayed in studies of fan culture" (58). I agree, and I will discuss the different kinds of capital that get exchanged and how 
in the next section, especially when I discuss Leon Jackson's theory of $19^{\text {th }}$ century publishing (from his The Business of Letters: Authorial Economies in Antebellum America).

It is important for me to stress at this point that fan activities are practices, in a new literacy studies perspective. In his work in The Logic of Practice, Bourdieu sets out to theorize the ways in which we experience and act within our daily, social lives. However, as Bourdieu cautions, theorizing practice is tricky, because it fits within the purely “mechanistic” or, perhaps, subjective experience, rather than, say, a more "rational" or objective process. We can, perhaps, see this division with the Enlightenment, and the Cartesian schema-“Cogito, ergo sum”-that separates the "mind” from the "body,” suggesting that the "body” can act on its own just as much as the "mind," and, what's more, that the "mind” can "discover” knowledge that is somehow "out there" in the world. Or, as Bourdieu puts it, "Objectivism, which sets out to establish objective regularities (structures, laws, systems of relationships, etc.) independent of individual consciousnesses and wills, introduces a radical discontinuity between theoretical knowledge and practical knowledge” (The Logic of Practice 26). What Bourdieu is building here, then, is a praxis approach, where theory and practice not only meet, but have always been in conversation.

As was discussed above, Bourdieu’s praxis approach depends highly upon his theories of habitus and field. Within these theories, the world in which we are socialized provides us with a relatively limited set of possibilities of being or, I would argue-along the lines of Judith Butler's theory of performativity_of doing our identity. In Gender Trouble, Butler theorizes gender as sets of repetitive performances which can fit within a 
normative schema of "proper gender representations"-of being "properly feminine” or "properly masculine”-and which can subvert these normative discourses. In particular, as Butler theorizes the activity of drag within the LGBTQIA+ community, she argues that, "In imitating gender, drag implicitly reveals the imitative structure of gender itselfas well as its contingency. Indeed, part of the pleasure, the giddiness of the performance is in the recognition of a radical contingency in the relation between sex and gender in the face of cultural configurations of causal unities that are regularly assumed to be natural and necessary" (187, emphasis in original). For Butler, drag performances are troubling to the dominant discourse of gender because they, through their "imitation" of "proper gender performances” highlight the non-essential and performative aspects of gender. As Butler argues: "Significantly, if gender is instituted through acts which are internally discontinuous, then the appearance of substance is precisely that, a constructed identity, a performative accomplishment which the mundane social audience, including the actors themselves, come to believe and to perform in the mode of belief" (192, emphasis in original). That is, while drag is troubling to the dominant discourse on gender precisely because it demonstrates that gender is not an internal essence, the repetitive acts of doing gender can come to be seen as essential and internal to the actors, making the very performance of gender identity invisible qua performance.

I turn to Butler here because while I argue that fanfiction activities are practices, I also argue that these practices are performative in nature. And they are performative in different kinds of ways. In one sense, fanfiction activities invisibly perform certain identity features - certain features of one's habitus. Take the passage from a WWE Raw fanfiction story, Somebody to Love (above) as an example: within this passage, the writer 
performs what she sees as “proper masculine gender identity” through Randy Orton by asserting that he and his fellow performer, the male John Cena can only be friends. The writer, harleysjoy, continues this invisible performance of "proper masculinity" by highlighting Randy Orton's violent protectiveness towards his adopted daughter in the story. However, harleysjoy subverts this “proper masculinity,” in small ways, by allowing John Cena and Randy Orton to maintain an intimate friendship, and by allowing Randy Orton to act as a nurturer towards the children in the orphanage, and certainly towards his adopted daughter. As a complication, I would argue that this subversion is incomplete; Randy Orton's nurturing activities towards his adopted daughter still fit within a "properly masculine" identity of fatherhood. What's more, I would argue that these apparent subversions are probably not seen as subversive at all by the writer. It is likely that harleysjoy, and her audience of WWE Raw fan readers, would probably read Randy Orton's fatherly identity as essentially true aspects of his manhood.

However, I must stress here that even this "performative” interpretation of Somebody to Love is limited. Earlier, I argued that fanfiction practices are always both subversive and conservative in nature. Therefore, while I argue that fan activities are practices and that they are performative, just as there are self-aware moments of subversion in some fan works, and just as there are elements of choice in Bourdieu's theory of the habitus, I would argue that performativity as theory can only provide a portion of the picture of fanfiction as both practices and performances. As Hills argues in Fan Cultures, when he discusses the nature of the "performance" and the "performative" in relation to fan costuming and impersonation, the "performative” in Butler’s theory suggests a situation in which voluntary choice is absent, while "performance" suggests 
volitional action. In the case of fan cultures, as Hills goes on to argue, fan engagement is always both un-self-aware and volitional:

The 'problem' for performative theory is that fans display a type of 'non-volitional volition' (Frankfurt 1988) which disrupts Butler's poststructuralist separation of voluntarist 'agency' and 'power/knowledge'. Fans are 'self-absent' to the extent that they are unable to account, finally, for the emergence of their fandom, but they are also highly self-reflexive and willfully/volitionally committed to their objects of fandom. Each and every expression of fan identity is hence both a nonvolitional citation and the (consumerist) 'choice' of a volitional fan-subject. The performative consumption which characterises media fandom...is hence both an act and an iteration-without-origin. (159)

In the example of Somebody to Love, then, while we might interpret harleysjoy's representation of Randy Orton’s “manhood” as iterative, as performative of dominant ideologies of masculinity, we must also acknowledge harleysjoy's choice to engage in WWE Raw fanfiction writing, not to mention her choices to make Randy Orton and John Cena close friends, and to make Randy Orton a nurturing and sensitive male character, when in the "source text" of WWE, he plays an often negatively-portrayed character.

This model of fan practices as practices and as performative not only fits within the new literacy studies major theory of design (The New London Group), but it is what de Certeau meant when he described his theory of "textual poaching." In his theory, de Certeau does not see reading in the traditional view—as the passive uptake of another's ideas (in the words of Street, he does not see literacy as "autonomous"). Rather, de Certeau theorizes that a reader engages closely with a text, "poaching" it for things that 
s/he can use in "making sense” of her/his daily life: "[The reader] invents in texts something different from what they 'intended.' He detaches them from their (lost or accessory) origin. He combines their fragments and creates something un-known in the space organized by their capacity for allowing an indefinite plurality of meanings” (169). As we saw, while some may be suspicious that fan practices can be (and I argue are) creative and critical, as can be seen with Andrew Keen's disgust with most of online participation done by those whom he does not consider "experts," most fan scholars have taken up de Certeau's theory of “textual poaching” as its major defining feature (see, certainly, Jenkins’ Textual Poachers; Bury; Bacon-Smith; Penley; Scodari; and certainly those who appear to "straddle" the fields of fan scholarship and literacy studies, Williams and Black, especially).

In de Certeau's theory, reading is always shaped by and implicated within systems of power, especially “ideologies of social class” or "social stratification” (167; 172). Therefore, textual poaching has the potential of being a responsive and resistant practice. It has the potential, and in fact appears to enact a certain "tactics" against the privileged, dominant regime. In de Certeau's theory, "The place of a tactic belongs to the other. A tactic insinuates itself into the other's place, fragmentarily, without taking it over in its entirety, without being able to keep it at a distance” (xix). In the cases of the fanfiction practices that both Jenkins and Bacon-Smith investigated in their earlier works, participants took dominant language, made changes to it, and then circulated their stories among their relatively small group of fellow fans. In this way, we could see these practices as "tactics" to subvert some of the dominant regimes of power without entirely dismantling them. In Scodari and Felder's language, these "tactics" are "pocket 
universes” (252; 254). In the case of online fanfiction, however, there is a much greater potential for wide circulation—or institutions of power to both see and potentially be affected by the "tactics" of fan practices. So, in the case of "remix," as it is described by Knobel and Lankshear, individuals can take images produced by huge media franchises and rework them into their own creations through the ready availability of free software that is often relatively easy to learn.

In these cases, these "remixed" projects—perhaps especially in the case of YouTube videos_-are incredibly visible, and contain the potential of de-centering some systems of power. They have the potential, in the theory of de Certeau of becoming "strategies"-“the calculus of force-relationships which becomes possible when a subject of will and power (a proprietor, an enterprise, a city, a scientific institution) can be isolated from an 'environment'” (de Certeau xix). However, as we saw with Gee, and as Jenkins describes in Convergence Culture, in some ways, these online, remix practices (or online fan practices more generally) often tend to either be taken up by powerful media franchises (metaphorically or literally)—as in the case of Heather Lawver's “educational,” Harry Potter-related website, The Daily Prophet—or these institutions seek to police these practices, as in the case of the Warner Brothers threatening legal action against those who post videos using content from the Harry Potter films (Jenkins Convergence Culture 171-4). I mention these examples here because understanding the complex ways in which class is at work in fan activities requires that we look not only at ideological systems of power, but also at the important roles that technological tools and economies play in fan practices. 


\section{The Difference of Online Fanwork: Conversation and Competition within “Literacy” Economies}

Of course, the work of new literacy and digital-new media scholars has raised some important questions for us as literacy scholars, especially in our increasingly "globalized” and "technological” world: How is it that digital-new media and digital technologies work? What is it about these technologies, media, and spaces that provide such tantalizing new frontiers for us as writers, researchers, scholars, and teachers? What is it about these technologies, media, and spaces that engage so many people in so much interaction and composing? The answer lies in part, I argue, in the kinds of economies that digital technologies operate within. Furthermore, the answer lies with the different kinds of economies that those who engage in digital technologies might create in response to the larger, fast capitalist, largely financially-based economy. Digital technologies (perhaps especially the internet) allow for quick and wide circulation, which is perhaps why they seem so seductively democratic to us as literacy scholars.

In her work, Bury seeks to problematize and largely to undermine what she calls the “'dream of disembodiment”" (3) of a lot of early theorizing of online practicesnamely, that the online environment can "render irrelevant physical markers of race, gender, sexuality, ability and age” (3). Of course, this same “dream of disembodiment” has somehow been retained, to some degree, in current studies of online practices, though I would argue it is not only a "dream of disembodiment” but a dream of true democratization. Scodari and Felder's work undermines this "dream of disembodiment” to some degree, but it also highlights the possibility for wide and quick distribution of materials. In many ways, the recent focus in digital-new media studies on the potential of 
the quick and wide distribution made possible by the internet is also a democratizing dream - it provides the promise of widely shared and discussed knowledge that does not depend upon highly powerful and dominant institutions (like the state, school, or family), but rather on the very public themselves. Scodari and Felder complicate this view by pointing out that, in fact, while wide distribution is possible, it does not necessarily reflect the reality, and, perhaps even more troubling, what will distribute widely in these online spaces are often materials that already neatly fit within dominant narratives.

In describing the activities students engage with in online environments such as fan forums, Williams is concerned first and foremost with the ways in which popular culture provides an outlet for individuals to gain authority and credibility over texts in ways largely decoupled from the sanctions of the "adult world" (41). He argues that earlier iterations of "popular culture” occurred on the local level and required immediate audience interaction. With industrialization, “popular culture became an industry of commodified, standardized, reproducible content created and distributed by professionals with highly specialized jobs" (Williams 32). Furthermore, "the reliance on the reproduction and distribution of professional popular culture content also changed audience members' relationship to the texts they encountered” (Williams 33), such that audience members were more removed from the immediacy of the event, as well as from the participation and shared meaning-making practices that would have been an everpresent feature of earlier popular culture events (and texts).

Fan communities, therefore, have developed ways to make the texts their own-to use those texts in ways that position them as meaning-makers along with the authors of said texts. The increasing ubiquity of digital technologies and online spaces has created 
unique affordances for individuals to engage with popular culture texts in authoritative ways, because through these sites, "it is possible to connect immediately to a group of people with the same interest, to have one's ideas supported, one's interpretations responded to, and one's questions answered" (Williams 38). Importantly, here, online spaces allow for relatively accessible and relatively quick production, circulation, and reception. In other words, online fan culture exists within a unique system of exchangenot only of dialogue, but of authority, meaning, and friendship. As I discussed above, one way, perhaps, to account for these complex exchanges in fan communities is to appeal to Gee’s theory of "affinity spaces." I believe, to a certain extent, that "affinity space” is a useful term in fan scholarship because it highlights the choices that fans can and do make, as well as the importance of the deeply affective, deeply emotional ties among fanwriters (especially, I would argue, in the case of the fanwriter-beta reader relationship). However, as scholars such as Bronwyn Williams and others have argued, the "affinity space" is problematic because, while it highlights choice, it fails to account for larger ideological structures that are still at work in fans' performances of identity, and certainly in their engagements with each other. Nonetheless, I will argue that "affinity” and friendly exchange are very central aspects to fan practices.

Likewise, Jenkins' work in Textual Poachers highlighted the features of friendly exchange and goodwill that tended to define fanwriting practices in earlier fanzine communities. He argues that "fan reception cannot and does not exist in isolation, but is always shaped through input from other fans and motivated, at least partially, by a desire for further interaction with a larger social and cultural community " (Jenkins 76, my emphasis). Online fanfiction communities function in very similar ways. It is 
commonplace in these forums for fans to not only help each other with their writing, free of charge, but to set each other challenges, to write stories for each other, and to support each other through positive reader reviews—-not to mention the lively discussions that take place on these websites' writing forums (spaces where writers can discuss story ideas with those other than their editors or "beta readers"). In this sense, then, we might see fanwriting culture as existing within a system of exchange, but different from the larger, more familiar system of commodity exchange in larger society. What is exchanged at these websites is not profit. Rather, stories are exchanged for friendship (symbolic capital) and authority (social capital). The exchange on these websites is best described as affective, and fits best within what we might call a "gift economy” rather than a "commodity economy."

In The Business of Letters: Authorial Economies in Antebellum America (hereafter Business), Leon Jackson argues that authorship in the $19^{\text {th }}$ century existed within multiple types of economies in addition to monetary, and that production, circulation , and reception of these texts existed within a cultural precedent of "gift exchange.” Similar to online fanwriting, $19^{\text {th }}$ century authorship worked within economies that were embedded and embedding (a term he borrowed from Karl Polanyi, economic anthropologist), wherein authorial economies "served not simply to convey goods and money from one party to another, but also, and at the same time, functioned to create and sustain powerful social bonds” (2). Jackson does come to argue that these authorial economies became more “disembedded" in the latter $19^{\text {th }}$ century, and certainly by the $20^{\text {th }}$ century. However, I would argue that the case of online fanwriting is unique. While it may be true that the production, circulation, and reception of texts produced by 
corporations for profit within a commodity economy may well be fairly disembedded (and perhaps they must be, given the unique distance these kinds of texts set between reader and author, leading to the different avenues for meaning-making that we find in fan communities, according to Williams' argument), fan texts are, notably, deeply embedded precisely because they cannot exist within a system of monetary exchange. These texts necessarily violate copyright laws, given their content, and they can only gain some limited form of freedom (and sanction) if they are not circulated for money.

Because fan texts cannot be exchanged for profit (at least not in the case of a large majority of fanwriters, that is), the systems of exchange that have been developed among fans have largely been gift-centered. I am using the term "gift" here in the way that Jackson addressed it in Business. Here, gifts are not totally free, and they are "hardly unilateral” (Jackson 91). As Jackson points out of gifts in $19^{\text {th }}$ century book culture: A gift given ... is always part of an exchange. Second, because gifts tend to be situated in exchange economies, they are somewhat less free than they might otherwise appear. To receive a present is to be drawn into a relationship freighted with expectations to reciprocate. Gifts both create and sustain bonds, that is, and in this respect, gift-giving is both an embedded and an embedding economy. Third, the sense of gratitude and indebtedness one intends to conjure up in bestowing a gift can, under some circumstances, be experienced as resentment and obligation, so that while a gift can be given out of goodwill and esteem, it can also be given to manipulate or be received with suspicion. (91-2, my emphasis) 
Jackson complicates earlier views of "gifts" among $19^{\text {th }}$ century authors. Before this passage, Jackson included two examples of $19^{\text {th }}$ century authors "giving gifts" of their works: in the first, Daniel Pierce Thompson sends his work to John Neal (a newspaper editor and writer (89)) along with a cover letter wherein he basically tries to order a really positive review of the work; in the second, Emily Chubbuck sends her work to an old friend, Urania Nott, with a note describing her friendship (90). Jackson notes that earlier scholarship saw "gifts" within these "gift exchanges" as "dynamic, free, embracing, and spiritually rich, while commodities are static, costly, isolating, and spiritually impoverishing” (90). He does this not to suggest that these kinds of exchanges did not include gifts, nor to suggest that none of these exchanges were out of friendship, but rather to show ways in which authors of the $19^{\text {th }}$ century might have spoken about "gifts." In complicating this earlier view of "gifts," Jackson argues that there are multiple types of gifts, and that these "gifts" are dependent upon the relationship between those who exchange them (do they know each other well?), their expectations of that exchange (are they asking to be printed and/or reviewed?), as well as their relative status to one another (Jackson remarks in an endnote that: "to give a thing of value to a social superior is to make a tribute, while to bestow it upon an inferior is a form of charity" (274)). Moreover, Jackson explains that gifts are not dependent solely upon the "intention" of the giver, but will be interpreted by and mediated through the value system of the receiver, as well as that receiver's view of the giver and the giver's possible intentions.

Importantly, Jackson argues that gifts aren't free or completely outside of economies or systems of exchange. Gifts typically have or receive some kind of value in the exchange, which shapes the tenor of that exchange. Jackson goes on to say that, "The 
'full truth of the gift,' according to Pierre Bourdieu, lies neither in insisting on its generosity...nor in exposing its duplicity... but rather in accepting the validity and intertwinedness of each" (92), and furthermore that, "Indeed, the very definition of the gift, according Bourdieu, boils down to the fact that it is an object that hides its economic nature yet relies upon it" (92). From that perspective, then, Jackson is arguing that something can still be a "gift" even while it is doing other work. I argue that this is true of fanfiction communities as well.

It seems clear that digital technologies (perhaps especially the internet) allow for quick and wide circulation, which is perhaps why it seems so seductively democratic to us as literacy scholars. It seems perhaps especially so when we consider the limitations of the institution on the classroom—such that circulation goes from student to teacher, in exchange for a grade that will then limit where a student might "circulate" his/her cultural and social capital (grades) for, well, financial capital (a job). Lemke, in particular, is concerned with circulation in the sense of what he calls "transmedia clusters" (140). "Transmedia clusters," here, and given the examples he provides of "transmedia franchises," for example, Harry Potter fans moving from book to film to theme park to merchandise such as Harry Potter's wand to fanfiction websites (149) seems to suggest a complex sense of process, identity, and meaning (re)making. As Lemke argues:

Our encounter with these media is not simply a trajectory through a single coherent work. It is a traversal across the boundaries between works, media, genres, sites, institutional contexts, activities, etc. And along such a traversal we are construing and cumulating across timescales transmedia effects which do not occur within single works, or between inter-texts in the same medium, 
or indeed within the scope of any theory of meaning-making or multimodal analysis that exists today (145).

In other words, Lemke's approach urges us to pay attention to multiple aspects of digital media at once: identity, circulation (spaces and places), and time.

Importantly, I argue that the exchanges that take place in online fan communities occur within a different kind of economy than the dominant one we contend with in everyday life. Every day, we engage in a commodity economy, where any number of things can become objectified, valued, and exchanged for monetary capital—or capital that might lead to monetary capital, i.e. cold, hard cash. In the morning, we might go to Starbucks for coffee: we go in with a certain expectation of the monetary value of that item, the cup of coffee. We then exchange that amount of money for the cup of coffee and we go on our way. The economies in fanfiction websites are both the same and different. They both reflect the commodity economy and resist it through creating an economy of the exchange not only of some kinds of social and cultural capital (fame and credible status as a fanwriter) but also of friendship. Fanwriters engage closely with their editors or beta readers; they write stories for each other; they set writing challenges for each other; and they positively review each other's work. In other words, their economy is, at times, commodity-centered, and often, at others, largely affectively-centered or giftcentered.

However, as I was mentioning above, the economy of fanwriting is certainly not entirely different from the one with which we contend every day. First, I will reiterate what I discussed earlier in regards to Hills’ Fan Cultures: that while both academics and fans alike might sometimes pit the "mere" consumer against the "true fan," that the 
situation is not nearly so simple. The larger capitalist economy in which we live allows fans access to their loved, fan objects. What's more, it is always there, in conversation within the potentially more "gift-centered" economies one might find on any individual fan website, even one such as Archive of Our Own, where the mission statement asserts fans' rights over those of corporations:

The Organization for Transformative Works (OTW) is a nonprofit organization, established by fans in 2007, to serve the interests of fans by providing access to and preserving the history of fanworks and fan culture in its myriad forms. We believe that fanworks are transformative and that transformative works are legitimate.

We are proactive and innovative in protecting and defending our work from commercial exploitation and legal challenge. We preserve our fannish economy, values, and creative expression by protecting and nurturing our fellow fans, our work, our commentary, our history, and our identity while providing the broadest possible access to fannish activity for all fans. (“About the OTW”)

While certainly, again, we can see this "alternative economy” especially hard at work in this mission statement, I cannot help but argue that we see also what Hills would call a "moral dualism" between "good transformative fanwork" and "bad commercial exploitation."

Secondly, I will mention that, even within online fan communities, there exists the potential for the social, symbolic, and even cultural capitals writers gain through their participation to eventually be transferred into a system of financial capital. After all, New 
York Times bestselling author of the Fifty Shades of Grey series, E. L. James, got her start in Twilight fanfiction communities, and Cassandra Clare, author of the Mortal Instruments series, got her start in Harry Potter fanfiction communities. Just as Jackson argued that not all gifts would be completely free of commodification, not all of the "gifts" in fanfiction are free of the potential for commodification.

\section{Fanfiction Practices are Critical to Rhetoric and Composition}

As scholarship across different fields has demonstrated, research into fan activities provides insight into many areas: learning of and engagement in sets of literacy practices in out of school sites; how literacy practices are shaped by, engage with, and (can) reimagine structures of power such as gender, sexuality, race, nationality, and class; and, finally, how online literacy practices are shaped by (and shape) the increasing ubiquity of digital technologies within an increasingly globalized world. As I have stated in this chapter, fanfiction activities are complex: they are simultaneously resistant and conservative; they are highly emotional and critical; they are performative practices and they are performances. They are bound up in and depend upon capitalistic exchange, and they imagine and enact other forms of exchange. Fanfiction practices can demonstrate in very distinct ways how ideologies, systems of power, economies, and identity are at work in learning and literacy. For example, even just the short passage from harleysjoy's Somebody to Love explodes with the collision points of capitalism and "affective exchange economies," dominant and pervasive but also more "tender" expressions of masculinity, and even a hint at the tensions between socio-economic status (Randy Orton has a lot of money because of his celebrity status) and class dispositions (yet Randy 
Orton tends to identify with more "working class" dispositions often stereotypically linked with the rural and less educated).

Furthermore, I argue that this short passage from a fanfiction story, especially in conversation with the Office of Transformative Works (the founders of Archive of Our Own), demonstrates not only the complexities of learning literacy, which in the field of rhetoric and composition we are still trying to understand, but also the importance of "payoff" for the literacy learner/user-i.e., the "use value" of fanfiction. And it is this combination of complex situatedness and payoff (which we might call "use value" or "transfer," perhaps) that is so central to the work that we do as rhetoric and composition scholars, because of our dual dedication to writing and to teaching. As a rhetoric and composition scholar, I do see that fanfiction practices bear similarities to composition's "best practices," and that there is something distinctive to fanfiction activities that can help us to reimagine praxis. Furthermore, I see fanfiction activities as a kind of critical remixing of salient popular culture texts (Knobel and Lankshear; see also "textual poaching" and "the mosaic"-Williams), and as a situated and significant "designing” and "redesigning" (New London Group) of not only the universe presented to readers in any source text (or combination thereof), but also of the ideologies and discourses that shape and limit any community.

However, I argue that the significance of fanfiction for literacy scholars goes beyond its similarity to school literacy practices; and its importance certainly moves beyond its distinctive, "non-school” position. Fanfiction can help us to better understand the ways in which class, especially as it intersects with gender, sexuality, race, and nationality, informs and intersects with literacy practices in complex ways. In my 
dissertation, I look closely at the ways in which identity intersect with the texts that fans write in online fan communities. I also look at how these features are constructed on the websites that invite and archive fan stories. I conduct textual analysis of fan texts (how to writing guides, creative fiction, and reviews) in order to see the complex ways in which identity features (imagined, assumed, and performed) get coded into texts by both the writers and the readers alike. In addition, in order to better understand the intersection of social class and material circumstances in fanwriters' lives, I conduct interviews with some fanwriters (seven total). In the next chapter, I discuss in depth the importance of a complex, thoughtful, and "goodwill-based" methodology of online research. I conduct a focused and critical discussion of online research methodology because, as I argue, studying fanfiction practices can help us to better refine what it means to do the work of rhetoric and composition in an ever-more globalized, technological, and assessmentfocused world. Finally, I argue that part of doing that work well requires that we revisit our positions and practices as researchers. 


\section{CHAPTER 2}

\section{NEVER "POWER SANS RISK": TOWARDS A GOODWILL ETHICS OF ONLINE RESEARCH METHODS}

On February 13, 2015, an article appeared in the online version of The Daily Californian about a new course at UC Berkeley—The Theory of Fanfiction. In the course, students read and discuss fanfiction stories, considering their genre features, especially as these features are related to gender, sexuality, and "kink." This course is an intriguing potential case study of what really happens when we bring fanfiction to the college classroom. It is especially interesting, perhaps, because the course design allows students the potential to engage with writers in real time, as it requires students to leave comments on the stories they've read for class. The practice of critically commenting on course reading seems to be business as usual for a university-level course. Until the fanwriter responds to these comments, that is.

Just a few days after the release of the article by The Daily Californian article (and ostensibly weeks after the start of the course at UC Berkeley), fanwriter and blogger Waldorph ${ }^{10}$ updated her or his blog to warn the fan community about the course. At first completely confused by all the comments on one of her/his older stories, s/he found out it was required reading. Waldorph's response is telling, as s/he says:

\footnotetext{
${ }^{10}$ Waldorph is a member of multiple fandoms. I do not know Waldorph personally. I have contacted Waldorph, and s/he consented to my use of her/his blog post, but s/he has not since consented to participate in other elements of my research.
} 
The comments I received were bizarrely tone-deaf, condescending, rude, and more than that, completely out of step and touch with all fannish norms.... Unfortunately, I dealt with this all week before one of the teachers stepped in, and that was only when I started receiving flaming trolls.

For this reason, I've alerted all of the authors listed on the syllabus that they're about to experience this because, frankly, I would have appreciated a heads up.” (“So Your Fic is Required Reading: Hahahanope”)

This particular situation raises one very important question about both the consequences and, yes, the ethics of applying one set of literacy practices in a completely different context, namely: What does it mean to explore, study, and respond to community practices in an academic way when the practices under study are not aligned with academia? Waldorph's comment that s/he "would have appreciated a heads up" reads to me as a serious understatement. It is clear that for Waldorph, the creation of this course without any kind of communication with the fan community was a serious breach of protocol.

Waldorph's closing paragraph is an especially poignant reminder that the academy's actions in relation to online communities can have very significant material and felt consequences: “Ultimately, there’s nothing we can do about people examining works that we never meant to be examined this way. I think we all have to accept that the way fandom gets interacted with is changing, not just the way that we interact with the rest of the world. I do think that as a community we can and should support each other" ("So Your Fic is Required Reading: Hahahanope").This quotation suggests that, to Waldorph, the course design was not only unwelcome, but highly disruptive. While I maintain that 
academics should have the freedom to engage critically with cultural texts, including online fan texts, I would also point out that, unlike authors of officially-published works, fanwriters are often not protected from censure; they are, in many ways, a marginalized group of writers. Online fan spaces were created as safe zones for fans to engage in reading and writing that was otherwise unsanctioned, and as such, these spaces have developed certain rules of engagement in order to both support and protect the very fans that participate. From that perspective, then, it is very easy to see how an outside, powerful group (the academy) coming in and acting against these protocols could be seen not only as annoying, but even threatening.

Therefore, this case raises important questions about pedagogy, the University and its relationship to other communities, and certainly of the possible disconnect between different sets of literacy practices. But, even more so, this event raises important questions about our daily navigation of ever-developing digital technologies, such as:

- Where does the "private" life end and the "public" life end on the internet?

- Who counts as a "person" in the online environment?

- Who can and should have control over content about themselves on the internet? As these questions show, internet technology, especially its ability to distribute information nearly instantaneously to a nearly world-wide audience, makes things such as “public” versus "private," and "informed consent” somewhat uncertain. What's more, though the above is, ostensibly, an example of teaching, it is nonetheless relevant for thinking about all academic work, including research and scholarship. In fact, the example of the UC Berkeley course and Waldorph's response, what has come to be referred to in fan communities as "Fangate," was on the minds and lips of all fan studies 
scholars at the 2014 PCA/ACA Conference in New Orleans, Louisiana, where most sessions ultimately came to discuss the ethical responsibilities we hold as academics when we go into fan spaces: as fans, as researchers, and as teachers. I start with this example, then, because it is incumbent upon us as academics, and certainly those of us who identify as aca-fans, to rethink and then rethink again the ethics of our online research methods, in fan spaces and beyond.

In order to trace what a more ethical, and what I will call goodwill approach to online research methods might (and should) look like, in this chapter, I will start by examining ethical values of research methods as they are defined by the IRB. I will then describe an extended set of ethical values as they have been described and defined by prominent scholars in face-to-face (hereafter F2F) research-from those conducting ethnographic research to those conducting action research. Next, I will describe the theoretical and practical difficulties the internet raises for the online researcher, as well as studies that have made use of F2F values in their own methods. Finally, I will discuss my online recruitment/fan profile, focusing on my own self-positioning and selfrepresentation and how these have been crucial in developing a goodwill ethics approach in my own research. Ultimately, I argue that all online research should use a goodwill ethics approach, and that this approach is chiefly characterized by a researcher's willingness to abdicate her/his “expert” status where necessary; ongoing negotiations between researcher and participants; and sufficient time to establish both an emic perspective of the community and/or site being researched, as well as relationships with participants.

\section{Values of Goodwill Ethics of Research}


Research within the context of a university position, such as mine as a doctoral student and graduate teaching assistant, does include certain well-established and monitored processes, namely training with the Human Subjects Protection Office and Internal Review Board (IRB) certification. Before even these processes, however, are required methods courses as well as personal mentoring between students and advisors. In most cases, departments understand that if they have a vested interest in churning out successful scholars ${ }^{11}$, they must then develop methods to bring these graduate students into the fold by teaching them: the stakes of research for different parties, including the researchers, the institution, and the researched; the different manners in which research can be achieved — textual, in person, quantitative, qualitative, etc.; and the end goal of research — to add to the collective knowledge of The Field ${ }^{12}$ (and, sometimes, to give back, in Action Research). Because the English Department, where so many of our Rhetoric and Composition programs are housed, is so text-focused, they not only host a wide range of research methods, but they risk a more idiosyncratic approach to methods, especially when it comes to questions of ethics in studies that go online ${ }^{13}$. Because of the relatively wide range of research foci and methods practiced within an English Department, by the time some students are directed toward IRB certification, they will likely have spent a good deal of time considering the practical concerns of their research, and even the legal concerns, but perhaps less so the ethical concerns. This is especially

\footnotetext{
${ }^{11}$ Generally, "successful students" are discussed, directly and indirectly, as those who go on to work toward the tenure track at similar academic institutions. This is, of course, not always the case, and it is problematic, but it is generally the dominant model, especially within programs at research 1 universities. ${ }^{12}$ I capitalize this purposefully, to suggest that in many cases, additions to the field are heralded above other types of benefits in the research process, especially within R1 institutions.

${ }^{13}$ See especially Anderson's "Simple Gifts" for an in-depth consideration of the gap between methods in rhetoric and composition and other fields such as psychology and anthropology. It is an old article (1998), but it is still largely relevant today.
} 
true of students conducting online studies because the degree of oversight for these kinds of studies is still highly variable across institutions.

The very first document researchers are provided as they begin IRB training is The Belmont Report, first released by the National Commission for the Protection of Human Subjects of Biomedical and Behavioral Research in 1979, which initially focused largely on biomedical and social sciences research. It has since become the standard of legal research ethics in academic institutions. I'd like to focus here only on "the Basic Ethical Principles" that all researchers are introduced to through this report, and how these have largely been codified into the official application documents. The entire IRB process is outside the scope of this article, and it has been discussed in depth before by rhetoric and composition, research ethics scholar, Heidi McKee, namely in "Changing the Process of Institutional Review Board Compliance ${ }^{14}$." The Belmont Report and the IRB process is entirely structured around three main "ethical principles": (1) respect for persons; (2) beneficence; and (3) justice. The Belmont Report defines "respect for persons" in the following way: "[It] incorporates at least two ethical convictions: first, that individuals should be treated as autonomous agents, and second, that persons with diminished autonomy are entitled to protection." The Belmont Report further defines "beneficence" as mainly assuring two things: "(1) do not harm and (2) maximize possible benefits and minimize possible harms." And finally, "justice" is conceived of as providing "equal" opportunities for people / communities to participate in a study: "(1) to each person an equal share, (2) to each person according to individual need, (3) to each person according to individual effort, (4) to each person according to societal contribution, and (5) to each person according to merit." These principles certainly can

\footnotetext{
${ }^{14}$ See also Anderson (1998).
} 
cover a wide range of research situations, but, largely, they have been codified in the following ways: (1) informed consent forms; (2) anonymizing and/or de-identifying data through the use of pseudonyms, etc.; (3) keeping all files in a locked cabinet; and (4) constraining these principles to the time of research, which is typically one year from the date of certification.

While I would not argue that The Belmont Report's stated ethical principles are insignificant, I would argue that how these ethical principles have been codified in official documents serves only as a starting place for the ethically-minded researcher, rather than the end point. Furthermore, I would argue, similarly to Mary Brydon-Miller in "Covenantal Ethics and Action Research: Exploring a Common Foundation for Social Research" [hereafter "Covenantal Ethics"], that the IRB process is shaped by, nay, complicit within not only a legalistic enterprise, but a capitalistic and biomedical, corporate model:

Such concerns place the entire research enterprise more starkly within the broader economic and political systems which favor an individualistic, entrepreneurial relationship to research that emphasizes grantsmanship, the patenting of specific products and processes, and a capitalist approach to knowledge generation quite at odds with the collaborative, egalitarian, social change focus of action research. Placed within this broader economic context, even the seemingly altruistic efforts to bring new, more effective drug therapies to the market are understood as driven by the economic interests of large pharmaceutical companies and the importance of reenvisioning a research ethics truly designed to support the 
common good rather than common greed becomes all the more apparent. (246, my emphasis)

In other words, the IRB process, alone, will not account for the complexities required of truly goodwill relationships among researchers and participants. Once a researcher has achieved IRB certification, s/he then still has many decisions to make in order to maintain a certain level of ethical responsibility in her/his work.

For example, in my own work, it soon became clear from both IRB training and interactions with particular representatives from the Human Subjects Protection Office on my campus that, while these individuals were certainly concerned that I would conduct research ethically, they had no real precedents for processes of full disclosure, consent, and even collaboration for online studies. My full, signed consent form was reduced to a preamble consent, and no one seemed concerned about the texts I would be exploring, only about my interviews. I would never argue that these were some sort of malicious oversights by the IRB office. But I will argue that the process did leave me with quite the job of developing and asserting my own sets of research values that were clear enough to effectively enact goodwill with my participants, but flexible enough to change as participants needed. Here, then, I'd like to discuss sets of ethical values of research methods from F2F to online research.

My discussion of research methods to this point has suggested that there are two levels of concerns: 1) legal, and 2) ethical. While certainly these two levels overlap and inform each other, they do not account for all of the same concerns, as I will come to discuss below. As I mentioned above, when I renewed my IRB certification, my full consent form was replaced with a preamble consent form, which includes a significantly 
shorter explanation of the project (one to two paragraphs, rather than almost three pages), and it does not require participant signatures. While it is true that all of my research activities, including my interviews and questionnaires are occurring online, which was the justification given for the form change, I remain unconvinced that the preamble consent form is sufficient to prepare both new and ongoing participants for the research process in my study, from recruitment, to data collection, to analysis, to reporting at conferences and in publications. It has required me to establish and consistently revisit a set of research values. In fact, it is the values of research ethics that inform and shape the majority of discussion of methods in F2F research, as these researchers have expanded and added to the IRB values of "respect," "beneficence," and "justice."

\section{From Legalistic Forms to Ethical Processes of Respect, Reciprocity, and}

\section{Transparency}

"Respect" is an underlying value that is maintained and/or is similar from IRB to more generalized research methods. Within the tradition of F2F and action research or AR, "respect" is greatly expanded from its definition in The Belmont Report, which focuses on "subjects' autonomy." As Mary Brydon-Miller has argued in "Ethics and Action Research: Deepening Our Commitment to Principles of Social Justice and Action Research" [hereafter, "Ethics and Action Research"]:

Respect for persons, for example, under the guidelines of the Belmont Report and most sets of human subjects research guidelines, is limited to providing research subjects with the opportunity to decline to participate in a particular study and is assumed to be addressed through the informed consent process. 
In action research, on the other hand, this principle extends to our conviction that all individuals have the capacity to contribute to the process of knowledge generation and the right to play an active role in shaping policies and processes that affect their own well-being and that of their families and communities" (202).

These additional values of collaborative and/or joint knowledge generation and policy shaping mean different kinds of things in different types of studies, but very generally, they have meant that researchers should consider:

1. Care in the representation of participants and researchers

2. Opportunities for collaboration with and/or at least reciprocity between researchers and participants

3. (and) When and where possible, total transparency through the research process These underlying values require that we view research as a recursive (McKee and Porter "The Ethics of Archival Research"), rhetorical (Cushman; Herndl; Powell and Takayoshi), and (self) reflective/reflexive (Brydon-Miller "Ethics and Action Research"; Fine; Kirsch and Ritchie; Mckee "Ethical and Legal Issues"; and especially, Williams and Brydon-Miller) process (McKee and Porter The Ethics of Internet Research [hereafter Internet Research]).

It would seem that respect has been one of the most concerning and difficult ethical values to fully define, especially when we understand ethical research practices as "a continuous process of inquiry, interaction, and revision throughout an entire research study, one involving and inviting regular critique; interaction and communication with various communities; and heuristic, self-introspective challenging of one's assumptions, 
theories, designs, and practices" (McKee and Porter Internet Research 28). Within this process-oriented approach to respect in person-focused research, respect expands to include, first, an ongoing consideration of representation —of the participants, the study, and, from recruitment to reporting, the researcher. It is this latter representation (or selfpositioning) that can introduce some of the most risk of misinterpretation, appropriation, and even ideological violence, given, as Newkirk refers to it, the "seduction" of participants into a study by the affirmed "objectivity" of a researcher and the "professionalism" and "authority" of the institutional consent forms.

In "Seduction and Betrayal in Qualitative Research," Newkirk argues that, while it is important to have consent forms, and while it is certainly pleasant for a researcher to have an approachable demeanor, these same elements could (and perhaps often $d o$ ) invite participants to share more than they might otherwise. And as I said above, while consent forms approved in the IRB certification process certainly address legal concerns in doing research, they may, in fact, stand in the way of or undermine our ethical values precisely because, as Newkirk argues:

Paradoxically, the measures devised to protect those being studied often aid the researcher in the seduction. An opening ritual is to sit down with prospective subjects and go over an 'informed consent form' approved by the institution's committee on human subject research. Typically these forms provide a very brief and often vague description of the project, and then provide a number of assurances - that the subject can decline to participate and can withdraw at any point, that he or she will remain anonymous, and that results of the study will not 
affect grades in any course related to the research or be communicated to supervisors. (4)

And certainly, I have seen some evidence of possible "seduction" even with my own study when I asked participants to respond to the research process so far. Many responded that they had enjoyed the experience, and one even remarked that, "The process working with you has been great. It has a professional and impersonal feel to it....There were some forms [too] that really eased some concerns." (Not to mention that the very process of asking participants in a friendly manner for evaluation can itself be another seduction and potential betrayal.)

Some ways to mediate this problem of seduction and betrayal is to warn participants that not all conclusions will necessarily put them in a favorable light (see especially Newkirk 13 on this point). Another approach is to take special care in how participants are represented. Even better is to share the report with participants as soon as possible, and to be willing to talk through the writing, so participants can have a chance to negotiate different meanings, and even to pull out of the research entirely. But another particularly productive avenue is for researchers to take great care in how they position and represent themselves throughout the research process: they should work through what Brydon-Miller has called "structured ethical reflection."

Brydon-Miller has argued that, as part of the preparation process of research, "we might begin with a critical examination of ourselves as individual researchers using a first-person action research approach" ("Ethics and Action Research" 204). This approach requires the researcher to do an in-depth and recursive exploration of her/his ideological and ethical foundations — to ask, "What am I taking for granted?" Or, as Brydon-Miller 
instructs her students using "the metaphor of dance training in which you are encouraged to find your center" ("Ethics in Archival Research" 205). Furthermore, this process not only requires researchers to examine and name their core values, and to call these values into question, but also to, as Michelle Fine has put it, "work the hyphen": "By working the hyphen, I mean to suggest that researchers probe how we are in relation with the contexts we study and with our informants, understanding that we are all multiple in those relations" (72). In other words, not only should we critically examine and position ourselves, we should take care in representing both our relationships with our participants and their own self-positioning in their communities. We should take an emic perspective. However, while this process absolutely requires sharing the "personal," it does not mean confessing the personal for the personal's sake. Rather, it means sharing the personal while considering what participants might make of our positions and selfrepresentations. As Gesa Kirsch and Joy Ritchie warn in "Beyond the Personal: Theorizing a Politics of Location in Composition Research" [hereafter "Beyond the Personal"]:

We argue that it is not enough to claim the personal and locate ourselves in our scholarship and research. In doing so, we risk creating another set of 'master narratives,' risk speaking for and essentializing others, and risk being blinded by our own culturally determined world views. Instead, we propose that composition researchers theorize their locations by examining their experiences as reflections of ideology and culture, by reinterpreting their own experiences through the eyes of others, and by recognizing their own split selves, their multiple and often unknowable identities. Further, we propose changes in research practices, such 
as collaborating with participants in the development of research questions, the interpretation of data at both the descriptive and interpretive levels, and the writing of research reports. (8, my emphasis)

Put another way, a truly goodwill, ethical positioning, as I would call it, requires that we abdicate the throne of expertise, and open ourselves even to possible vulnerability. What's more, as Powell and Takayoshi have argued in "Accepting Roles Created for Us: The Ethics of Reciprocity," sometimes (often) it is essential in goodwill research methods that we respond to participants' needs—-that we at least understand and sometimes enter roles participants might wish for us to play in addition to our status as researchers.

This is where respect and representation meet reciprocity in the value system of ethical research methods. Powell and Takayoshi describe reciprocity as a "nonhierarchical, reciprocal relationship, in which both researcher and researched learn from one another and have a voice in the study, [that] is informed by a feminist desire for eliminating power inequalities between researchers and participants and a concern for the difficulties of speaking for 'the other'" (395). Important in their definition of reciprocity is a developed sense of Kairos - that researchers must learn to pick and choose the right moments to respond to and within participants' roles for us. However, an ethical approach to research methods includes not only consideration for participants, but a sense of what Brydon-Miller would refer to as "covenantal ethics": "With its focus on the development of caring and committed relationships, on respect for people's knowledge and experience, and on working with community partners to achieve positive social change, covenantal ethics clearly provides a framework more consistent with the values underlying action research than the existing contractual model" ("Covenantal Ethics” 253). The term 
covenant is crucial here, as it suggests a deeper, "sacred" duty to one's study participants, or, as Brydon-Miller defines it, from a more secular perspective, "a solemn and personally compelling commitment to act in the good of others" ("Covenantal Ethics" 255). In this case, and as I have found for myself, a set of ethical research values that effectively enact goodwill require the forging and maintaining of relationships between researchers and participants.

Finally, these relationships can neither be ethically forged nor maintained without full transparency. In terms of F2F research, transparency has not only meant the inperson negotiation of consent forms, interview questions, and methods, say, of observation, but a sense of collaboration with participants. As Williams and BrydonMiller have put it in "Ethics and representation": " In the case of digital research, two additional principles seem to us to be especially salient: transparency (i.e. the extent to which the entire research process is clearly articulated to participants and those using the research) and democratic practice (i.e. the extent to which participants are able to contribute to the research process from the creation of research questions through decisions regarding dissemination of results)" (185). Importantly, since research is a recursive process, the value of transparency requires a researcher to continually revisit her/his goals of the study and to discuss these with all participants to make sure they know what's at stake: for them, for the researcher, and for the research report. Crucially, a truly goodwill ethics of research requires not only that a researcher lay out all the demands and potential risks of the study at the beginning, or even at multiple intervals as these develop, but rather that the researcher always be willing to negotiate with participants about the goals, conclusions, gains, and risks of the study. 
Respect, reciprocity, and transparency form a solid set of guiding values for ethical research methods in studies with human beings. Many of these values translate directly into online research. But many must also be amended in the digital environment because of this technology's different affordances for production, circulation, and access. In particular, as was seen with the case of Waldorph above, the online environment raises some very important concerns regarding:

1. Public versus Private

2. Ownership and/or Authorship

3. Traceability

In the next section, I will first address new concerns that the internet poses for the ethical researcher. Then I will discuss how fan studies scholars have addressed these concerns as they have moved online. Lastly, I will discuss a set of important heuristics for taking human-centered research into online spaces.

\section{Control, Consent, and the Tricky Case of the Cyborg}

While the first world wide web website—or, rather, the internet as we (sort of) know it today — was not available until the early 1990s, the internet has by now become almost entirely ubiquitous and, perhaps, pedestrian. It forms such a central part of our daily routines (I start almost every morning checking Facebook, email, and the weather on my smart phone), that we've come to feel that we really know it intimately. I think we tend to see the internet as a tool, though it is rather all-consuming for a tool. And we often talk about "online spaces"—-the canonical term is website, after all—but are we really going somewhere when we use this tool? In fact, despite its ubiquity, it's still important to begin by considering two questions: 
1. What is the internet?

2. What does it mean for something to be digital?

Indeed, what is it to be "cyber" and "plugged in" and "networked"?

A useful starting place comes not from academia or critical theory, but from science fiction—William Gibson's definition of "cyberspace" from his Neuromancer series is of particular interest: “'Cyberspace. A consensual hallucination experienced daily by millions of legitimate operators. ... A graphic representation of data abstracted from the banks of every computer in the human system. Unthinkable complexity. Lines of light ranged in the nonspace of the mind, clusters and constellations of data. Like city lights, receding"' (as cited in Bell Cyberculture Theorists 2). Even the term cyberspace, here, is misleading, because it suggests that what we can find online is an object. The term suggests that what exists online is something that can be specifically and accurately measured. And the term suggests that "cyberspace" is something that can be held in the hand and/or filled — that it is a container to be filled with "data." It does seem fair to say that this is the way "cyberspace," "going online," and the internet have been figured by theorists. It is, perhaps, especially easy to do this in rhetoric and composition (and the humanities more generally) because so many of us are so completely steeped in the study of print texts. And these print texts are so static - they really are things that we can measure and hold, and that act as containers for printed words. But even here, poststructural theory should help us to escape the power of a text qua text. Even Gibson's definition suggests that "cyberspace" is almost a misnomer, by calling it a "consensual hallucination." When we use the term "cyberspace," and certainly when we treat it as a container of texts to be taken and used as we please, we are complicit in the 
"hallucination." What's more, we risk reifying a whole set of ideologies and metaphors that even make this "hallucination" possible. It is important, furthermore, to point out Gibson's "cyberspace" is "a graphic representation of data abstracted from the banks of every computer in the human system." Therefore, just as with print texts, and any other type of symbol we might use to communicate, "cyberspace" is only possible through the moving and shaking and posting of real-world people.

Moreover, because "cyberspace" exists within a human system, it is never entirely abstract: it is also always deeply embodied and deeply emotional. As Bell argues:

Sitting at a computer, logged onto the Internet, for example, we are constantly clicking between the embodied sensations of staring at a screen and typing and the disembodied dream of surfing cyberspace as uploaded consciousness, but also connecting to other stories, other images and ideas—-for example, ideas about the 'world wide web' as a free source of information on an infinite multitude of topics, or ideas about the new forms of connectivity between people that the Internet has provided. (Cyberculture Theorists 6)

I agree that the idea of "disembodiment" is certainly a dream. But it is precisely this dream of disembodiment, in tandem with the dream of true democracy, that can render the internet as a simple tool filled with things that can and should be "shared ${ }^{15 "}$ widely and openly. The internet is a weird sort of space-tool-construct-activity both because the ease of access and use can almost always feel so personal, so intimate, so individual, and because it is something that can so often make us forget ourselves. To some degree, when we "plug ourselves in," we become veritable cyborgs.

\footnotetext{
${ }^{15}$ Even when "sharing” sometimes becomes total "co-opting.”
} 
In A Cyborg Manifesto, Donna Haraway famously defined the cyborg in the following way:

A cyborg is a cybernetic organism, a hybrid of machine and organism, a creature of social reality as well as a creature of fiction. Social reality is lived social relations, our most important political construction, a world-changing fiction....The cyborg is a matter of fiction and lived experience that changes what counts as women's experience in the late twentieth century. This is a struggle over life and death, but the boundary between science fiction and social reality is an optical illusion. Haraway's Cyborg Manifesto was always meant to be a highly critical, serious, theoretical, yet also tongue-in-cheek text. It was meant to highlight the dangers of damaging ideologies and the corporate-focused, capitalist economy, while at the same time suggesting an alternative to these. For Haraway, the metaphors of "cyberspace" and the "cyborg" make it possible to imagine something that is beyond human experience, and beyond human systems. As the ill-fated Fritz remarks in an early, tech-y episode of Buffy the Vampire Slayer, "The only reality is virtual. If you're not jacked in, you're not alive" ("I Robot...You Jane”). While, even the tech-positive characters in the episode ${ }^{16}$ dismiss Fritz' comment as the hyperbolic assertions of a cold, almost asocial individual, the general sentiment of the episode does seem to be that the internet really is the next (most wondrous) frontier. And while I would certainly not make the statement that we have come to our "cyborg" selves because we want to be somehow superhuman through digital technologies, I would argue that, by this point, it does seem true that we cannot be alive without "jacking in" on a daily basis.

\footnotetext{
${ }^{16}$ This scene occurs in the first few minutes of season 1, episode 8, which initially aired in April of 1997, or, in other words, the early days of the world wide web.
} 
I must state at this point that I am fully aware that these views of the internet are somewhat outdated, and that many of these assumptions have been fully problematized in academia. However, I do feel that these more "old-school” views of the internet persist, especially in dominant media. In this dominant view, the internet brings the world together, keeps us informed, and allows more people to share their opinions. In our current environment where the internet is a ubiquitous tool that can make us forget ourselves as we also feel that it takes us beyond ourselves ${ }^{17}$, it can be easy to forget just how many people in the world can potentially have access to what someone posts. It is likewise easy to forget that we make snap judgments about what is "private" material online, what is "semi-private," and what we'd like to consider as "public." We depend on others in our online spaces to both know and follow the rules of use within these spaces much as we would a smaller, in-person network. It can also be easy to assume that, because so much of what gets posted is in printed form, what has been posted is meant for public distribution, and that as long as we properly cite the source, no harm can be done. That is why it is so important to consider, and then reconsider, and then reconsider again the values underlying our online research methods. Furthermore, because the internet cannot exist without human activity, it is particularly appropriate to turn to the sets of ethical research methods values from F2F scholarship.

Perhaps it was because of the widespread use of ethnographic methods in early fan studies (especially Jenkins and Bacon-Smith), but as fan studies moved online, fan scholars continued to make use of ethnographic research methods and perspectives that highlighted people acting within communities, rather than texts solely as artifacts.

\footnotetext{
${ }^{17}$ Indeed, how can we really understand that, in a matter of seconds, we can send a message to someone across the world whom we've never met?
} 
Continuing the trend of ethnographic approaches to fan studies, Christine Scodari ${ }^{18}$ looks closely at the intersections of TV show content, the largely capitalistic concerns of TV producers, and media fans in Serial Monogamy: Soap Opera, Lifespan, and the Gendered Politics of Fantasy. Specifically, Scodari follows the development of an older womanyounger man pairing in different soap operas in the 1990s, especially Another World. She explores the shows' content, official interviews and statements released by major media producers in press, as well as online fan discussions of these shows in special forums. Ultimately, Scodari argues that neither soap operas nor fan discussions are ever entirely hegemonic nor resistive, but rather that fans take up concerns that they feel track with their personal experiences in active ways. Furthermore, Scodari demonstrates that, in some cases, online fandom can have an effect on what media giants will choose to produce. However, Scodari's study is not just about soap opera fandom, but about how online fandom carries different responsibilities for its researchers: "The issues surrounding ethnography as an approach to audience analysis are numerous and, when virtuality enters the picture, doubly so. The ability to traverse virtual space with alacrity and, many times, anonymity can cultivate in Internet users, including ethnographers, a sense of power sans risk. This further complicates issues inherent in naturalistic ethnography" (155). As the title of this chapter suggests, this is particularly my focus (and fear) when it comes to the academy's presence in online spaces.

Scodari largely does a good job of meeting the ethical concerns of working with people's texts online as, like with her and Felder's joint study of online $X$-Files fans, Scodari positions her study as person-centered, and herself as a "naturalistic" ethnographer. She states, specifically of her research methods that:

\footnotetext{
${ }^{18}$ The methods in this study are very similar to her and Christine Felder's earlier study.
} 
Three types of data collection were used in the virtual audience study. The first involved

Lurking — that is, anonymously observing and/or downloading messages and transcripts

without actually contributing to bulletin boards or online chats. The second entailed joining these discussions, with a periodic reminder to other fans that I was also engaged as a researcher. Participation in a small, informal mailing list was the third source of data, with the other e-mailers having expressly consented to be included in the study. None of the online scholars previously mentioned utilized all three methods. This naturalistic approach precluded the imposition of standardized methodological procedures in situations in which they undermined the normal flow and tenor of cultural activities of fans on the Internet. Emergent guidelines for this manner of virtual ethnography were, therefore, identified.

\section{(Serial Monogamy xxv)}

Scodari is careful to make sure that she clearly states her dual status as researcher and fan in her participant-observation of an open forum. In addition, she creates a focusgroup-type closed forum for those who have consented to be a part of the study. These methods, alone, show a particular concern for participants' privacy as well as respect for them as participants and humans rather than just as subjects. Not only was this a concern in the moments of data collection but, for Scodari, in the long term, as she says: "I felt an ethical obligation to reveal my coexistent status as a researcher to those with whom I might be repeatedly interacting. Although none did, participants could then request that I 
not include their comments in the study" (176). For Scodari, maintaining good relationships with fans over time is both a practical and an ethical concern.

Overall, I would argue that this study is a remarkable example of how to do "good" online research, especially with fan communities. It largely represents the values of respect, reciprocity, and transparency discussed above. However, I must take issue with Scodari's "lurking" method, especially given Waldorph's statement that, "Frankly, I would have appreciated a heads up" (“So Your Fic is Required Reading: Hahahanope”). From a "naturalistic" perspective, "lurking" could be seen as a useful research approach since it, first of all, does not disturb the site's environment (until the study is published, that is), and, second of all, it is a frequent form of actual online engagement. However, I argue that lurking is in danger of breaching Scodari's own concern that because the internet allows researchers access to so many materials so quickly, they can lose sight of their own ethical responsibilities. It does seem that Scodari mitigated some of the risk of this method by anonymizing the data. Nonetheless, I argue that lurking is a dangerous position to take, especially if it is never balanced with both an emic perspective of the site's "rules" of interaction as well as, when necessary (and possible), anonymizing the data.

\section{Goodwill Methodology and Online Research}

In The Ethics of Internet Research: A Rhetorical, Case-Based Process, Heidi McKee and James Porter conduct an in-depth examination of previous internet studies, and they argue for a rhetorical and "casuistic” approach to developing methodologies for online research. Essentially, this "rhetorical and casuistic” approach requires researchers to consider both the rhetorical situation—audience, purpose, genre, and exigence- of not 
only the web sources in question, but also of the eventual "research write-up," and a closely-reasoned, case-based approach to methodology. I would argue that this approach, from the perspective of New Literacy Studies, requires researchers using internet sources to take an "ethnographic perspective" on their research: most importantly within this perspective, the researcher will engage in an inductive, "theory-building enterprise" (Heath \& Street, 2008, p. 29) where s/he will use the "constant comparative” (Heath \& Street, 2008, pp. 32-38), and s/he will approach all data collection from an emic or participant-based disposition. In their collaborative text, On Ethnography, Shirley Brice Heath and Brian Street (2008) distinguish the "ethnographic perspective” from ethnographic methodologies because while the "ethnographic perspective" is based in the same theoretical premises, it often does not take place over the same lengthy periods as typical ethnographic research, and it does not use the same combinations of metrics.

In the case of my online study of fanfiction, for example, it would be easy for me to assume that because fanwriters post text under a penname, usually accompanied by some sort of “avatar" or source-text-related image that: 1) these participants' identities are protected; and 2) that writing about and reproducing fans' online commentary is not of a sensitive nature. McKee and Porter address these kinds of assumptions in depth, stating that anonymity and relative harmlessness cannot be assumed of any online environment, even where the bulk of the discussion surrounds a favorite text, as well as the craft of fanwriting (as is the case in most FanFiction.net communities). As McKee and Porter argue, features of "public v. private” and "topic sensitivity" are highly context-dependent, and exist on a continuum (Internet Research 87). They suggest a continuum-based heuristic to help researchers consider whether they should engage in a process of 
informed consent. This heuristic chart asks researchers to map out the likelihood or degree of several factors on a sliding scale: private to public; high sensitivity to low sensitivity; high interaction with participants to low interaction with participants; and high subject vulnerability to low subject vulnerability (McKee and Porter Internet Research 88). In general, the more private and the more sensitive the material, the more "likely" it is that a researcher should engage in a process of informed consent. Building upon what I have said before, I argue that any online project requires both a firm understanding of the social rules of the online communities, and getting in touch with participants/posters personally, so that the research can initiate and continue a complex process of consent that good research with real, human participants requires.

Based on these concerns, I have adjusted my own online research methodology in the following ways for my dissertation work:

1. I work from an emic perspective on the expected and acceptable engagement with and uses of online fanfiction communities.

2. I consider the complex prospective (and likely) audience(s) of my work, for example:

i. The primary audience for my work are academics trained in the related fields of rhetoric and composition, education, and cultural studies, and this audience demands not only detailed, systematic analysis of my sources, but also in-depth examples that bear out my argument.

ii. The online fanfiction participants themselves are an audience, and they demand the same amount of goodwill and generosity from me as they provide to each other. 
iii. And, the larger, non-academic audience - the "public" audience, that is also concerned with the implications and potential consequences of internet technology in this “global,” "fast capitalist,” and information economy.

3. Finally, I consider the purposes behind my research, which are: to better understand the literacy practices of communities of people (and their chosen identities); to intervene in fan scholarship by introducing a much more vigorous and detailed examination of both identity features and emotion in these literacy practices; and, in addition, to intervene in social sciences and humanities research more generally by enacting a methodological ethics of goodwill and generosity.

Based on all of these complex concerns, online research methods must also be complex. This kind of project requires both that I have a firm understanding of the social rules of the online communities, and that I get in touch with fanwriters personally, so that I can initiate and continue the complex process of consent that good research with real, human participants requires.

\section{Making Myself Vulnerable: The Fangirl Reaching from Her Ivory Tower-a Case}

\section{Study}

So far in this chapter, I've focused heavily on themes of person-based research and IRB certification, as well as sets of values that have tended to inform and shape qualitative research methods, both F2F and online. What I have not yet discussed in any depth is the tricky positioning and (self-) representation of the researcher. But as Fine made clear, it is essential that we probe the complexities and values of a researcher as s/he positions herself/himself in her/his field, in her/his publications, and, in fact, with 
her/his (potential and even ongoing) participants. Strangely, then, I will start this section with the story that another academic and fan (an aca-fan ${ }^{19}$ ) recently shared with me. S/he explain to me how s/he had agonized over the decision to openly use the word "fan" in her/his work, because s/he was deeply concerned about whether identifying as a fan would compromise the integrity of her/his scholarship. I was particularly struck by this moment, not only because it resonated with my own experience, but because it raised two crucial questions for me:

1. Isn't our research always heavily shaped by the so-called "personal"?

2. When the bodily and the emotional are such central components in our daily work and learning, why deny their roles in our research?

However, I admit that these questions were occurring to me nearly a year after I struggled with the very same things— to be or not to be a fangirl?

It was the end of January 2014, and I was working hard on my prospectus. I had completed my qualifying exams the semester before, and I was certain I could get the prospectus done by the end of February, and really starting the dissertation by March. I believed this absolutely and completely—until I began the IRB process, that is. I had always known I would need IRB approval, since I wanted to do interviews, but I always figured this would be no big deal. I had started work on the project that had become my dissertation two years before, in an archival research methods course. At the time, I became obsessed with exploring my favorite fanfic websites as living, breathing archives. I collected and presented a great deal of information about a writer on one of these sites in papers and presentations to fellow students, professors, and even colleagues at a couple

\footnotetext{
${ }^{19}$ I will come back to this term later, because, while it is beginning to be in fairly common usage in the fan studies community, it raises some important issues to question, especially what it means not only as a term but for research ethics.
} 
of major conferences. But I began, now years later, to feel deeply conflicted and even embarrassed about how I'd gone into these online spaces, picking and choosing texts as if they were my own to use any way I wished. I realized anyone could have done / could do the very same to materials I'd posted to Live Journal and My Space in high school and college, saying whatever they were able to conclude from such an incomplete record of my perhaps too public growing pains.

But that's precisely the kind of world we live in now—it's almost fully digitized, globalized, and interlinked, with text, image, and sound-bytes constantly circulating so much further beyond our more narrow geographical communities than ever before. And in a very corporate, liability-obsessed, capitalist fashion, the onus of protecting privacy and controlling one's reputation has, until very recently, largely lain with the internet user (see especially MacKinnon; McKee "Ethical and Legal Issues”). What's more, because so much of internet traffic, especially early traffic, was print-based, internet content was viewed largely through an inadequate analogy to published print texts. As long as proper citation was provided, the texts could be copied, reproduced, and excerpted however another user wished. But this approach is entirely inadequate, especially if we finally admit that the internet is not a neutral (and absolute) tool, but rather shifting set(s) of social practices (see especially the work of Hine; Jenkins Convergence Culture). I began to realize I needed not only to be more thoughtful in the consent and data collection processes, but I needed to be willing to make myself potentially vulnerable to academia and (prospective and current) participants by proudly proclaiming my fangirl status—as well as my aca-fan position. 
This process started simply_-by writing an open profile for inclusion on my fanfiction sites of study—Fanfiction.net, Sycophant Hex, Live Journal, and The Petulant Poetess. This profile (which is a variant of the recruitment email I developed for the IRB certification process) is excerpted below.

Hi! My penname is PhoenixSongFalling, and I've been a Harry Potter fan since I was 15 years old. I first discovered fanfiction during my junior year of college in 2007. I had just finished reading through the whole series (for the third time), and I was chomping at the bit for the seventh book to come out that next summer. Needless to say, I got hooked on fanfiction. I loved all kinds of pairings, but especially Harry and Draco, and, to my surprise, Hermione and Severus. I loved dystopian, "Voldemort wins" stories, and fluffy, romantic stories, and Time Turner stories. I lurked for a long time. I then started writing my own fanfiction story about Severus Snape, an original character, and a Time Turner accidentThe Unfortunate Incident. I'm embarrassed to say that I haven't finished it yet, but I hope to do so soon (when I have more time for creative writing).

I also love Doctor Who, Firefly, Buffy the Vampire Slayer, and games like Dungeons and Dragons and Mansions of Madness.

So, I'm here as a fellow fan, and still developing fanwriter.

But I'm also here as a researcher. My academic alter ego also really loves fanfiction. My name is Brittany Kelley, and I am currently working on a $\mathrm{PhD}$ in 
English at the University of Louisville. I am most interested in researching how people write in different kinds of spaces - school v. personal v. work v. online, etc. I'm really interested in researching fanfiction for a number of reasons. First and foremost, reading and writing fanfiction in college was what brought me back to my first love - storytelling. Really, discovering fanfiction provided me solace as I completed a degree program I realized I wasn’t passionate about (Linguistics), and what inspired me to get a degree in English. But I'm also interested in it because fanfiction is, well, really fascinating to me. How I think about myself as a writer, and how I think about what good, supportive writing communities can look like, is heavily influenced by my engagement with fanwriting.

So, while I am on this website, I will be reading fics, trying to write some of my own, and I will be doing research. This research will include collecting data about fanwriters’ demographics (through questionnaires), but it will also include looking closely at fanfics, reader reviews, and forum discussions. I will never quote anyone’s review and discussion forum comments without gaining permission first. Eventually, I'd also really love to do interviews with some fellow fanwriters.

If you have any questions, comments, concerns, etc., feel free to email me at bnkelley86@gmail.com. You can also check out my blog, “My Textual Romance: Fanfic, Cyborgs, and Stumbling into the Digital” at bnkelley86.wordpress.com! 
Looking at this document now, a little over a year after it was first composed and then approved by the IRB, it is striking to me just how vulnerable even this somewhat vanilla move made me feel. I was worried that the academy would think my work was a sham, because I loved it. I was worried that I'd get known as "that weird fanfiction lady," or somehow associated with sexual fetishes. I was even worried that my students would have less respect for me, thinking of me as some kind of immature, undertrained, obsessive weirdo. In short, I was worried about being "the fan." But why? I suppose this is because the fan may be allowed her/his devotion, but is not truly allowed any kind of objectivity (see especially Jenkins Textual Poachers).

But upon reviewing this document, it's interesting to me just how unfannish it seems. I do begin by self-identifying as a fan. And, sure, I list some favorite fandoms. But the degree of my fannishness still seems pretty questionable here. It doesn't even come close to revealing my love of cosplay (especially as Harry), my years-long engagement in tabletop RPGs (role-playing games), especially D\&D (Dungeons and Dragons), how much time in any given week is spent viewing and re-viewing favorite fandoms. Or the fact that I've read every Harry Potter book at least three times, and seen every movie at least five times over the years. I cringe slightly over even mentioning these activities here. And I admit to becoming more and more circumspect about my fannishness (especially my cosplay activities or purchases of fan merchandise) the more invested I become in academia. By the same token, I cannot help but wonder whether the same fear made me both certain yet uncertain I should admit any fannishness at all. I didn't want to appear too fannish. I wanted to appear professional. Legitimate. Authoritative. Not only to academia but to fans as well. I wanted to have my cake and eat 
it too. Nonetheless, it's interesting that I start by identifying as a fan, and then I identify as a graduate student, scholar, and researcher. From a procedural, legalistic perspective, there is nothing wrong with the document—it was certified, after all. From an ethical perspective, however, there are still some issues to consider. In particular, it is important for me to ask: How does this profile enact the goodwill research ethics of respect, reciprocity, and transparency?

In terms of the legalistic concerns of transparency, this document performs well, as it clearly states that I am a researcher, my academic affiliation, the general interests of my project, my methods, and importantly, my contact information for any potential complaints (and/or negotiations). However, first, it is uncertain to what extent this document goes beyond the solipsistic use of the personal (see Kirsch and Ritchie). While the first paragraph does state my "fan" status, it seems very shallow when compared to the three paragraphs that follow, establishing me as a scholar and researcher. The declaration of the "personal" here almost seems to be a very cheap effort to establish ingroup status. It bears incredible resemblance to the "arrival story" trope of the ethnographic tradition in anthropology. Except, instead of landing as a unique stranger in an alien world, I'm cast as a sympathetic fellow fan who just happens to be in graduate school. But these statements do nothing to invite discussion or negotiation with other fans, nor do they do any critical work, as Kirsch and Ritchie, Brydon-Miller, McKee, and McKee and Porter have called for.

Even worse, this document relies heavily on establishing my academic, institutionally-affiliated ethos. As such, it bears a great deal of risk of seduction (and potential betrayal—see Newkirk). What's more, especially when I state at another point 
in the profile that, "I'm also interested in it because fanfiction is, well, really fascinating to me. How I think about myself as a writer, and how I think about what good, supportive writing communities can look like, is heavily influenced by my engagement with fanwriting," I appear to place the focus of study on myself, rather than more openly stating that I will be critically reading fans' work. This document does nothing to follow Newkirk's advice that, "Ultimately those of us in the university must question the automatic belief in our own benevolence, the automatic equation between our own academic success and ethical behavior" (14). So, I suppose, then, that I need to do this here in this article, as well as conferences for the academic community. And then again in my profile and blog for the fan community.

In terms of respect, here, I do openly identify my positions, and my contact information in this document. I'm also very positive about fandom without stating generalizing assumptions about what it IS. And while I do not openly make any statements about reciprocity beyond inviting questions, I have enacted this in other ways in my research. For example, with participants who have agreed to engage in case studies, I have invited their perspectives on my analyses, I have openly provided the possibility for negotiation, and I have sent all drafts of my work that deal with each participant to them for their comments, questions, and approval. In addition, I have fulfilled other roles I did not at first foresee when participants have asked for them (see Powell \& Takayoshi). For example, with one participant, I have discussed the process of applying to graduate school. In another case, I have written reviews of a writer's original publications both because I have enjoyed the books, but also because I cared about helping her out as a somewhat unknown writer. 
I have—as I believe most researchers do—done my honor best to develop, adjust, and enact a goodwill ethics of online research methods in this project. Importantly, this means an ongoing process of reconsidering "goodwill," "ethics," and "methods." In particular, for me, this has meant inviting vulnerability. Vulnerability is a tricky term here. According to the Oxford English Dictionary Online (hereafter OED), the word "vulnerable" comes from the Latin vulnerabilis or "wounding." It has generally meant being open to attack. But vulnerabilis comes from the Latin verb vulnerare or "to wound," so earlier, now obsolete uses from the 17th century have included "the power to wound." I'd like to rehabilitate this double meaning here. When I use the term "vulnerable" in my work, I am admitting that my academic position gives me the power to wound, which then requires that I be willing to accept being wounded myself. Of course, "vulnerability" often carries with it the connotations of being weak, inept, and, perhaps, overly emotional. I admit that I cannot shake off these troublesome connotations. In fact, I argue that these connotations can be helpful in my structuring of "vulnerability" as they highlight the emotional and embodied elements of experience, which are crucial to what I am trying to openly incorporate into my work. I argue that it is possible—à la Micciche—-to do vulnerability, to turn vulnerability into a calculated, rhetorical move or device that may undermine the potentially violent appropriation of communities by academe. If I do vulnerability, then I must open myself up, truly, to critique by fans, in order to mediate and/or rid myself of the unnecessary wounding my work could do.

It is from this perspective of the double-edged blade of doing vulnerability that I'd like to "work the hyphen" (Fine) of the troubling / troublesome term "aca-fan." Even the 
shape of the term suggests several things: that an academic can be/is a fan, and vice versa (on a horizontal, equalizing plane); that the aca-fan is always academic first and fan second; that the aca-fan is something of a contradiction in terms, so much so that the words have to be forced together via hyphen; and, finally, that one element of the ratio must not only be primary but more powerful—-the "aca(demic)." Hills referred to this conundrum as a "moral dualism." Fine would refer to this particular structure as the "Self-Other" form: "The hyphen at which Self-Other join in the politics of everyday life, that is, the hyphen that both separates and merges personal identities with our inventions of Others" (70). Therefore, a term such as "aca-fan" primarily breaks down in the following way: Self $=$ academic while Other $=$ fan, where part of Self is isolated and even excised as the troublesome Other-an Other who is entirely too emotional, subjective, bodily—even feminine (see Jenkins on the "feminine/feminized fan"). However, through doing vulnerability, as I discussed above, we could see the term as, first, admitting the power to wound that our academic positions allow us, while also opening ourselves to wounding by owning our fan Selves. In fact, fully owning our fan Selves might create terms such as acafan. But this would run the risk of reifying damaging research methods, whereas doing the vulnerable aca-fan requires us to carefully tread the hyphenated space between academia and fandom such that both worlds really can exist horizontally and overlapping, rather than in a violent vertical hierarchy where the myth of the distant, disinterested "mind" of the academic always prevails.

\section{My Methods - Goodwill Ethics, Practicality, and an Emic Perspective}

In this particular study, I look at the following fanfiction communities ${ }^{20}$ :

\footnotetext{
${ }^{20}$ For more information on the participants, see Appendix I. For information about the questionnaire, interview, and case study process, see appendices II, III, and IV, respectively.
} 
- Online Harry Potter fanfiction communities at the very large Fanfiction.net (especially the "Femme Harry" (or female Harry Potter) community), as well as at the much smaller Sycophanthex.com and The Petulant Poetess, the homes of one particularly prolific fanwriter, and a particularly engaged participant-partner, Chivalric.

- Online $X$-Files fan communities on Live Journal, including the Porn Battle community. This fandom was particularly large in the early to mid-1990s at the height of the show's run, but has since become much smaller when compared to Harry Potter and Twilight fandoms. However, the community is still ongoing, still dedicated, and particularly prolific.

- An online WWE/RAW (wrestling) fanfiction community at Fanfiction.net. There were far fewer communities dedicated to this practice, but they represented a particularly interesting counterpoint to the other, much more popular fan communities available on fanfiction.net (such as communities dedicated to Harry Potter or Twilight). The community presented as many consistencies in fanfiction practices as differences, and thus became an interesting point of contrast to the other communities under my examination.

By closely investigating this range of fan communities and activities online, I have found a fairly large range of both performed and imagined identities. What's more, these communities include a wide range of content, forms, and certainly material realities of the users. In addition to the communities, I have conducted questionnaires and interviews with seven fanwriters, and I have engaged in detailed case studies with the participation of three of these fanwriters. 
The largest part of my project contains in-depth textual analysis. Because of the difficulties of easily distinguishing the public from the private in online spaces, when any text that is not password-protected is technically "public" in most fanfiction spaces, I will distinguish which texts I can and will treat as truly "public," as well as "published" by “authors,” and, therefore clearly covered by Fair Use laws. These choices are based entirely on my understanding of the wishes and dispositions of fanwriters themselves, which I have gathered as an already long-time (if largely lurking) participant in these communities. I distinguish fanfiction texts in the following ways:

1. Fan Stories: Publicly posted fan stories are understood as truly public by the fanwriters. More importantly, fanwriters wish for these texts to be treated as both public and published. They also wish for these stories to be associated with their online, fanwriter penname ${ }^{21}$. Therefore, because fans treat these texts as "truly" public, and wish to treated as authors of published texts, I treated these texts in the same way. I did not require an informed consent process for these texts, though I did announce my presence in these spaces as a researcher via an open profile statement.

2. Discussion Forum Posts: However, almost all of the texts posted to discussion forums are seen as at least partially private: participants see themselves as conversing only with other website participants - those who have "fan cred" through frequent participation and deep engagement with the source text. Therefore, I have only reproduced the comments by administrators or moderators,

\footnotetext{
${ }^{21}$ It is also important to point out that fans are highly aware that they are reworking and extending legally copyrighted materials. Moreover, even while fans understand that they are always, in a sense, "plagiarizing," they nonetheless discuss, revile, and police "plagiarism” of a fan’s work by another fan. This suggests, at least in part, that fans are aware that their material is widely accessible, but also that they wish to receive acknowledgement for their work.
} 
which were meant to be shared publicly with all users. I asked for consent for all other comments. This was hard to achieve in most cases, and it did limit the material I was able to work with, but the relationship I was able to establish with other participants was well worth it.

3. Fan Reviews (and Author Responses): Finally, reviews are viewed by website participants as some of the most private communications that take place in these online spaces. They are viewed as akin to a quick, private exchange on the phone or in person. Because of this view, I have only reproduced review comments and author responses to these comments (by quotation) with the express, informed permission of the posters.

It would be easy to assume that because fanwriters post text under a penname, usually accompanied by some sort of "avatar” or source-text-related image (my SycophantHex and Fanficiton.net penname, for instance, is PhoenixSongFalling) that: 1) these participants' identities are protected; and 2) that writing about and reproducing fans' online commentary is not of a sensitive nature. McKee and Porter address these assumptions in depth—as I have already discussed above—stating that anonymity and relative harmlessness cannot be assumed of any online environment, even where the bulk of the discussion surrounds a favorite text, as well as the craft of fanwriting (as is the case in most FanFiction.net communities).

While the actual methods section of this chapter is fairly short, I do feel that these methods, to this point, reflect the goodwill values of respect, reciprocity, and transparency that I discussed earlier. Not to mention they also take the IRB legal concerns as a starting place for expanded ethics. For example, all participants have read 
the extended consent form, even though the IRB requires me only to share the Preamble Consent form. However, as I have worked toward forging lasting relationships with these fanwriters, I have found, as I expected (even hoped), that while these methods are both advisable and effective, even they are not sufficient to meet concerns, especially, of respect, reciprocity, and transparency. The full meaning of those values could only be met by my willingness to potentially put myself at risk. I had to be willing to openly identify myself as a fangirl and an academic with vested (but often conflicting) interests in both communities. It has been this latter move which has proved the most difficult, and it is one that continually concerns me as a researcher. In the next section, I will discuss this process of constant unease in depth, but I will argue here that it is this vague sense of unease and self-risk that, at times, can mean a researcher is truly moving towards an ethics of goodwill.

\section{Conclusion: Still Towards a Goodwill Ethics of Online Research}

"Ultimately, there's nothing we can do about people examining works that we never meant to be examined this way. I think we all have to accept that the way fandom gets interacted with is changing, not just the way that we interact with the rest of the world. I do think that as a community we can and should support each other."

(Waldorph “So Your Fic is Required Reading: Hahahanope”)

"In the twenty-first century, many of the most acute political and geopolitical struggles will involve access to and control of information. Human freedom increasingly depends on who controls what we know and therefore how we understand our world. It depends on what information we are able to create and disseminate: what we can share; how we 
can share it; and with whom we can share it. It also depends on the extent to which we have any control - or any say in - how our own information is shared with other people, private companies, and governments." (MacKinnon Consent of the Networked xxiii) I began this chapter with the case of UC Berkeley's fanfiction course-how it brought academic literacy practices (and values) into fandom without first considering how fans might feel about this, even though both creators and supporters of the course identify as fans. Potentially, their failure to contact fanwriters before the course began points to a different fan experience for those who started the course. I am sure that they did not mean any harm. Nonetheless, it would have been better for both them and the students taking the course to consider the ethical and emic-centered skills of the contemporary ethnographer. Waldorph's highly negative response to the course is just one of a complex network of fans' perspectives on academics' research into their community activities. This is not to say that all fans oppose research into fandom, simply that, especially in the case of online fan communities, our research methods should take on more of the values of F2F research in order to more ethically address fan concerns. In the case of fan studies, there has been very little work that explicitly argues for particular ethical research methods with online fan communities. If we are academics who are fans, then we have an especial responsibility to "support each other," as Waldorph states. But even if we are not also fans in the same sense of our study participants, we still owe it to both these communities and future generations of academics to act ethically in all of our scholarly endeavors. 
As the quotation from MacKinnon demonstrates, and as I wholeheartedly agree, the nearly global ubiquity of digital and internet technologies has raised some crucial concerns about privacy, ownership, and representation. In the current moment, the entities with the most power over representation are institutions-corporations, the government, and even academia. This situation places the onus of developing ethical research methods on us as scholars. In an effort to work toward this goal, I have argued in this chapter for a goodwill ethics of online research methods. I have taken the concept of "goodwill" from my own participation within and understanding of fanfiction communities. Within these communities we share a tacit understanding that we strive to both maintain the integrity of the universes we so love, and to truly, positively encourage others to keep reading/watching, discussing, and writing about these universes. What best defines these goodwill ethics are the values of respect, reciprocity, transparency, and, as I have added just above, vulnerability. We show respect by openly and carefully representing ourselves, as complex as that is, as well as representing fans in ways they might represent themselves. We can enact reciprocity by not only providing balanced accounts of fandom, but also by accepting and fulfilling some roles fans might ask of us. We are properly transparent when we state our positions, values, institutional affiliations, and methods, as well as remaining flexible enough to negotiate the latter. And, finally, we best achieve these first three values by doing vulnerability: where we reach out as emotional and embodied humans to the emotional and embodied humans on the other sides of our computer screens. 


\section{CHAPTER 3}

\section{THE EMOTION ECONOMIES OF ONLINE FANFICTION}

"The spokesman for the Christopher Little literary agency said: 'JK Rowling's reaction [to fanfiction] is that she is very flattered by the fact there is such great interest in her Harry Potter series and that people take the time to write their own stories.

'Her concern would be to make sure that it remains a non-commercial activity to ensure fans are not exploited and it is not being published in the strict sense of traditional print publishing.'

He said writers had to ensure that the stories were not obscene and were credited to the author and not to JK Rowling."

(Darren Waters, "Rowling Backs Potter Fan Fiction," BBC News Online, 5/27/04) $\sim \sim \sim$

13-Year-Old Daughter Reading Porn Disguised as Fan Fiction: I discovered my 13year-old daughter has been reading fan fiction for a very popular all boy band which describes in explicit detail sex acts between the male band members. I immediately instituted parental control and blocked the sites. We had a brief talk-need a longer one, but I'm not sure what to say? This can't be good for her at 13-reading about explicit sex between ANY two people. Am I overreacting?

(Emily Yoffe, "Bedtime Stories: Prudie advises a letter writer whose 13-year-old daughter reads pornographic fan fiction," Slate, 9/8/14). 
The examples above suggest that, at least in the past decade, fanfiction has gained something of a grudgingly accepted/acceptable status. In the first example, Rowling is represented by her talent agency (a very much capitalist institution) as being very welcoming to fans' endeavors to expand the Harry Potter world. In fact, Rowling has been expanding the Harry Potter universe along with fans through the Pottermore website, releasing portions of the universe in books such as The Tales of Beedle the Bard (originally released in 2008), and even, more recently, commenting upon the romantic relationship between main characters Ron Weasley and Hermione Granger (January $2014^{22}$ ). Though this latter move was highly controversial among fans, perhaps in part because they feel the text has come to belong to its audience, nonetheless it demonstrates a very different positioning towards fanfiction activities than Henry Jenkins found in his research in the late 1980s and early 1990s. It is particularly interesting, here, that Rowling expresses concern that fans not be exploited. In his foundational work on fan practices, Textual Poachers, Jenkins encountered a world very much suspicious of fan activities: " If the term 'fan' was originally evoked in a somewhat playful fashion and was often used sympathetically by sports writers, it never fully escaped its earlier connotations of religious and political zealotry, false beliefs, orgiastic excess, possession, and madness, connotations that seem to be at the heart of many of the representations of fans in contemporary discourse" (12). Of course, despite the relative "mainstreaming" of fanfiction activities, the above examples also demonstrate a widespread discomfort with the often sexual nature of fanfiction stories.

\footnotetext{
${ }^{22}$ In January of 2014, in an interview with actress Emma Watson (who plays Hermione Granger in the Warner Brother's Harry Potter film series), J.K. Rowling argued that Harry and Hermione should have gotten married, rather than Hermione and Ron. Many fans reacted with shock and vitriol against this move, generally stating that the books were already written, and that Rowling was not allowed to turn back on her decision to pair Hermione and Ron.
} 
This discomfort is certainly a symptom of more, shall we say, Puritanical ideologies, particularly of American culture. But it is perhaps also related to a Western, Cartesian, middle class suspicion towards the bodily: "Significantly, if the comic fan and the psychotic fan are usually portrayed as masculine, although frequently as de-gendered, asexual, or impotent, the eroticized fan is almost always female" (Jenkins, Textual Poachers 15). While the respondent to the concerned mother in the Slate article assures her that this kind of sexual curiosity is perfectly normal for young women, she also remarks, offhand, that, "I'm guessing that the writers of this series didn't think their most avid fans would be teenage girls!" (Yoffe). This response does attempt to normalize the bodily, yet it also suggests that the writers cannot, in fact, be teenage girls. There's a tension of apparent propriety here. It is a tension that includes gender, sexuality, and certainly class. As I will come to discuss in this chapter, these tensions, in particular, are in the very makeup of fanfiction practices, and they are a large part of why fan practices are so important to examine as rhetoricians and literacy educators.

In this chapter, I intend to look very closely at the current practices of online fanfiction, including the content and writing communities and economies fans have built. In order to examine the specifics of online fanfiction communities and economies, I have conducted textual analyses of fan stories (and art), authors' notes, and administrator and moderator introductions to forums and posting rules. I focus on these texts in particular in this chapter because, first, these are the texts with the highest degree of accessibility in these sites, and second, these are the texts that new and continuing fans use to enter into, learn about, and then engage in fan literacy. These texts certainly do not represent all of fanfiction activity, but they do provide a very clear starting place for educating new fans, 
and for examining the meta-features of fandom, such as "canon" $\mathrm{v}$ "fanon," community cultures, and economies. I will expand upon these textual analyses with case studies in the next chapter. For now, however, I would like to focus on fandom's meta-features rather than their daily materiality for individual fans. In order to do so, I will examine three major different fandoms at different websites: Harry Potter fandom at SycophantHex.com, The X-Files fandom at LiveJournal.com, and WWE Raw fandom at Fanfiction.net.

I look at these three fandoms and sites because they provide very different aspects in terms of tensions among gender, sexuality, and class. To reiterate what I stated in chapter one, I am approaching intersectionality in this dissertation, looking at how class relates to other features of identity, the different exchange economies of fanfiction, and (in chapter four) the daily material realities of practicing fans ${ }^{23}$. Class always includes much more than financial income and material circumstances. It is also comprised of a complex nexus of dispositions: towards education, literacy practices, popular culture engagements, gender roles, sexuality, even clothing. While I do not believe that class dispositions are easily mapped (if they can be usefully mapped at all), I do believe that we tend to represent class dispositions as mappable. In other words, as scholars, we can map the ways in which social class dispositions seem to affect our expectations, interpretations, and judgments of texts and practices. Importantly, while social class and socio-economic status are not interchangeable terms, they are related to each other. Understanding the complex ways in which class is at work in fan activities requires that we look not only at ideological systems of power, but also at the important roles that technological tools and economies play in fan practices.

\footnotetext{
${ }^{23}$ For a more in-depth discussion of class, see chapter one.
} 
In addition, these fandoms demonstrate several consistencies in fanfiction practices and economies, especially in terms of emotion and the bodily that I have begun to discuss. I will examine each fandom in turn, including a discussion of the source texts, starting with Harry Potter. Harry Potter fandom is one of the most popular online fandoms, and it demonstrates well the uneasy tensions between an emotion economy and the middle class expectations of "good writing," "proper language," and publishing. I will then look closely at $X$-Files fandom, which, though television-based, maintains a very similar middle class expectation of "good writing" and community politesse, while raising some interesting questions about dominant v. resistant positions of gender and sexuality. Moreover, $X$-Files was one of the first fandoms to go online. Finally, I will examine $W W E$ fandom, which, while it makes use of the largely middle class tradition of fanfiction activities, exists in a markedly uneasy relationship to this tradition. Moreover, it presents some very different representations of gender, sexuality, and class, and it raises the additional questions of celebrity and "reality" in ways the other two fandoms do not.

\section{Harry Potter-From Boy Wizard to International Phenomenon}

The famed Harry Potter series, which now consists of seven main books (plus two "resource" texts, The Tales of Beedle the Bard (which plays a large role in the final Harry Potter book, The Deathly Hallows) and The Hogwarts Library) and eight films, tells the story of a young orphan, Harry Potter, who at eleven years old, learns he is actually a wizard, and that he is to attend a special school by the name of Hogwarts. In these books, a classic bildungsroman meets high fantasy, and readers are invited to experience a world of magic, dark wizards, whimsy, and war from the protagonist's point 
of view. Harry Potter, while he is represented as "no ordinary boy" is also represented as "no ordinary wizard," and is tasked, by prophecy, with fighting and eventually killing a megalomaniacal and despotic dark wizard who goes by the name of Lord Voldemort. The books and films have captured the imaginations of children and adults worldwide since the initial publication of Harry Potter and the Philosopher's Stone in the United Kingdom on June 30, 1997. Since then, Harry Potter has become a veritable international franchise, including a multitude of merchandise (wands, Time Turners, costumes, action figures, etc.) and even a Disney-run theme park, Harry Potter World (in Orlando, Florida). The books have heralded the coming of age not just of Harry and his friends, but of an entire generation of young readers, and, as such, they have often been celebrated as literacy aids for youth between the ages of 10 and 15 (see Jenkins Convergence Culture).

At the risk of sounding like a nighttime infomercial, I think it is fair to say that Harry Potter has truly captured the imaginations of an entire generation of young adults. These books have been able to achieve this status not only because of the popularity and success of the major motion pictures made by Warner Brothers, but because they play upon important human themes of love, hardship, and the extraordinary arising from the apparently ordinary. Not only do these books play upon recognized themes of "human" interest, but they are also highly classed. They follow the lives of three, ostensibly middle class students, Harry Potter, Hermione Granger, and even Ron Weasley. They focus on these students' schooling at a relatively small, prestigious, and competitive boarding school, in which students are asked to complete a number of intensive reading and writing assignments. Students who are able to attend the school are then expected to enter into positions as educators, healers, or in government. It is notable that, when the topic of 
individuals who were not able to attend Hogwarts is breached (in the case of Stanley Shunpike, for example), it is notable that these individuals largely enter positions of service (as a bus conductor, in this case). It is perhaps for these reasons, and more, that these books have often been lauded by literacy educators worldwide.

While perhaps the story of Harry Potter might suggest a particularly niche audience, as has been discussed, Harry Potter enjoys a truly global presence. In fact, if one types "Harry Potter" into Google, one receives over 23 million hits, including an extensive Wikipedia article, official information from Scholastic, Universal Studios Orlando, and even J.K. Rowling's personal website, as well as the Harry Potter Wiki (a crowd-source website for information on Harry Potter source texts and fan texts). Unsurprisingly, Harry Potter is also one of the largest and most popular fandoms online. By typing in "Harry Potter fanfiction" in Google, one receives over nine and one half million hits, including fan-made resources such as the Harry Potter Wiki and the Harry Potter Lexicon (a fan-made encyclopedia designed to capture any and all minutiae of the Harry Potter "universe," from character birthdays to the effects of Potions ingredients). Multiple websites exist to host Harry Potter fanfiction, with the two largest appearing to be the relatively long-standing Fanfiction.net and the newer Archive of Our Own. Fanfiction.net, alone, hosts well over 100 sub-communities (C2s) dedicated to Harry Potter, with something approaching 700,000 stories. These stories fit along a large range of potential genres—including "general" stories to Severus/Harry novellas about forbidden love and lust.

\section{Emotion Economies and the Curious Case of Plagiarism at SycophantHex}


Sycophant Hex presents itself as "a site for quality Harry Potter fanfiction," and contains five fanfiction archives - Ashwinder ${ }^{24}$ (“SS/HG shipper fics”), Occlumency (Severus Snape-centric stories), Lumos (“general” Harry Potter stories), Eros \& Sappho ("slash" and "femmeslash" fics ${ }^{25}$ ), and Chaos (a general archive). Ashwinder is by far the most popular archive on the website ${ }^{26}$, making Severus Snape the most popular character, as well as the actor who portrays him in the films, Alan Rickman. These are striking facts, given that, in the book series, Severus Snape is 19 years older than Hermione Granger, and is, furthermore, written as a truly nasty human being. Worse, while Rickman portrays Severus with a great deal of empathy, he is closer to 45 years older than the actress who plays Hermione - Emma Watson. Despite the characters' (and actors') age gap and differences in personality, SS/HG is one of the most popular pairings in the world of online Harry Potter fanfiction.

What is particularly striking about this website are the ways in which so-called "good" writing is defined, as well as the ways in which it is presumed to be achieved. On the one hand, "good" writing appears to be defined as a product achievable with simple technical know-how (formatting and grammar and punctuation conventions), as well as a highly rule-based knowledge of "canon" - source-text features, and the accepted fan interpretations or alterations thereof, known as "fanon." Moreover, "good" writing is framed as appealing to its target audience (other fans) who are, furthermore, framed as elite knowledge-makers and owners who expect "quality" work. On the other hand, all

\footnotetext{
${ }^{24}$ It is interesting to note that this archive takes its name from the Ashwinder egg, a Potions ingredient from the Harry Potter Universe (Severus Snape is the Potions Master and professor at Hogwarts school). Importantly, too, according to the Harry Potter Lexicon, these eggs are typically used in love potions. The name, therefore, is a sign of a widely-accepted fan interpretation of the source text, or "fanon."

${ }^{25}$ Stories focusing exclusively on LGBTQ relationships.

${ }^{26}$ Ashwinder boasts 3,825 stories, compared to: Lumos, 1,871; Occlumency, 1,156; Eros \& Sappho, 652; and Chaos, 325 (as of 26 August 2014).
} 
writing on the website is framed as a process - Sycophant Hex is presented as a place where emerging authors can practice their craft to, one day, achieve success (publication) in their original work.

What becomes clear, even just from a cursory inspection of the writing resources presented on the main website page is that there is a preoccupation with "grammar" (relatively vaguely defined, and mostly concerned with proper punctuation and spelling) and "appropriate" canon - or "getting canon right." As Valis 2, an administrator, writes regarding grammar, in the guide, "Avoiding Mistakes in Fanfiction Writing: A Beginner's Guide," "You can break the rules after you know them. [...]Not knowing the difference between its and it's, tenses, grammar, and all of the other mechanics of writing will bring your work down a notch in the eyes of those that care." It is notable, too, that the website contains two articles regarding grammar (comma rules and punctuating dialogue), as well as links to the Purdue Online Writing Lab (OWL), a webpage entitled Common Errors in English, and one dealing with proper British English. Moreover, in the "SycophantHex Submission Rules," half of the webpage is concerned with grammar, punctuating dialogue, spelling, and "canon" spelling (in fact, the website includes a list of all proper, Harry Potter canon spellings). The submission rules describe the importance of grammar errors much less forcefully than Valis2, but they make it clear that stories with "major errors" will be rejected outright. However, they also urge the use of a beta ${ }^{27}$ reader, suggesting that writing is understood as a process inasmuch as it is viewed as a product.

The most troubling views of grammar, however, are communicated within the website discussion forum, "The Daily Prophet," which is limited to website administrators. In a post entitled, "Reminder Regarding Forum Posting Rules!",

\footnotetext{
${ }^{27}$ The website term for editor or proofreader.
} 
administrator Diana (a "Head Moderator") urges members that they "are not an exception [sic] the rules." Regarding grammar, she says, "Correct English. This includes proper capitalisation, grammar, and spelling if at all possible. Again, we realise that not all of our posters are native English speakers, but you should know where the shift and the punctuation buttons are on your keyboard: use them!" (Diana). While, perhaps, this particular administrator may have felt that by recognizing that some website users were not native speakers of English, she was invoking a spirit of open access, it seems clear to me, given her comment, "but you should know where the shift and punctuation buttons are on your keyboard!", that Diana is likely responding to previous user complaints. In stark contrast to both the more general view that online communities are more democratic, as well as to the website's seemingly friendly welcome - "We are delighted to provide this service to you free of charge. [...] Now sit back, relax, choose your poison -and enjoy!" - this vehement directive concerning "correct" English suggests that, while most members are subject to a standard of perfection, the website administrators, as the "inner circle," are not ${ }^{28}$.

The case of Harry Potter canon is often stated just as vehemently, though it is sometimes unclear who is judging what "counts" as "canon." For example, Valis2 writes: "The rules of the fandom universe are what makes the universe that particular universe. If you obliterate the rules, you may as well write 'Quacky McDuck Sings the Blues' and do something entirely original instead of forcing someone else's characters to do odd things." Certainly, this hints at audience - how to appeal to readers, something we value very

\footnotetext{
${ }^{28}$ In fact, when azazello, an administrator, addresses user complaints about website standards, she expresses bewilderment at the complaint, but, nonetheless, comes to argue that "correct" English and "correct" canon are paramount and, furthermore, apolitical and unproblematic - they just are. See "Sycophant Hex - Submission, Validation and Rejection."
} 
highly in rhetoric and composition. On the other hand, this audience appears to care more about surface features and common knowledge than on creative, new possibilities for Harry Potter characters and settings. This preponderance is reminiscent of "current traditional rhetoric," bringing to mind authoritarian classrooms highly focused on formulaic writing activities, wherein "good writing" is narrowly defined within surface features, as well as one particular set of academic interpretations. Given all we have done in rhetoric and composition to combat those kinds of practices in our classrooms, we might believe that fanwriting communities are better defined by their gatekeeping practices than by their seemingly democratic views of access and their exchange of largely symbolic and cultural capital.

While it is certainly true that these websites do maintain some gatekeeping practices, it is interesting to note that, even within the essay urging new community members away from "the pitfalls of novice fanfiction writers" (Valis2), writing is also framed as a learning experience, a chance to develop, stating, "We're all here to improve, right?" It is interesting, too, that, while this essay is clearly written by a website administrator (ostensibly, an individual who has advanced to the "inner circle," as it were, of this fanwriting community), s/he (likely she), self-locates on an equal level to incoming fanwriters, saying, "Being a novice fanfiction writer myself, and having made all of these mistakes and more, I feel fairly confident about prattling on about them." Of course, this example alone is not enough to show that website participants all appear to feel as if the fanwriting process at the website is nurturing to them.

However, it becomes very clear in reading authors' notes that authors cherish their relationships with their beta readers, and that they feel these relationships have 
encouraged them to become better writers, even when those relationships meant strict corrections of authors' writing. Chivalric's notes preceding another of her top-rated stories, At the Beach, for example, read like this within the first chapter: "This story is for notsosaintly. Thank you - for everything! / Dreamy_Dragon has done the main work on this story *hugs you tightly* / Additionally, I had help from Sampdoria, CharmedForce, Arabella Bloodgood, and sunny33. That only proves that betaing for me is not an easy job. Thank you, ladies!" That is to say, while posts concerning website submission rules appear to privilege gatekeeping above any teaching role the site might play, that is clearly not the full story.

Ironically, in fact, this can best be seen by examining the curious treatment of "plagiarism" on the website. It is difficult, first of all, to find a definition of plagiarism on the website, even in the submission rules and "Terms of Service," though it is not particularly difficult to find vehement directives against plagiarism. In fact, it is defined only once on the website, deeply embedded in the Writers' Resources - The Enchanted Quill pages in the discussion forums. azazello, the author of the definition, as well as a website administrator, explains:

What's yours? What do you, the writer of the fanfic, own? Essentially, everything that is not JKR's. The characters you the ficcer made up, the plot, the settings. The dialogue. It's yours but you have no legal recourse if someone nicks your characters, plot, settings. That's because you are operating in the world of fanfic and therefore do not hold intellectual copyright on your stuff. Technically, JK Rowling does. ("Plagiarism - what's hot and what's not...") 
In many ways, this is exactly what we might expect to find ${ }^{29}$; a vague but vehement distinction between "one's own original" work and the work of another. Moreover, the definition goes on to explain that writers should always acknowledge all uses of other fanwriters' concepts, characters, or features (e.g. original spells), and, regarding fellow fanwriters, that authors should always ask before making use of ideas they may have read elsewhere. However, it is unclear, even within this post, where the line should be drawn between concepts that must be borrowed and those that are "common knowledge" to the Sycophant Hex community. Of course, that is the difficulty in any definition of plagiarism - website users will only learn this through deeply engaged participation ${ }^{30}$.

What is more striking about the view of plagiarism on the website, however, is the way in which it is seen not necessarily as a lack of authenticity - "First off, in a sense, we are all plagiarizing. That's to some extent what fanfiction is about" (azazello) - but rather, that it is a direct offense against the affective economy of the website. Just as shoplifting "steals" items from a store and money from the pockets of its employees, plagiarism, here, appears to "steal" sincere, affective engagement, not to mention cultural capital (credibility) within the website's knowledge-making, interpretive community. As azazello puts it: "Plagiarism is hurtful, it's offensive to writers and readers alike. It's insulting [...] to those who work hard on their own stuff (even if it is not exactly brilliant, but honest work) only to see the work of a copyist ${ }^{31}$ get better reviews and more attention"

\footnotetext{
${ }^{29}$ For an in-depth treatment of fanwriting's relationship to copyright laws, see Rebecca Tushnet 2007.

${ }^{30}$ For a discussion of how plagiarism might be better taught in the classroom, see Margaret Price 2002. It is possible that fanfiction could be brought into the classroom to discuss the concept of plagiarism, though I believe, in general, in careful circumscription when transferring features of out-of-school sites into classrooms.

${ }^{31}$ It is notable, here, the parallels between this representation of plagiarism and the fuzzy boundaries of intellectual property as they were discussed regarding copyright in the 19th century. For an in-depth discussion of reprinting and copyright in 19th century book culture, see McGill. It seems likely that we will face many of the same issues with copyright laws in relation to online authorship.
} 
(“Plagiarism - What's hot and what's not,” my emphasis). Chivalric, in fact, bears out a similar interpretation when she discusses plagiarism of her fanfiction on fanfiction.net ${ }^{32}$ : "kittylefish informed me today that one of my stories has been stolen and posted to FF.net [...] In case you want to check if one of your stories has been stolen by the same person, go check here" (Chivalric55).

What is emerging here, then, is a complex (and, at times, self-contradictory) view of what it means to be a fanwriter at Sycophant Hex. As I have suggested, I believe that this community is more representative of deeply affective exchange economies, though I do also admit that they are beset with issues of power differentials and gatekeeping. It is particularly interesting that Sycophant Hex displays many parallels with 19th century authorship and book printing. While, today, there is still a dominant representation of the lone-author, brilliantly spouting new and "original" ideas from her/his head from the isolation of a cramped, dank office ${ }^{33}$, in fact, we see through fanfiction communities that an author is never fully singular -she or he always exists within complex, personallyengaged communities. Jackson remarks that much of 19th century book culture exists within a "gift exchange" economy; that, "Gifts are dynamic, free, embracing, and spiritually rich, while commodities are static, costly, isolating, and spiritually impoverished. To treat one's gift as a gift is to create a generous and genuine community of the imagination" (90-1). Moreover, he argues that authorship (and certainly what we might call professionalization) in the 19th century existed at the center of a large nexus of

\footnotetext{
${ }^{32}$ When I discuss Chivalric in more depth, I will not deal with her presence on fanfiction.net, because Sycophant Hex and The Petulant Poetess seem to be her main bases of operation.

${ }^{33}$ And, in fact, this is the way in which J.K. Rowling is generally represented by the media. An example is Sean Smith's biography, 2003.
} 
different economies, not just within a financial economy. It is this particular view of authorship that I am arguing is at work in the Sycophant Hex community.

\section{“I want to believe": The X-Files as Accessible TV (Fannish) Object}

The first episode of The X-Files aired on September 10, 1993, and it presented the story of an up-and-coming F.B.I. agent, Dana Scully, who is rational, scientificallyminded, and eager to make her mark on the Bureau. She is assigned the duty of spying on fellow agent, Fox Mulder, who, once a brilliant profiler, has become obsessed with investigating the large stack of still open, unexplainable files in the basement, or the "X" files. He is disposed to believe whole-heartedly in the paranormal and/or supernatural aspects of these cases, and seeks to expose these things to the world. The show soon gained huge cult, and then widely popular status. It enjoyed nine seasons, running from 1993 to 2002, and the franchise released two feature films (The X-Files (1998), and The X-Files: I Want to Believe (2008)), not to mention multiple action figures. In fact, even the city of Vancouver, Canada enjoyed some increase in tourism during and after the show's run with "X-Files"-themed tours of the show's long-time filming location (see Hills, and Jenkins, Ford, and Green). At its peak, both the show and its creator, Chris Carter, enjoyed truly international fervor. Even a fannish song was written (and performed by singer and songwriter Bree Sharp) about the show's "hunky" protagonist, actor David Duchovny, and a whole slew of late 90s pop culture icons participated in the filming of the music video, including Sarah Michelle Geller-the main star of Buffy the Vampire Slayer, Pamela Anderson—the major star of Baywatch, and even Jerry Springer - the host of the wildly popular late 1990s daytime gossip/talk show. 
The $X$-Files as source text certainly differs from Harry Potter in that it is, primarily, a television show, and one that aired largely during prime time on the large American network, Fox. The show eventually invited nearly nine years of avid watching and serious speculation and was, in many ways, widely accessible to multiple audiences. It originally aired on Fox, a major television network that was most often offered in basic cable packages, and was relatively easily accessible through an antenna for those without cable. Its primetime status also suggests that it is available to audiences within a wide range of class positions. Finally, while there were large, serialized storylines on the show (the so-called "Mythology" episodes, as well as the long development of the ScullyMulder relationship), the show's highly episodic, "masculinist" weekly format made it as how one could largely pick up at any point, which again makes it much more readily accessible than Harry Potter, which required an initial, dedicated, and sustained reading period and/or, at least, watching period. Finally, The $X$-Files was geared towards an adult audience (which is made clear, especially in the United States, by the presence of graphic violence as well as sexual themes), while Harry Potter was always marketed as a youngadult set of texts.

\section{X-Files Fandom: Emotion Economies Meet Scandal, PrOn, and “Good” Taste}

The work of cultural studies ethnographers such as Henry Jenkins, Camille Bacon-Smith, and Constance Penley demonstrates the long-standing tradition of fanwriting within zine culture, often linked to the development of Star Trek fanfiction, especially "Spirk" pairings from the early 1970s onward. $X$-Files fandom, and certainly $X$-Files fanfiction seems to have ushered in much of the online fan activity that is so familiar in 2014. It is likely that most fan work went online because of fans' concerns for 
widespread accessibility. In any case, The $X$-Files enjoyed an early online presence (see Penley, Scodari, and Bury). However, despite this, searching for "X-Files fanfiction" in Google yields only 1,820,000 results, compared to Harry Potter's 9.78 billion. Furthermore, Fanfiction.net hosts only eight very small C2s dedicated to $X$-Files fanfiction. Nonetheless, there is an extremely detailed and well-maintained $X$-Files wiki, and very vibrant and ongoing $X$-files communities continue to be maintained on LiveJournal.com. One such community, xfiles.livejournal.com not only hosts $X$-files fanfiction, but also continues to follow the work of actors David Duchovny and Gillian Anderson. In fact, a recent post (11/4/14) mentions the second season of The Fall, a gritty, BBC crime drama starring Gillian Anderson as a detective following the trail of a serial killer, which premiered in 2013 (The X-Files TV series completed in 2002, and the final $X$-Files movie was released in 2008).

This community, similar to other fanfiction communities, e.g. Harry Potter, is moderated but clearly fan-sourced and fan-maintained. In addition, it is clear that "goodwill" ethics are the order of the day in this community as well, given that the community rules specify that: "1. Do not make personal attacks or insult each other. Be decent" and "All ship ${ }^{34}$ preferences, whether they be MSR, DSR, DRR, WHATEVER will be respected and welcomed.... As well, if a person is posting, for example, icons of a ship you do not like, don't go out of your way to start nagging on that person's ship. That's not why they're here." Again, this "goodwill" focus, in its highly middle class politesse, is in a particularly interesting relationship with the very middle class values of "good communication through clear writing" that we saw most vehemently stated on Sycophant Hex in the Harry Potter fandoms. For example: "8. Please write in a way that

\footnotetext{
${ }^{34}$ Fan community abbreviation for "relationship.”
} 
allows everyone to understand you. Netspeak isn't going to go over well, and it just makes people cranky when they have to struggle to read what you have to say." I say that these two features are highly representative of "middle class" traditions because, in the case of politeness, while it has been asserted that middle class children are typically socialized in ways to prepare them for negotiation and therefore, management (see Peckham), middle class women are socialized to be agreeable. Furthermore, the directive against using "netspeak" above is reminiscent of multiple examples in scholarship of some teachers' responses to the written forms used by students with working class and/or multilingual backgrounds as “incoherent," "disorganized,” or even as representative of “simple thinking” (see Peckham’s discussion of a GTA's response to a working class student’s writing as “incoherent,” 29-30; see also Shaughnessy, Heath, Silva, Canagarajah, Matsuda, Lu, etc.). So, while The X-Files has a long tradition of being potentially accessible to multiple audiences, and while present-day internet technology is highly accessible to those with many different material realities, the traditions of fanfiction economies remain fairly middle class.

This is likely because these online sites are tapping into and making use of the long tradition of zine-publishing, which, while often resistant, was also always highly dedicated to legitimizing alternative (women's) writing spaces, and to the craft of writing. In fact, Penley noted this particular feature of fanwriting culture in the early 90s, as she analyzed her experiences with fanwriters from the early to late 1980s, saying: "The strong pull toward 'professionalization' is described by the fans in terms of getting 'hooked' or 'contaminated' by the writing and editing process. One fan writer and editor came up with what she calls 'the virus theory of fandom'....The virus theory of fandom 
attempts to account for the tendency to become fascinated and then obsessed with the craft of writing, to want to delve ever deeper into its techniques to produce something that pleases both the author and the readers" (111). That is to say, while the reason for "proper grammar and punctuation" even in fan discussion forums is often represented as an issue of accessibility (and it may well be), it cannot be entirely separated from its function as a legitimizing and, perhaps, even policing function of "proper" writing. While fan activity is perhaps exciting because of its very unsanctioned status, this same lack of sanction seems to present a highly problematic anxiety to participants, perhaps especially as many of these participants are already embodying marginalized positions.

Of course, I must be careful to point out that arguing that fanwriters are marginalized, tout-court, is an oversimplification. Certainly, the practice itself is largely unsanctioned in ways that often criticize both it and its participants for being overly "feminine," "romantic," and out of touch with reality. There is a long-standing tradition of this particular representation, that can be captured well in Henry Jenkins' retelling of the famous Saturday Night Live skit from December 20, 1986, in which William Shatner, annoyed with Star Trek fans, urges them to "'Get a life, will you people? I mean, I mean, for crying out loud, it's just a TV show!"' (quoted in Jenkins Textual Poachers 10). In particular in this example, Shatner not only suggests that Star Trek fans have no grasp of daily reality, but that they are to be further chastised because of their emasculated state as fans, saying to a male fan, "'You, there, have you ever kissed a girl?"' (quoted Jenkins Textual Poachers 10). In fact, even with the recent "Geek chic" trend, evidenced in part by the huge popularity of shows such as The Big Bang Theory, fans are often depicted as largely sexless, social pariahs. For example, in the first season of The Big Bang Theory, 
the protagonist, Leonard Hoftstadter, and his friends dress up in the costumes that largely represent their fannish interests for their neighbor, Penny's Halloween party. In this episode, "The Middle Earth Paradigm" (which aired on 29 October 2007), Leonard dresses as Frodo for Halloween, and his character, represented as smart, soft-spoken, and gentle in the show, is pitted against Penny's ex-boyfriend, who is tall, athletic, pugnacious, and dim-witted, though nonetheless popular "with the ladies," as it were. So, while the show overwhelmingly focuses on the experiences of its "geeky" characters (especially Leonard and his roommate Sheldon Cooper), it is nonetheless quite clear that engagement in fandom is a still somewhat unsanctioned, almost shameful activity.

Despite many fans' ardent following of particular celebrity figures, and even chosen (tongue-in-cheek, no doubt) website names such as SycophantHex.com, "Far from [sycophantic], fans actively assert their mastery over the mass-produced texts which provide the raw materials for their own cultural productions and the basis for their social interactions" (Jenkins Textual Poachers 23-4). I would argue, in addition to Jenkins' position, that fans' emotional engagement with source and fan texts both allow and invite them to engage in meaningful interactions with power structures and ideologies within larger society, and in microcosm in the source texts and the communities fans willingly create. In order to see the complications among resistance v. complicity, marginality v. privilege, and critical v. emotional work, it is particular useful to explore one small facet of $X$-Files fandom online, the Live Journal porn battles. These are especially evocative because, through their scandalous, almost marginalized status, these forums allow for the distinctive mix of resistant yet accepting positions—marginal yet privileged—fans might inhabit. 
Live Journal, an online personal blogging website, is host to several fanfictionrelated pages and forums. In addition to the more general $X$-Files fan forum discussed above, Live Journal hosts a set of webpages for $X$-Files-related pornographic challenges, called, The X-Files Ball of Wrong Porn Battle: The kind of battle where everyone WINS! Wins pron! Initial battles seem to have been set in 2009, and the front page hosts a picture of actor David Duchovny, as FBI Agent Fox Mulder, sitting slightly to the side in bed in his underwear. The site is careful to let readers know that they are "about to view content that may only be appropriate for adults," but is otherwise easy to access. It is not password protected. It appears that these particular Live Journal pages were established for sets of porn battles for 2009, and seems to have closed since then. The "X-Files Porn Battle III" invited writers to participate and post a short, pornographic story, between September 26 and September 30 2009. The battle includes two pages with a total of 312 comments, some of which are stories, others of which are replies to the posted stories. The majority of the stories, here, seem to focus on Mulder-Scully (or heteronormative) pairings, though a few stories feature Mulder and $\operatorname{Krycek}^{35}$, and a few feature Scully and an original character, as well as another featuring Gillian Anderson and Mary McDonell (the actor who plays the famous President Laura Roslin in the rebooted Battlestar Galactica series, 2004-2009). Regardless of these other offerings, however, the majority of the writers seem focused on Mulder-Scully pairings. This tendency is likely due to the format of the original series, in which Mulder and Scully were not only the titular

\footnotetext{
${ }^{35}$ Alex Krycek originated as a one-shot character to fill Dana Scully's shoes while her character was offscreen for several episodes. He first appeared in season 2, episode 4, "Sleepless," which aired on October $7^{\text {th }}, 1994$. The character of Krycek eventually became a major nemesis for Mulder, and, near the end of the series, an uneasy ally.
} 
characters, but their relationship was largely based upon mutual respect and friendship, rather than romantic interest.

In the original series, Mulder and Scully maintained a solely platonic relationship for a long time. In fact, a sexual relationship (forget about a romantic relationship) is only hinted at for the first time near the end of the seventh season, in the episode "All Things" (7.17), which begins by showing Scully quietly dressing in Mulder's bathroom while he sleeps naked on the bed behind her. In fact, the possibility of a relationship between the characters was a major feature of early online fan debate. Examining early online $X$-Files fandom and its resistant potential in "Creating a Pocket Universe: 'Shippers,' Fan Fiction, and The X-Files Online," Christine Scodari focuses in particular on two opposed groups of fans: "shippers," or fans who are dedicated to exploring the possibilities of certain romantic pairings in the show, particular that of Agents Fox Mulder and Dana Scully, and "NoRomos" who see this romantic pairing as an adulteration of the show's original intent: “[Shippers'] anti-essentialist feminist endeavors to reclaim the concept of romance rather than rejecting it out of hand because of its patriarchal misappropriation. While the Mary Sue dynamic operates for Shippers insofar as they identify with one agent as the romantic interest of the other, the relationship itself, in light of its political dynamics, is their primary object of devotion” (244). Scodari found that, of many self-identified female fans, the Mulder-Scully romance, or MSR, is either staunchly rejected or enthusiastically supported on largely the same grounds: the representation of these characters as intellectual equals. Interestingly, for those who really support MSR, Scodari found that this was because of the alternative to heterosexuality as usual that the pair offered. As one fan comments: "'This is exactly why I find the M\&S relationship so 
important....I think they are attempting to define the heterosexual romantic relationship for the new century"' (quoted in Scodari "Creating a Pocket Universe" 244). It is particularly interesting to note of these more recent "pr0n" fanfics that they either take mutual respect as a given or they play with both privileged ideas of dominance and power, especially in terms of gender.

A particularly evocative example from this Live Journal porn battle is the story, "Balm in Gilead" by writer aloysiavirgata. This story is short, as all of the porn challenge stories are, but it packs together quite a few themes: gender, heterosexual fantasy, heteronormative pairings, dominance, and class difference. In this one-shot, Mulder's character is painted as having grown up in the upper middle to upper class-New England old money—as the story takes place at the family's summer home in Martha's Vineyard. In the original series, it is made clear that Mulder's father was a scientist and FBI agent, which by itself would certainly not have made such a privileged lifestyle possible. However, in the original series, Scully and Mulder do visit his childhood summer home (which is actually in a coastal town called Quonochontaug, Rhode Island) searching for clues about the facts surrounding Mulder's mother's stroke (all of which can be seen in the episode, "Talitha Cuma," 3.24), which does suggest that Mulder may have had something of a privileged childhood.

Nonetheless, Mulder's upper middle class position is established in this story as making Scully nervous:

They've been going through the house at Martha's Vineyard for two days, sorting the accumulations of a life. Scully seems uncomfortable in the presence of 
his privileged childhood at times, her eyebrows twitching at outgrown skis, the dog-eared snapshots from cruises.

Her hair, too short for a ponytail, is tied beneath a blue bandanna, her nose smudged with dust. Mulder wants to breathe her in like a basket of clean laundry. He imagines her riding a red bicycle along the road to Lake Tashmoo. (aloysiavirgata "Balm in Gilead,” my emphasis)

This example is particularly distinctive, because it moves beyond the original source-text focus on the tension between Mulder's willingness to believe (his arguably "feminized" role) and Scully's more or less strict adherence to scientific rationality (her arguably more "masculinist" role, see especially Christine Scodari's "Creating a Pocket Universe"). Here, the writer presents us with the further tensions of sexual desire, gendered differences in terms, perhaps, of a more assertive versus a more passive position, and, notably, different class positions.

The collision of gender role expectations and class in this example is particularly interesting in the ways that it suggests a constituted and performed woman/"female" positionality that is at once complicit within yet resistant against dominant ideologies. For example, not only is the class tension stated in this scene--"Scully seems uncomfortable in the presence of his privileged childhood"—-but it is nimbly and neatly written into the very bodies of the characters ${ }^{36}$. Scully is not only assumed, by Mulder, to be "uncomfortable" with the outward signs of his presumably higher socioeconomic status (here, associated as class), but she bears the very signs of the working class on her person, from the dirt on her face to her practical hair: "Her hair, too short for a ponytail,

\footnotetext{
${ }^{36}$ Notice, also, the double level of class tension here, as this story is told in Mulder's point of view, so the writer is assuming and performing his class privilege.
} 
is tied beneath a blue bandana, her nose smudged with dust." What's more, Mulder seems to wish to take the dominant position over Scully's body—-[Mulder's] fingers move over her collarbone, sliding down to unbutton her yellow shirt. It falls open and he sees her swallow hard. / 'It wasn't a mistake,' he murmurs against her ear"—but over her class as well. Mulder first fantasizes about re-"dressing" Scully’s childhood as his own, and later as he literally de-frocks Scully of her "working class" costume and re-vests her with his family's middle class legacy by way of his mother's necklace:

"Go on," he says, setting it before the vanity. "Take it for a spin." He wipes the mirror clean with his forearm, then guides her to the seat. He tugs the scarf from her head, keeping his face level with hers.

Shafts of light play across the room, warming up her hair and the old wood with amber and gold. She stares into the mirror, watching him as he rests his hands upon her shoulders.

Finally, not only does Mulder ceremonially induct Scully into his class position by redressing and then dominating her, but he then "settles" for the less her class signifies:

He presses the key into the lawyer's hand, feeling as though he's raising anchor.

"That's all you want?" the man asks.

Mulder looks at the car, which has a few boxes in the trunk. Scully sits on the hood, face upturned to the mackerel sky.

"Yeah," he says. "That's all."

I would not argue that Scully disappears entirely in this scene, just as the writer does not disappear entirely into the ideological power of the source text-the writer takes the 
freedom to pair Mulder and Scully—nor entirely into the ideological power of class and gender roles of society, as Scully retains her own space: "Scully sits on the hood, face upturned to the mackerel sky." These multiple levels of play among gender, sex, and class are interesting, especially as they stand in stark relief against the highly classed features of the porn battle's posting rules.

At first, the rules here seem a lot "chattier" than they did in the $X$-Files general Live Journal page, and certainly much more so than they were at Sycophant Hex in the Harry Potter fandom: e.g. "2. You do not need to claim a prompt. You can take any prompt you'd like and use it in any way you seem fit, you pervert. You can use one prompt or even more than one at once, if that's the way you like it." This is, perhaps, because the writer imagines only other adult readers (which, in itself, is an interesting complicity within U.S. and "western" ideologies of "appropriate" sexual desire), and therefore wishes to assert a sense of solidarity with the readers, rather than an authority over them. This same tone is clearly playful, and in keeping, on the one hand, with a light-hearted portrayal of the otherwise quite (potentially) scandalous nature of the activity here-writing pornographic stories. In addition, then, the playful and "chatty" tone seem to mitigate the pornographic element of this challenge and, by extension, denying it its scandal status, and almost de-sexualizing not only the stories but writers' very participation in the challenge. The writers are almost denuded of their desire.

Despite this "neutering" move, the anxiety of the sexual taboo remains in play, from the age limit-"1. Participants must 18 or older. If your momma comes crying to us because you've been corrupted, we will NOT be happy"—-to a tongue-in-cheek but offhand denial of the participant in "you pervert," to the sheer amount of information 
about formatting rules for posts. In that sense, then, these rules portray, in a similar way to "Balm in Gilead," an intriguing tension between complicity with "proper" gender and class positioning in relation to sex and desire, and resistance against this propriety in the very creation of this pr0n battle.

Beyond the anxiety of desire in the very content of these rules, there is an interesting tension between "proper," middle class, "masculine," and dominant understanding of creative composition, authorship, and publication. Of course, the very existence of these rules is not just a matter of legal and technological concern. They are a reflection of a much larger system of middle-class, "objective," masculinist, "big Company" or capitalistic literacy. The existence of these rules is certainly an aspect of this power structure, as is their overwhelming focus, nay, expectation of print media, despite asserting that the writer may "write the porniest bit of fiction you can, or make the hottest manip/fanart or painting or vid or song. " But, within just a few lines of this claim, which highlights print in the first place, the rules state that, "If you have written more than one story," and later, when a slew of rules about character and word limits dominate the page.

Likewise, within this print-obsessed dominant literacy position, the author as singular and autonomous is largely asserted, especially through the use of direct address, and certainly the single, genius author notion reflected in: " 3 . You must post something new. It can be part of something longer you're working on, but it must not have been previously posted anywhere else." In other words, the battle "needs" an author. One rule does assert that, "6. Collaborative fics are welcome!" but this is not elaborated upon, as if it can be safely assumed that most entries will come from a single, author source. So, 
while this forum presents an alternative, in part, to the masculinist model of authorship and publishing, through the chatty tone of the rules, the cachet through the scandal of bodily desire, to the potential of collaborative work. Nonetheless, this forum is still complicit within that model.

Perhaps, as Jenkins asserted of fanzine writers in the 1980s and 1990s, "Like the poachers of old, fans operate from a position of cultural marginality and social weakness. Like other popular readers, fans lack direct access to the means of commercial cultural production and have only the most limited resources with which to influence entertainment industry's decisions" (Texutal Poachers 26). Of course, these fans aren't really powerless and completely weak. These rules exist within a dominant format, but they were written by a fan with an alternative notion to the capitalist publishing machine, and this alternative is used to create space to state bodily desire and for alternative, supportive communities:

7. Remember that anonymous posting/commenting and sockpuppetry do not allow you to be an asshat and flame or troll the community.Don't like $a$ pairing/grouping? Don't read it. Don't like a particular author/creator? Don't read/view their work. Don't like a story? Keep your snark to yourself. We will delete any such posts, ban users who can't act like adults, and may disable anonymous commenting. THIS IS WHY WE CAN'T HAVE NICE THINGS ANYMORE!

The focus here is on goodwill, an economy of mutual support and dedication outside of the stability of "intellectual property" in a legal sense. Yet, again, this rule is also located 
within a structure of middle class politesse, especially a more feminized one, which highlights nurturing and communal engagement over the agon.

So, while, in keeping with the tradition of fanzines and online fanfiction both before and concurrent to it, the $X$-Files fanfiction space, even within the porn battle, creates a space for personal and creative expression—a space for feminized nurturing, quotidian embodiment, and "feminine" sexual fantasies. It is true that many of these stories are highly heteronormative, and, what's more, largely silent on issues of class and race, it is still the case that this forum allows writers the space to state their fantasies in a protected environment, which in itself is something of a resistant act. After all, these writers have already been so deeply socialized into dominant ideologies about genderespecially "womanhood," "femininity," and desire—as well as class and sex.

Nonetheless, these online communities really do appear to provide an alternative spacea space for "women's writing": "The emergence of media fandom can be seen, at least in part, as an effort to create a fan culture more open to women, within which female fans could make a contribution without encountering the entrenched power of long-time male fans; these fans bought freedom at the expense of proximity to writer and editors" (Jenkins Textual Poachers 48). But this is not only an uneasy space, it is a limited space as well. There does appear to be "one" way to do Pr0n in this battle. This can be most clearly seen in the story, "The Red and the Blond," by hades 77.

Thus far, the fanfiction spaces discussed have provided participants with the opportunity to express themselves- to creatively rewrite the source text and even dominant ideologies_-in an environment that is largely goodwill-centered and emotionally supportive (if also largely middle class). However, while it is true that 
accessibility and goodwill engagement are part of the fanfic tradition, it is not fair to say that, somehow, "Our utopian communities are now to be found in the digital landscape, a non-hierarchical democratic space where global democracy can finally be realized” (Wajcman 57). Just as with any other face-to-face interaction, these spaces are, as we have seen with the issues of gender, sexuality, and plagiarism above, still shaped by larger ideologies of class, certainly, and the gatekeeping that goes with it. The story, "The Red and the Blonde," which I discuss below, is a particularly effective example of this because it alone of all the stories posted in the porn battle received deeply negative feedback. This negative feedback is significant not only because the fan-work below breaks the rules of the $X$-Files porn battle community, but it appears to incite other users to go against community traditions of support and goodwill. It is a clear example, in other words, that not just anything and everything really goes in fanfiction communities.

"The Red and the Blonde" was posted on September 29th, 2009 (right at the height of this battle), and it was accompanied by an original piece of fanart that was, presumably, done by the same writer. The image is extremely graphic in nature, and so I have chosen not to reproduce it here, but I will describe it below, as the image is a major reason why this story received such negative feedback. In the image caption, Dana Scully and Calleigh Duquesne, a popular character from CSI: Miami ${ }^{37}$, challenge each other to a game of strip shooting. Eventually, the two women progress to pleasuring each other with the empty guns, and then pleasuring two male colleagues. The content of both the image and the story are certainly pornographic, as was called for in the battle challenge, and the story even includes something of a femmeslash pairing. However, it is the only story in this battle to receive negative feedback. In fact, not only is the feedback negative, it is

\footnotetext{
${ }^{37}$ Played by actor, Emily Procter.
} 
also insulting ${ }^{38}$. Why might this be? I argue that the reasons for this are, first, that the content of both the image and the story are too overwhelmingly patriarchal—in fact, they are entirely misogynistic — to be seen as viable contenders in this particular community's fanfic challenge. This story is porn, but it's not prOn. Second, the story breaks with middle class expectations of narrative style, characterization, and, foremost, language.

As I discussed earlier with the story "Balm in Gilead," many of these stories could be said to be complicit within a patriarchal paradigm, wherein sex and gender are taken as more or less synonymous, biological facts, heterosexuality is not only "natural" but compulsory, and where dominance—especially sexual dominance—is the realm (and duty) of the man. Despite this, however, all of the other battle contenders do appear to provide the characters with a sense of agency and subjecthood. More importantly, I would argue, all of the other stories follow the tropes and protocols of romance fiction and previous shipper and slash fanfic, rather than the common tropes of the patriarchal and highly misogynistic pornography industry. Part of the faux pas with "The Red and the Blonde," then, is its reliance upon tropes that "seem" like "masculinized" porn without obviously parodying these same tropes.

The image is telling enough: the women are shown using the guns as sex toys. The guns appear huge in the diminutive hands and mouth of the female characters. What's more, though the guns have been fully "discharged," in the context of the story, the image highlights not just their dominating size (made all the more noticeable by the proportions and the use of composition to make the guns the first thing the viewer notices), but the constant possibility of their devastating and deadly violence. This, taken

\footnotetext{
${ }^{38}$ I did attempt to get in touch with those who responded to this text, but they never returned my messages. As such, I do not have permission to share their comments, and therefore have not reproduced them above.
} 
in combination with the baby-bottle, caricature nipples of the two women, suggests to readers these women's status as objects to be dominated, controlled, and violated by "the male." The women barely seem to hold the guns; they are at the mercy of these giant, violence-prone phalluses.

The mutual masturbation with the "discharged," yet still (symbolically) rigid guns plays out as the first, voyeur stage of the "skin-flick"-style story; but, halfway through the story, the male voyeur is invited to join in:

Their lesbian fun is interrupted by the voices of two men entering in the shooting range...

-Hey, don’t tell me you haven’t locked the door!- yells shocked the special agent gathering her clothes from the floor and trying to cover her body.

-What's the matter, Scully?- asks the blonde, not worried at all -I'm sure they have some bigger guns to offer us!-.

-What we have here ! - interrupts one of the men - our favorite CSI slut ready for us, and her shy friend! Lock the door, Charlie -.

-Hi Charlie, hi Jim. You’re earlier than usual-. -Sorry girl, but our cocks could not stay one more minute outside your pussy-. As they talk the naughty Calleigh has already dropped to her knees and is warming the men's dicks with her expert hands.

-What about your friend!- asks Jim -red hottie, join us, help her!-.

-Let her watch, she's still not familiar with Miami’s way of life- says the blonde agent - and you know that I don't need help to satisfy you two - . 
Told that, deciding she's too horny to go on with the foreplay she gets up, braces Charlie's neck with her arms and his hips with her legs, and finally inserts his thick cock in her pussy. Jim doesn’t waste time: he lubricates her asshole with saliva and then stuffs her from behind.

The "lesbian fun" was already violently represented through a misogynistic and heterosexual lens through the use of the guns; now, the two women are rent apart and taken control of by the arrival of two faceless but clearly powerful men. The men arrive (always) already rigid (like the guns), but even more violently dangerous, as they have yet to discharge. The story ends with the men disinterestedly ejaculating on Scully's prone body, and leaving. It is almost laughable to recount the elements of this story, but it is essential, because, clearly, this writer has relied upon the genre features of maleoriented, industry porn. In the context of this particular porn challenge, then, the story reads doubly as lacking in (bodily) desire, and as an unwelcome interruption into the more "feminized" space of pr0n. The challenge space is violated similarly to how Scully and Calleigh are violated first by the guns and then by their own male colleagues.

However, while it would seem that these genre differences would be enough to invite scorn by the community members, it is impossible not to point out that this story does not meet the same language expectations as the other contenders. Though the battle rules do not specify anything in regards to language, it is clear that the tacit, naturalized expectation of language here is U.S. or UK, middle class versions of English. While the language difference is first apparent only in the use of exclamation points at the beginning of the story--"At the end of the day they had not discovered the origin of the 
substance but Calleigh had decided she wanted to fuck Scully!" (hades 77)--it becomes very clear very quickly in the syntax through the story. For example:

"Dana has still her white stockings, her heeled shoes and her lingerie."

And

"Some seconds later they have taken away their slips and are masturbating each other with the guns: they have shot all the bullets but the thing keeps anyway a sense of danger that excites them even more. "

And

"-That's curious - comments Jim looking at Scully’s sperm covered body - it’s Calleigh that have made sex, but it's you that will have to take a shower!-." (hades

Finally, in addition to the foreign-reading syntax-it seems clear that the writer is multilingual, as the adverbs, especially, seem to have a wider potential range for the writer than in English syntax — the writer also does not abide by the same rules for dialogue punctuation (American) as the other stories. Compare:

-Hi Charlie, hi Jim. You're earlier than usual-. (hades 77) To

"Go on," he says, setting it before the vanity. "Take it for a spin." (aloysiavirgata) Moreover, from what I have seen of comments across the largely goodwill-centered, affective economies of fanfiction, if the language alone were the cause of writercommunity dissonance, the response would likely have been more didactic in nature. However, given the writer's failure to abide by the tacit genre rules of the space, in addition to the language differences, this piece invites only disgust and an insult. 
In order to understand the case of "The Red and the Blonde" in more depth, it is important for me to state that it is of interest here, not solely because of its content, nor solely because it is atypical of the stories for this particular pornographic fanfiction challenge (or, indeed, of many romantic and sexual fanfiction tropes across fandoms and websites), but because it breaks the rules, which is obvious not only through comparison, but more so because it is the only story in this group to attract denigrating language. Bourdieu's Distinction, especially his discussion of the concept of taste is helpful here:

It is found in all the properties—and property—with which individuals and groups surround themselves, houses, furniture, paintings, books, cars, spirits, cigarettes, perfume, clothes, and in the practices in which they manifest their distinction, sports, games, entertainments, only because it is in the synthetic unity of the habitus, the unifying, generative principle of all practices. Taste, the propensity and capacity to appropriate (materially or symbolically) a given class of classified, classifying objects or practices, is the generative formula of lifestyle, a unitary set of distinctive preferences which express the same expressive intention in the specific logic of each of the symbolic sub-spaces, furniture, clothing, language or body hexis. (173, my emphasis)

According to this theory, then, the story attracts this denigrating language for two reasons: 1) it does not abide by the taste (using Bourdieu's terms) of this Live Journal group's $X$-Files universe; and 2) it abides all too well with a dominant, patriarchal, and misogynistic view of gender, sex, and pornography. This porn battle community may well have set itself against a dominant set of "pornographic tastes," but the field of possibility for "pr0n" here is likewise limited, naturalized, and almost invisible, especially to the 
participants. So, then, what can we make of the kinds of spaces, interactions, and work that fanfiction makes? This is perhaps best investigated after looking at the dramatic differences of taste (in terms of gender and class, especially) that are available within WWE Raw fanfiction.

\section{WWE Raw-Monday Night Meets Hypermasculine Soap Opera}

WWE RAW, which stands for World Wrestling Entertainment's Raw series, filmed in front of a live studio audience, is a hugely popular television series, which presumably started in 1993 - though pay-per-view, previously-taped wrestling events existed before the show's debut. The general formula for Raw is simple-pit two professional wrestlers against each other, one standing in as the "hero" character, while the other will play the antagonist or "heel" ${ }^{39}$. The battles are tightly scripted and acted (which distinguishes them from events such as boxing or, say, cage fighting). Many battles and wrestlers make heavy use of Judeo-Christian references: namely, references to a more conservative, Protestant Christian tradition through use of Biblical names (WWE star/character Chris Jericho, for example) and themes (Brock Lesner's Go to Hell tour slated for October 2015, where WWE explores the dark/“heel” side of wrestling). WWE boasts an international following and, now, its own television network-The WWE Network. This international following is likely due not only to the relatively wide accessibility of these shows, but also because the show represents itself as including universal, human themes: struggle, love, and, especially, the victory of good over evil. What's more, these stories of good (and love) prevailing above all seem timeless because they are reminiscent of

\footnotetext{
${ }^{39}$ When I searched the question "What does heel mean in WWE?" in Google, I found the Answers.com WWE Wiki, which explained that a "heel" was basically a villain character. According to the OED online, the word "heel" originated in the United States around 1914 as a slang term meaning, "a double-crosser, a sneak-thief; more generally: a dishonorable or untrustworthy person.” In the crowd-sourced Urban Dictionary, the term has been defined as “(n) In professional wrestling, a 'bad’ guy.”
} 
ancient Greek hero sagas, where the hero exists in both no-time and all-time as he continues to struggle through and overcome the obstacles thrown his way (see Bakhtin's Forms of Time and of the Chronotope in the Novel).

The WWE franchise is a largely masculine/masculinized one: a majority of the featured wrestlers are men (for example, when I click on the Superstars link on WWE.com, I am presented with five "superstars," only one of which is a woman); and while women wrestlers do exist, and are gaining in popularity and visibility, they are often nonetheless referred to largely as “divas,” and they are often presented in more feminine/feminized color schemes, especially pink. However, women wrestlers have been gaining in prominence in the past decade or so. They have come to have their own title matches, "Divas Title" (first won in 2008-("Divas Championship")). However, it does appear that there is a longer history of "fighting Divas" in the WWF and later WWE world. Nonetheless, battling Divas seem to be a more recent phenomenon. And, despite their fighting status, they also star in "reality"-type programs such as Total Divas, which appears to be a show about their romantic relationships and domestic lives, similar to the Real Housewives of $X$ series. In a lot of ways, then, WWE appears to be an absolute spectacle of the hypermasculine and hyperfeminine.

WWE Raw is not only a hypermasculine viewing experience, however. It is also largely geared towards a (socially) conservative audience. This in part due to its heavy reliance upon a largely binary gender system, as well as a completely heteronormative system, not to mention its heavy use of Judeo-Christian themes. The show, though it started through live and pay-per-view performances quickly migrated, first, to the USA network, which has often been widely available through basic cable packages—which 
can often be accessed through use of an antenna within cities, and is often easier to gain access to in more rural areas, where high-speed internet might not be as available. Since then, it has also migrated to expanded cable offers, including its own television channel, the WWE Network, and to relatively cheap online TV services such as Hulu Plus. But the high accessibility of this network and series of wrestling shows are not conservative merely because they are highly accessible, even within material conditions with less access to specialized TV networks, fast internet, or even local cultural institutions such as art, history, and science museums, theater, etc. WWE represents itself as containing and reflecting more conservative values, which are also tied up within a working class set of values.

As I discussed above, social class is not necessarily something that exists "out there" in the world, but it is also parallel to and bound up in socioeconomic status, where certain incomes may suggest something about someone's tastes and values, but will sometimes very likely not (take the example of an adjunct professor, whose income makes him/her part of the working poor, while her/his education, values, tastes, and position places him/her more solidly within the middle class). As Peckham has argued convincingly of class features:

I am referring to a system of social relationships within which people act toward each other as if the groups did exist--as in their minds, they do. There is certainly some kind of objective hierarchy of social positions based on a differential distribution of resources and constraints that govern any individual's choice of actions (Breen and Rottman 1995). I am imagining this hierarchy as existing on a continuum from few resources and maximum constraints (e.g., prisoners) to 
maximum resources and few constraints (e.g., elites), but as Bourdieu (1984) makes clear, a linear model is an abstraction/distortion of a more comprehensive model that maps an individual's social space on the basis of several kinds of capital" (26).

In other words, to say that WWE appeals to / is geared towards a conservative and working class audience is not to suggest that statistics of viewership would show a neat breakdown of working class incomes and/or republican-registered voters. Instead, this means that WWE has come to identify itself with the "everyman" and "the hard-working man" who has a vested interest in an America of individual success, an unfettered capitalist market, and a system of "traditional" values of binary men and women, heterosexual marriage, etc. That is to say that certain class values can become taken up and more valued within certain ideologics ${ }^{40}$ : "working class" and the "everyman" has been firmly taken up in socially-conservative, Republican circles, along with heteronormativity, fundametalist Christian values, etc. This web of values has become so tightly entangled that it would be difficult to remove "Christian" from "everyman" from "America" from "men must be men." And, in appealing to a more "conservative" audience, WWE comes to reflect these values in the way it writes its entertainment. What's more, these kinds of working class values are more visible in WWE than they ever could have been in The $X$-Files, where class was totally absent (silenced), or in Harry Potter, which is firmly upper and middle class (yet somehow unclassed by American readers and viewers).

This conservative and, often, working class set of values extend even to the charities that WWE openly supports. Donation of funds to charity per se is not a socially

\footnotetext{
${ }^{40}$ A term I borrow from Sharon Crowley.
} 
conservative, working class, or "republican” activity, and WWE does support a fair number of charities, from childhood cancer to bullying to breast cancer. But the types of charities that the WWE chooses to fund, as well as how they choose to represent their involvement in these charities does reflect a larger conservative, working class, even rural and certainly conservative Christian ideologic. For example, they place a lot of focus on support of the United States military, including their "Hire a Hero" fund. This is not to say that the support of these charities is underhanded, simply that the choice of these charities, just as with the choices of battle themes, performer names, and spinoff show ideas fits within the realm of possibilities for the WWE "universe"—or, from a Bourdieuan point of view, the WWE taste profile or habitus.

\section{WWE Fandom - Making the Celebrity Really Real and the Everyman American Dream}

Compared to Harry Potter fanfiction, WWE fanfiction appears to be a much smaller community. A quick search on Google for "WWE fanfiction" yields only 449,000 results (compared to Harry Potter's 8,550,000 and X-Files’ 1,560,000 hits-as of 30 September 2015). These results include mostly links to Fanfiction.net and Tumblr. Despite the overall community's size, it is clear that a number of WWE fanfiction spaces exist. Moreover, even a cursory glance reveals that the stories are written about the actors, especially Randy Orton and John Cena. There are moments in Harry Potter fanfiction communities where fanwriters openly and unapologetically reference the actors of the films: e.g. In kittylefish’s story, “Any Time, Any Place,” Severus Snape and Remus Lupin go to see the movie, Dark Harbor (a 1998 film starring Alan Rickmanthe actor who plays Severus Snape in the Harry Potter films). In general, though, the 
focus in Harry Potter fanfiction is on the characters, and how they can be expanded. Similarly, as was seen with the $X$-Files Live Journal community, the actors are followed as much as the characters in the show; however, again, the main focus of these fandoms is on the TV show characters. What makes WWE Raw fanfiction most distinct from many other fandoms based on fictional book, TV, or film worlds is its almost exclusive focus on the WWE performers, rather than on the characters they play.

It is clear that part of this character-performer slippage is due to the very structure of WWE itself as a form of entertainment. Performers, which include wrestlers, announcers, referees, etc., often refer to the "WWE universe," a term intriguingly evocative of its fannish cousin—where a "universe" encompasses the characters, settings, and politics of the source text. Moreover, much of the drama of WWE is structured around representing some wrestlers as "friends" or even "best friends," while others "have beefs" with each other that are oddly personal and long-lasting. For example, in promotional buildup toward Wrestle Mania 2012, John Cena (a popular WWE wrestler from 2002 to the present) faces a packed auditorium and delivers a speech about the return of famed wrestler, The Rock—Dwayne Johnson, and their upcoming match. Not only does Cena continue to use both "The Rock" and "Dwayne" to refer to the performer, but he asserts his long-standing respect for Johnson, while simultaneously alleging his "very real beef" with him for leaving WWE for Hollywood. This example of performercharacter slippage does not exist in isolation, and therefore is highly representative of the WWE and WWE Raw viewing experience. Given this trend, it is fair to argue that in the experience of watching this TV event, it is difficult to distinguish performer identity from 
character identity—-to distinguish the "make believe" form "the real." In fact, the very possibility of "the real" is undermined at almost every turn.

On another level, however, WWE fanfiction pushes this slippage even further, by asserting the "really real" aspects of these performers' lives outside of WWE. Writer haleysjoy, for example, asserts in her story Somebody to Love that John Cena and Randy Orton are "actually" best friends, and that Orton is a truly feeling and caring kind of guy, despite his "heel" persona on WWE Raw. So, then, what can we make of this? Celebrity has always played a role in fanfiction practices, but the extent to which it is present in WWE fanfiction is truly distinctive. Is it, perhaps, as Emily Hogson Anderson puts it in her article, "Celebrity Shylock," that: "Such a crisis in representation becomes what Michael Ragussis dubs an example of 'metarepresentation, metatheater' in which not only cultural but also theatrical practices are exposed (Theatrical Nation 129). In this case, though, the metatheatrical moment trains audience attention on performances conducted by the character, not the actor himself" (942, my emphasis)? I would argue that this interpretation accounts, perhaps, for how WWE Raw structures the audience's experience of the text. They invite this slippage, which, perhaps, creates a driving need for fans to not only become more intimate with their fan object, but also to see it expanded as well as to "lovingly" critique it (as harleysjoy does of Orton's "heel" status above).

But why? There is something tricky happening here in terms of identity and identification. It has been well-documented that media consumption and fan activities are ways by which a fan can come to feel more intimate with her/his loved fan object/person/world: "When television fans experience face-to-face encounters with celebrities, they do so with the sense that they are expanding their knowledge of the 
actors as separate from the characters they are already familiar with" (Ferris 26). What's more, in a face-to-face encounter, and even in media such as promos, interviews, etc., fans can come to feel as if they are a part of the show, and, therefore, a veritable part of the universe they so love. Within this kind of fan positioning, as Ferris has argued in “Through a Glass, Darkly: The Dynamics of Fan-Celebrity Encounters": "Fans' interests lie in both the real and fictional incarnations: the people on the television screen embody both character and actor identities, and fans come to know the people on the television screen despite the fact that they are fictional personae" (27). In the case of WWE fandom, the very structure of WWE Raw has already pre-involved the viewers as part of the $W W E$ universe, and, as such, fans already come to feel as if they have an inside scoop into the performer-characters. This kind of approach strengthens the process of identification fans can and do feel for the source text and its associated values.

Moreover, especially in the case of WWE Raw, there's something happening in the self-referential quality of these performances that invites active fan engagement in the performance in ways similar to earlier theater culture: "In the eighteenth century, an emergent 'uncertainty in personal identity,' produced by everything from developments in religion to the onset of a newly minted industrial age, produced in turn a sense that one's true nature lurked behind some social surface (Braudy 7). This potential fueled the ability to craft new public personae, on the one hand, and the desire to seek out what these personae were hiding, on the other" (Hogson 936). Similar to how the very writing practices of fanfiction harken to $19^{\text {th }}$ century developments in publishing, fan interaction with WWE performances harkens back to early theater viewership. Furthermore, due to 
the total ubiquity of internet technology, the "public" and the "private" again become something of a contested space.

When I search "WWE" at Fanfiction.net, I find 46 communities. Six of these communities openly accept slash and femmeslash stories. Many of these communities or $\mathrm{C} 2 \mathrm{~s}^{41}$ are very small, and appear to have only tens of participants. The largest of these communities, by a wide margin, is WWE Fanfiction World, which archives 98 stories, includes one staff member, and 64 followers. The community was founded by babyxbxgurl in October of 2004, and is described in the following way: "This community is all about WWE Fanfiction. Most of the stories will contain John Cena, Randy Orton, Gail Kim, Lita, Christian, Ted DiBiase, and Cody Rhodes as the main characters, but some stories will have other WWE Superstars as the main characters as well. Their are various pairings here, but mostly OC pairings can be found. Some stories are one-shots and some stories are full length stories." It appears to host a relatively wide range of stories: from a tale about Randy Orton adopting a nine-year-old girl (Somebody to Love), to a romance between Orton and an original character (A Guy, A House, and A Hot House Mate), to a few Randy Orton/ John Cena slashfics (e.g. Inches Away from You). Most of the stories in this community have more than one chapter, but there are a few "one-shots." In addition, most stories seem to be paced pretty quickly, even in serialized fictions, though dialogue and detailed description is valued here. Importantly, the majority of writers in this C2 appear to desire getting into the minds of the actors who play the characters on the WWE Raw series. Writers seem to engage with the following kind of question: "Okay, let's put Randy Orton and/or John Cena in situation X. What would they think, feel, and say?" In a way, then, it is safe to say that there is a remarkable element of

41 "C2" is the term used at fanfiction.net for "(universe-specific) community." 
celebrity in this community, in ways that are often much more obscured in other kinds of fanfiction community, even Harry Potter and The X-Files (despite many fans' obvious admiration of actors such as Alan Rickman and Gillian Anderson).

In addition to the playful approach to character/celebrity in these stories, a majority of these stories appear to include an interesting tension between socio-economic status (what raw cash can buy) and social class (which seems to be more working class, somewhat rural, and "traditional American" in nature). Many stories appear to rely upon an ideologic of binary genders, as well as a patriarchal stereotype of highly feminine and often sexualized women. For example, women are often represented as liking shoes, clothes, makeup, men, and kids. The men, however, are often represented as being more nurturing and to have more intimate friendships than the WWE Raw world allows. That is to say, then, that in terms of content, this WWE fanfiction community is walking along yet blurring certain intersections and/or tensions between dominant and resistive gender role, sexuality, and class expectations.

Furthermore, beyond the tensions at play within the content of these stories, the WWE fanfiction community appears to function in very similar ways to the goodwill, emotion exchanges we saw at work in both the Harry Potter and The X-Files communities. Most of the reviews are expected to be polite and positive, as well as encouraging. And when criticism is offered, it is always offered politely, with specific details, and it always balances praise with criticism. On the surface, then, the economy of participation in the WWE communities appears to work very similarly to that of both The $X$-Files Live Journal communities and the various Harry Potter communities at Sycophant Hex and Fanfiction.net. Of course, all three fandoms feature the reading, 
writing, and appreciation of fanfiction. All three fandoms appear to include a system of exchange where: most readers will review, if they wish to be seen as really active members of the fandom; most writers will engage with reader questions and criticisms; fans will set challenges for each other; fans will dedicate stories to each other; and all three fandoms have a system of writers and beta readers. Of course, one major reason for the consistency, especially across C2s at Fanfiction.net, are the kinds of expectations of "good" practice that exist there in welcome messages, moderator and/or administrator comments, documents such as the Terms of Service, and, absolutely, an "initiate" fan's observation of other fans' behavior.

And, of course, while there is certainly some centralized, top-down control at work in these spaces (some more than others—Sycophant Hex appears more "top heavy" than Fanfiction.net, for example), the majority of the "moderating" or "policing" of participant behavior is "grassroots," "ground-up," and even self-initiated. Even more so, the other main reason for so much consistency in economies is the long tradition of "proper" fanfiction writing and engagement, handed down from the "Spirk" zine-writers of the 80 s and 90 s, to the AOL email lists and forums of early $X$-Files fans in the mid to late 90s, to the multi-page, interactive, and searchable archives of fanfiction sites today. As has been discussed, the work of Jenkins, Bacon-Smith, Penley, and Scodari, in particular, has provided a deep and detailed narrative of this tradition, foremost within it, fans' dedication to development of creativity, self-expression, and craft through supportive engagement—through what I call an emotion, "goodwill" economy. However, a closer inspection of the specific content, tropes, and styles of the WWE fanfiction community provides some particularly interesting issues of identity, in 
the face of power, especially in terms of how class meets gender. A particularly interesting example of the ways in which class and gender collide spectacularly in the fanfiction of WWE fandom is the story Somebody to Love by harleysjoy. It was first posted on 9/17/2010, and it is a story that focuses on WWE superstars John Cena and Randy Orton, as well as an original character, Gracie Ordenes—a nine-year-old orphan. The story opens with John and Randy's afternoon visit to an orphanage in a relatively small, semi-rural location. Randy becomes intrigued by a very quiet, reserved, and artistic girl, and asks to adopt her. The story focuses on the development of the father-daughter relationship between Gracie and Randy. The story was never completed, but it is a very highly-rated story within the WWE Fanfiction World C2. It is interesting that, in the source text, Randy Orton is the "heel," and that he is most frequently portrayed as conniving, "brutal," and "unrelenting." In this story, and in many within this C2, Orton's "gentler" side is highlighted—here, his easy friendship with John Cena (a frequent rival in the WWE source "universe") and his fatherly tenderness towards Gracie. The story straddles an uneasy line between socioeconomic status, class tastes, and gender role expectations. Throughout the story, there are two major tensions: first concerns the status and representation of "literacy" and vocabulary in this story; and second is the tension between material, especially financial, resources and where to spend these.

In terms of the former, there are several moments where the nine-year-old orphan, who was severely abused and does not appear to have had frequent schooling, reads relatively advanced texts such as Treasure Island, and tends to use very advanced vocabulary, in contrast to both John and Randy. For example, early in the story, before 
Randy adopts Gracie, they begin to write to each other. Gracie’s first response is included in full below:

Dear Randy,

I hope you are well. I am fine. I’ve never had a pen-pal either. Before we start, you must know something. My name isn’t really Gracie but it’s actually my nickname. Everyone calls me that and I never bothered to correct them, so it stuck. You didn’t get to hear about me when we met so I'll give you a little fact sheet now. ABOUT ME:

Full Name: Abigail Grace Ordenes

$D O B: 26^{\text {th }}$ September

Favourite Colours: green, blue and black

When I was little I wanted to be: an artist

I prefer dogs over cats as well.

Favourite food: I don’t have a favourite food, really. I don’t eat much.

My favourite subject: art

Scare of: Alex

Some of my drawings are enclosed in this envelope. Can you send me some of yours when you write next? I wanna see how you draw. By the way, my email is _ , so you can add me on MSN. We can talk on there too.

I gotta go now. Hope I didn’t bore you to death.

From, Gracie

(harleysjoy, my emphasis) 
This letter was striking to me, because it seems fairly unlikely that a nine-year-old, especially not one in the situation Gracie is in, would use abbreviations such as DOB, or words such as "prefer" and "enclosed" in a personal letter. It is true that she also includes "wanna" and "gotta," but the majority of the tone in the letter is very formal, and very mature. This letter represents Gracie as an unusually gifted child. This representation of "giftedness" seems to be predicated upon a "genius-status" or "you just know it" representation of intelligence, let alone literacy. In addition, because the letter is represented as having been easy for Gracie to write—at least mechanically if not emotionally—literacy is represented as something that appears to take one "natural form," even if that form reflects middle class expectations of usage (see "enclosed in this envelope" in particular). Indeed, the moment above is very short, but taken together with Gracie’s reading habits, as well as her vocabulary, and her savant-like knowledge of art, it is fair to argue that we are seeing a performance of social class that is in tension with the way it is represented within WWE Raw, and perhaps even in tension with the fan's knowledge of her own and other fans’ social class.

As Peckham has argued of social class and language (similar to arguments Bourdieu made in Distinction):

Language is a particularly effective mechanism for maintaining distinctions among social classes because it functions both to communicate and signal identity, with one function frequently disguised as the other. Teachers, for example, may correct working-class students' deviations from the conventions of middle-class English, telling the students that the errors make their writing difficult to understand when in fact the teachers are correcting social class 
behavior manifested through language codes. Behind this masking lies the clear message that the social groups speaking through these 'incorrect' language codes are incorrect social groups. (28, my emphasis)

In the example above, language is operating not only to mark Gracie as an exceptional child, but to perform the values of a middle class status that WWE performers have perhaps achieved (though, they have achieved "middle class" socioeconomic status (and higher, actually) due to their income). In addition, this kind of moment may also serve to mark the writer, harleysjoy, as a full-fledged member of an online fanfiction community, which carries with it a tradition of middle class literacy practices, tastes, and values. Gracie, then, falls within two powerful yet contradictory ideologies about literacy: 1) that intelligence and talent are something one is just born with (this is especially true of beliefs about writing); and 2) that, within individual effort, anyone from any background can "succeed" (the veritable American Dream). In this latter case, "success" means gaining an acknowledged status within the privileged, middle class power structure (and its largely capitalistic, financial exchange economy). Interestingly, as both Randy Orton and Jon Cena are represented as having less "refined" vocabularies, and as "not readers," the "American Dream" is represented as absolutely achievable, even without middle class literacy. These are tensions, ultimately, between the ideological promise of literacy and its reality; between socioeconomic status and class.

This latter tension between socioeconomic status and class is especially borne out in another example, where the financially well-to-do Randy takes Gracie on a shopping spree. In the story, as Randy Orton is introducing Gracie to all of his "WWE family" (this is the specific term he uses in the story), the Divas, Randy, and John decide to take 
Gracie shopping, because it's "the thing that makes every girl feel better" (harleysjoy). In the context of the story, this shopping trip allows Randy Orton the opportunity to get some more supplies for his new adopted daughter, and it gives both him and his "WWE family" time to get to know Gracie:

"Why did you have to choose shopping?" Moaned John as they all tiredly flopped onto a bench.

Gracie spoke up from Randy's lap, while sipping the last of her chocolate milkshake. "It's your own fault for coming, Pumba."

Randy, Trish, and Amy [the Divas] all snorted at John's new nickname. When they were all in Walmart looking at the DVD's, John had found The Lion King and stated that it was his favourite movie. Gracie saw her opportunity and lept at it.

"You know, John,” Gracie said cheekily, "You remind me of Pumba from that movie; your both pigs."

When they arrived in front of Walmart, Gracie took Trish and Amy's hands and took off towards the young girl clothes section. She had great fun trying on and modeling clothes for Trish and Amy while Randy and John sat on a bench outside, bored. (harleysjoy)

This scene combines an intriguing collision point of dominant gender roles and a strange tension between Randy Orton's clearly well-funded socioeconomic status-his material wealth—versus his more working class sense of taste. 
It seems particularly unlikely that, if Randy's class position aligned with his material wealth, that he would shop at Walmart. He might, for example, have taken Gracie shopping at Neiman Marcus or Nordstrom, in addition to more boutique book and art supplies stores. There is an interesting double level of class tension at work here, then, as the character (Randy Orton) is represented as performing a working-class personaincluding a workaday ethic, strength and protectiveness as "fatherly" attributes, and shopping at large, discount stores—not to mention showing no interest in clothing. On another level, it is important to point out that the writer is performing her or his sense of class tastes within the decisions s/he makes for her/his characters' actions. In that sense, then, it is possible to say that some of the working class taste profile here is not only being shaped by the original series, but by the writer's own sense of taste, which suggests, at least, that the writer is identifying as working class, rural(ish), and conservative in this piece.

This particular kind of taste profile is not specific to this writer either; the archive is filled with similar stories. Another example is "Happy Father's Day" by liloweewoah ${ }^{42}$. In this story, the protagonist goes to visit her parents' graves on Father's Day. She talks to her father's grave about her married life and her multiple children. The story ends by showing a joyful moment between the protagonist and her husband, Randy Orton, as they celebrate their first Father's Day. The story was published on June 21st, 2010, and is a relatively highly-rated story in the community. The writer summarizes the story in the

\footnotetext{
${ }^{42}$ I will remark here that, as we will come to see in chapter four, Liloweewoah’s performance of a workingclass and conservative taste profile is a quadruple performance, as it were, that is being mediated through WWE's representation of itself to its audience, through her own reading of these representations, through her understanding of the United States, and from her class position as it might be read specific to her life in the Philippines. For the purposes of this chapter, however, it is best to say how a certain ethos of working class and conservativism can be read, in part, in the stories that she has written.
} 
following way: "It was about celebrating those important men in our lives who made a difference. Who have sacrificed so much for us. Who loved and protected us. No matter where they were, they were always watching us even if it was just in spirit." Again, this story, like so many others in this community, reflects a dominant version of the everyman American Dream—with the heteronormative, working, white couple and their 2.5 children, performing their duties to each other and to morality. What's more, the synopsis harkens to the WWE Foundation's support of the military: "Our Mission: To share our strength with the brave men and women of the United States Armed Forces both at home and abroad through programs that boost morale for soldiers in the field, offer free entertainment for active military at home, and provide workforce assistance for veterans" ("About Military"). In that sense, then, Liloweewoah is not only identifying with the taste profile of WWE, but to other writers at WWE Fanfiction World. This identification is multi-faceted and carries with it a complex tangle of ideologics of hard work, binary genders, heteronormativity, and, in this case, the inherent good of serving in the military. These intersections of largely dominant, yet working class ideologies of gender, sexuality, work, and material resources are especially interesting when compared to the writing expectations of this community. This community is, in some ways, very different from the Harry Potter and X-Files communities that have been examined here. First of all, there are no posting rules in this community. What's more, the majority of the comments on stories, even those with a number of typos and mistakes in "proper" American punctuation, are highly positive, and generally focused on the content. That, of course, does not mean that there are no genre expectations in this space. The best way to 
see this is to examine a story that defies posting expectations_-Great American Bash 1997 by frostyfreezyfreeze 54 .

This story, Great American Bash 1997, is markedly different form the rest: it contains two chapters, but each chapter is less than 1,000 words, and contains neither dialogue nor reflections upon the wrestlers' emotional states. In order to see the differences, I've chosen to include the entire first chapter below.

Due to the demented behavior of Randy Orton, WWE Champion John Cena suffered an arm injury and was forced to vacate the title. All three General Managers decided that at The Great American Bash, there will be a 20-man battle royal for each brand. The winner of each battle royal will move on to SummerSlam and challenge for the vacant WWE Championship in a Triple Threat Match. Since Cena was on the DL, Orton, Shane McMahon, and 'Rowdy' Roddy Piper were the three biggest stars on RAW, also since Triple H took time off to pursue other interests with his dad. Although everyone knew that either Orton, McMahon, or Piper would win, rising stars like Ricky Steamboat and Rhyno could get a huge push by being in the RAW battle royal. Or legends like Bret Hart and The Rock could make a huge comeback and win the battle royal and the championship. Or big monster guys like Big Show and Vladimir Kozlov could make big splashes in their battle royal. Needless to say, the Great American Bash would be truly intense. (frostyfreezyfreeze54)

The chapter reads like a combination sports announcer slash event promo. It is short, covers the main thematic highlights, and is positioned to intrigue the reader in a way that promos are used to suck in future viewers. This story presents information rather than 
emotions. Furthermore, it includes mostly short sentences that feel like spoken language. This story, and the other one by this same author (within this community, that is), Survivor Series 1997, receive critical reviews. These reviews are not insulting, but they are didactic ${ }^{43}$. They stress that the author could write a "better" story if s/he included more emotion, actions, scenery, and dialogue. In fact, the reviews seem to reflect that familiar English teacher adage, "Show, don't tell." This suggests, then, that this space, like the others examined within the Harry Potter and $X$-Files fandoms, is largely focused on goodwill, supportive engagement with fanfiction. Moreover, while it might be said to abide by some middle class, "schoolish" expectations of both "good storywriting" and politesse, it also provides a different range of gender, sexuality, and class identification, a more conservative one, than Harry Potter and $X$-Files communities typically do.

\section{Conclusion: Emotion Economies}

The cases at Sycophant Hex, Live Journal, and Fanfiction.net demonstrate that online fanfiction communities operate in particularly distinctive ways. These communities are resistant yet complicit to larger power structures. They are creative. They are emotional. And these resistant-complicit and emotional aspects, in tandem with legal constraints, have required and inspired fans to develop a different system of exchange than the capitalist one in which we live. This alternative, largely emotion-centered, "gift" economy is not only an integral reason why fans continue to participate in online fanfiction, but it is also central to what makes these fans' distinctive re-imaginings and rewritings of their favored source texts possible. While I would not argue that the deeply engaged writing that takes place on Sycophant Hex, Live Journal, and Fanfiction.net is

\footnotetext{
${ }^{43}$ Because I have not received permission to reproduce these comments from the writers (though I have tried to contact them), I cannot include more specifics here.
} 
representative of all online writing (or even all fanfiction writing), I do argue that this exploration of its complexities does demonstrate the importance and necessity of more studies on out-of-school writing, particularly writing that occurs online.

While early work on fanzine cultures, such as that by Henry Jenkins and Camille Bacon-Smith, closely investigated the kinds of writing and learning communities that early fanzine writers created, the majority of the focus of these arguments was on the content of the zines, particularly to demonstrate the ways it was resistant to dominant ideologies. Certainly, this was likely in large part (as Matt Hills has argued in Fan Cultures) due to these scholars' drive to legitimate academic scholarship on fandom. Nonetheless, much of the scholarship on fandom, even online fandom, has tended to focus on its resistant content. Because of this, it seems that only more recent work (particularly by Jenkins and Hills) has begun to consider the central importance of emotion and in-group hierarchy in the functioning of online fanfiction writing. My analyses above demonstrate not only that fanwriting can be resistant, but that it is also subject to larger ideologies, as well as the constraints of the communities' agreed-upon interpretations. More importantly, my analyses have shown that these complex resistantcomplicit positions are not only structured within but made possible by the differing, highly emotional economies of these websites.

As has been seen, online fan culture exists within a particular system of exchange—not only of dialogue, but of authority, meaning, and friendship. Perhaps, one way to account for these complex exchanges in fan communities is to appeal to Gee's theory of "affinity spaces.” To a certain extent, "affinity space” is a useful term in fan scholarship because it highlights the choices that fans can and do make, as well as the 
importance of the deeply affective, deeply emotional ties among fanwriters (especially in the case of the fanwriter-beta reader ${ }^{44}$ relationship). However, as scholars such as Bronwyn Williams and others have argued, the "affinity space" is problematic because, while it highlights choice, it fails to account for larger ideological structures that are still at work in fans' performances of identity, and certainly in their engagements with each other. Nonetheless, I argue that "affinity” and friendly exchange are very central aspects to fan practices.

Likewise, Jenkins' work in Textual Poachers highlighted the features of friendly exchange and goodwill that tended to define fanwriting practices in earlier fanzine communities. He argues that "fan reception cannot and does not exist in isolation, but is always shaped through input from other fans and motivated, at least partially, by a desire for further interaction with a larger social and cultural community " (Jenkins 76, original emphasis). Online fanfiction communities function in very similar ways. It is commonplace in these forums for fans to not only help each other with their writing, free of charge, but to set each other challenges, to write stories for each other, and to support each other through positive reader reviews—-not to mention the lively discussions that take place on these websites' writing forums (spaces where writers can discuss story ideas with those other than their beta readers). In this sense, then, we might see fanwriting culture as existing within a system of exchange different from the system of commodity exchange in larger society. What is exchanged at these websites is not profit. Rather, stories are exchanged for friendship (symbolic capital) and authority (social

\footnotetext{
${ }^{44}$ A beta reader, as I stated above, is an editor within the fanfiction community. These editors cover a range from commenting upon content, to organization, and, certainly, to sentence-level features such as spelling and punctuation. Some of these editors, in Harry Potter fanfiction at least, will also comment on British English.
} 
capital). The exchange on these websites is best described as affective, and fits best within what we might call a "gift economy” rather than a "commodity culture," terms I borrow from Jenkins, Ford, and Green (2013) ${ }^{45}$.

\section{In The Business of Letters: Authorial Economies in Antebellum America}

(hereafter Business), Leon Jackson argues that authorship in the $19^{\text {th }}$ century existed within multiple types of economies in addition to a financial one, and that production, circulation , and reception of these texts existed within a cultural precedent of "gift exchange ${ }^{46}$.” Because fan texts cannot be exchanged for profit (at least not in the case of a large majority of fanwriters), the systems of exchange that fans have developed have largely been gift-centered. I am using the term "gift” here in the way that Jackson addressed it in Business. Here, gifts are not totally free, and they are "hardly unilateral" (Jackson 91). Jackson argues that there are multiple types of gifts, and that these "gifts" are dependent upon the relationship between those who exchange them (do they know each other well?), their expectations of that exchange (are they asking to be printed and/or reviewed?), as well as their relative status to one another (Jackson remarks that, "to give a thing of value to a social superior is to make a tribute, while to bestow it upon an inferior is a form of charity" (274)). Moreover, Jackson explains that gifts are not dependent solely upon the "intention" of the giver, but will be interpreted by and

\footnotetext{
${ }^{45}$ In their groundbreaking study, Spreadable Media: Creating Value and Meaning in a Networked Culture, Jenkins, Ford, and Green focus on how fan activities are always operating within two intersecting systems of value, stating specifically that, "It's crucial to realize that audiences and producers often follow different logics and operate within different economies (if, by 'economies,' we mean different systems of appraising and allocating value). Painting in broad strokes, we might describe these two worlds as 'commodity culture' and 'the gift economy.' One (commodity culture) places greater emphasis on economic motives, the other (the gift economy) on social motives" (p. 63).

${ }^{46}$ While I will not dwell on this argument in this chapter, I do want to argue that many aspects of the fanwriting economy are very similar to writing economies as they developed in book-printing culture in the $19^{\text {th }}$ century. Moreover, the current debates surrounding copyright and fair use are reminiscent of the copyright struggles that existed between the United States and the United Kingdom in the $19^{\text {th }}$ century (see Meredith McGill's American Literature and the Culture of Reprinting 1834-1853).
} 
mediated through the value system of the receiver, as well as that receiver's view of the giver and the giver's possible intentions. Importantly, Jackson argues that gifts aren’t free or completely outside of economies. Gifts typically have or receive some kind of value in the exchange, which shapes the tenor of that exchange. Jackson goes on to say that, "The 'full truth of the gift,' according to Pierre Bourdieu, lies neither in insisting on its generosity...nor in exposing its duplicity... but rather in accepting the validity and intertwinedness of each" (92), and furthermore that, "Indeed, the very definition of the gift, according Bourdieu, boils down to the fact that it is an object that hides its economic nature yet relies upon it" (92). From that perspective, then, Jackson is arguing that something can act as a "gift" even while it is doing other work. This is certainly true within fanfiction communities.

The exchanges that take place in online fan communities occur within a different kind of economy than the dominant one we contend with in everyday life. Every day, we engage in a commodity economy, where any number of things can become objectified, valued, and exchanged for financial capital—or capital that might lead to financial capital. In the morning, we might go to Starbucks for coffee: we go in with a certain expectation of the monetary value of that item, the cup of coffee. We then exchange that amount of money for the cup of coffee and we go on our way. The economies in fanfiction websites are both the same and different. They both reflect the commodity economy and resist it through creating an economy of the exchange not only of some kinds of social and cultural capital (fame and credible status as a fanwriter) but also of friendship. Fanwriters engage closely with their beta readers; they write stories for each other; they set writing challenges for each other; and they positively review each other's 
work. In other words, their economy is, at times, commodity-centered, and often, at others, largely emotion-centered or gift-centered.

However, I must stress that the economy of fanwriting is not entirely different from the one with which we contend every day. First, I will reiterate what I discussed above in regards to Matt Hills' Fan Cultures: that, as he argues, while both academics and fans alike might sometimes pit the "mere" consumer against the "true fan," the situation is not nearly so simple. The larger capitalist economy in which we live allows fans access to their loved, fan objects. What's more, this capitalist economy is always there, in conversation with the potentially more "gift-centered" economies one might find on any individual fan website. Secondly, I will mention that, even within online fan communities, there exists the potential for the social, symbolic, and even cultural capitals writers gain through their participation to eventually be transferred into a system of financial capital. After all, New York Times bestselling author of the Fifty Shades of Grey series, E. L. James, got her start in Twilight fanfiction communities, and Cassandra Clare, author of the Mortal Instruments series, got her start in Harry Potter fanfiction communities. Just as Jackson argued that not all gifts would be completely free of commodification, not all of the "gifts" in fanfiction are free of the potential for commodification.

As has been seen above, the literacy practices of the fanfiction communities discussed above rely heavily upon an emotion economy. I will come to address emotion, the body, and literacy in much more depth in Chapters 4 and 5, but for now, I argue that emotion, in combination with the body, are the key to expanding our understanding of community literacy practices that take place outside of school (as well as how these same 
communities interanimate and are interanimated by school and work literacies). Laura Micciche conducts important work on reintroducing and reinvigorating emotion in academic theory in her recent book, Doing Emotion, and she argues, importantly, "As a result, then, of historical processes that have constructed emotion as dangerous and untrustworthy, emotion has been the object of a large-scale dismissal, rendering invisible its principal work on how we come to orient ourselves to the world, including how we develop, interpret, and analyze our own investments in the things we value through complex social and cultural rituals and norms" (6). But, as I have begun to argue in this chapter, emotion is clearly a huge part not only of these communities' appeal and success, but certainly of literacy and learning in general. In order to get a better understanding of how this works, in the next chapter, I will examine the daily, material, and, yes, emotional resources and experiences of two fanwriters as they engage with fanfiction, "original" creative work, and workaday jobs 


\section{CHAPTER 4}

\section{RESPONSE, ORIGINALITY, AND EXPRESSION: THREE CASE STUDIES OF}

\section{FANWRITER REALITIES}

"Coming to the crest of the hill, the campground emerged through the trees, lit by security lights. Both Scully and Mulder could instantly tell what the EMTs meant by the

'Midgetville' moniker as they looked around the fringes of the campground when they pulled into the gravel parking lot behind dozens of cars. Instead of normal-sized cabins

like one would expect at a campground, there were tiny structures that appeared that they were built for people no bigger than the average little person. 'We're supposed to stay in these?' Mulder mumbled to Scully as they got out of the car, looking around in bewilderment." (Madshrubbery, "Welcome to Midgetville," 5-6)

"While the supporting characters within are completely fictional, all historical details, notable figures and locations are real and painstakingly researched....No profit is sought to be gained from the publication or circulation of this booklet. All other intellectual property is C 2009 Madshrubbery ${ }^{47}$." (Madshrubbery, "Welcome to Midgetville," 1)

\footnotetext{
${ }^{47}$ In the original booklet, Madshrubbery chose to use her real name in this disclaimer statement, as well as on the cover. However, in order to protect her identity, the writer and I have decided to use her fanfiction penname here instead.
} 
"This booklet is dedicated to LiveJournal.com user [X-Files fan ${ }^{48}$ ]. A very Merry Christmas and Happy New Year to you. May 2010 bring you all the happiness you deserve and may it be filled with X-Files fun all year long." (Madshrubbery, "Welcome to Midgetville," dedication, 1)

The excerpts from above can all be found in a carefully written, designed, and produced PDF booklet entitled, "Welcome to Midgetville." The booklet was prepared by Madshrubbery for a fellow fan she met through an $X$-files community on the personal blogging website, LiveJournal.com. Just these few fragments suggest a rich world of emotional, intellectual, and I would call it, disciplinary engagement in the $X$-Files fanfiction world. The first excerpt introduces both the characters and the readers to the main setting for the investigation to come. Here, a strong sense of locational verisimilitude is established. In fact, it nearly rivals this excerpt's sense of $X$-Files genre verisimilitude, as it obeys the typical tropes of location establishment that could have been seen on the show. This focus on verisimilitude has already been established by the writer in her disclaimer on the first page (which can be read in the second excerpt). It is extremely clear from this second excerpt that this writer takes a great deal of pride in her research skills. In fact, I would argue that this disclaimer statement hints at an intense dedication to craft. This latter focus is bolstered by the carefully designed, clean lines of the booklet itself (see Figure 1 below).

\footnotetext{
${ }^{48}$ I have removed the original fan's penname because s/he has not consented to participate in this study.
} 


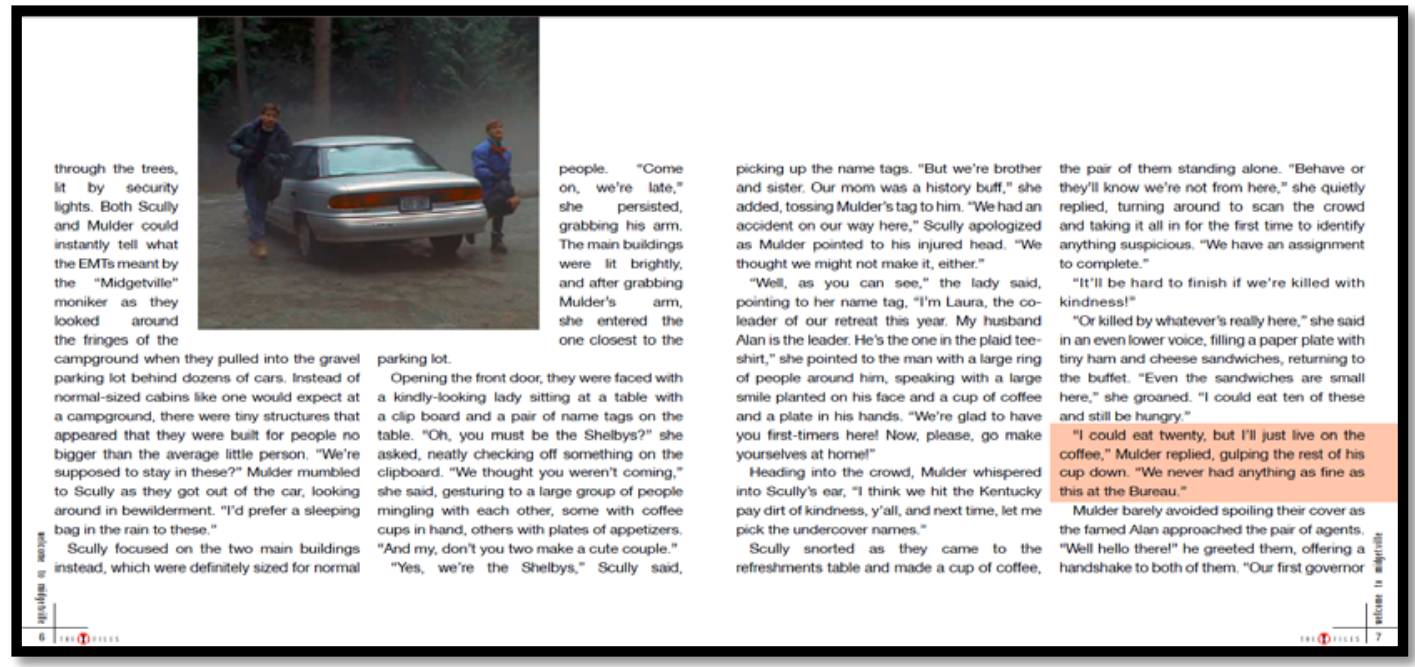

Figure 1 - A screenshot from Madshrubbery’s PDF for “Welcome to

\section{Midgetville”}

Finally, the dedication on the first page of the document suggests that an essential aspect of this writer's engagement in fanfiction is interpersonal: in this writer's world, perhaps, craft, verisimilitude, expertise, and friendship are all inextricably linked in fanfiction practices.

In the previous chapter, I focused largely on the content and economies of participation in online fanfiction, as it can be seen on the screen. In this chapter, I intend to deepen my exploration and analyses of the material, embodied, and emotional elements of fanfiction practices by conducting three small case studies of real fanwriters: 1) chivalric, a Harry Potter fanwriter; 2) Madshrubbery, an X-Files fanwriter; and 3) Liloweewoah, a WWE fanwriter. Through this investigation, I will find intriguing and distinctive relationships among friendship, emotion, craft, and textual engagement in fanfiction practices that can help us to reflect deeply on literacy education. For each case study, I will first investigate how the fan was initiated into her fandom of choice, and 
how fanfiction practices fit within her material and felt experience. Ultimately, I will find that multiple different types of fanwriter realities exist within different fanfiction communities (and likely within individual fandoms as well), and that these realities are both resistive to yet complicit within dominant ideologies of "good writing” as well as gender, sexuality, and class.

\section{chivalric, Who Is Sam C. Leonhard?}

Born out of instinct, he made a decision: he, the predator, knew that she should be his prey, not the one in the white bikini who now flirted with Raoul, the melon seller.

'Rose! Please don't fall into the water, dear!' the blond woman called. She hadn't seen him yet, and her concentration was on the little girl anyway. Perfect, he thought, She has a child - two, if the boy is hers as well - and she is most definitely married. Unhappily married, I would bet my life on it. Which certainly would make this a challenge for him. Unhappily married or not, as her children were with her, she would hesitate in surrendering to him" (chivalric At the Beach)

These few lines appear in the serial fanfiction, At the Beach, by writer chivalric, and can be found at the Harry Potter fanfiction website, SycophantHex.com. In it, Hermione Granger, married to Ron Weasley with two children, becomes estranged from Ron as he pressures her to give up her career to be a stay at home wife and mother. She takes a beach vacation with her two children, meets Severus Snape (who has changed his appearance, given up magic, and renamed himself "Carlos"), and they fall madly in love with each other, only later realizing who the other is. They share a secret, second family for several years before she divorces Ron and moves in with Severus. The story is a top- 
rated fiction within the SycophantHex community, and resides within the Ashwinder archive at Sycophant Hex, which is geared towards "SS/HG" "shipper fics," or stories dealing with a romantic and/or sexual relationship between Severus Snape and Hermione Granger. I will argue that what the short example above shows is the intensive, often very gift-like engagement that takes place on fanfiction websites like Sycophant Hex. What's more, I will come to argue that chivalric’s story demonstrates to us one possibility for how fanfiction can fit within and function within an individual participant's life.

One of the most striking features of fanfiction websites is the degree to which the identities of the authors are constructed. Often, the markings of identity work differently in the online environment than they would have in earlier fanzine communities (see Jenkins and Bacon-Smith), or even in earlier email lists (see Bury and Scodari). It is possible to obscure some features of race, class, gender, sexuality, and even language, or, perhaps, to perform them in certain ways. Of course, as I have argued in chapter three, there is slippage in these performances, because: 1) acting in the world draws upon years of socialization and internalization of highly pervasive and powerful ideologies (Bourdieu and Butler); and 2) what can be seen on the screen itself has been heavily mediated not only by the writer himself/herself, but also by the input of beta readers (editors), by the possible policing of website moderators or administrators, and certainly through the readers and the reviews they might leave on any given story. Add to this the complication that online fanwriters are operating with pennames and avatars, rather than their given names and recent photos, it can be difficult to trace the online fanfiction engagements of any one fan, or certainly to make any assertions about how fanfiction might fit into this fan’s life. 
Nonetheless, it is sometimes possible to find more information about the authors than their chosen pennames, their avatars, and their associated stories. One such case is that of chivalric. Chivalric participates in two major fanfiction websites, namely The Petulant Poetess (or TPP) and Sycophant Hex (SH). We learn from her profile at The Petulant Poetess that her "real ${ }^{49}$ " name is Sam C. Leonhard, that she is from Germany, and that she is around forty years old with a son and a dog. It becomes clear immediately, of course, that chivalric is also bilingual. Furthermore, we learn from her Live Journal account that she is a freelance journalist, that she is not only bilingual but that, as she says, "I raise my boy bilingual and prefer to write in English, too. Strange, that. It sounds wrong when I write fanfic in German. Occasionally, I translate a story (from Dreamy_Dragon), and that, too, feels odd" (chivalric. "Profile" Live Journal). Both The Petualant Poetess and Sycophant Hex show Chivalric to be a prolific writer, with 62 and 20 stories respectively. Finally, as she advertises on the Petulant Poetess, she has published four original novels through Dreamspinner Press, including Tainted Blood and Tainted Soul, both of which are available through Amazon Kindle.

On the screen, chivalric appears to be a highly dedicated and engaged fan, and a particularly prolific fanwriter. Moreover, while her fanworld status is a little unclear on the screen, her naming of multiple other fans in author's notes suggests that she is very active in online fan spaces. Furthermore, the sheer volume of work available suggests that chivalric is likely middle class: she has access to the technology, leisure time, and education necessary to engage in depth in the fanworld. Finally, while I am not entirely sure I could call chivalric's participation typical, I will note that her story appears to be

\footnotetext{
${ }^{49}$ I put this in quotation marks here because this is another penname, and I am protecting chivalric's personal identity.
} 
very similar to what has been found in previous fan ethnographies (see especially Jenkins and Bacon-Smith). For example, in her discussion of how fan world "neophytes" are initiated into the community in Enterprising Women, Bacon-Smith describes the yearslong initiation of her Star Trek community friend and mentor, Beverly:

Beverly explained that she enjoyed reading science fiction long before she saw Star Trek. She threw herself into her first Star Trek convention in 1974 with enthusiasm and made a number of friends, among whom was her mentor. Her mentor bought Beverly her first fanzine at the convention; however, “... I hadn't read it [the fanzine] until 1976. The reason is, I took one look at it and I said, 'I don't know what they are talking about in here. I'll put it away and maybe someday I'll understand.’

And sure enough, in 1976, a friend, my friend [name deleted], she said, 'Look, you don't know what you're missing. You have to read this!'

'Okay,’ I said, ‘Okay, I'll give it a try.'

Well, here, she gave me—well, actually, she gave me two fanzines, and I said, 'This isn't too bad, it's interesting...let me read some more.'

And I said, 'I think I'm falling in love with this.'

And she said, 'Good,' and she brought me over a hundred fanzines and I read them over three or four nights, and I was in love.

And from then on in, I just bought fanzines continuously.” (88)

In this excerpt is a fairly common story of fanworld initiation: fan discovers media product (here, Star Trek, for chivalric, Harry Potter); fan seeks more information on media product; fan discovers conventions or forums or online fan-made website; fan 
reads fan-made materials for a long time, making other fan friends along the way; fan writes something of her/his own. In general, Jenkins and Bacon-Smith describe fans (mostly women) who have made what they see as a life-long dedication to the fan community. These women are generally multi-talented—meaning that they often work hard to develop skill in writing and artistic endeavors, as well as in technical know-how, such as video editing and publishing. Moreover, they are often engaged in several fan activities, such as conventions, fanfiction, fan forums, and even gaming. Importantly, however, these women are also singularly invested in their fan activities, "requiring as high a degree of commitment as any job, town, or religion" (Bacon-Smith, Enterprising Women 87). In many ways, these attributes do describe chivalric as a fanwriter, but in some very specific ways, chivalric's story is very different.

Chivalric first came to fanfiction soon after the release of the seventh installment of the Harry Potter series, The Deathly Hallows in 2007, mainly because she was disappointed with the way the series ended. She wanted to rewrite the story for herself, and she eventually sought out a community of like-minded individuals in a Harry Potter forum on Amazon.com. Eventually, she was pointed towards Harry Potter fanfiction: Another forum member then mentioned I should check out the HP fanfic sites, namely SycophantHex.

I did. And I was flabbergasted that people were pairing Snape with Hermione. The thought had never occurred to me—in my mind, I had paired him with an original character of mine. But it made sense. I think I read one or two stories, didn't like them too much, but was thrilled to see that people left reviews for the 
stories. Reviews! Feedback! The prospect of people telling me they liked what I had written!

It is what drove me ever since: the reviews. The contact with my readers. I wrote my first story about a week after I had discovered SH, submitted it, had it rejected, had it betaed, submitted it again to The Petulant Poetess, and kept writing fanfic more or less continuously for about a year. (chivalric, Personal interview, 16 June 2014).

In many ways, as we saw above, this is a very familiar story. However, chivalric was only an active writer in the community for two years (though she was very prolific during this time, writing 80 stories, 60 of which she has posted). After this period, she dedicated herself full time to her own original fiction ${ }^{50}$. Perhaps more different still is that, while chivalric continues to stay in touch with the beta readers and writers she met at Sycophant Hex and The Petulant Poetess, she has never spent much time reading fanfiction. It would perhaps be tempting, given these details, to argue that chivalric is entirely atypical for fanwriters, or even that she is no fanwriter at all. However, this would be highly reductive and problematic. It is more accurate to say that chivalric's experience is more illustrative of the potential range of fanfiction participation. For her, the point of fanfiction was always the interactions, the friendship, and, crucially, the critical yet supportive response of her fellow fans. Because chivalric has stated how important fan reviews as well as beta reader responses are to her, I will explore these in more depth in the next section.

\section{A Fanwriter and her Betas- the Heart of the Online Fanfic Economy}

\footnotetext{
${ }^{50}$ Chivalric has shared with me in personal communication that part of her move away from fandom was because she stopped receiving the same degree of feedback.
} 
One of the most striking features of chivalric's fanfiction participation can be read in her author's notes—in both her fanfiction stories and her original fictions. For example, in her story, "Divorce," chivalric's authors' notes read in the following way: Many thanks to my wonderful betas, Dreamy_Dragon, Sampdoria, and kickthemoon. They pointed out the little inconsistencies in the story; I owe each of them a big box of chocolate frogs!

In addition, I want to thank Gryffkat for her effort turning this into an MP3. It is currently not online, but anyone interested is welcome to get in contact and I'll mail it asap. (chivalric "Divorce")

What we find in this acknowledgement is typical of the fanfiction genre at Sycophant Hex. Writers will include thanks and dedications at the top of the page (much like a preface), and may include further notes about inspiration, unusual plot and/or characterization choices, and previews of another story or story chapter at the bottom of the page. "Betas" are voluntary editors; they read for grammar, punctuation, plot, characterization, etc. There are also "beta readers" who check for British dialect features, "Britpickers."

What I would especially like to point out about these author's notes is not only that they acknowledge the hard and dedicated work of beta readers but, more so, that they belie a complex system of largely private exchange of symbolic capital -i.e. friendship. In fact, it is likely due to this intense exchanging of symbolic capital, of true fondness, that many of these relationships are very long-lasting, as is clear from chivalric, or rather, Sam C. Leonhard's acknowledgements within one of her recent books, Tainted Blood: 
Special thanks to my very own petulant poetess, Theresa, not only for editing the manuscript and getting it ready for submission, but for creating and maintaining her fabulous website too. Without the site, I would never have gathered enough motivation to write at all, and without her support and friendship, I would have given up pretty soon. (Leonhard 43-56)

This quotation alone shows the importance of the writer-beta reader relationship at The Petulant Poetess, Sycophant Hex and other fanfiction websites like it. It hints at, however, something even deeper than the "importance" of these relationship; it hints at their intensity as well.

While Sam C. Leonhard/chivalric is a particularly prolific fanwriter, and a published author, which might suggest that we see her as highly atypical of "common" fan engagement, I would argue that her relationships with her beta readers (stated in author's notes, acknowledgements, and in personal communication) demonstrate that she is, to some degree, a very typical fanwriter as well. Online fan readers can email website participants, and many within the fandom community actually do come to know each other not only by name, but to share features of their daily lives. Moreover, through the beta process, fanwriters interact intimately and energetically with their editors, developing, so it would seem, long-lasting friendships, even if the two individuals never meet in person. For instance, chivalric/Leonhard not only thanks her betas in the authors' notes for every story, but the acknowledgements in her two published books mention these individuals as well: "I would like to thank the following people for betaing" (Leonhard 49-56, my emphasis). What's more, many fans do get to know each other 
eventually - as is the case with chivalric and her beta readers kittylefish and Dreamy Dragon.

As Bacon-Smith remarked of early convention and fanzine communities in the 1980s:

In the fan community, the very process of creation generates the social situation. Fans gather to trade and sell their fanzines, to tell stories, to watch the source products and the music videos, and to construct lives based on the tenets they build into their fiction. Among the most important beliefs are the trustworthiness of fans and the willingness of fans to contribute to the good of the community in the spirit of IDIC — the joy of Infinite Diversity in Infinite Combinations. (Enterprising Women 219)

As we saw above with chivalric's emphasis on the possibility of feedback-"It is what drove me ever since: the reviews" (chivalric, Personal interview, 16 June 2014)—in terms of the intensity and depth of the writer-beta reader relationship in fandom, chivalric's experience of fanfiction highlights what I would consider the real cornerstones of fanfiction communities: friendship and trust.

Chivalric's recounting of a particularly unpleasant early experience with beta reading especially highlights the elements of trust and care that define a successful writer-beta reader relationship:

One of my early stories (2007) is called Time to Heal, and I never posted it although it is finished and betaed. The reason is my back-then beta. [...] Anyway, I got Time to Heal back and my beta had complained about the lack of canon, that is, the fact that I had Remus Lupin as a side character in the story. 
Snape survives the snake attack, but Lupin is simply still alive without explanation.

She disliked it a lot. But instead of mailing me beforehand and talking to me about her concerns, which I expect from any of my betas, she simply decided to change my story: she replaced the name "Lupin" with the name "Arthur Weasley," having chosen him as Snape's friend simply because he was available. Man, was I stinky. First, I dislike anyone rewriting my stories for whatever reason. Second, I expect my betas to talk to me. An author-beta-relationship is based on trust; what she did was, imo ${ }^{51}$, inacceptable.

I did not contact her afterwards ever again. And I never got around to post the story, either. (chivalric, Personal interview, 5 Oct. 2014, my emphasis) This particular story demonstrates not only the importance of writer-beta reader relationships, nor only of good ones, but that these relationships are also rule-driven.

This example above demonstrates, on the one hand, the kinds of struggles that can and do occur in fandom when it comes to "proper" interpretation of canon (remember Valis2's vehement argument for honoring canon elements in Chapter 3). On the other hand, however, it better demonstrates the importance of mutual respect in these relationships, where respect is both shown and maintained through honest yet polite dialogue. This beta reader's choice to simply rewrite chivalric's story without bothering to contact her shows a level of dismissiveness and controlling behavior that is insupportable in the writer-beta reader relationship of fanfiction. It is quite possible that this occurred because chivalric's story appeared to break community codes. Or, perhaps, it occurred because the beta reader herself was unaware of community codes (though this is unlikely,

${ }^{51}$ IMO = “in my opinion.” 
as she had worked with chivalric before). At any rate, this instance demonstrates the importance of open and caring dialogue—and, perhaps, part of why not all fanwriters will use beta readers (see Madshrubbery and liloweewoah below).

Based on this experience, then, as well as chivalric's more positive experiences (see kittylefish below), I would tentatively suggest the following rules of beta reader conduct:

1. Engage in frequent and open dialogue with the writer

2. Show care and respect through criticism and questions

3. Fulfill only the role agreed upon (For example, of her betas, chivalric says: "I use different betas for different things. Like, kitty[lefish] is more for the fine-tuning and [Beta $2^{52}$ ] is more for the first, rough read. If possible, I use more than one beta for my [original] fics" (Chivalric, Personal interview, 16 June 2014).

While these rules are only tentative, they seem to be consistent across participants, including kittylefish.

The strength of these exchanges, as well as of the emotional economy which allows for them to exist, is best seen in their longevity. A long-standing beta reader (and friend) of chivalric's (from fanfiction to original work), kittylefish, has described their relationship in the following way:

She asked me if I would be willing to beta the sequel because her usual beta was not interested in betaing a threesome with Snape/Lupin/Hermione. I said sure I would, lol. At that point I didn't know it was Chivalric who was asking, but I suspected it might be her. I was already a fan of her work.

\footnotetext{
${ }^{52}$ In order to protect the identity of fanwriters who have not agreed to participate in this project (at least as much as possible), I have chosen to change the name of this particular beta reader.
} 
That was in August of 2008 - I just looked it up. [... I enjoy helping people to polish their stories and make them as good as possible. I've always felt like my job as a beta/editor is to suggest every single thing I think would make the story better, and then let it go, so I don't expect everyone to take every suggestion, though if I notice that somebody isn't taking any of them, that might make me not want to spend the time to work with them again. [...]

And she betas my stories for plot and character, which I immensely appreciate. (kittylefish. Personal interview, 19 July 2014, my emphasis)

This quotation clearly demonstrates the importance and the strength of long-standing writer-beta reader relationships on TPP and SH (and other fanfiction websites). It also demonstrates how these deeply emotional exchanges allow for transformative work within the Harry Potter canon and fanon universes.

Moreover, the importance of these relationships is even further reflected in Chivalric's recollections of her work with her beta readers: "I could not work without beta.... [There] are my girls who do the hard work, the grammar stuff, the orthography. Without either of them, I could not publish/post a single line.” We can say from this acknowledgement that not only have chivalric's interactions on Sycophant Hex and The Petulant Poetess provided, perhaps, an escape from the mundane, they have engaged her in sophisticated interpretive practices, as well as sophisticated learning that has allowed her to develop both confidence and rhetorical effectiveness. But, furthermore, these practices have engaged her in a complex and highly important economy of exchange which appears to have played a major role in inspiring chivalric to continue working 
towards developing her craft as a writer, especially (and eventually) within her own original works.

\section{Outgrowing Fanfic?: From Fandom to Original Publication}

It is not a new phenomenon for fanwriters to enter the world of commercial publication; Penley, Scodari, Bacon-Smith, and Jenkins have all discussed it. And wellknown authors E.L. James and Cassandra Clare both engaged in fanfiction before achieving international success. In this way too, then, chivalric fits with a long-held cultural element of fandom. In another way, however, chivalric's experience seems very atypical, because she only engaged in fandom for two years before moving away from almost all of her fandom activities. She says of her move from fanfiction to original writing that:

I figured I had written every happy ending I could come up with for all the characters I cared for. I saved Snape in many different ways; I paired him with Hermione, Lupin, once with Lucius Malfoy. I saved Dumbledore, and I wrote a few darkfics. Once I was through with it, I became bored. I still log in about once a month and answer reviews, but other than that, I am done. The unfinished fics on my hard drive will stay unfinished, I guess. Starting again would be like moving back in with my parents: I have grown out of it and there is no way back. (chivalric. Personal interview, 16 June 2014, my emphasis)

This particular quotation seems to suggest a complete break from fandom. However, the case is much more complicated.

It is true that chivalric has chosen to focus largely on her own original fiction, and the majority of this fiction is set in a fantasy universe. However, chivalric is still in many 
ways a fan. For example, her Tainted series characters' names are references to two beloved source texts: "Aleksei Tennant's character is built after the actor David Tennant, who played Doctor Who. Gabriel Jordan is a completely original character, but the name is nicked from Lee Jordan out of HP" (chivalric. Personal interview, 16 June 2014). And another story, Hero Worship, taps into chivalric's love of Tolkien: "Hero Worship is fantasy and basically about Gandalf and Aragorn- not that anyone would have noticed, and I didn't intend anyone to notice, either. It was my personal fun game to come up with that story. It is about a gray-haired wizard who, unexpectedly, finds someone who can deal with his dark moods after centuries of loneliness" (chivalric. Personal interview, 8 Dec. 2014). What's more, while the Tainted series is entirely original fiction, chivalric does admit an initial Harry Potter fanfiction-related scene:

I did not want any copyright wars so I stayed well away from the HP fandom. Different kind of magic, different kind of world, different characters. I like tattoos, so I came up with the idea of the tattoo on Gabe's neck, and from there to runes it was a small step.

Neither Gabe nor Aleksei should have any similarities to HP characters. I did not create Gabe after Lupin, nor Aleksei after Snape. However, the initial idea was HP related. I had a scene I had originally planned for Snape (the encounter with the centaurs). But in the end, I never wrote the story and hence, had no use for the scene anymore. So when I came up with the idea for Tainted Blood, it started with that scene. I built the rest around it. (chivalric. Personal interview, 16 June 2014) In terms of content, then, chivalric very much retains ties to the fandom world. Furthermore, it is likely that chivalric anticipates readers who are also engaged in 
fandom. Finally, chivalric maintains a long-term relationship with betas she met in fandom (they still work together), and she still betas for some writers at Sycophant Hex and The Petulant Poetess (her two main fanfiction websites). In this sense, then, I would argue that the texts have never been as much of a focus for chivalric as much as the close, emotional relationships as friends and critics she was able to find in the fan community.

These close, intimate, and certainly emotional relationships are a consistent feature of fanfiction participation and fanwriterly reality, as we will come to see with $X$ Files writer, Madshrubbery, and WWE writer, liloweewoah. However, we will also come to see that other elements of the fanwriter reality, such as engagement with beta readers, types of content, ideas about craft, and certainly leisure time available for writing and/or reading differ quite a lot across fanwriters. What's more, as we saw above with chivalric, while fanwriter realities often reimagine the work of writing both in relation to a favored source text, and in relation to writing more generally, they are also often implicated within and highly shaped by dominant ideologies. Next, as I discuss the fanwriter reality of Madshrubbery, I will paint a portrait of a fan who is just as emotionally-invested in her source text, The $X$-Files, but whose investment is largely textual, rather than interpersonal.

\section{Madshrubbery Finds an Old Friend in The X-Files}

I discovered a community on Live Journal called The X-Files, and a lot of them were into fanfiction. So, I decided I enjoyed writing short stories, and I enjoyed, loved the show to pieces - I watched every episode since it began — and now I was getting a refresher course in the show. So, I just started out writing these short stories about the show, and 
over the course of Sci-Fi airing those reruns, that's when I started writing the stories and sharing them with the $X$-Files community.

(Madshrubbery. Personal interview, 29 Aug. 2014)

In the above lines, Madshrubbery ${ }^{53}$, an avid fan and fanwriter reflects upon her initial experience of re-encountering The $X$-Files and discovering fanfiction for the first time. It was 2010, and at the time, she began watching reruns of The $X$-Files on the Sci-Fi channel, which aired at 2:00 a.m. As Madshrubbery states above, it was around that same time that she began seeking and found other like-minded fans to converse with, in this case in an online community. Soon after, she wrote her first fanfiction story. This story was an extension of the episode, "Agua Mala" $\left(6.13^{54}\right)$, in which Mulder and Scully investigate an unusual creature that seems to be killing and dissolving people during a hurricane in Florida. Madshrubbery's first story was 1,000 words, and it took her approximately 90 minutes to write immediately after she watched a rerun of the episode. She posted the story to the Live Journal X-Files community soon afterward, and it received a lot of positive reviews, which inspired her to keep writing more fanfiction.

In many ways, Madshrubbery's fan story is very similar to chivalric's: she sought out media to help her pass the time; she soon developed the desire to discuss this media with other people, with fans. Not long after that, she began authoring her own fan work. Moreover, as with chivalric, this story is very similar to other fan initiation stories. In Enterprising Women, Bacon-Smith argues that it is very common for individuals to feel

\footnotetext{
${ }^{53}$ Madshrubbery has reported in personal communication that she chose her penname based on a mash-up of her affection for Matchbox Twenty's album, Mad Season and Monty Python and The Holy Grail. Her name apparently combines the album title with the "shrubbery scene" with "the knights who say ni" in the film.

${ }^{54}$ Which initially aired on February 21, 1999.
} 
as if they have come to fandom because of feelings of discontentment or incompleteness, and that participation in fandom helped them to begin addressing those feelings: "Among members I have interviewed, almost all point to their decision to involve themselves in the Star Trek community as part of a series of major life changes they experienced at the time. Judy Segal was finding her work as a science teacher burdensome, and she credits her involvement in the Star Trek community with helping her through a period of teacher burnout” (92). While Madshrubbery does not report any specific discontentment, she does represent her fanfiction journey as that from one version of herself to another version who has a better sense of her life goals: “I'd just like to say that fanfiction was definitely a precursor to my wanting to become an English major” (Personal interview, 29 August 2014). Similarly to chivalric, then, Madshrubbery entered the fanfiction community because of a desire to discuss $X$-Files more, but her participation led to a desire to develop as a writer.

Madshrubbery is in her thirties, and works 35 to 40 hours per week in office jobs as a temporary worker, frequently fulfilling administrative assistant roles. She has a Bachelor’s degree in English and Graphic Design from a large, urban, Southern university, and she uses these skills, particularly of document design, in her work. She lives in a suburban area with her elderly parents, for whom she is the main caretaker. Though Madshrubbery is a temporary worker, she has a middle class material reality. She has had both the opportunity and the resources to complete a four-year college degree. What's more, her father has completed an advanced degree. She continues to have access to her own vehicle and her own laptop computer, on which she does the majority of her composing. In addition, she has access to book-binding materials, as she designs and 
creates her own books for sale at local craft fairs. In the sense of class (and socioeconomic status), then, Madshrubbery’s fanfiction initiation story is similar not only to chivalric’s but to many other fans, especially those within sci-fi and fantasy communities (see Bacon-Smith, Jenkins, Bury, and Scodari). Madshrubbery has many of the resources available to engage intensively in fanfiction: leisure time, digital and computer technology, education, and certainly advanced university-level literacy.

In particular, in Madshrubbery's story we find a sense of the professional in her view of her own fan engagement: "I think some of the better writers in the community give me a better sense of purpose into creating new stories. I mean, it’s not just Mulder and Scully in different skin. It's actual new, multiple characters in genuine, new situations” (Personal interview, 29 August 2014). This quotation highlights that, for Madshrubbery, fanfiction has inspired her to work towards creating something — a story, a space, an artifact—of her own. This is especially compounded by her Live Journal profile statement: "She strived to make her "work of art" so, and put pen to paper in hopes of coming up with an idea that wasn't "so much less.” It was to be her goal to take everything, examine it in the most exquisite form possible, and hope it would all turn out grander than previously imagined....[Madshrubbery] would write the journal herself.” Madshrubbery openly links this profile statement to the works of Virginia Woolf, particularly Mrs. Dalloway, and in so doing, she identifies as someone who strives toward art, toward individual writing experiences, toward, as it were, writing as a "room of her own.” While chivalric's fan participation is geared largely towards the social element of fandom, Madshrubbery represents her own fan participation as geared largely towards the text. 


\section{Changing Tastes: Out of XF to Ofic and Madshrubbery's Writerly Identity}

[A good fanfiction writer is someone who] isn't a Mary Sue. Someone that takes the time to really apply their craft to the show. Someone who you can probably tell is into English as a major or minor or...Someone who takes writing seriously. Someone who...The better writers are usually...their stories are usually longer, so you really have to get invested into reading it. Although, there are writers who are 500 words or less and they're excellent stories. But, it's kind of...Just, when you read it. You know it. It's like, some kind of instinct, or something. (Madshrubbery. Personal interview, 29 August 2014, my emphasis)

Madshrubbery is a fanwriter who is particularly concerned with the concept of craft, which for her includes "genuine" and "new" ideas_-"Not just Mulder and Scully in different skin" (Personal interview, 29 Aug. 2014)—and "accurate" research. The above quotation builds upon these ideas as Madshrubbery highlights terms-concepts such as "craft," "taking writing seriously," and "instinct." All of these terms depict writing as something entirely separate from the mundane and the everyday. Here, writing is something entirely different from, say, exchanging texts and emails and filling out forms. It is different, even, from fanfiction reimaginings. Writing cannot be writing unless it is new, unless it is unique. Furthermore, here Madshrubbery is careful to distinguish what I would call the capital "W" Writer from the Mary Sue. Within the fan community, a "Mary Sue" (or "Gary Stu") story is one in which the main character, usually an original character or OC, is overly powerful.

What's more, it is typically understood that the Mary Sue is a stand-in for the writer, for her/his desires. The term "Mary Sue" was apparently coined by Trek fanwriter 
Paula Smith in her satire of the genre, "A Trekkie's Tale," in 1974 (see Bacon-Smith Enterprising Women 94), and the term has always been used to describe a form of writing that "is also the most universally denigrated genre in the entire canon of fan fiction" (Bacon-Smith Enterprising Women 94). This is likely because it is often viewed as shallow, immature, and, it would seem, stereotypically romantic. In a way, perhaps, we could see the Mary Sue, in fandom tradition and in Madshrubbery's view, as a writer too immature or lacking in skill to go beyond her/his bodily desires toward the realm of craft. Madshrubbery has left "craft" undefined here, but the implication is that it is something that is born of true talent. In this section, I will trace the ways in which Madshrubbery depicts the work of writing and the identity of The Writer. This depiction will be full of tensions that are, I would argue, afforded and delimited by dominant ideologies of literacy, and are, furthermore, part of the makeup of any literacy story because we are all always-already implicated within Ideology.

Similarly to chivalric, Madshrubbery has largely transitioned from writing fanfiction to her own original fictions: "I do more reading now than I do writing, mainly because my tastes have changed in what I like to write about. Nowadays I just write, um-I don’t really want to call them "generic” short stories—but they're short stories that don't have a fanfic topic.... I just create characters out of nowhere, and put them in situations that just pop into my head, so they don't belong in the fanfiction community” (Personal interview, 29 Aug. 2014). Here, Madshrubbery presents evidence that, for her, participation in the fan community has encouraged her to keep writing, and to delve deeper into her own potential story universes outside of fandom. Furthermore, this comment suggests that reading fanfiction continues to encourage Madshrubbery to keep 
delving into original universes. Unlike chivalric, Madshrubbery does not see this transition as a growing up or "progress" narrative, but rather as a, perhaps, unforeseen but nonetheless very pleasant development. In this sense, then, Madshrubbery is a typical fanwriter: it is the support of the more emotionally-focused aspect of the fanfiction economy, perhaps, that has allowed Madshrubbery to seriously take up writing. When we investigated the fanwriting practices of chivalric, we found a writer for whom the dialogue — between a writer and betas as well as writer and readers—was the essential element of the work of writing. In her case, a writer's identity depended upon her/his ability to openly and critically interact with any of her/his respondents is as important as her/his ability to come up with new or distinctive ideas and use "proper" grammar. In other words, as we discussed, sponsorship through dialogue, especially with privileged native English speakers is a leading defining factor for chivalric's fan literacy practices, and her writing practices more generally.

In this latter sense—of dialogue, that is—Madshrubbery is a very different kind of fanwriter from chivalric. While she did write both "Mitchell" and "Welcome to Midgetville" for fellow community members, and while she continues to read fanfiction occasionally, she has never established any kind of beta reader-writer relationship: "No, I never asked to be a beta reader, and I never asked anyone to be a beta reader for me....I trusted my own gut, my own skill as a writer to be able to put it out there without needing four or five, twelve, people reading this story. I know that I am a strong enough writer to be able to produce something without having it proofread by other people" (Madshrubbery. Personal interview, 29 Aug. 2014). This statement seems particularly striking, especially since the give and take of writer and beta reader relationships has 
been demonstrated as such an important element of fanfiction practices. However, while Madshrubbery does not engage in the beta reading process at all, Madshrubbery's engagement in fanfiction is nonetheless dialogic. For example, as she reflected on her experience of writing and posting her very first fanfic, Madshrubbery said: "It was very short—just about a thousand words—and I posted it and I got several positive comments back from users in the community. And that really prompted me to go further" (Madshrubbery. Personal interview, 29 Aug. 2014, my emphasis). This quotation certainly suggests that it is likely that reader comments and reviews have played a larger role in Madshrubbery's fanwriting experiences.

Though Madshrubbery was firm in explaining that she did not use beta readers, and that she was highly unlikely to share her stories with another person, she did state that she will talk to friends about her stories in their early stages:

I will talk to a couple of close friends who know that I like to write. I like to bounce plot ideas off of them or show them one-page plot treatments of what the eventual story may be like. If they think it is worthy of exploration, then I will go ahead and expand the treatment into a full-fledged story; otherwise, I will leave it as the one-page short story. This way I feel like I'm not "wasting time” on a story that isn't going to end up being a dud. I'd rather spend time fleshing out a story that will be fun and intriguing to read." (Personal interview, 8 Dec. 2014).

This quotation demonstrates that Madshrubbery is engaging in some degree of dialogue in her composing processes. This process of sharing plot features and short "plot treatments" with friends is highly reminiscent of the "talking story" phenomenon that Bacon-Smith described in her own fanzine initiation story: "I was introduced to one of 
the most widespread practices in fandom—-'talking story.' Talking story is literally a verbal narrative of the community's fiction. The story so 'talked' may be one the talker has written, or plans to write, or one that she has read and particularly liked" (Enterprising Women 93). Bacon-Smith describes this practice as central to the fan community because it provides a safe space for women to work through concepts they identify with, struggle with, or even detest not only in the source texts but in their daily lives. In one sense, Madshrubbery’s depiction above is "talking story," and it is highly likely that this sharing does often occur within more intimate conversationsMadshrubbery is sharing with "a couple of close friends" after all. However, Madshrubbery shared this element of her writing process only after some prodding, and she shared it in an offhand manner, as if it were an afterthought. Within Madshrubbery's representation of writing, this more intimate, emotional element of a composing process simply does not accurately fit within the work of writing.

Therefore, while Madshrubbery does engage in some form of dialogue or "talking story," overall Madshrubbery backgrounds the interpersonal dialogue in favor of a more individual writing journey. As Madshrubbery said of her decision never to seek a beta reader, "I know that I am a strong enough writer to be able to produce something without having it proofread by other people" (Personal interview, 29 Aug. 2014). While for chivalric, beta reading is an intensive process of exchange-of ideas, content, and yes, style_-it is part of "craft," Madshrubbery's reference to beta reading as "proofreading" suggests that, for her, beta reading is only a shallow, technical exchange. It is mechanical. This suggests that, for Madshrubbery, a writer must already know her/his technical and mechanical elements of writing (ostensibly, grammar and punctuation rules). The above 
quotation suggests that this is because what she would consider a "strong" or "good" writer should spend her/his time on immersing herself/himself into idea, world, and character development.

This particular view is compounded by the way Madshrubbery talks about her plan to become an English major. Intriguingly, Madshrubbery takes care to distinguish "writing" from "art" here:

I'd just like to say that fanfiction was definitely a precursor to my wanting to become an English major. Because it started out with my wanting—it developed my desire to write. And, from there, it has pulled more and more on the urge to want to create. In making the books, it helped me find somewhere where I could make books on my own, and then start to self-publish those two books that I made. And I am considering self-publishing some more books. So it's turning not just into writing, but it's turning into a real art now. I'm, sort of, grateful to the world of fanfiction for developing my writer's itch. And, without it, I probably would never have taken so many creative writing classes in college. I probably would have never gone and sought out the information to become an English major. (Personal interview, 29 Aug. 2014, my emphasis).

To this point, I have been developing a portrait of Madshrubbery as a more solitary, individual writer-one who perhaps does not engage in the emotion economy of fanfiction. I must first state that I believe Madshrubbery's participation is one viable material fanwriter reality. I must also point out, here, that it is entirely possible to argue that Madshrubbery's choices to work without beta readers and to only "talk story" with drafts she feels are mostly completed, are a reflection of her personality and idiosyncratic 
writing style. We do know that people engage with the work of writing in very different ways, and the quiet, lone drafting of materials is certainly a potential preference. Famous compositionist Peter Elbow sometimes urged students to write only to themselves as an attempt to help them shrug off the anxiety-inducing baggage of an authoritative external audience (see particularly “Closing My Eyes as I Speak: An Argument for Ignoring Audience" ${ }^{55}$ ). And the recent Locations of Writing series in CCC is a tribute to different contexts of writing, including personal preferences. Moreover, plenty of those contributors discuss the experience of lone writing. For example, Michael J. Faris represents himself almost as a spot of silence in a noisy and lively environment: "I sit alone, typing on my MacBook Air, sipping on coffee, and listening to the conversations around me and the rockabilly playing through Caffetto's speakers" (21, my emphasis). Faris' main points here are the mediation of technology in writing and the very bodily experience of writing near others, even if you do not "talk story" with them.

Thus far, Madshrubbery's fanfiction literacy experiences seem to be made up of very strong tensions_-even dichotomies: because she does not use beta readers (nor does she act as one), she appears to value the solitary individual over dialogue. Because she strongly distinguishes "art" from "just writing," she appears to value not just a dominant view of mastery but of acceptable or proper writing over less sanctioned writing forms

\footnotetext{
${ }^{55}$ Elbow says specifically that, "It's not that writers should never think about their audience. It's a question of when. An audience is a field of force. The closer we come-the more we think about these readers-the stronger the pull they exert on the contents of our minds. The practical question, then, is always whether a particular audience functions as a helpful field of force or one that confuses or inhibits us” (51). Here, Elbow is mainly concerned with helping writers to get words on the page. He admits that there is no escaping "audience," but he believes it is possible to conceive of oneself as the most important audience, at least for the time being. It is notable that this concept is very similar to the fan concept of the "alpha reader" as opposed to the "beta reader." The idea is that the writer must always be the primary and most engaged but critical reader of her/his own work, and that the beta reader is there to lend a different opinion or to expose any gaps the writer cannot see. This view, however, is different from seeing The Writer as always solitary.
} 
and of "novicehood." And, finally, because she places so much emphasis on finished objects $^{56}$, she appears to value product over process. As I mentioned earlier, it is possible to equate these tensions to personal preference. However, as I argued earlier, it is striking the degree to which Madshrubbery's views of writing align with dominant views of writing. In part, what we are seeing in play with Madshrubbery (and chivalric) are the affordances and limitations of how choice operates within the larger sea of capital "I" Ideology. Madshrubbery, just as much as anyone else, is deeply influenced by the dominant field of possibilities for writing. In that sense, I would argue that while Madshrubbery's fannish activities are largely textual, they are nonetheless embodied, emotional, and dialogical. As I forecast above, we have seen a second fanwriter reality that is mostly focused on the product and on the text in Madshrubbery's $X$-Files fan participation. In the next section, I will come to trace yet a third possibility for fan participation as I discuss liloweewoah’s WWE fanfiction practices, especially her focus on writing as self-expression.

\section{Where you can let your imagination go!: liloweewoah and WWE Fanfiction}

"On her way [to the locker rooms] she had walked right into another person since she could barely pay attention. Luckily nothing flew apart since Isabella was such an organized person and usually kept things paper clipped together or stapled together.

Though her landing on her butt didn't do her justice, she shook her head as she took in the sight before her. 'Lilo, are you all right?' She heard someone say.

\footnotetext{
${ }^{56}$ For example, she has said of her self-published books that, "I've always had offers to sell them, but I don't want to part with what I've made at this point in time. I could easily make a duplicate copy to sell, but I simply prefer the idea of having only one inexistence" (Madshrubbery, Personal Interview, 8 Dec. 2014, my emphasis). It is interesting, in this quotation, that Madshrubbery focuses not only on the "finished-ness" of these pieces, but their singularity. Again, this not only demonstrates her apparent valuing of product over process, but also her valuing of the "lone genius" ideology of The Writer.
} 
Isabella took in the voice. She knew who it was but the sound of her name rolling off their mouth with that sexy accent made her wish that they would just continue talking to her. She looked up and met their brown eyes staring back down at her. They helped her off the floor before picking the papers up. They handed the sheets back to her and smiled.

'Thanks, I'm fine, PJ.' Isabella whispered as she took in the sight before her. Paul Lloyd Jr. was standing right in front of her. He was giving her that wonderful smile that made her weak in the knees. And she watched as his hand touched her bangs to move them away from her eyes. God she could kiss the man.

'You sure, babe? You seem kind of flustered.' He whispered he pulled her closer to him. 'Yes I'm fine. It's just been a long day. Aren't you supposed to be with Stu right now?' She asked as he looked down at her.

'I am but he's with Sammi and I wanted to come find my adorable girlfriend who reminds me of Lilo from Lilo \& Stitch.' He said as he leaned down to place a kiss on her lips." (liloweewoah "Take a Chance")

The scene above can be found in the WWE Fanfiction World community on the website Fanfiction.net. The story focuses on three couples, particularly on the trials of Isabella Hilario, nick-named "Lilo" and her boyfriend, famous South African professional wrestler, Paul Lloyd Jr., whom she refers to as "PJ." At an off-hand comment PJ makes about wanting to walk in on some friends of theirs in flagrante delicto, as it were, the couple quarrel. Both "Lilo" and "PJ" make sure to kiss their best friends in front of each other to make each other jealous. The story ends happily with the couple making up and spending a special night together. The story is a romance fic featuring major WWE 
wrestlers and an original character, here, Isabella Hilario or "Lilo." It is also a songfic featuring the lyrics from Katy Perry's "Teenage Dream." The story was published on October 13, 2010. It has been listed as a favorite story by seven participants, and features six reviews. While it is not as closely-followed as others of liloweewoah's stories, it is nonetheless unanimously celebrated by its readers.

Of particular interest, here, the main character of this story is an "OC" or "original character," and her nickname is "Lilo," just like the writer. Liloweewoah shares on her user profile that she has chosen this name because "people say I resemble Lilo from Lilo \& Stitch. And that's the simplest way to remember me" (in personal communication she has further explained to me that she chose to add "wee" and "woah" to show how "Lilo" was meant to be pronounced). Immediately, then, any reader of fanfiction would be likely to ask—“So, is this a Mary Sue story?" Ultimately, I would argue that it does not matter whether this story is a so-called "Mary Sue." It is more important to investigate the affordances the author creates by linking the character to herself, as she writes imaginative stories about her favorite characters from a television series she has loved since she was a child.

Liloweewoah, who prefers to go by "Lilo" for short, is between 18 and 25 years old, and she identifies as a straight woman. She is a Filipina-American, and a college graduate who currently works in retail at a mall in her hometown. She owns her own computer, though she often prefers to compose in a notebook. She estimates that she spends five to ten hours per day on her laptop (a Mac), two to five of which she spends on fandom. These features alone suggest that she is much like chivalric and Madshrubbery, in that she has not only the requisite educational, technological, and 
temporal resources that fandom often requires—especially leisure time. However, Lilo's particular fan material reality raises an important distinction: fan reading versus fan writing. She communicated to me that, "Before I graduated college, I used to write every day or every chance that I got. Now it's a bit harder to find an opportunity to write because of work. I usually try to write before work or after work" (Personal interview, 20 Feb. 2015). In this way, Lilo presents a fan experience as-yet unseen in this current study: one where writing time is much scarcer, especially if one wishes to make use of beta readers. Lilo appears to straddle a more complex material circumstance: she is, in some ways living with a working-class socio-economic status. What's more, her views on fanwriting, in combination with her main choice of fandom, suggest a potentially more working class taste profile/identity ${ }^{57}$, though this is unclear, given that she wished not to discuss her parents' educational backgrounds. What her comments on writing time begin to get at more than that, however, is that, without as much available leisure time for writing, the nature of this writing —in terms of motivation, process, and even content will also likely be significantly different.

In terms of content, Lilo tends to prefer writing romantic stories with happy endings. Her Fanfiction.net profile shows her to be an engaged writer across fandoms, including Harry Potter, Teen Wolf, Covenant, and, of course, wrestling. Her profile also shows her to have written 17 stories (that she keeps posted) in her more than ten years of membership (2004 to present). The majority of these stories are set in the WWE universe.

\footnotetext{
${ }^{57}$ I would like to point out that my sense of class here, especially as I investigate Lilo as a writer within the WWE community, is aligned in many ways to Irvin Peckham's understanding of class: "I have explored classification theory to explain what I mean by class. I am referring to a system of social relationships within which people act toward each other as if the groups did exist—as in their minds, they do" (26). In other words, I cannot know for certain whether it would be appropriate to label Lilo's material reality as "working class," but I can note the ways in which she codes as working class or as middle class or as some in-between-ish point.
} 
While all self-proclaimed fans and fanwriters dearly love their fan objects, Lilo's love for WWE not only links to her early childhood, but her family as well:

I discovered WWE when I was a little girl. My dad's side of the family had always been big fans of the WWE, which includes the time that they were known as WWF. So I vaguely remember what was going on at the time but I do know that I started watching around 1995-1996. When I first discovered it, my experience was pretty amazing. I had never seen anything like this sport nor did I ever think that I would become so intrigued or so interested in the sport. $[\ldots$.

I first sought out WWE fanfiction around 2004. It was the time where the tag team division was one of the best things that happened to the sport. You had superstars such as The Dudley Boyz, Edge and Christian, and The Hardy Boyz who changed the tag team division. At the time, my favorite wrestlers to follow were Team Extreme. I loved everything about them and I definitely had a crush on Jeff Hardy. I looked up to Lita because she just seemed to be the perfect rolemodel. That was one of the things that inspired me to want to write. I wanted to bring out female characters who were strong on their own and didn't have to rely on that certain prince charming to help them become strong." (Personal interview, 20 Feb., 2015, my emphasis)

Both chivalric and Madshrubbery represented their discovery of fandom in a more "revelatory" but also more self-focused way. For them, the source text and the fandom served to address a nagging emotional need. Lilo, however, more directly links her fandom to her upbringing. What's more, Lilo specifically relates that she was drawn to 
WWE Divas because she yearned to see more representations of strong women in media. Lilo's stories tend to present women who are family and relationship-focused, though they often have their own careers. For Lilo, these women have the power to choose careers, friendships, and romantic partners that they value.

Finally, in terms of process and/or motivation, Lilo's stated sense of writing differs from both the dialogic yet "original" focus of chivalric and the more "product"oriented focus of Madshrubbery. She has stated of her fan initiation that "The first time that I discovered fanfiction was around 2004. At the time, I think I was looking for a place to like let my creative imagination flow. When I found the site, I was pretty ecstatic because it was like I had found the perfect match to where I could let my imaginations go" (Personal interview, 20 Feb., 2015). Lilo sought fanfiction, perhaps, as a release, and this release is achieved through writing down the things she might otherwise have only daydreamed about. Furthermore, of writing more generally, Lilo has said, "Writing is about letting your imagination go and seeing where it takes you" (Personal interview, 20 Feb., 2015). This suggests that she takes what I would call a highly process-oriented and self-expression-oriented view of writing. While perhaps Madshrubbery's view of the author is as the romantic, single/singular genius type, Lilo's view of the author is similarly romantic. However, in Lilo's romantic view of authorship, this author has a singular connection to certain imaginative, even "original" ideas that s/he then transports directly to the page. In this section of this chapter, I will compare and contrast these three fan(writing) realities by investigating, how fanwriting fits within Lilo’s lived experiences. Taking Back Mary Sue: Expression is the Work of Writing

"Writing is about letting your imagination go and seeing where it takes you." 
(liloweewoah. Personal interview, 20 Feb. 2015)

"Hey guys, so babyxbxgurl and I decided that we were going to write a co-written story together. So we hope that you guys enjoy the story. I, Bubblyjayy ${ }^{58}$, only own Nicole and babyxbxgurl owns Kimberly. Hope you guys like this story! ....Love you guys!" (liloweewoah, Author's Notes for Fallin' For You)

Lilo represents a writer who is very engaged in and in-tune with her fan community. She shows herself to be in contact with fellow writers, as she asks permission to use certain OCs ${ }^{59}$ in her stories (see both "She is Love" and "Taking a Chance"), and she has taken the time to co-write a story with friend and fellow fanwriter, babyxbxgurl. This expands our understanding of Lilo as not only "engaged" but enthusiastic and gracious. I would like to start my discussion of Lilo's (fan)writerly identity here with her collaboratively-written story, Fallin' For You, because it addresses three themes that I believe are absolutely essential in Lilo's writing philosophy: 1) it is important to connect with the personal in writing, through "Mary Sues" and otherwise, because it helps the writer to create "characters [that] can relate to the readers" (liloweewoah. Personal interview, 20 Feb. 2015); 2) fan engagement means goodwill and friendship with other fans; and 3) as I quoted above, for Lilo, the work of writing is about imagination.

Fallin' For You was published on June 29, 2010, and Lilo and babyxbxgurl describe it in the following way: "Love has its ways to bloom. One can be from an

\footnotetext{
58 "Bubblyjayy" is another nickname that Liloweewoah uses.

59 "OC" stands for "original character" in fandom.
} 
obsession, while another can be from friendship. Take the journey with Nicole and Kimberly as they find the love of their lives in ways they would never expect." In the time since its publication, it has received 16 reviews (all positive), 5 favorites, and 4 follows. It recounts the stories of OCs, Kimberly ("owned" by babyxbxgurl) and Nicole ("owned" by Lilo), both of whom are talent agents. Kimberly discovers new bands and is best friends with famous wrestler, Randy Orton. Nicole is a talent agent for wrestler John Cena. The characters begin the story casually dating (Kimberly) or single (Nicole). Ultimately, the story pairs Kimberly with Orton and Nicole with her favorite wrestler, Cody Rhodes (friends with John Cena, her client). Fallin' For You is an excellent example of this c2's common themes or tropes, especially biological sex-genders, naturalized gender roles, and compulsory heterosexuality. More than that, however, it is an excellent example of the ways in which both this c2 and Lilo value the personal and even the bodily as part of "good writing"—especially through the unapologetic use of characters other fandoms might immediately dismiss or even denigrate as Mary Sues.

Lilo's OC, Nicole, is of particular interest here. Nicole is in her early 20s, just like Lilo. She is Filipina, just like Lilo. And, while Nicole is never referred to by the same nickname as liloweewoah, she does share traits with the other "Mary Sue" in liloweewoah’s story "Taking a Chance": both Isabella and Nicole are clumsy, and both do important work behind the scenes for WWE. While these elements of the "Mary Sue" might lead to suspicion or even disgust in another fan community, in WWE Fanfiction World, the Mary Sue-ish OC is not only a common occurrence but an expected and celebrated one. The responses to Fallin' For You are uniformly positive. Moreover, that this story was collaboratively written with another fan, and the one who founded this C2 
at that, suggests even more so that this community not only does not accept the dominant distaste for the Mary Sue, but that they, in fact, reject it entirely. This poses a very striking, opposing writerly identity to those taken on by both chivalric and Madshrubbery: it is an identity that, perhaps, pushes for collaboration, that values personal and bodily experience, and that, in contrast to its socially-conservative content, poses an almost feminist philosophy of writing.

As I discussed above, chivalric's writerly identity is focused largely on process and dialogue. But she is, nonetheless, concerned with a proprietary element of writing, especially as she has "grown up" out of fanfiction. Meanwhile, Madshrubbery, who has also left fanwriting for the more demanding "craft" of "original" fiction, espoused a writerly identity that was largely individual, text-based, and product oriented. By contrast, as Lilo's works, especially Fallin' For You, have demonstrated, Lilo's writerly identity is not only best described by a dialogic focus, but an openly collaborative one. And though Lilo does report a form of progress narrative of her writing skill—“I've ventured out into trying new things such as writing differently. I challenge myself to do things I haven't done before" (Liloweewoah. Personal interview, 20 Feb. 2015)— ultimately she is focused on writing as self-expression, as the opening epigraph to this section demonstrates. I would argue that Lilo's main fanwriterly identity is of a similarly process-oriented school to chivalric's, but it also contains a more romantic element of art as an extension of the self. And while this appears to be a less-prominent identity in fan studies (Jenkins and Bacon-Smith discussed fanwriters who were more similar to chivalric), it is still available within a dominant ideology of writing ${ }^{60}$.

${ }^{60}$ In fact, searching “writing is about self-expression” in Google yields 8,490,000 hits, as of 5 March 2015. 
While this particular view on writing as process, what James Berlin would have termed "expressivism," has received criticism ${ }^{61}$ since its initial proponents began writing about it in the 1970s and 1980s—especially Ken Macrorie and Peter Elbow—it nonetheless remains as an important philosophy of what it means to write. In Macrorie's view in his famous Telling Writing (first published in 1976), writing well means being able to tap into the personal:

The trouble with bad student writing is the trouble with all bad writing. It is not serious, and it does not tell the truth. This is the first requirement for good writing: truth; not the truth (whoever knows surely what that is?), but some kind of truth-a connection between the things written about, the words used in the writing, and the author's experience in a world she knows well—whether in fact or dream or imagination" (299-300, my emphasis).

This is certainly reminiscent of Lilo's view of writing, where she has stated in a personal interview that, "I like writing fics [where] characters can relate to the readers or to yourself, the writer" (20 Feb. 2015). This suggests that, for Lilo, "good" writing, and a "good" use of imagination is to write about things that can and do relate to personal experience. In fact, as she reflected on the process of writing her story, "Happy Father's Day" (discussed in Chapter 3), Lilo explained that "The idea of course came to me on Father's Day and while my family had gone to visit our loved ones at the cemetery. And while being there, I thought about how this story could show the story of Rachelle's parents [the main character of this story] while keeping in mind that it was a day to celebrate all fathers" (Liloweewoah. Personal interview, 20 Feb. 2015). This quotation

\footnotetext{
${ }^{61}$ See Lester Faigley's "Competing Theories of Process: A Critique and a Proposal” and, especially, James Berlin's "Rhetoric and Ideology in the Writing Class."
} 
suggests that, for Lilo, being able and willing to draw upon the personal in the work of writing means not only that the writer will write what s/he wishes to write, but that s/he will be more likely to connect with her/his audience(s).

In addition to this sense that a writer must draw upon the personal, Lilo also believes in using fanfiction (and perhaps writing more generally) to just "let...creative imagination flow" (Personal interview, 20 Feb. 2015). For Lilo, this appears to mean focusing mainly on ideas that the writer would like to share. In fact, Lilo shared that she generally composes in a notebook or loose-leaf paper before moving to composing on her computer. It was of course possible that this was an issue of access. But Lilo explained in her interview that she owned her own computer, and that she had ready access to the internet, but that the notebook allowed her to share her thoughts in a way that the laptop could not:

I prefer to write in a notebook because it's easier for me to travel around with it. Plus if I randomly have an idea pop up in my head, I can easily write it down in my notebook and develop an outline on how to go about that idea. Also, I can trust that I won't lose any of my work because I don't have to always save the file since it's already written in the notebook. It's also a great way to keep your thoughts organized and together. I've noticed that writing in a notebook has helped me improve my writing because I go between ideas that I've previously written down and ones that I may have thought of later on then from there I see which ones will work better together. (Liloweewoah. Personal interview, 20 Feb. 2015, my emphasis) 
This quotation suggests that Lilo composes mainly in a notebook not only because it is more easily portable than a computer, but also because a notebook is less final and less intimidating than the empty screen. Plus, it is likely, as this suggests here, that it is easier to keep track of ideas when a person can shift back and forth across physical pages, rather than scrolling through a digital document.

This particular element of Lilo's writing process is highly reminiscent of Elbow's view not only of free writing, but of the important separation between composing and revision: "Most of the time it helps to separate the creating [composing] and criticizing [revising] processes so they don't interfere with each other: first write freely and uncritically so that you can generate as many words and ideas as possible without worrying whether they are good; then turn around and adopt a critical frame of mind and thoroughly revise what you have written" (Writing with Power 7). Within the field of Rhetoric and Composition, the process theories of Macrorie and Elbow are an early problematizing of the issues of "academic" discourse and student engagement in the composition classroom. Within a more dominant ideology of writing, writing for selfexpression is seen as, it would seem, a step towards freedom (especially within a Western perspective). Within the fan community, the fanwriting reality of self-expression acts as a way to really write one's desires into existence. It is a resistant positioning, though it is as implicated within dominant ideologies as any other writing reality. And it is, furthermore, one that is most openly focused on the emotions of the writers and the readers. And it is, particularly, this element of emotion that I would like to explore in more depth next.

\section{Conclusion: Moving Toward the Body, Emotion, and “Women’s Writing”}


In this chapter, I have discussed three different fanwriter realities in depth. In the first fanwriter reality, we found a Harry Potter fan, chivalric, whose deep engagement with the fan communities she first encountered on The Petulant Poetess and Sycophant Hex is still ongoing, though only through the continuing friendships with her beta readers as well as the writers for whom she betas. Her fan participation is and always has been focused on the potential for intensive, emotional, and critical dialogue about the source text, the craft of writing, and, to some extent, personal life. Interestingly, though chivalric has moved away from reading and writing fanfiction, the writing process of drafting stories, discussing them in depth with other fanwriters, and certainly exchanging these stories with betas for comments and corrections has been maintained as her writing process. In that way, then, chivalric's writerly identity is ultimately a fanwriterly identity, as she is always clear to foreground the importance of the strong, emotional bonds she has forged with her betas/friends. In the second fanwriter reality, we found an $X$-Files fan, Madshrubbery, whose fan identity is maintained mostly through reading—-through her interaction with texts—but whose stated writerly identity is one that is entirely product-focused. Unlike chivalric, Madshrubbery sees her texts as singularly hers. She does not seem to have forged any strong or long-lasting friendships in fandom, though fan texts still hold an appeal for her. Finally, in the third fanwriter, we found a $W W E$ fan, liloweewoah, whose fanfiction engagement seems to bridge the gap between chivalric's and Madshrubbery's fan dispositions: Lilo's fanwriter reality foregrounds the deep emotional connections she has with other fans, as well as the process of writing, but she also maintains a highly romantic view of authorship that values self-expression above all else. 
Of course, as I state these generalizations about these authors' writerly identities, I must also admit that, in each case, each writer’s “writing identity” is always bound up in idiosyncratic preferences as much as dominant ideologies. The romantic "lone writer as artist," one who either writes entirely in private, or one, at least, whose ideas are always unique to her/him, is not only a dominant representation of writing, but is, in fact, often represented in many people’s stories about their writing experiences. For example, Deborah Brandt traced a very similar trend in participants’ earliest memories of reading versus writing in Literacy in American Lives: "People typically remembered their first reading experiences as pleasurable occasions, endorsed if not organized by adults. On the other hand, many early writing experiences, particularly those set outside of school, were remembered as occurring out of the eye of adult supervision and, often, involving feelings of loneliness, secrecy, and resistance" (149-50, my emphasis). Brandt argued that there was a cultural disconnect between the valuing of reading (seen as inherently valuable and shareable) and that of writing (seen as economically productive, but more private). The larger trend that this argument outlines is not only that writing seems to carry with it a sort of more naturalized, “genius” status (Brandt 157), but that this status is a dominant representation of writing. I do grant that there is a certain element of the idiosyncratic in the work of writing. Nonetheless, I must also stress that these choices of "writing style" are afforded and constrained by Ideologies of "the writer." That is to say that, while both chivalric and Liloweewoah highlighted more of a dialogic and interactive element to their writerly identities, they both still highlighted the uniqueness or singularity of the writer and her ideas. 
Moreover, in all three cases, whether writing is about sharing and response, or about expression, or about the finished text, the writers have represented not only themselves but their writing as unique. For example, Madshrubbery's distinction between "art" and "just writing" above is particularly striking both because it is so current and so ancient. There is an entire industry of resources, both digital and print, that positions itself as capable of providing the workaday Jane with that elusive quality that will make her a writer too. And this tension between "just a writer" and "an artist" is old—really old — dating back to Plato's dialogues on the nature of rhetoric: is it or is it not a techne? In Plato's Gorgias and Aristotle's Rhetoric, we find an ancient disagreement about the nature of rhetoric: Plato sees rhetoric as a mere knack, and a suspicious one at that, while Aristotle sees rhetoric as a true techne or art. Joe Sachs has chosen to translate the Greek term techne as "art," meaning: "the skilled, practised, know-how to achieve an end reliably, in any realm from horse-riding to shoemaking to doctoring to poetry to mathematics" (285). In fact, in Gorgias, Plato has Socrates compare rhetoric to "cooking tasty food":

Well, it seems to me, Gorgias, that [rhetoric is] not an artful pursuit at all, but belongs to a soul that's good at guessing, brave, and clever by nature at dealing with people. The crux of it I call pandering. It seems to me that there are so many other parts of this pursuit as well, and that one of them is cooking tasty food, which seems to be an art, but, the way my speech has it, isn't art but a matter of experience and repetition." (page 47 in Sachs trans; 463A-463C)

Here, then, insofar as contemporary Western culture is influenced by ancient Greek traditions of rhetoric and dialectic (oratory and philosophy, perhaps), we see the root of 
the "true author" versus "hack" dichotomy. Madshrubbery's views on writing particularly align with this dichotomy, but there are elements of it present in all three case studies.

Furthermore, beyond the elements of idiosyncratic yet also dominant aspects of these case studies' writerly identities, all three writers' fanfiction engagement is mediated mainly through digital means over time, and that it is mainly textual. In fact, we could see this engagement with fanfiction as an intensive "textroom." I am borrowing the term "textroom" from Alexandria Peary, who first discussed it in "Walls with a Word count: The Textrooms of the Extracurriculum," saying, importantly for our discussion here, that, "Textrooms are constructed from works; like a face-to-face writers gathering at a neighborhood coffee shop, textrooms are participatory. Unlike these groups or books, textrooms are learning spaces constructed by individuals as they write and publish— essentially establishing a coauthored classroom" (44, emphasis in original). Moreover, Peary argued that, "Textrooms are also generative and democratic: the more learners discuss, publish, and post, the more extracurricular opportunity they afford other writers: the higher the word count, the more learning opportunities exist for participants" (44). As we know from chivalric, it was the volume of positive responses she received that both took and held her interest in the fanfiction community. Furthermore, she has stayed in touch with several of her beta readers from her fanfiction participation. Perhaps, then, chivalric's engagement with fanfiction has occurred within several different yet adjacent textrooms (in this case, stories and comments on different fanfiction websites, as well as several emails about fanfiction and original fiction). In addition, given Madshrubbery's enthusiastic celebration of fanfiction and the influence it has had on her own desire to develop herself as a writer, despite her lack of interaction with beta readers, it seems to 
me that this element of online fanfiction websites as textroom is especially relevant. Finally, while Lilo came to WWE fandom through her family's interest in the show, eventually she came to see herself as a writer through the textrooms of WWE Fanfiction World and email exchanges with her friend babyxbxgurl.

So far, I have been describing writerly identities that seem to be in tension with themselves, for example: "true writer” versus "hack," "writer” versus "artist," the “solitary writing” versus participation and dialogue. One way to begin accounting for these tensions, beyond simply saying that they are the leftover baggage of Ideology, or saying merely that things are always complex, is to appeal to Deborah Brandt's theory of sponsorship, especially as it intersects with Peary's more recent theorizing of the textroom, and Paul Prior's work on emotional, embodied, and inherently dialogical elements of discourse in his theory of cultural-historical activity theory (CHAT), from his collaborative Kairos article, "Re-Situating and Re-Mediating the Canons: A CulturalHistorical Remapping of Rhetorical Activity." I will start with Brandt, here, because the concept of sponsorship is especially productive as I have begun to trace the relationships fans tend to cultivate — with other fans, including beta readers, readers, reviewers, administrators and moderators, as well as with other texts.

It is important to note, first, that Brandt views literacy as a resource that is deeply implicated within an economic system of value (Literacy in American Lives 5). Within this framework, Brandt theorizes sponsors in the following way:

Sponsors, as I have come to think of them, are any agents, local or distant, concrete or abstract, who enable, support, teach, and model, as well as recruit, regulate, suppress, or withhold, literacy—and gain advantage by it in some way. 
... Although the interests of the sponsor and the sponsored do not have to converge (and, in fact, may conflict), sponsors nevertheless set the terms for access to literacy and wield powerful incentives for compliance and loyalty. Sponsors are delivery systems for the economies of literacy, the means by which these forces present themselves to - and through - individual learners....Sponsors are a tangible reminder that literacy learning throughout history has always required permission, sanction, assistance, coercion, or, at minimum, contact with existing trade routes. (19, my emphasis)

In the case of all three fanwriters, influence from comments and reviews, not to mention the stories that they read, are two types of sponsors. What's more, all three have had some sort of engagement with fan website administrators and (C2) moderators, which are another sort of hierarchical sponsor. In chivalric's case, beta readers became her main sponsors, both into fanfiction and towards original fiction. What's more, we could, upon first glance, say two things about how this might apply to Madshrubbery: first, she is perhaps at odds with administrators and/or moderators, as sponsors, who stress the use of beta readers; and second, that she is potentially more strongly motivated by friends and readers as sponsors. In Lilo's case, her sponsors were not only those she came into contact with online, but her family as well, as they were a major reason she came to WWE fandom in the first place. This more intimate, more familial type of sponsor sets Lilo apart from the sets of potential and real sponsors with which chivalric and Madshrubbery engage.

In the fanworld, there are multiple different sponsors, and every participant has the potential to act as a sponsor. In Brandt's view of sponsorship, sponsors are "Usually 
richer, more knowledgeable, and more entrenched than the sponsored" (Literacy in American Lives 19), though they also "nevertheless enter a reciprocal relationship with those they underwrite" (Literacy in American Lives 19). In other words, there is a hierarchical element even as there is the potential for democratization. Importantly, in Brandt's view here, these two possibilities — centripetal and centrifugal forces in Bakhtinian terms—are ever-present in each sponsor-sponsor(ed) relationship. This same tension abounds in the relationships in fan communities. The typical fan initiation story would suggest that high-ranking insiders come to the fanworld periphery to both welcome new fans and usher them into fan practices (a very Lave and Wenger-esque, "Community of Practice" view, indeed), and while to some degree this does happen, there are plenty of situations in which these networks of sponsorship are much less clearly hierarchical, much more diffuse, and often much less dependent upon the immediate presence of people. Firstly, in online fanwriting communities, all encounters are mediated through digital technology and, more importantly, largely through print. In this sense, then, in a way it could not necessarily be when Brandt started her work in the 1980s, texts become veritable sponsors in online fanworlds ${ }^{62}$. In addition, it is very difficult to name all of the potential sponsor-sponsored relationships in fanfiction: firstly, this is because all participation is voluntary and not tied up in educational or career success. Secondly,

\footnotetext{
${ }^{62}$ It should be noted that Brandt does acknowledge the importance of computer technology in the mediation of literacy sponsorship: she refers to it sometimes as an "agent" in this realm, but she also views it as a tool that has to some degree changed the nature of literacy's relationship with a Capitalist economy, especially within the Fast Capitalist age, which is dominated by an information economy. This distinction is especially clear when she compares the literacy sponsorship story of the highly computer-literate Raymond Branch to the story of Dora Lopez in chapter 6, "The Means of Production: Literacy and Stratification at the Twenty-First Century" in Literacy in American Lives, pp 169-186, and again in chapter 1 of Literacy and Learning, pp 23-46. She says particularly of technology in the information economy that: "Literacy takes an unusual status in an information economy. It is a form of labor power, to be sure, a human skill, an input. Yet it also is an output, a product of varying value in use and exchange” (Literacy in American Lives 171). I stress this point here, because it is true that Brandt was interested in the role of technology in the literacy learning of her participants, but she also was not focused on the ways in which technology both affords and constrains sponsorship relations in literacy development.
} 
this is because all members would call themselves fans. And thirdly, this is because delineating specific terms in an attempt to categorize specific boundaries of goals and practices within the range of fan engagement is not only nearly impossible, but also does not accurately reflect the fannish world. This is not to say that the fannish world is entirely democratic, simply that different participants will use different terms for themselves, not to mention they will take up different practices to greater or lesser degrees based upon both their current emotional engagement and the complex nexus of their material realities, including their fan reality, work reality, family reality, etc.

Therefore, it is most productive to adjust Brandt’s theorizing of "sponsors" and "sponsorship" to include both Paul Prior's theorizing of cultural-historical activity theory or CHAT and Peary's theorizing of the textroom (as seen above). I would argue that within Brandt’s theory, “sponsors” must generally be live people with some more direct, present, even potentially intimate role in the sponsored's daily life. Additionally, the concept of sponsorship hinges largely on more recent or even real-time interactions. However, this simply cannot be the case in fandom. Paul Prior has described CHAT in the following way in his collaborative Kairos article, "Re-Situating and Re-Mediating the Canons: A Cultural-Historical Remapping of Rhetorical Activity”:

It argues that activity is situated in concrete interactions that are simultaneously improvised locally and mediated by historically provided tools and practices. Those tools and practices range from machines, made-objects, semiotic means (e.g., language, genres, iconographies), and institutions to structured environments, domesticated animals and plants, and, indeed, people themselves. Mediated activity involves externalization (speech, writing, the manipulation and 
construction of objects and devices) and co-action (with other people, artifacts, and elements of the social-material environment) as well as internalization (perception, learning).” (“What is CHAT?” my emphasis)

If we add CHAT, we add history, time, and a more prominent role for artifacts (here, fan texts of different types) to the story of sponsorship, while still admitting its embodied elements. Finally, by adding Peary’s theory of the textroom, or "text-based locations" (43) to the mix, we can posit fanfiction websites as multifaceted textrooms that are not just locations or “spaces” but “time-spaces” or chronotopes (see Bakhtin’s Forms of Time and of the Chronotope in the Novel). They carry both history and the present and point toward the future of interactions and uses.

Ultimately, what these three stories demonstrate, especially in conversation with previous fan research, is that there are multiple possibilities for fan engagement, and these will differ across individual personalities, as well as fandoms, c2s, and websites. Another, perhaps more intriguing set of common themes across these writers, however, were the elements of, first, "women's writing, " second, emotion, and third, embodiment. First, all three are self-identified heterosexual women who wish to write "strong" and "interesting" women characters. Second, all writers express deep emotional commitment to fandom, in terms of fan-to-fan engagement, in terms of the experience of the source text, and in terms of personal histories and (future) desires. And third, all of their fan engagements involve the body in one way or another, from the fantasy content of the stories to actions of watching and reading and writing. In the next chapter, I will argue that it is these elements of the body, emotion, and "women's writing" that are particularly important in any discussion of fanfiction, and I will theorize what these elements can 
mean not only for our continued understanding of fanfiction, but certainly of what it means to learn, identify with(in), and practice literacy more generally. 


\section{CHAPTER 5}

\section{TOWARDS EMOTIONED LITERACY PRACTICES}

"Re-creating the Adolescent Self: Mary Sue."

(Section title, Camille Bacon-Smith, Enterprising Women 94)

"'Mary Sue' stories, as the fans call them, are utterly reviled, even though such stories are often the first story that a fan will write. A 'Mary Sue' is any story where a young, bright, gorgeous new ensign (usually a transparent stand-in for the author) falls head over heels for Kirk or Spock." (Constance Penley, NASA/TREK 141).

Meet Leilani Lachesis. She's average height, lean, and muscular. She has long blond hair and dark blue eyes. She's intelligent—almost a genius. She's young, about 23, but she's already a seasoned spy. She is a natural Occlumens and Legilimens. She is an uncannily strong witch. But she finds it hard to connect with anyone. She's haunted. She's coming apart at the seams, because of PTSD. She is also the main character of my yet unfinished fanfiction story, The Unfortunate Incident. I chose her name carefully: she's named after one of the three fates, the one who measures a person's lifeline (Lachesis), and the Hawaiian word for "heavenly flowers" or "royal child" (Leilani-at least according to www.behindthename.com). Her dark blue eyes are meant to resemble my own. She's strong and emotionally controlled. Her steady control over her own mind lends her the ability to control others' minds. In short, she's got the intelligence and strength I've always wanted to see in the women characters in books and TV shows and movies. Is she a Mary Sue? 
According to the quotations above, a "Mary Sue" is a one-dimensional, immature, and even solipsistic self-aggrandizement on the part of an author who is often assumed to be both "new" and "young" in a fanfiction community. But why should that be so? Why is it that, "Mary Sue is also the most universally denigrated genre in the entire canon of fan fiction" (Bacon-Smith, Enterprising Women 94)? Is it because she rises above her station? Is it because she often celebrates her body, her desires, and her mind? And is a Gary Stu likewise reviled because he has emasculated himself? I guess I've just really been wondering lately: Why care if a character is a Mary Sue or Gary Stu?

An important aspect of feminism is being able to, indeed, focusing on daily experiences and emotions. On felt life. On embodiment. This is different from a patriarchal, Western, Cartesian focus on writing the somehow distinct, somehow separate mind. So, I can't help but feel highly suspicious of derision against a so-called Mary Sue, especially when I read Bacon-Smith's thoughts on women's writing in Enterprising

\section{Women:}

When women in fandom write about women they are talking to each other about themselves in the symbolic language of their literature. With their efforts they pass through stages of their own development as individuals, from the superteen Mary Sue who lingers in the consciousness even of middle-aged matrons who have steadfastly refused to let go of the active agent of their prepubescent years (or fantasies), to the matriarch struggling for dignity against a society that pressures the family into systems of oppression. Few of the stories about women seem to postulate institutional dignity or equal status for women, but in the fan 
fiction the fan women talk about their struggle for dignity in their relationships.

This is important for women. For the LGBTQIA+ community. It's important for cisgendered, heterosexual-identified men. It's important to take back desire, especially a desire for a "better" self, however that might manifest.

The website, The Mary Sue, succeeds in taking back the term "Mary Sue," as they state:

The Mary Sue sits at the nexus of pop culture and the uncharted universe. We love and live geek culture, comic book movies, genre television, space exploration, emerging technologies, the coolest video games, and the weirdest finds on the internet. We promote, watchdog, extoll, and celebrate women's representation in all of these areas and work to make geekdom safe and open for women. (“About Us”) The above quotation represents a way of taking back a term and an idea that is damaging because of its connection, I would say, to both internalized sexism and the myth of the master/novice dichotomy. But, why is this important to literacy scholars? As teachers it's important for us to tamp down on damaging dichotomies that deride the writing of some in favor of others, especially when that writing is said to be "bad" or "weak" because it is feminine or "womanly." It's important because we care about how writerly identities come to develop. It matters because fanfiction is powerful, even if distinguishing it from other genres of writing is largely arbitrary. It's important because the Mary Sue is so much like the typical male hero—Luke Skywalker say, or James Bond, or Neo—yet she’s somehow incomplete. She's "too perfect."

Well, I'm tired of it. 
I embrace Mary Sue. I AM Mary Sue.

According to fan folklore, the Mary Sue story is a common practice of "n00b" fanwriters, who are often depicted as young, naïve, less educated, and overly driven by their romantic desires (see especially Bacon-Smith's Enterprising Women and Penley's NASA/TREK). I start here not to look at the figure of the Mary Sue per se, but rather as a symbol of the ways in which the fan community—particularly media fans and especially fanwriters — has tended to be represented. The denigration of the Mary Sue as overly bodily, overly self-indulgent, overly "feminine" serves as a microcosm of the fan(fic) community, which is denigrated for similar reasons. I embrace Mary Sue not as an empty gesture, but as a sign of my very real commitment to better serve the identities, needs, values, and desires of writers.

In this chapter, I move first from the figure of the Mary Sue to looking at the admittedly resistive and admittedly “woman”-centered features of online fanfiction. I start here to agree that, indeed, my own study of online fanfiction communities has confirmed that the writing does seem to be undertaken largely by woman-identified writers, and that it is done to address issues that are often belittled in popular discourse as "women’s stuff.” In a way, I agree that a great deal of fanfiction is important because it does appear to provide spaces for "women's writing" and/or/as well as feminized writing — what I call écriture feminine. I show the different ways in which both overtly resistive and more seemingly conservative online fanfiction does work to re-body characters and storylines so that they might reflect “women's” experience through looking at examples from Fem!Harry and Harry-Draco slash fanfiction communities. 
However, I come to call the label “women’s writing” and even écriture feminine into question, as I believe that fanfiction moves beyond the dominant system of binary genders. I then move on to say that what is most important about fanfiction writing is the way in which it not only works through embodiment and emotional experiences—what I'd like to call embodied-emotional experience—but it also celebrates these same experiences as paramount. This move from "women’s writing” toward the embodiedemotional is also not made as an empty gesture, nor as a blind turning of the patriarchal (high) tables, as it were, but rather to rehabilitate emotion and embodiedness from the denigrated "feminine" back into writing. I want to do more than say that feminized and women's writing are important-I want to show how and why. Online fanfiction is important to literacy scholars because it opens up the possibility of better understanding emotioned literacy practices.

\section{Écriture Feminine—Emotion, the Body, Desire, and “Women's Writing”?}

Past work in fan studies has not only tended to focus on its resistant aspect, nor only on gender, but rather to assert that fanwriting was largely resistant because it became a space where women could write freely. It is a place, perhaps, where previously uncharted territory could be charted. It is a place, often, as Constance Penley argued of K/S slash, where women can gain a degree of credibility because they dare to write their own pornography. Basically, it has been argued that fanfiction is a sort of "women's writing" or écriture feminine, wherein, "Woman must write her self: must write about women and bring women to writing, from which they have been driven away as violently as from their bodies—-for the same reasons, by the same law, with the same fatal goal. Woman must put herself into the text—as into the world and into history—by her own 
movement" (Cixous 875). Certainly, fanfiction stories include narratives of quotidian life, and certainly many stories focus closely on the emotional experience and journeys of the chosen characters. But, I do wonder, is it appropriate to call fanfiction "écriture feminine"? And, in what sense or to what degree?

In part, I'd like to argue that there is something about the economies of online fanfiction that could perhaps qualify it as women's writing —in that it does seem that in line with earlier fanzine traditions, these are often spaces created, used, facilitated, and frequented by women for the very purposes of: creating a voice and developing writing craft. In fact, as I have mentioned several times, there are some striking parallels to be drawn between online fanfiction and the development of print culture in the 19th century. Fanfiction.net, Archive of Our Own, and Sycophant Hex sometimes seem to function as a veritable modern-day Godey's Lady's Book, with betas as almost modern-day Sarah Josepha Hales. In her article, "Walls with a Word Count: The Textrooms of the Extracurriculum," Alexandria Peary conducts a diachronic study of the parallels between the community and writing practices of Godey's Lady's Book in the nineteenth century and modern-day, online diaries at websites such as Mother Writer Mentor, Her Kind, and She Writes. In particular, Peary argues that these two types of "publication" are similar because they provide spaces for women to encourage and nourish "women's writing." She argues that both Godey's Lady's Book and the online diary blogs are "textrooms," which are "learning spaces constructed by individuals as they write and publish— essentially establishing a coauthored classroom" (44, emphasis in original). Peary argues that these spaces allow women to develop their own voices in a world that otherwise reserves "authorship" and "publication" for men. Importantly, for Peary, these spaces are 
worthy of study for compositionists particularly because they demonstrate the complexities of writing as a life-long process that is, furthermore, deeply influenced by daily and embodied experiences.

In many ways, as I have discussed with the exchange economies of online fanfiction websites in Chapter 3, sites such as Fanfiction.net, Sycophant Hex, and Live Journal are "textrooms": "Textrooms are...generative and democratic: the more learners discuss, publish, and post, the more extracurricular opportunity they afford other writers: the higher the word count, the more learning opportunities exist for participants" (Peary 44). While certainly I would argue that these fanfiction websites are not solely texts, but rather spaces of dialogue, negotiation, and even performance, and while I would hasten to caution against the interpretation of these spaces as precisely "democratic," I will argue that the engagement, dialogue, and performances of online fanfiction are happening through text (and images) —-through secondary symbol systems. I will also argue (and have argued) that these kinds of sites are important for compositionists to investigate because they demonstrate ways in which literacy development-practice works outside of a classroom context. These "textrooms" "[help] identify the types of resources individuals seek after their time with us (presuming a formal education)" (Peary 63); and, in turn, these textrooms —-these alternative literacy spaces-places—can help us to more critically reflect upon our practices as both writers and writing teachers.

In this particular section, I would like to focus on emotion, the body/embodied, and "women's writing" as a way to understand the function and importance of online fanfiction websites. I will conduct an analysis of online fanfiction by working with the 
complex concept of "écriture feminine." I will begin this analysis by looking closely at the differences between Fem!Harry and Harry-Draco slash fics.

As I discussed in depth in Chapter 3, there are multiple possibilities online for Harry Potter alternatives: there are communities dedicated entirely to Dark! Harry; there are entire communities dedicated to Harry and Draco slash fics; and, there are a few communities that not only ask but answer the questions, "But why can't Harry be a girl? And what would happen if that were the case?" Fanfiction.net hosts 54 Fem!Harry communities alone. One of these communities is called Miss Potter. It was founded by BF110C4 in July of 2005, and it currently hosts 1,434 stories (as of 9/2/15), and welcomes 683 followers. It represents itself as "A C2 dedicated to the Fics where Harry is a girl, either born or created, temporal or permanent." This particular C2 (or themed community) hosts a range of Fem!Harry stories: in one highly rated story, A Cold Hand (which boasts 1,049 followers, 616 of whom have voted this as their favorite story) mixes Harry Potter, Fem!Harry (Harriet Lily Potter, in this case), and Norse mythology; in another highly rated story, Fate Be Changed (which boasts 4,323 followers, 4,019 of whom have rated this as a favorite story), we find a mixing of The Hobbit, Lord of the Rings, Harry Potter, Fem!Harry, and Fem!Hobbit ("fem!Hobbit!Harry"). This C2 includes cross-over stories, multiple possible pairings, etc. Importantly, in each of these stories, Harry is reimagined as a female character.

Why stories about a female Harry Potter exist seems to be a very straightforward question to answer. And, really, it is—on the one hand. In this day and age, young women are surrounded largely by male heroes: Batman, Captain America, Iron Man, and, yes, even Harry Potter. Men not only get to be heroes, but they get to do so through being 
singularly-focused, intelligent, and unparalleled in strength. In fact, not only are these male heroes superhuman and hyperproductive (as well as hyperefficient), they all share a common side interest and weakness—-the female love interest. No matter how intelligent or capable she may seem upon first glance, she will inevitably fail both him and the audience. She will inevitably become his fatal flaw. What's more, when young women are presented with heroines, they are so often overly-sentimental, underproductive beings who yearn for true love above all things. Of course, this is not always the case. But I think that it can be said that characters such as Katniss Everdeen (of the Hunger Games trilogy), and Hermione Granger of Harry Potter (and even Black Widow of the Marvel universe) are, in many ways, the exceptions that prove the rule. So, yes, of course Fem!Harry exists. Of course writers have created a female Harry. Women need to write themselves (Cixous, "The Laugh of the Medusa"). Women need to see their own faces, their own bodies, their own emotions and desires and decisions reflected somehow before them in ways that might read as more legitimate. Woman, perhaps, needs to "[live] her desire" (Irigaray 323) as more than "an attempt to possess at long last the equivalent of the male sex organ" (Irigaray 323).

One particularly striking story in the Miss Potter C2 is An Avalanche, a Harry Potter-Lord of the Rings crossover serial by writer Lady Hallen. It was originally published on April 25 (the year is not listed). In this story, "Heather" Potter (so-called "Feather" by her friends) has fulfilled her prophecy by killing Voldemort, but she has lost the war. At their wits' end, story characters Heather, Hermione, Luna, and Draco decide to travel to another dimension, feeling there is nothing left for them in England. The group travel to a world of multiple creatures and somehow become embroiled in political 
intrigue, and yet another battle against great evil. The story is still incomplete, but all characters have been placed in politically important positions within their new world. It is implied by Lady Hallen, the story's author, that the LOTR universe is not particularly welcoming to women with power. In this way, then, perhaps Lady Hallen’s Fem!Harry is not only a re-embodiment of the very character of Harry Potter, but a re-bodying of the LOTR universe to include more powerful, fully-described female characters.

Heather, the protagonist of An Avalanche, is a particularly interesting character for many reasons. She wears her hair long, and she identifies as being particularly short. However, she is also represented as "cranky" and "tired" (Lady Hallen "Ideas that just happened"). What's more, as the story progresses, Heather is represented as identifying as a veritable warrior, rather than a private school girl like her friends. In fact, she briefly joins a small band of warriors for eight months, picking up both their masculine mannerisms, and, apparently, their "degraded" language (Lady Hallen An Avalanche)— which perhaps could be interpreted as "working class," or, at least, as "non-middle-class language." Upon being questioned by the band of three warriors after being discovered as a woman, the following particularly illustrative scene ensues:

"'I know,' she cried out, real tears stinging her cheeks. 'I'm likely to get myself killed, but who would teach a girl? I'm doing the best I can!'

The encampment turned slightly awkward. The young man was on the receiving end of many irritated glances, but no one spoke to reprimand him.

A series of arguments later and she ended up in the company of a rough riding group of men. They set a harsh pace and looked at her with respect when she did not complain of the lack of comforts. 
The three of them had a rotation in teaching her. There were survival skills, learning how to distinguish sounds and the Art of Staying Still and Quiet. And lastly, there was sword fighting. Draco's lessons were quickly trashed and they all scoffed at her etiquette.

'It's sword fighting, not sword play. It's a choice between your life and your enemies" they told her.

Initially, the gaudy sword of Gryffindor received some insult from the youngest of the rangers. But after she divulged that it was her ancestors' sword, (which it technically was) passed down from father to son, he clammed up. That was also the reason why the men were calling her Gryffon. They had asked after the runes engraved on the sword and she had translated it to them in Westron." (Lady Hallen An Avalanche, my emphasis)

This scene is not merely interesting because "Heather" immediately appears to identify as a "warrior" (though she admits she may be considered deficient because of her gender), but how she continues to re-identify as a warrior throughout the chapter, in a way that takes her far away from a female Harry Potter, but also away from the world of Harry Potter in general.

On another level, Lady Hallen is clearly performing the self-conscious feminized / woman character appropriating more masculinized / "manly" roles and tasks (such as sword fighting and warriorhood): when Heather is initially questioned by the warriors, she tells them that she is "avenging her family," thinking later, "Heather knew she was making stories in her mind to stay in character, and she allowed the story to become her. The righteous female anger swept through her. She was young enough—and short 
enough—-to act out the adolescent angst. Besides, these men felt like old souls" (Lady Hallen An Avalanche, my emphasis). Lady Hallen knows that Heather knows that she has to perform proper femininity here if she is to get the training she desires (and requires). Furthermore, Lady Hallen can expect that her readers probably assume a sexist / essentialist mind-frame for the Lord of the Rings characters. On yet another level, Lady Hallen is also performing proper masculinity on the part of the male warriors who take Heather in; they do not bathe often, they are hard, they curse frequently, they fight, they have few comforts, yet they are almost paternal towards her.

While Lady Hallen is clearly playing with (and undermining, I would argue) some sticky boundaries of gender roles in this story, she is also, nonetheless, relying heavily upon the relationship between sex and gender. On the one hand, she seems to do this tongue-in-cheek, as when she has Heather say, "I'm likely to get myself killed, but who would teach a girl?"' However, on the other hand, Lady Hallen seems to be relying upon, or perhaps is constrained by larger societal ideologies that something inherent in the sex of the body reflects what a gender will be able to be. While it would perhaps be easy to argue that these elements are in play in these scenes only because of, say, audience anticipation and expectation. Or, even, it would be especially easy to say that these scenes merely reproduce and, therefore, reify gender norms. However, I would argue, first, that this view is shortsighted. It could be argued that these men, represented as "still," "quiet," but often cursing and dirty warriors is a facile and traditional representation. And while it could certainly be said that Heather's response of tears is, too, a facile representation, I think it is more appropriate to argue that these 
representations reflect some very real limitations on gender features in a somewhat selfaware way.

After all, these representations are clearly preceded by Heather's reflection of her assumed identity, and that "she allowed the story to become her" (Lady Hallen An Avalanche). In this way, then, Lady Hallen is representing to readers a sort of tricky, identity double-bind — where one performs while very aware of the performance, and yet often forgetting that same performance. As Judith Butler said in Gender Trouble, "'becoming' a gender is a laborious process of becoming naturalized, which requires a differentiation of bodily pleasures and parts on the basis of gendered meanings....In other words, some parts of the body become conceivable foci of pleasure precisely because they correspond to a normative ideal of a gender-specific body" (95). In the case of Heather in Lady Hallen's An Avalanche, the protagonist has created a story that both accounts for her female-bodiedness while allowing for her to take on the attributes of a "warrior," despite its normative association with the male body. Her self-aware struggle with telling / being her own story is, in some ways, a representation of the performative struggle we face with gender every day.

What's more, Heather clearly chooses one gender performance and the universe which allows for it over the other.

Eventually, they parted but not before she met their captain, Aragorn. The man had taken in the additional person in the expected encampment without a single reaction.

“Guests?” he had asked in his soft, unused voice.

"She's leaving soon,” his second-in-command answered. 
Aragorn had cocked an eyebrow at the almost defensive note in his voice but said nothing of it, he had noted the girl's calloused hands and the easy way the sword hung at her side, even if it was rather...noticeable. She was a warrior, and felt like a kindred spirit. For that alone, sharing a fire needed no explanation. (Lady Hallen An Avalanche)

Both Lady Hallen as writer, and Heather as character, are allowed to choose a space of "masculine femininity," perhaps, that more closely suits something in their bodily desires. And this choice is recognized by fellow characters in a way that is represented as, largely, uncomplicated.

In addition, I argue that, while a feminist scholar might be quick to judge the content of a story or website as either "resistant" or "complicit" (which, as Hills argued is an unhelpful distinction—see Fan Cultures), I think it can sometimes be more helpful to remember that something such as the Miss Potter Fem!Harry fanfiction C2 provides fans with a "room of their own." It is perhaps easiest to see this argument in a more exaggerated case. In "Who's Really a Cyberfeminist? Women Write Back: The Rhetoric of Pro-Ana Web Sites," Christa Downer, Morgan Gresham, Roxanne Kirkwood, and Sandi Reynolds examine the spaces and rhetorical appeals used by young, (largely) female writers on pro-anorexic websites, as well as the backlash against them. They find that the women who make use of these websites are developing powerful spaces for themselves in a world in which they are otherwise largely absent, not merely because they are female, but because they are not trained in the medical profession. Specifically, Downer et al argue that these spaces need to remain open and unchanged (though certainly monitored) for the benefit of allowing these women true "rooms of their own": 
I find the efforts of these critics [to shut down pro-ana websites] to be troubling ways to engage the pro-ana online communities because by shutting down the Web sites they are effectively silencing the pro-anorexic and the experience she is attempting to legitimate. Our motives, as feminists entering these spaces, are not to judge, label, or silence; rather, our motives come from feminist principles such as those defined by feminist rhetorician Sonja Foss, to enter into a relationship that strives to 'eliminate relationships of domination, oppression, and elitism' and to create 'relationships of self-determination, affirmation, mutuality, equality, and respect' (Foss \& Foss, 2004, p.2). And key to our achieving these principles is entering into respectful dialogue. (Christa, 95, my emphasis)

In the case of Lady Hallen's An Avalanche, I think it is particularly important to remember that despite some issues of specific politics, this writer is nonetheless writing her own space on fanfiction.net. What's more, this is a space that is openly collaborative with other readers, as she states very clearly in her final author's notes to the first chapter, "Ideas that just happened" that, "Guys, I would appreciate it very much if you review....And if you people want pairings, state it now or forever hold your piece." What's more, Lady Hallen not only writes at fanfiction.net (she has reportedly written 11 stories for this website alone), but she offers her services as a beta reader as well. Clearly, then, Fanfiction.net, and this "Miss Potter C2, are important places-spaces for Lady Hallen. They are not only spaces for individual imagination, but they are spaces for dialogue — between and among different source texts, and, even more importantly, between and among different fanreaders and fanwriters around the world. 
Fem!Harry allows writers to reappropriate the male-sexed body of Harry Potter and female-sex it-take control over it, and re-embody this character's experiences so that they better reflect themselves. But this is only one avenue. Next, I will discuss how this practice compares to that of Harry-Draco slash fiction. If we can argue that Fem!Harry stories provide fanwriters, especially, perhaps, woman-identified fanwriters with spaces to re-embody the character of Harry Potter in ways that better capture their experience— that these places-spaces provide writers with some degree of control over the bodies of the source text, this phenomenon is perhaps best demonstrated in the practice of slash fics. "Slash" as has been discussed, is a practice whereby fanwriters reimagine LGB(T) pairings - typically gay male, or male-male pairings. In Harry Potter fanfiction, the most popular slash pairings appear to be Harry Potter and Ron Weasley (his best friend in the book series), Remus Lupin and Severus Snape (high school nemeses, and both teachers at Hogwarts during Harry's third year), and, by far the most popular, Harry Potter and Draco Malfoy (HP/DM). This is striking, though understandable within an "opposites attract" trope of romance stories, as Draco Malfoy and Harry Potter are school enemies in the original book series. This is largely because Draco's family chooses to follow Voldemort, as well as Draco's very wealthy, "pureblood" (aristocratic) status, versus Harry's largely "muggle" (non-magic) cultural capital and middle class status. At any rate, the potential for this pairing captures the imagination of many Harry Potter fans. Fanfiction.net hosts 38 C2s focused exclusively on this pairing alone. What's more, this pairing can be found in many other C2s, including general $\mathrm{C} 2 \mathrm{~s}$, or those focusing on other popular pairings, such as Hermione Granger and Severus Snape. Finally, HP/DM slash provides a fruitful point of inquiry for 
this project not only because it is one of the most popular Harry Potter slash pairings, but because Harry Potter and Draco Malfoy are paired frequently in Fem!Harry stories, presumably because some writers do not like the idea of romantically and/or sexually pairing two male characters.

Interestingly, it is difficult, at first, to track down Harry Potter slash on Fanfiction.net. In fact, it can be easier to find "NO SLASH PLEASE!" This is perhaps an important point of discussion for this online space (not to mention it is already a characteristic that problematizes the concept of "affinity spaces"). Nonetheless, some slash C2s can be found. One of the most popular of these, with 20 staff members and 1,943 followers (as of 2 Sep. 2015) is Harry and Draco's Love Shack. The description for this C2 reads: "Have you ever searched and searched for Harry and Draco slash but you've never found the right one to read that has you feeling like your a part of it. Well look no further than here because if you click this you will get access to the BEST HD SLASH out there. So Click, Subscribe and HAPPY reading." Clearly, perhaps, this particular slash pairing has had difficulty vying for space on this website. Nonetheless, this C2 currently hosts 683 stories ranging from: flirtatious one-shots to Dark!Harry serial sagas, to sentimental mPregs (or stories focusing on male characters who become pregnant).

One interesting story is "A Thousand Cranes," by Bambeah. Published on March 1, 2011, this one-shot hints at a burgeoning affection and love between Harry Potter and Draco Malfoy. In the story, while sitting in Transfiguration class, hundreds of white paper cranes come zooming into the classroom, eventually settling around Harry's feet. When Harry finally inspects one of the cranes, he finds that it reads "I love you" in plain 
black letters. It becomes clear near the end of the story that these notes were from Draco. One particularly interesting moment occurs after all the students realize all of the notes are meant for Harry: "Murmurs filled the classroom as to who the sender was. And there were a few snickers and giggles as a few of them murmured the meaning behind the hundreds of paper crane. A few girls giggled over how romantic it was, never mind the fact that he was a boy and boys don't get romanced by girls" (Bambeah "A Thousand Cranes"). This moment is incredibly interesting, particularly because it serves to highlight several difficulties: 1) the pervasive and ideologically powerful (and violent) association between sex and gender; 2) the pervasiveness of the heteronormative patriarchy, here played out in the (if unstated) uneasy relationship among sex, gender, and sexuality; and 3), I would argue, the difficulty of resistance when faced with a certain discourse community or even habitus.

First, it is clear that the writer here is expressing male-sexed bodies as inherently men-gendered or masculine, and vice versa. Secondly, this moment seems to suggest that these "naturally" sex-gendered bodies also carry with them inherent and unavoidable roles—here, "boys romance girls," with the "boys do not romance boys" left unstated yet nonetheless very obviously implied. Finally, it is possible to imagine a scenario in which Draco's romantic overture invited no shocked speculation at all, or perhaps only on the grounds that Draco is so different from Harry in both personality and social class. However, this is clearly not the case with this story. It seems to me that the nature of the scandal of this "romantic" gesture is not only its recipient but its sender, and this is due in large part to ideological limitations deeply felt by Bambeah in her/his habitus (and body) because of years of socialization. That this scandal goes unquestioned by reviewers 
suggests that many of Bambeah's readers identify with a similar habitus. I would also like to point out, however, that the highlighting of this sexed-gendered-body scandal serves to place Draco's overture in even sharper relief. In that sense, then, while it might be easy to read this moment as disappointing or even complicit, I think it does do some work to take back some control of bodies, genders, and sexualities. The taboo is stated and known by writer and readers, and it is flouted regardless-even gleefully.

Perhaps an even more striking example of this taking back control of bodies, genders, and sexualities is in the story Our Baby, by writer jessica499499. In this oneshot HP/DM story, Harry and Draco have been happily married for a while, and have just broached the conversation about possible future children. Harry is eager to adopt, while Draco would like to have biological children. After a misunderstanding is resolved, Draco excitedly agrees to carry the couple's children to term. This particular sub-genre of the HP/DM slashfic is called an "mPreg" story. While these stories are not necessarily hugely popular among fanwriters, a fair few of them exist - at least enough for there to be a definitive subgenre title, "mPreg." The mPreg story is precisely what it sounds like—a male character becomes pregnant with a child. Though the search functions for specific content or categories is temperamental on Fanfiction.net, a quick search revealed well over 12,000 mPreg stories on the website across several fan universes (as of 3 Sep. 2015). The genre in and of itself is particularly intriguing because: first, "pregnancy" is so often the realm, "boon" yet "curse" of women; and second, the "horror" of birth, especially in a male-sexed body, is the subject of multiple horror movies (the Alien series, for example). In that way, then, mPreg stories are arguably, perhaps especially in slash fic 
communities, the ultimate re-embodiment of the male sex. Or, put another way, it is arguably the ultimate problematization and reversal of "essential" gender roles.

What is perhaps even more interesting than the taking of control over a male body in this story through impregnating it, are the ways in which Draco's (male) body becomes more and more feminized (the patriarchy would refer to this as emasculation) throughout the story. In a way, Draco becomes important mainly because of his body, as in the following example:

"[Draco] thought that Harry loved him! When Harry had suggested that now was the time to start considering a family he'd been so happy! He loved the thought of have Harry's children.

Then Harry starts going on and on about adopting some wizard child at an orphanage! He'd rather have some stranger's kid than one of their own? Draco barely had a chance to excuse himself before running out the door, tears streaming down his face. Was Harry worried their child wouldn't be beautiful or intelligent? Or something more then that?

Was he ashamed that their child might look like him? Like a Malfoy? Like his father? Harry loved Draco for himself, not his looks. But did that mean that his looks repulsed Harry? He'd made love to Harry before and he'd never felt insecure about his appearance" (jessica499499 Our Baby).

Here, we find the ultimate embodiment of Draco's "male"-sexed body, through Draco's total preoccupation with his appearance, particularly as it relates to his sexual appeal and, therefore, his suitability as a viable partner. In a way, this seems to be almost a fantasy of subverting some aspect of the female-bodied experience within a patriarchal world. Then 
again, this is at once resistant and problematic, even perhaps complicit within a heteronormative patriarchal world, as female-sexed-gender role associations are assigned to Draco as a homosexual male. In that way, then, this piece can be read as gaining some space for the "female" experience—for "women's writing"—while also being homophobic.

This subversion of the body experience is especially striking in the following scene, where Draco finally reveals to Harry that they are, indeed, capable of having fully biological children:

"You see Harry, when a muggle male chooses a male mate, they have to adopt.” Draco leaned closer and nibbled on Harry's ear gently.

"But when a pureblood chooses a male mate things are a little different."

“...How so?” Harry muttered as Draco moved to nip at his neck.

Draco smiled against Harry's skin.

"Well, when a pureblood male claims a mate and he and his mate wish simultaneously during love making...”

Draco kissed Harry softly on the lips as he stared at his beloved.

“....They can have children too.”

Harry's eyes shone with such happiness and love at that moment it was breath taking.

"Really Draco? We can have little ones too?!"

Draco laughed sweetly in relief.

"As many as you want Love.” 
Draco could practically see Harry's eyes glaze over as he imagined Draco heavy with his child. ((jessica499499 Our Baby, emphasis in original)

In this scene, Draco goes from being important because of his body to being almost nothing more than his body. In fact, in this case, it is difficult even to refer to Draco as a body; he has become more like a vessel. What's more, Harry and Draco have been reembodied to the point that they both are subject only to a sex-is-gender patriarchal paradigm.

The examples I have used in this section—of Fem!Harry and HP/DM slash, including the HP/DM mPreg tale—appear to paint a very direct and (almost) unproblematic picture of "true women's writing," following Cixous: "Woman must write her self: must write about women and bring women to writing, from which they have been driven away as violently as from their bodies—-for the same reasons, by the same law, with the same fatal goal. Woman must put herself into the text—as into the world and into history—by her own movement" (875). In other words, "women's writing” is writing by women, about women, and for women. And, certainly, Fem!Harry is a woman, if one sometimes (somewhat) rebellious against her inevitable-sex-role. And even romantic Harry and "maternal" Draco certainly seem to be tales by, about, and for women. In fact, early research into zine culture by Jenkins, Bacon-Smith, and Penley (as well as research into the first online fanfiction communities by Bury and Scodari) demonstrate veritable, dedicated craft and labor by women—women's writing groups. Even my own investigation into online fanfiction economies does, indeed, uncover a number of women writing in supportive, affective, emotional and embodied communities. So, perhaps it could be argued that fanfiction really is women's writing — a women's 
Discourse that reminds us of the body and emotion in literacy in only a way that the feminine can?

In her essay, "E-Criture Feminine: Women's Online Diaries and the New Female Discourse," Deborah Bowen investigates the rhetorical and community practices of some online women diarists, and how their practices could be considered "cyberfeminist." She argues that these online diary websites are absolutely "cyberfeminist webbing," because they become spaces-places that women build for themselves, so that they can have "rooms of their own" in which to voice their experiences, opinions, and feelings. In which they can feel free to express their "women's writing," or écriture feminine, which Bowen describes as an action that, "embraces and embodies these ideals [of women drawing together] with polyvocality, relationality, and in the new cyberworld, hypertextuality" (310). As I have demonstrated in previous chapters and above, fanfiction practices appear to follow a similar path of écriture feminine-especially in terms of their heteroglossic and deeply "relational" features of participation.

Of particular interest in Bowen's argument about women's online diaries is her argument that "women's discourse" includes the autobiographical body experience:

Cixous postulated a writing from the body that pushes past boundaries of syntax and patriarchal content. But this writing, she says, has been rarely committed to paper. This is why the diary page becomes such a critical medium for women's self-expression. Cixous (1990) demanded a paradoxical writing from the body, even as the body is left behind, de-commodified. On the Internet, this paradox is achievable, even necessary for the creation of autobiography. (315) 
As the examples above clearly demonstrate, there is something to be said about the body as a space of contestation, reimagining, and struggle for control in at least some fanfiction practices. So, perhaps it is the body that makes fanfiction, in part, "women's writing." Part of what makes "women's writing" women's writing, after all, is that it deals with daily experiences—a woman's quotidian body. It deals with, perhaps, the woman's body as simultaneously excess and lack, and what that might mean for her experience of the world. And while fanwriting is not really autobiographical (well, it may be in some cases, but it is generally presented as "fictional"), I cannot help but think of the body and women's writing when I think of online fanfiction practices. In part, this is because of previous scholarship—like that by Henry Jenkins and Camille Bacon-Smith—where fanzines were theorized, in part, as a distinctive and resistant women's writing practice. In part, this is because I have actually found a number of woman-identified fanwriters. But, I still cannot help but ask: "Is this all it takes?" Is "women's writing" just writing that happens in women-created and women-facilitated and women-frequented spaces? Is that enough?

Perhaps more importantly, I cannot help but admit how deeply problematic these assertions of écriture feminine are, because they assume a consistent, self-evident, and unproblematic meaning of "women" in "women's writing." But what, indeed, is woman? It is perhaps possible to say that a "woman" is a (at least partial) "person" whose body is female-sexed—and that is certainly the reigning biomedical definition of "woman.” This definition is also one of the main ways in which woman is understood, if the frequent synonymity of "women's health" and "women's reproductive health" is any indication (just take a quick glance at the available links on Womenshealth.gov, for example). This 
biomedical definition is powerful not only because of the strength of Medicine as an Institution, but I would argue, because it focuses on the body in ways that it has often been associated with women. As Irigaray argued in the late 1970s (similarly to Cixous and other "second wave" feminists), a woman is not only just a body, but a lacking body: "Woman and her pleasure are not mentioned in this conception of the sexual relationship. Her fate is one of 'lack,' 'atrophy' (of her genitals), and 'penis envy,' since the penis is the only recognized sex organ of any worth. Therefore she tries to appropriate it for herself, by all means at her disposal....Woman lives her desire only as an attempt to possess at long last the equivalent of the male sex organ" (323). In this way, perhaps, "woman" is the ultimate natural being, and perhaps the ultimate threat.

But none of this is particularly satisfying. It is hardly satisfying because while experience is embodied, it is not a body. It is hardly satisfying because a pair of chromosomes- $\mathrm{X}$ and $\mathrm{X}$ - cannot be proven to cause attributes such as submission or tenderness or "maternal instinct." This definition of "woman" (of gender) falls apart upon looking at the example of an exultant, pregnant Draco Malfoy:

But this was like a dream come true to the young wizard. Draco, his Draco was pregnant with their child and was already round and heavy with their little bundle of joy. The weight had done nothing to Harry's appeal and attraction to his husband, if nothing he was even more in love with him then ever before. Morning sickness had left Draco paler then death at first and his mood swings had been hard to deal with, but they had gotten threw it together. All the while he cooed over Draco's enlarging stomach and his love had even taken to humming under his breath lullabies he'd heard from his own mother. Draco was the picture of 
maternal bliss. He so contented and peaceful it was breath taking. (jessica499499 Our Babies)

Certainly, one way to read this moment in fanfiction would be to say that it reifies dominant patriarchal and heteronormative ideologies by turning Draco into the woman and "glowing mother," while Harry gets to be the "proud father." At the same time, it flouts these very ideologies by making a mockery of them through their very presence in this slash space.

Butler is particularly helpful in this case, as she has argued significantly that, "Gender is not to culture as sex is to nature; gender is also the discursive/cultural means by which 'sexed nature' or 'a natural sex' is produced and established as 'prediscursive,' prior to culture, a politically neutral surface on which culture acts" (10). Moreover, she has argued that, "The replication of heterosexual constructs in non-heterosexual frames brings into relief the utterly constructed status of the so-called heterosexual original. Thus, gay is to straight not as copy is to original, but, rather, as copy is to copy" (43). In other words, Our Baby and Our Babies could be read as mere reifications of the heteronormative gender script, or as a total flouting or at least "parodying" (see Butler Gender Trouble 187) of that text. I argue that the most satisfying answer, here, is somewhere in between these two interpretations. It would be not be fair to see either extreme possibility as the "proper” way to view this story. Instead, I think that the author is aware of both possibilities. Furthermore, it is also likely that the author is providing Harry and Draco with her own version of a married fantasy. Finally, the author is not the only factor in play here: other readers on the website and their own interpretations of this story are also important. Some readers might accept the fairy tale romance of the story. 
Others might find it offensive in a slash space. And still others might see it as sweet yet also tongue-in-cheek. It would be unfair, especially outside of this space, to claim only one of these possibilities as the True possibility. This story can do more culture work than was originally intended by the author.

Furthermore, if we are to understand more fully the nature of literacy practices in online fanfiction spaces, we must contend with the body, with emotion, and certainly with desire. We must contend with what we can and should call écriture feminine. This is, in part, because of the tradition of multiple women-identified participants in the world of fanfiction. But, more than this, it is also because, I would argue that, to actually receive the name "fanfiction," the writing has to be somehow unsanctioned—in this case, breaking with the single-genius-author-function (likely male). This might seem like a jump, until one considers that fanfiction has often been viewed as the obsessive activity of (feminized) "people" who cannot distinguish fantasy from reality, and who naively try to live their desires in their writing. In fact, the stance of the fan, let alone the practice of fanfiction, has long been a feminized one. As Jenkins recalls of a Saturday Night Live episode starring William Shatner, in which male "Trekkies" swarm "the Captain," overwhelming him with questions about both his personal life and minutiae from the television series, which eventually leads Shatner to shout, in frustration, " 'Get a life, will you people?'" (Textual Poachers 10), this representation of fans shows them as not only obsessive or even infantile, but perhaps even emasculated: "['Trekkies'] are feminized and/or desexualized through their intimate engagement with mass culture ('Have you ever kissed a girl?' [Shatner yelled this question at one male "Trekkie" on the same episode of SNL])" (Textual Poachers 10). As this example suggests, fans are seen as fans (short for 
fanatic) in part precisely because of their perceived overly bodily, over desirous, and under-objective stance in relation to the source text. In short, fanfiction is writing that is unsanctioned precisely because it deals with the bodily, with desire, with the "feminine."

\section{Emotion and the Body in Literacy Learning and Practices}

However, as I began to discuss above, "women's writing" is a troubling term because it relies upon a problematic assumption—-that "woman" is a consistent and natural entity out in the world to be discovered and/or lived. It reifies the false sex-togender binary, and it limits the possibilities for writing contents, styles, and audiences (outlets?) as it is overly-determined within the impossible sex-genders of "woman" versus "man." However, as I also began to argue above, within our current patriarchal hegemony, the content and style choices of much of online fanfiction are highly feminized, because it is seen as so bodily, so "touchy feely," so "romantic." A further complicating factor is that this writing does seem to be carried out by mostly womanidentified participants. Because of the highly feminized nature of fanfiction, it is appropriate, I argue, to refer to it as écriture feminine, if not women's writing. That is, fanfiction is a particularly evocative example of writing that is emotional and emotioned, as well as bodily and embodied in its content, style, and circulation (see Chapter 3, especially). But, while I do argue it is appropriate to use the term écriture feminine for fanfiction, I also argue that even this nomenclature is misleading and, if we are to apply any of this writing community's lessons, overly limiting.

Therefore, here, I will break from the phrase "écriture feminine," and take up emotioned literacy instead, as I believe that the latter really is one of the key lessons scholars can take from online fanfiction communities. In order to do this properly, I need 
to start by defining "emotion" (as well as emotional and emotioned), especially as it is a social, relational, and embodied set of (potential) understandings, orientations, and practices (to borrow from Wetherell).

Emotion is a particularly tricky concept to address — and certainly a difficult word to define. What do we often mean when we use the term emotion? What do we really mean when we say that something is "emotional"? In general, the term "emotional" carries with it some negative connotations. We often hear sentences such as:

"She's just overly emotional"

and

"Try not to be so emotional"

and the related,

"Be professional. Leave your personal life at home."

Emotions have tended to be relegated to the realm of the feminine or the weak. To be emotional is to be unprofessional, and irrational, and even, sometimes, unreliable. And in the Western, Cartesian theory of being, let alone learning and working, with which so many of us are so (sometimes tragically) familiar, learning and working are largely wrenched from the body and from emotion. They are wrenched ever so mysteriously from a social world. Within this formulation, "emotion" becomes an individual side effect of the body that a "good" and "rational" human being (read man) can overcome. But I argue, along with many others (Ahmed, Chaput, Micciche, and Wetherell, especially) that this formulation is not at all satisfying because it does not come close to actually capturing what happens when we learn. When we be. 
So, how can we define emotion in a more useful way? First, we have to start by seeing the available ways in which this term has already been defined or denoted. For example a quick Google search reveals the following definition: "A natural instinctive state of mind deriving from one's circumstances, mood, or relationships with others." At first, this definition appears to be very straightforward and clear. But if we even askwhat is "natural"? What is "instinctive"?—we already run into trouble. These terms suggest that emotions arise from the ether to affect the body and then disappear just as easily again. However, it is good that this definition mentions relationships. So we can say, perhaps, that emotions are relational. If we look to a very popular dictionary, Merriam-Webster online, we find an even less helpful definition: "A strong feeling (such as love, anger, joy, hate, or fear)." But what, indeed, is a "feeling"? What makes it "strong" or weak? This definition places emotion in the realm of the indefinable, making it all the more mysterious.

Taking a more historical and etymological approach would lead us to the Oxford English Dictionary Online, which provides some very interesting additions to these definitions, including: "3a. Originally: an agitation of mind; an excited mental state. Subsequently: any strong mental or instinctive feeling, as pleasure, grief, hope, fear, etc." and "3b. As a mass noun: strong feelings, passion; (more generally) instinctive feeling as distinguished from reasoning or knowledge." Here we begin to see words like "agitation" and "mind," and its application as a mass noun allows us to potentially see the social/societal element of emotion. In addition to these familiar definitions, the $O E D$ includes the now obsolete meanings of "movement" and "political agitation, civil unrest; a public commotion or uprising" (seen as late as 1822 and 1797 respectively). Now these 
definitions are really taking us somewhere. They begin to show the depth of meaning in "emotion" that, in the public and popular realm, we often no longer consider. Of course, as rhetoricians, we do often consider where something is "moving" and, therefore, effective for the particular audience in question. It is particularly interesting that some of these meanings of “emotion” have been largely lost to time. What happened to emotion's sense of movement, of unrest, of society, of gathering together to affect and effect change?

In public and popular discourse, then, emotions are individual, they are physical, they are irrational_ out of control. And it is true that we tend to think of emotions always in these ways. In fact, I still tend to speak of them in these ways when I am outside of the academic realm. And, to some extent, I would like to argue that even if something is somehow "irrational," that does not mean it has no value-especially in literacy practices. On the one hand, I would like to own and value the role of the "personal," the "gut," and the "visceral" in re-acknowledging emotion in the academy. On the other hand, I also understand that emotions and the body play much more integral and complex roles in daily life and learning than we tend to consider, and it is essential that we begin to theorize these. Ahmed and Wetherell are especially helpful in this regard.

In The Cultural Politics of Emotion, Sara Ahmed theorizes emotion as an ideological and rhetorical system, what she calls the "society of emotion" (8) and "affective economies." Ahmed explores a number of cases, such as Neo-Nazi websites and Australia's campaign to nationally acknowledge their shame over their treatment of aboriginal communities, in order to describe the workings of emotions such as hate, love, shame, anger, etc. She argues of emotion that: "I do not want to think about emotionality 
as a characteristic of bodies, whether individual or collective. In fact, I want to reflect on the processes whereby 'being emotional' comes to be seen as a characteristic of some bodies and not others, in the first place. In order to do this, we need to consider how emotions operate to 'make' and 'shape' bodies as forms of action, which also involve orientations towards others" (Ahmed 4). Moreover, she argues that certain images and artifacts—certain signs become so heavily circulated that they can then become almost synonymous with the emotions they are used to represent and describe.

Ahmed says of "affective economies" that:

I am using 'the economic' to suggest that objects of emotions circulate or are distributed across a social as well as a psychic field, borrowing from the Marxian critique of the logic of capital....What I am offering here is a theory of passion not as the drive to accumulate (whether it be value, power or meaning), but as that which is accumulated over time. Affect does not reside in an object or sign, but is an effect of the circulation between objects and signs (= the accumulation of affective value). Signs increase in affective value as an effect of the movement between signs: the more signs circulate, the more affective they become. (45) Of course, this use of "affective economy" is, in some ways, very different from how I've used it in chapters 3 and 4, where I describe online fanfiction as spaces where friendship, love, excitement (and sometimes hate) are circulated among writers. But Ahmed's concept of "affective economy" can begin to account for and extend the ways in which identification with and against certain fandoms and their representations. Ahmed's view of emotion is particularly useful because it moves away from the assumption that emotion lives/arises only in an individual body, and it shifts toward a societal view of 
emotion, where certain combinations of signs come to be highly associated with certain emotions. While Ahmed does not couch it in these ways, I would argue that Ahmed's theory of emotion takes us out of a biomedical approach toward a Bourdieuian-esque approach; in her formulation, emotion is very much like the habitus. In this way, then, emotions, like the habitus, are structured and structuring, they are learned throughout the course of our lives, they are generative, and they are neither set nor "natural."

Margaret Wetherell provides an infinitely useful way for understanding and theorizing emotions in Affect and Emotion: A New Social Science Understanding. In many ways, Wetherell's account of what she calls affective practice is very similar to habitus, though she argues that Bourdieu's approach is too ordered. She agrees that emotion is best defined as a societal system, but she also brings the body back to this equation of affectivity by referring to affect (emotion) as "embodied meaning-making" (10). She argues specifically of emotion that:

To recapitulate my earlier arguments, I see affective practice as a moment of recruitment and often synchronous assembling of multimodal resources, including, most crucially, body states. It is the participation of the emoting body that makes an assemblage an example of affect rather than an example of some other kind of social practice. I agree with Ahmed that this assembling and recruiting is onto-formative, meaning that it constitutes subjects and objects....Affective practice in this way sets up relations between subjects and objects through their intertwined formations and constitutions. But we also need to locate affect, not in the ether, or in endless and mysterious circulations, but in 
actual bodies and social actors, negotiating, making decisions, evaluating, communicating, inferring and relating. (159, my emphasis)

It is this rehabilitation of the body in the formulation of "affect" or what I would like to call emotion that is especially important here. Not only is the body, like emotion, either denigrated as the realm of the feminine or broken up into little pieces a masculinized biomedical approach can deal with easily, but it is also the place where emotions appear to arise, where they are negotiated, developed, etc.

I'd like to discuss the body, the bodily, and embodiment here, because this is and has always been an integral component of defining emotion (not to mention experiencing it). As was discussed above, the body as part of the formulation of emotion or the emotional has always been assumed as an individual, natural, and often highly automatic space — a container of viscera, neurons, synapses, blood, bile, and certainly feelings or emotions. It has often been asserted that one can somehow "rise above" or "move beyond" the "bare" and "base" needs and desires of the body, especially if one is male (and also, probably, white, middle class, and Christian). And it is through this process that emotion has gotten (bitterly) divorced from learning, knowledge, and meaning making. Of course, none of this is true. The body is an essential component in learning. But just saying that we should acknowledge the body is not enough. Just as Linguists understand that language cannot develop in a non-social body, neither can what we would recognize as emotion(s).

As Wetherell argues, and I agree, "Body states are always situated and always taking place in the midst of some activity, and the medium in which they are situated is culturally and socially constituted" (42). In other words, while emotions can seem as if 
they just are, they are always shaped by the social. They are learned. And, in turn, they are shaped by and continue to shape learning. In this formulation, the body is situated, social, and malleable, rather than natural, individual, and largely set. What's more, in this formulation, emotion cannot come to be without situated sociality or without embodiment. I would argue, then, that when we engage in literacy practices, we are engaging in very complex processes that situate us into our bodies in particular ways, both in terms of other bodies (human, text, spatial) and in terms of our past and future bodies - in other words, we are situated into our bodies both synchronously and spatially as well as diachronically and non/multi-spatially. Learning and literacy are always embodied and emotional.

Finally, I'd like to argue that fanfiction and literacy practices more generally aren't "feminine" or "womanly" or even "emotional," exactly, but, to borrow from Micciche, emotioned. As Micciche argues, "We do emotions—-they don't simply happen to us" (2) and "To speak of emotion as performative is to foreground the idea that emotions are enacted and embodied in the social world" (1). This is important because this view of emotion allows room for agency, for resistance, and for transformativity. And these, after all, are what the emotion and emotioned economies of online fanfiction really do for participants.

\section{Conclusion: Towards Emotioned Literacy Practices}

I started this chapter by involving the figure of the Mary Sue as a way to argue that fanfiction is important because it represents a set of writing, reading, and engagement practices that are often viewed as "feminine” and weak. While fanfiction has always been viewed by scholars as interesting or useful because of its "resistive" 
elements, I argue here that fanfiction is useful even when it is not overtly resistive, and even when it is blatantly conservative. I argue that this is so because fanfiction—even and perhaps especially the practice of the Mary Sue story—does important, often transformative, work for its participants. Fanfiction is important because it can provide us as literacy scholars with an opportunity to turn away from potentially limiting and even harmful views of "feminine," "feminized," and "womanly" writing, and instead begin to see the different ways and arenas in which writing is an embodied-emotional experience.

To conclude this chapter, I'd like to argue that we make a move toward theorizing, and teaching, emotioned literacy. And that online fanfiction is a particularly robust example of how emotioned literacy can and does happen. To be clear, emotioned literacy means embodied-emotional practices that are temporally, spatially, and socially-situated. Like the habitus, emotioned literacy is shaped by previous texts, people, and encounters, as well as experience gained through lifelong learning. What's more, engagement in emotioned literacy continues shaping/being shaped by a person's situatedness. Emotioned literacy are practices that do something in the world for the practitioners, that are shaped by embodied-emotional life, and that are done in complex exchange economies. 


\section{CONCLUSION}

\section{LET'S BRING EMOTION BACK}

In this dissertation, I have explored the community practices of online fanfiction. I began this project from a position of enthusiastic love, as a long-time fanreader and onetime fanwriter. I knew that fanfiction had been powerful for me, and for many others that I'd known. And I saw a disconnect between how writing was imagined as happening in a classroom versus other environments - the home, for example. There was a disconnect between writing sometimes and "being a Writer." And there was a disconnect between so-called “original” writing and the "faking” in fan spaces. And I just knew this wasn’t right. PhoenixSongFalling (my fanfiction penname) was an extension of me. It was a version of me that got to be incredibly intelligent, smooth, educated, and articulate. She was strong, confident, and powerful. She was beautiful, even. She was self-aware, and she wrote original and well-rounded characters (maybe). She was an aspect of myself that got to be all mine. She operated in a room of her/my own, and it was what made all the difference for me in redirecting my life. And even for fans whose experiences haven’t ever or always been that profound, fanfiction provides the important space to be an active participant in a cultural moment-text-artifact, and to write one’s experience into a world that might not have represented it before. It's also a place for self-indulgence, romantic and sexual fantasy, and friendship. In short, it’s a particularly robust example of a space where writing is completely integrated into every aspect of daily life. And I knew that this was why it was so important for the field of rhetoric and composition. 
When I began this project, I knew that I needed to do more than textual analysis, as texts, even an array of different ones, are incapable of fully representing any community. Ideally, I would be able to devote months and even years to establishing a full-fledged fan-researcher identity in these spaces, and to engage in ethnographic research like Heath, Jenkins, and Bacon-Smith. However, the limitations of a four-year (five at most) PhD program did not grant me the time. So, I compromised. I decided to approach these sites from an ethnographic perspective, which Heath and Street have defined as: “" the use of theories of culture and inquiry practices that derived from anthropology or sociology to guide research'” (121), and the use of tools such as interviews and observations. This means that I have gone into these online spaces ready to strike an emic or participant-centered view and to spend time consuming and considering real fan texts as well as communicating with real fans. I conducted textual analysis, questionnaires, interviews, and case studies. However, all of this work was done over the course of one year. In that time, I have only uncovered the very surface of life in fanfiction. In future research, I will need to continue widening my fan network and communicating with fans over several years, in order to gain a much more nuanced and sophisticated picture of the fan and fanwriter. Doing so would be better able to inform what we can know about literacy practices throughout a lifetime.

Not only was I limited by time, however, but by scope. I began knowing only the fansites Sycophant Hex, The Petulant Poetess, and to some extent Live Journal. I began really only knowing Harry Potter fanfiction. This means that my project started with a limited view of the field of possibilities for fans, as most of my access was with Harry Potter and literary-based fandoms, small fan communities, and communities self- 
identifying as consisting mostly of women from the US and UK, between 20 and 60 years old. I attempted to open this up by adding the long-standing, much larger Fanfiction.net, which did widen the age, gender, and class range of my project, as well as making it more global. In addition, I chose an unfamiliar fandom, WWE, which widened the possible field of class taste profiles considerably. However, I was still limited here in my view of the possibilities of fandom. Sub-communities of Fanfiction.net are still very small. What's more, since I first envisioned this project, many fans I know have moved to Archive of our Own. In these ways, my project began with the limitation of not necessarily representing the most current fannish activity. Future research would engage with sites such as Archive of our Own and Tumblr, and it would cover a much larger range of beloved source texts.

Finally, as my research progressed, it became clear that my choices of sites as well as my own positioning as a white, middle class woman obsessed with Harry Potter, had limited me in terms of gender and class. WWE did reveal some degree of more working class values, but the writers I've made contact with in that community are all international, which complicates what I can confidently say about class. What's more, only one participant out of seven identified as agender, while all other participants identified as women. What's more, only one participant identified as being a member of the LGBQA+ community ${ }^{63}$. In many ways, then, this project has been quite limited to mostly middle-class, straight-identifying women. However, five of the seven participants are from outside the United States (Germany, Denmark, and Philippines). Furthermore, this project has uncovered a great deal in terms of circulation, embodiment, emotion, and

\footnotetext{
${ }^{63}$ I am leaving out some of the letters here to show that I am focusing particularly on sexuality, rather than gender identity, and differences in bodily sex.
} 
fanwriter material realities that will form a good foundation for future work, which should, as I have said, engage in more fansites, with more fandoms, and for much more time with all participants. Doing so would be able to go beyond the "crust" of fanfiction, as it were, and be able to uncover more about the ever-shifting, ever-growing elements of literacy practices, identit(ies), and material circumstances.

When I set out to work on this project, I was not completely certain what I would find, but I was certain I would find something deeply useful to those of us interested in how writing works. How it's learned. How it's developed. What keeps people going and why. I did know I'd find sophisticated and imaginative writing that is often otherwise represented as mimicry, and lesser. I knew I'd find many strong and deeply engaged woman-identified writers whose craft would be doubted and dismissed and denigrated by all except those within the community. I knew I'd find exciting conversations queering the dominant binary and cis-gendered, masculinist, and heteronormative ideologies. I also anticipated finding more depth in terms of class as a factor in fanwriting. And, while I did find many of these things in the course of conducting my research, I was somewhat surprised but pleased to find the two following take-aways for the field of rhetoric and composition: 1) important ways to rethink our online research methods; and 2) that emotion plays a pivotal role in learning and literacy practices, and needs to be further theorized.

As so much of our reading and writing practices are moving into digital, online spaces, there's more and more we'll have to understand about the interactions among embodiment, emotions, cognition, ideology, the physical and mental acts of writing, and the technology itself. Doing so well requires a goodwill mindset (even if spaces such as 
Reddit, 4Chan, end comments, and even the Amazon review can often makes us feel quite the opposite). There is no longer any excuse for going into fan spaces and reproducing any of what we find there without first attaining consent. In fact, we've got to establish a firm understanding of the workings of that space (an emic perspective) before we even consider ourselves as “collecting data.” For example, while a "goodwill ethics” of many fanfiction spaces means that fanfiction stories are meant to be shared publicly while comments and discussion forums are not, these things are variable across online spaces and communities. While variable, “goodwill” practices are best characterized by the values of respect, reciprocity, transparency, and doing vulnerability. We show respect by openly and carefully representing ourselves, as complex as that is, as well as representing fans in ways they might represent themselves. We can enact reciprocity by not only providing balanced accounts of fandom, but also by accepting and fulfilling some roles fans might ask of us. We are properly transparent when we state our positions, values, institutional affiliations, and methods, as well as remaining flexible enough to negotiate the latter. And, finally, we best achieve these first three values by doing vulnerability: where we reach out as emotional and embodied humans to the emotional and embodied humans on the other sides of our computer screens.

I must stress here that goodwill ethics of research are not only crucial in fan studies - they are crucial in the field of rhetoric and composition, in our work as scholars and researchers, and as teachers and mentors. So much of everyone’s daily activity, including entertainment and work, has gone digital. This trend rightly raises questions about how composing might be changing and in what ways. The internet consists of multiple spaces with real people engaging in very complex sets of practices with equally 
complex though often unstated expectations for these practices. Therefore, studying these spaces effectively requires clear processes for ethical research (as McKee and Porter refer to them in Internet Research). But more than that, as more and more of our teaching goes online and toward digital and multimodal composing, it is all the more important that we treat what is capable of being done with these spaces as more than "just" texts and images and tools, but as shaped and shaping situated, living and breathing people. Doing so not only helps us to better help our students to protect themselves, but to provide them with a much more dynamic sense of audience and context as these meet genre(s) online. This is crucial as we teach composing and as we mentor graduate students and junior faculty in their own teaching, research, and scholarship. Furthermore, doing so minimizes the potential for harm such as we've seen in Fangate (Chapter 2) and in popular websites such as Shit My Students Write, but it also carries the possibility of better preparing us to utilize these ever-developing digital technologies within literacy education.

In addition to a goodwill approach to research methods, fanfiction provides an example of what it might mean to have a goodwill approach to literacy practices. Embodied-emotion is the key. Literacy is emotioned. Emotioned literacy means embodied-emotional practices that are temporally, spatially, and socially-situated. Like the habitus, emotioned literacy is shaped by previous texts, people, and encounters, as well as experience gained through lifelong learning. What's more, engagement in emotioned literacy continues shaping/being shaped by a person's situatedness. Emotioned literacy are practices that do something in the world for the practitioners, that are shaped by embodied-emotional life, and that are done in complex exchange economies. What, precisely, this means for rhetoric and composition is an open question. It means, first, as I 
practiced with my approach to research methods, an entirely different starting disposition than we might have had before. It means acknowledging that while elements of emotion were once a true cornerstone of rhetorical education, these have somehow faded away from current educational practices. We must draw these back in again. But how, and in what ways, and to what degree are still in question.

My time in fanfiction certainly reinvigorated my love for writing, and the key was through acknowledging and connecting with my emotions. As I have engaged in research and teaching since then, I have only become more convinced that emotion is key. Firstly, truly engaging in a student-centered classroom and using students' knowledge as a starting place absolutely requires an open disposition toward learning and literacy as embodied, positioned, and emotional. Being a responsible teacher and scholar also requires more acknowledgement of our embodied and emotional selves—of our whole selves, if we are to ever better understand our quarry: How does literacy learning work? But more so, it's important for self-care and, therefore, more effective work as academics. This is all the more important as studies show that mental health issues are on the rise in college student populations. And that mental health has been a long-standing yet relatively little discussed issue among graduate students and faculty. Furthermore, acknowledging and integrating embodiment and emotion also provides us with a much better ability to address discrimination towards people of color, people with disabilities, LBGTQIA+ people, and women in the academy—not to mention bringing many more folks from these communities into positions of power and influence within academia. Focusing on emotion in reading, writing, and learning makes for better classrooms, teachers, writers, and researchers. 
Fanfiction really is a particularly robust site of exploration for the scholar interested in better understanding how we come to read and write what we do. Not only is fanfiction widespread and still growing, but unlike phenomena such as Facebook, Instagram, and Twitter, it feels like and is celebrated by participants as writing. When Henry Jenkins set out to study fans in the 1980s, he knew he would find truly unique engagement with culture and media. And he did. When I set out to study online fanwriters in the 2010s, I knew I would find evidence of truly sophisticated writing practices-I would find what happens when writing occurs in small, intimate-seeming spaces with love and enthusiasm as the main goal. And I did. As Bacon-Smith commented on the fanfiction community in Enterprising Women:

In the fan community, the very process of creation generates the social situation. Fans gather to trade and sell their fanzines, to tell stories, to watch the source products and the music videos, and to construct lives based on the tenets they build into their fiction. Among the most important beliefs are the trustworthiness of fans and the willingness of fans to contribute to the good of the community in the spirit of IDIC—-the joy of Infinite Diversity in Infinite Combinations. (219)

Goodwill really is what makes fanfic work. Therefore, the most robust take away for the field of rhetoric and composition from fanfiction practices is to engage the fanfic-inspired values of goodwill ethics, emotion economies, and emotioned literacies in other contexts over time, as these values already do inform a lot of our daily scholarly, teacherly, and administrative work, even if they remain largely under-theorized.

Our scholarship is already always coming from our positions in our worlds, which cannot help but be embodied and emotional. But, just as with issues concerning identity 
(such as gender, sexuality, race, ethnicity, class, etc.), just stating that our work is emotional and embodied is not enough. We have to question and challenge and utilize these elements in our starting dispositions in our research. Furthermore, just as we can't divorce our scholarship from our embodied-emotional positions, we cannot separate research from teaching from our administrative work. And so we cannot help but be embodied and emotional teachers and administrators. An emotioned literacy pedagogy can provide the potential for better student-teacher interactions and therefore better student engagement and success. An emotioned approach to administration, especially for the WPA or Graduate Program Director, can provide for better, more supportive teacher and graduate student training. And it can even open us up to better communicating the worth of our work to other departments, administrators, and to the public.

The work we do in rhetoric and composition is profound, and it is whole body and whole person work at its very best. Just as McKee and Porter argued for creating a clear set of processes for ethical online research methods, future research in rhetoric and composition should pick up on goodwill ethics of research and emotioned literacy as starting points, and then look at how these might operate in other communities, and sites, and contexts, and then develop goodwill processes for emotioned literacy pedagogy and administration. Rather than concluding this dissertation by establishing firm and specific answers for how fanfiction practices can specifically inform the daily work of compositionists, I'd like, instead, to end with questions, which are more productive in the health of a dynamic field. Questions that future research should address as it develops goodwill processes for research, teaching, and administration should include: How might goodwill ethics and emotioned literacy operate in school environments, especially in 
writing? What about in graduate student development? Faculty development? What are the gains and risks of a potential emotioned literacy / emotion theory pedagogy? What role can emotioned literacy or emotion theory effectively play in administrative work? And how might that help us to continue to establish our worth in the university and beyond? 


\section{REFERENCES}

“About Military.” www.community.wwe.com. WWE. 2015. Web. 31 Oct. 2015.

“About the OTW.” Archive of Our Own. Office of Transformative Works. n.d. Web. 16 Nov. 2015.

“About Us.” The Mary Sue. The Mary Sue. 2015. Web. 1 Nov. 2015.

“Agua Mala.” The X-Files. Writ. Chris Carter and David Amann. Dir. Rob Bowman. 20 Century Fox, 1999. Television.

Ahmed, Sara. The Cultural Politics of Emotion. Edinburgh, UK: Edinburgh UP, 2014. Print.

Alien. Dir. Ridley Scott. Perf. Tom Skerritt, Sigourney Weaver, Veronica Cartwright, Harry Dean Stanton, Jon Hurt, Ian Holm, and Yaphet Kotto. Twentieth Century Fox, 1979. Film.

“All Things.” The X-Files. Writ. Chris Carter and Gillian Anderson. Dir. Gillian Anderson. $20^{\text {th }}$ Century Fox Television, 2000. Television. aloysiavirgata. “Balm in Gilead.” The X-Files Ball of Wrong Porn Battle. Live Journal. Oct. 2009. Web. 31 Oct. 2015.

Amazon.com. Amazon.com, Inc. 1996-2015. Web. 1 Nov. 2015. Anderson, Emily Hogson. "Celebrity Shylock." PMLA 126.4 (2011): 935-949. Print. Anderson, Paul V. (1998). Simple Gifts: Ethical Issues in the Conduct of Person-Based Composition Research. College Composition and Communication, 49.1 (1998): 63-89. JSTOR. Web. May 282015. 
Araceil. Fate Be Changed. In Miss Potter. Fanfiction.net. 21 June 2014. Web. 1 Nov. 2015.

Archiveofourown.org. 0.9.19.1. Organization for Transformative Works. n.d. Web. 10 May 2014.

Aristotle. Rhetoric. Ed. Joe Sachs. Trans. Joe Sachs. Newburyport, MA: Focus, 2009. Print.

azazello. "Plagiarism - what's hot and what's not." "Writers’ Resources” in The Enchanted Quill at SycophantHex. n.p. 28 Dec. 2004. 16 April 2012. . "Sycophant Hex - Submission, Validation and Rejection." The Daily Prophet at Sycophant Hex. n.p. 12 April 2005. Web. 5 March 2012.

Bacon-Smith, Camille. Enterprising Women: Television Fandom and the Creation of Popular Myth. Philadelphia: U of Pennsylvania P, 1992. Print. . Science Fiction Culture. Philadelphia, PA: U of Pennsylvania P, 2000. Print. Bakhtin, M.M. Discourse in the Novel. In Holquist, 1981. 259-422. Print. . Forms of Time and of the Chronotope in the Novel. In Holquist, 1981. 84-258. Print.

Bambeah. “A Thousand Cranes.” In Harry and Draco’s Love Shack.Fanfiction.net. 1 March 2011. Web. 1 Nov. 2015.

Battlestar Galactica. Writ and Dir. Glen A. Larson and Ronald D. Moore. Perf. Edward James Olmos, Mary McDonnell, Jamie Bamber, James Callis, Trivia Helfer, Grace Park, and Katee Sackhoff. British Sky Broadcasting, 2004-2009. Television. 
Baywitch. Writ. \& Dir. Michael Berk, Gregory J. Bonann, and Douglas Schwartz. Perf. David Hasselhoff and Pamela Anderson. GTG Entertainment, 1989-2001. Television.

Bell, David. Cyberculture Theorists: Manuel Castells and Donna Haraway. London and New York: Routledge, 2007. Print.

Berlin, James. "Rhetoric and Ideology in the Writing Class.” The Norton Book of Composition Studies. Ed. Susan Miller. New York and London: W.W. Norton \& Company, 2009. 667-684. Print.

Booth, Paul. Digital Fandom: New Media Studies. New York: Peter Lang, 2010. Print. Bourdieu, Pierre. Distinction: A Social Critique of the Judgment of Taste. Trans. Richard Nice. Cambridge, MA: Harvard UP, 1984. Print. . The Logic of Practice. Trans. Richard Nice. Cambridge, UK: Polity Press, 1990. Print.

Bowen, Deborah Silverman. "e-Criture Feminine: Women's Online Diaries and the New Female Discourse." Webbing Cyberfeminist Practice: Communities, Pedagogies, and Social Action. Ed., Kristine Blair, Radhika Gajjala, and ChristineTulley. . Creskill, NJ: Hampton, 2009. 309-326. Print.

Brandt, Debora. Literacy in American Lives. New York; London: Cambridge UP, 2001. Print. . Literacy and Learning: Reflections on Writing, Reading, and Society. San Francisco, CA: Jossey-Bass, 2009. Print.

BreeSharpDD. “Bree Sharp’s David Duchovny in HD.” YouTube.com. YouTube. 23 Nov. 2011. Web. 31 Oct. 2015. 
Brydon-Miller, Mary. "Covenantal Ethics and Action Research: Exploring a Common Foundation for Social Research.” The handbook of social research ethics. Ed, D.M. Mertens \& P.E. Ginsberg. New York; London, UK: Sage Publications, 2009. 243-258. Print.

. "Ethics and Action Research: Deepening Our Commitment to Principles of Social Justice and Redefining Systems of Democratic Practice.” The SAGE handbook of action research. Ed, P. Reason \& H. Bradbury. $2^{\text {nd }}$ ed. New York; London, UK: Sage, 2008. 199-210. Print.

Buffy the Vampire Slayer. Writ. Joss Whedon. Dir. Joss Whedon. Perf. Sarah Michelle Gellar, Nicholas Brendan, Alyson Hannigan, Anthony Michael Head, and James Marsters. Fox, 1997-2003. Television.

Burnett, Cathy et al. "The (im)materiality of Literacy: The Significance of Subjectivity to New Literacies Research." Discourse Studies in the Cultural Politics of Education. 35.1 (2012): 1-14. Print.

Bury, Rhiannon. Cyberspaces of Their Own: Female Fandoms Online. New York: Peter Lang, 2005. Print.

burr-fect. A Cold Hand. In Miss Potter. Fanfiction.net. 12 April 2014. Web. 1 Nov. 2015. Butler, Judith. Gender Trouble: Feminism and the Subversion of Identity. New York and London: Routledge, 1990. Print.

Canagarajah, Suresh. “Codemeshing in Academic Writing: Identifying Teachable Strategies of Translanguaging.” Modern Language Journal, 95.3 (2011): 401-17. Print. 
Chaput, Catherine. "Rhetorical Circulation in Late Capitalism: Neoliberalism and the Overdetermination of Affective Energy." Philosophy and Rhetoric 43.1 (2010): 125. Project Muse. Web. 8 July 2015.

Chivalric. At the Beach. Sycophant Hex. n.p. 24 April 2009. Web. 3 March 2012. . "Divorce." Sycophant Hex. n.p. 10 Jan. 2008. Web. 2 Feb. 2012.

Chivalric. Personal Interview. 16 June 2014. . Personal Interview. 5 Oct. 2014. . Personal Interview. 8 Dec. 2014.

Chivalric55. Live Journal. n.d. Web. 3 March 2012.

Cixous, Hélène. "The Laugh of the Medusa." Signs. 1.4 (1976): 875-893. Trans. Keith Cohen and Paula Cohen. JSTOR. Web. 14 Sep. 2009.

Clare, Cassandra. The Mortal Instruments Series. New York: Margaret K. McElderry Books, 2012. Print.

Crowley, Sharon. Toward a Civil Discourse: Rhetoric and Fundamentalism. Pittsburgh, PA: U of Pittsburgh P, 2006. Print.

Cushman, Ellen. (1996) “The Rhetorician as an Agent of Social Change.” College Composition and Communication. 47.1 (1996): 7-28. JSTOR. Web. 28 May 2015. CSI: Miami. Writ and Dir. Ann Donahue, Carol Mendelsohn, and Anthony E. Zuiker. Perf. David Caruso and Emily Procter. CBS, 2002-2012. Television. Dark Harbor. Writ. Adam Coleman Howard, Gretchen Hayduk-Wroblewski, and Justin Lazard. Dir. Adam Coleman Howard. Perf. Alan Rickman, Polly Walker, and Norman Reedus. Hart-Sharp Entertainment, 1998. Film. 
De Certeau, Michel. The Practice of Everyday Life. Trans. Steven Rendall. Berkeley: U of California P, 1984. Print.

Diana. "Reminder Regarding Forum Posting Rules!" The Daily Prophet at SycophantHex. n.p. 7 March 2005. Web. 5 March 2012.

Donati, Sara. Into the Wilderness. Surrey, UK: Delta, 2008. Print.

Downer, Christa et al. "Who's Really a Cyberfeminist? Women Write Back: The Rhetoric of Pro-Ana Web Sites." Webbing Cyberfeminist Practice: Communities, Pedagogies, and Social Action. Ed. Blair, Kristine, Radhika Gajjala, and Christine Tulley. 85-106. Creskill, NJ: Hampton, 2009. Print.

Dunbar-Odom, Donna. Defying the Odds: Class and the Pursuit of Higher Education. Albany, NY: State U of New York P, 2007. Print.

Elbow, Peter. "Closing My Eyes as I Speak: An Argument for Ignoring Audience.” College English. 49.1 (1987): 50-69. JSTOR. Web. 2 December, 2015. . Writing with Power: Techniques for Mastering the Writing Process. New York and London: Oxford UP, 1998. Print.

Faigley, Lester. “Competing Theories of Process: A Critique and Proposal.” The Norton Book of Composition Studies. Ed. Susan Miller. New York and London: W.W. Norton \& Company, 2009. 652-666. Print.

Fanfiction.net. n.p. n.d. Web. 5 March 2012.

Faris, Michael J. “Coffee Shop Writing in a Networked Age.” College Composition and Communication. 66.1 (2014): 21-24. Print.

Ferris, Kerry O. "Through a Glass, Darkly: The Dynamics of Fan-Celebrity Encounters." Symbolic Interaction 24.1 (2001): 25-47. JSTOR. Web. 30 September 2015. 
Fine, Michelle. "Working the Hyphens: Reinventing Self and Other in Qualitative Research." Handbook of Qualitative Research. Eds. Norman K. Denzin and Yvonna S. Lincoln. London: Sage, 1994. 70-82. Print.

frostyfreezyfreeze54. Great American Bash 1997. In WWE Fanfiction World.

Fanfiction.net. 23 July 2010. Web. 31 Oct. 2015.

. Survivor Series 1997. In WWE Fanfiction World. Fanfiction.net. 24 July

2010. Web. 31 Oct. 2015.

Gee, James Paul. Situated Language and Learning: A Critique of Traditional Schooling. New York: Routledge, 2004. Print.

. "The New Literacy Studies: From 'Socially Situated' to the Work of the Social.”

Situated Literacies: Reading and Writing in Context. Ed. David Barton, Mary Hamilton, and Roz Ivanic. London and New York: Routledge, 2000. 197-209.

Print.

hades77. "The Red and the Blond.” The X-Files Ball of Wrong Porn Battle. Live Journal.

Oct. 2009. Web. 31 Oct. 2015.

Haraway, Donna. "A Cyborg Manifesto: Science, Technology, and Socialist-Feminism in the Late Twentieth Century." In Simians, Cyborgs and Women: The Reinvention of Nature. New York: Routledge, 1991. 149-181. www.egs.edu .Web. 7 April 2015.

harleysjoy. "Somebody to Love.” WWE Fanfiction World. Fanfiction.net. 17 Sep. 2010. Web. 31 Oct. 2015.

Harry and Draco’s Love Shack. In www.fanfiction.net. Fanfiction.net. 14 Feb. 2015. Web. 1 Nov. 2015. 
Harry Potter Lexicon. n.p. 20 July 2006. Web. 2 Feb. 2012.

Harry Potter Wiki. Wikia. n.d. Web. 30 Oct. 2015.

Hartwell, David. Age of Wonders: Exploring the World of Science Fiction. New York: Walker \& Company, 1984. Print.

Heath, Shirley Brice, and Brian V. Street. On Ethnography: Approaches to Language and Literacy Research. New York and London: Teachers College Press, 2008. Print. Herndl, Carl G. "Writing Ethnography: Representation, Rhetoric, and Institutional Practices." College English 53.3 (1991): 320-332. JSTOR. Web. 4 June 2015. Hills, Matt. Fan Cultures. London; New York: Routledge, 2002. Print. Hine, Christine. Virtual Ethnography. London: Sage, 2000. Print.

Holquist, Michael, ed. The Dialogic Imagination: Four Essays by M. M. Bakhtin. Trans. Caryl Emerson and Michael Holquist. Austin, TX: U of Texas P, 1981. Print. Irigaray, Luce. "This Sex Which is Not One." The Second Wave: A Reader in Feminist Theory. Ed. Linda Nicholson. New York; London: Routledge, 1997. Print. 323329.

“I, Robot... You, Jane.” Buffy the Vampire Slayer. Writ. Joss Whedon, Ashley Gable, and Thomas A. Swyden. Dir. Stephen L. Posey, S.L. 20 ${ }^{\text {th }}$ Century Fox, 1997. Netflix. Web. 15 Sep. 2015. Television.

Ito, Mizuko, et al. Hanging Out, Messing Around, and Geeking Out: Kids Living and Learning with New Media. Cambridge, MA: MIT Press, 2010. Print.

Jackson, Leon. The Business of Letters: Authorial Economies in Antebellum America. Stanford, CA: Stanford UP, 2008. Print.

James, E.L. Fifty Shades of Grey. New York: Vintage Books, 2012. Print. 
Jenkins, Henry. Convergence Culture: Where Old and New Media Collide. New York; London: New York UP, 2006. . Fans, Bloggers, and Gamers: Exploring Participatory Culture. New York; London: New York UP, 2006. Print. . Textual Poachers: Television Fans and Participatory Culture. London; New York: Routledge, 1992. Print.

Jenkins, Henry, Sam Ford, and Joshua Green. Spreadable Media: Creating Value and Meaning in a Networked Culture. New York: New York UP, 2013. Print. jessica499499. Our Baby. In Harry and Draco’s Love Shack. Fanfiction.net. 27 March 2009. Web. 1 Nov. 2015.

. Our Babies. In Harry and Draco’s Love Shack. Fanfiction.net. 20 Aug. 2009. Web. 1 Nov. 2015.

Johnson, Derek. "Fan-tagonism: Factions, Institutions, and Constitutive Hegemonies of Fandom." Fandom: Identities and Communities in a Mediated World. Jonathan Gray, Cornel Sandvoss, and C. Lee Harrington, eds. New York; London: New York UP, 2007. 285-300. Print.

Katy Perry. “Teenage Dream.” Teenage Dream. Capital, 2010. CD.

Kirsch, Gesa E., and Joy S. Ritchie. "Beyond the Personal: Theorizing a Politics of Location in Composition Research." College Composition and Communication 46.1 (1995): 7-29. JSTOR. Web. 9 June 2015.

kittylefish. “Any Time, Any Place.” The Petulant Poetess. 17 Sep. 2010. Web. 31 Oct. 2015. . Personal Interview. 24 June 2014. 
Knobel, Michele, and Colin Lankshear. "Remix: The Art and Craft of Endless Hybridization." Journal of Adolescent \& Adult Literacy. 52.1 (Sep., 2008): 22-33. Web. 2 Feb., 2012.

Kramsch, Claire. "Pierre Bourdieu: A Biographical Memoir.” Pierre Bourdieu and Literacy Education. Ed. James Allbright and Allan Luke. New York; London: Routledge, 2008. 50-67. Print.

Lady Hallen. An Avalanche. In Miss Potter. Fanfiction.net. 25 April 2014. Web. 1 Nov. 2015

Lave, Jean, and Etienne Wenger. Situated Learning: Legitimate Peripheral Participation. Cambridge, UK; New York: Cambridge UP, 1991. Print.

Leander, Kevin, and Gail Boldt. "Rereading 'A Pedagogy of Multiliteracies': Bodies, Texts, and Emergence." Journal of Literacy Research 45.1 (2013): 22-46. SAGE. Web. 25 June 2014.

“Leilani.” www.behindthename.com. n.p. n.d. Web. 1 Nov. 2015.

Lemke, Jay. "Multimodality, Identity, and Time.” The Routledge Handbook of Multimodal Analysis. Ed. Carey Jewitt. London and New York: Routledge, 2009. 140-150. Print.

Leonhard, Sam C. Personal Interview. 16 June 2014. . Tainted Blood. Dreamspinner Press, 2010. Kindle - ebook. . Tainted Soul. Dreamspinner Press, 2011. Kindle - ebook.

liloweewoah and babyxbxgurl. Fallin' For You. In WWE Fanfiction World. Fanfiction.net. 29 June 2010. Web. 1 Nov. 2015. 
liloweewoah. “Happy Father’s Day.” WWE Fanfiction World. Fanfiction.net. 21 June 2010. Web. 31 Oct. 2015. . Personal Interview. 20 Feb. 2015. . Profile. Fanfiction.net. Fanfiction.net. 10 Aug. 2004. Web. 1 Nov. 2015. . "She is Love.” WWE Fanfiction World. Fanfiction.net. 6 Jan. 2011. Web. 1 Nov. 2015.

. “Taking a Chance.” In WWE Fanfiction World. 13 Oct., 2010. Fanfiction.net. Web. 12 Dec., 2014.

LiveJournal.com Live Journal. 1999. Web. 30 Oct. 2015.

LoveToTheCucumber. Inches Away from You. On WWE Fanfiction World.

Fanfiction.net. 7 Jan. 2010. Web. 31 Oct. 2015.

Lu, Min-Zhan. “An Essay on the Work of Composition: Composing English against the Order of Fast Capitalism.” College Composition and Communication. 56.1 (2004): 16-50. JSTOR. Web. 13 Feb. 2013.

Lydon, Christopher. Interview with J.K. Rowling. WBUR Radio, October 1999. MacKinnon, Rebecca. Consent of the Networked: The Worldwide Struggle for Internet Freedom. New York: Basic Books, 2012. Print.

Macrorie, Ken. “Telling Writing.” The Norton Book of Composition Studies. Ed. Susan Miller. New York and London: W.W. Norton \& Company, 2009. 297-313. Print. Madshrubbery. Personal Interview. 29 Aug. 2014. . Personal Interivew. 8 Dec. 2014. . "Mitchell.” Dec. 2010. Print. . “Welcome to Midgetville.” Dec. 2009. Print. 
Matsuda, Paul Kei. "Second-Language Writing in the Twentieth Century: A Situated Historical Perspective.” Second-Language Writing in the Composition Classroom: A Critical Sourcebook. Ed. Paul Kei Matsuda, Michelle Cox, Jay Jordan, and Christina Ortmeier-Hooper. Boston; New York: Bedford/St. Martin’s, 2006. 14-30.

McGill, Meredith L. American Literature and the Culture of Reprinting 1834-1853. Philadelphia, PA: U of Pennsylvania P, 2003. Print.

McKee, Heidi. “Changing the Process of Institutional Review Board Compliance.” College Composition and Communication, 54.3 (2003): 488-493. JSTOR. 15 May 2015

. "Ethical and Legal Issues for Writing Researchers in an Age of Media Convergence." Computers and Composition 25 (2008): 104-122. Elsevier. Web. 21 April 2015.

McKee, Heidi, and James Porter. "The Ethics of Archival Research." College Composition and Communication 64.1 (2012): 59-81. CCCC. Web. 8 June 2015. The Ethics of Internet Research: A Rhetorical ,Case-Based Process. New York: Peter Lang, 2009. Print.

Metamuse. "Plagiarism." The Daily Prophet at Sycophant Hex. n.p. 28 Dec. 2004. Web. 5 March 2012.

Micciche, Laura. Doing Emotion: Rhetoric, Writing, Teaching. Portsmouth, NH: Boynton/Cook, 2007. Print.

Miss Potter. In www.fanfiction.net. Fanfiction.net. 26 July 2005. Web. 1 Nov. 2015. 
Mrs Bridget Orton. A Guy, A House and A Hot House Mate. On WWE Fanfiction World. Fanfiction.net. 15 July 2006. Web. 31 Oct. 2015.

Newkirk, Thomas. "Seduction and Betrayal in Qualitative Research." Ethics and Representation in Qualitative Studies of Literacy. Ed. Gesa E. Kirsch and Peter Mortenson. Urbana: NCTE, 1996. 3-16. Print.

New London Group. "A Pedagogy of Multiliteracies: Designing Social Futures." Harvard Educational Review. 66.1 (1996): 60-92. Print.

Peary, Alexandria. "Walls with a Word Count: The Textrooms of the Extracurriculum." College Composition and Communoication. 66.1 (2014): 43-66. Print.

Peckham, Irvin. Going North, Thinking West: The Intersections of Social Class, Critical Thinking, and Politicized Writing Instruction. Logan, Utah: Utah State UP, 2010. Print.

Penley, Constance. NASA/Trek: Popular Science and Sex in America. New York, NY: Verso, 1997. Print.

Plato. Gorgias. Trans. Joe Sachs. Newburyport, MA: Focus Publishing, 2009. Print.

Powell, Katrina M., and Pamela Takayoshi. "Accepting Roles Created for Us: The Ethics of Reciprocity." College Composition and Communication 54.3 (2003): 394-422. JSTOR. Web. 9 June 2015.

Price, Margaret. "Beyond 'Gotcha!': Situating Plagiarism in Policy and Pedagogy." College Composition and Communication. 54.1 (Sep., 2002): 88-115. Web. 10 March 2012. 
Prior, Paul et al. "Re-Situating and Re-Mediating the Canons: A Cultural-Historical Remapping of Rhetorical Activity, a Collaborative Core Text.” Kairos. n.d. Web. 5 Feb. 2015.

Room of Requirement. Sycophant Hex. n.p. n.d. Web. 2 Feb. 2012.

Rowling, J.K. Harry Potter and the Deathly Hallows. In J.K. Rowling, 2009. . Harry Potter and the Philosopher's Stone. In J.K. Rowling, 2009. . Harry Potter Paperback Box Set, 1-7. New York; London: Scholastic, 2009. Print.

. Pottermore. Pottermore Ltd, n.d. Web. 30 Oct. 2015. . The Hogwarts Library. New York; London: Scholastic, 2013. Print. . The Tales of Beedle the Bard. New York; London: Children’s High Level Group, 2008. Print.

Scodari, Christine, and Jenna L. Felder. “Creating a Pocket Universe: ‘Shippers,' Fan Fiction, and the X-Files Online.” Communication Studies 51.3 (2000): 238-257. ProQuest. Web. 3 March 2015.

Scodari, Christine. Serial Monogamy: Soap Opera, Lifespan, and the Gendered Politics of Fantasy. Creskill, NJ: Hampton, 2004. Print.

Sharp, Bree. "David Duchovny.” A Cheap and Evil Girl. Trauma Records, 1999. CD. Shaughnessy, Mina P. Errors and Expectations. New York: Oxford U.P., 1977. Print. Sheridan, Mary P. and Jennifer Rowsell. “'Fearless Creativity’: Participation Structures and Sponsorship in Dense Media Networks.” Design Literacies: Learning and Innovation in the Digital Age. London: Routledge, 2010. 43-71. Print. 
Silva, Tony. "On the Ethical Treatment of ESL Writers.” Second-Language Writing in the Composition Classroom: A Critical Sourcebook. Ed. Paul Kei Matsuda, Michelle Cox, Jay Jordan, and Christina Ortmeier-Hooper. Boston; New York: Bedford/St. Martin’s, 2006. 154-158. Print.

"Sleepless.” The X-Files. Writ. Chris Carter and Howard Gordon. Dir. Rob Bowman. 20 Century Fox Television, 1994. Television.

Smith, Sean. J.K. Rowling: The Genius Behind Harry Potter. London: Arrow, 2002. Print.

Star Trek. Creator Gene Roddenberry. Perf. William Shatner, Leonard Nimoy, DeForest Kelly, George Takei. Paramount, 1966-1969. Television series.

Sycophant Hex. n.p. 2003-2006. Web. 20 Dec., 2011.

"Sycophant Hex Submission Rules." Sycophant Hex. n.p. 3 April 2010. Web. 2 Feb. 2012.

“Talitha Cumi.” The X-Files. Writ. Chris Carter and David Duchovny. Dir. R.W. Goodwin. $20^{\text {th }}$ Century Fox Television, 1996. Television.

"Terms of Service." Sycophant Hex. n.p. April 2010. Web. 16 Jan., 2012.

The Fall. Writ and Dir. Allan Cubitt. Perf. Gillian Anderson, Jamie Dornan, John Lynch, Bronagh Waugh, and Niamh McGrady. BBC Northern Ireland, 2013-Present. Television.

The Jerry Springer Show. Starring Jerry Springer. NBC, 1991-Present.Television. The Last of the Mohicans. Dir. Michael Mann. Perf. Daniel Day Lewis, Madeleine Stowe, Russell Means, and Eric Schweig. 20 ${ }^{\text {th }}$ Century Fox, 1992. Film. 
“The Middle Earth Paradigm.” The Big Bang Theory. Writ. Chuck Lorre, Bill Prady, David Litt, Robert Cohen, and David Goetsch. Dir. Mark Cendrowski. Warner Brothers, 2007. Television.

The Petulant Poetess. n.p. n.d. Web. 2 February 2012.

The X-Files. Writ. Chris Carter. Dir. Chris Carter. Perf. Gillian Anderson and David

Duchovny. Twentieth Century Fox. 1993-2002. Television Series.

The X-Files. Dir. Rob Bowman. Perf. Gillian Anderson, David Duchovny, William B.

Davis, and Mitch Pileggi. Twentieth Century Fox, 1998. Film

The X-Files Ball of Wrong Porn Battle. Live Journal. Oct. 2009. Web. 31 Oct. 2015.

The X-Files: I Want to Believe. Dir. Chris Carter. Perf. Gillian Anderson, David

Duchovny, and Mitch Pileggi. Twentieth Century Fox, 2008. Film.

The X-Files Wiki. Wikia. n.d. Web. 31 Oct. 2015.

Tolkien, J.R.R. The Hobbit. $75^{\text {th }}$ Anniversary Ed. New York: Houghton Mifflin Harcourt, 2012. Print. . The Lord of the Rings. $50^{\text {th }}$ Anniversary, One Volume Ed. New York: Mariner Books, 2005. Print.

Tumblr. n.p. n.d. Web. 31 Oct. 2015.

Tushnet, Rebecca. "Copyright Law, Fan Practices, and the Rights of the Author." Fandom: Identities and Communities in a Mediated World. Jonathan Gray, Cornel Sandvoss, and C. Lee Harrington, eds. New York; London: New York UP, 2007. 60-74. Print. 
United States. The National Commission for the Protection of Human Subjects of Biomedical and Behavioral Research. The Belmont Report, 1979. (DHHS Publication No. 45 CFR 46) www.hhs.gov. Web. 6 Sep. 2015.

Valis2. "Avoiding Mistakes in Fanfiction Writing: A Beginner's Guide." SycophantHex Writing Fanfiction. n.d. Web. 2 Feb., 2012.

Van Tooke, R.P. "Students Explore Erotica in Fan Fiction DeCal at UC Berkeley.” The Daily Californian. 13 Feb. 2015. Web. 5 March 2015.

Wajcman, Judy. TechnoFeminism. Cambridge; Malden, MA: Polity, 2004. Print.

Waldorph. "So Your Fic is Required Reading: Hahahanope.” Tumblr. 22 Feb. 2015. Web. 5 March 2015.

Warnick, Barbara. Rhetoric Online: Persuasion and Politics on the World Wide Web. New York: Peter Lang, 2007. Print.

Waters, Darren. “Rowling Backs Potter Fan Fiction.” BBC News UK. BBC. 27 May 2004. Web. 30 Oct. 2015.

Wetherell, Margaret. Affect and Emotion: A New Social Science Understanding. Los Angeles; London: Sage, 2012. Print.

Williams, Bronwyn T., and Mary Brydon-Miller. "Ethics and representation." SAGE Handbook of Dissertations and Theses. Ed. Richard Andrews et al. Los Angeles and London: Sage, 2012. 181-197. Print.

Williams, Bronwyn T. Shimmering Literacies: Popular Culture and Reading and Writing Online. New York: Peter Lang, 2009. Print.

Williams, Bronwyn, and Amy Zenger, eds. New Media Literacies and Participatory Popular Culture Across Borders. New York; London: Routledge, 2012. Print. 
WWE: Fanfiction World. At Fanfiction.net. n.p. n.d. Web. 30 Oct. 2015

WWE Network. WWE. 2015. Web. 31 Oct. 2015.

WWE World Wrestling Entertainment. On Answers.com. Answers. n.d. Web. 17 Nov. 2015.

WWF Raw. Created Vince McMahon. USA Network, 1993-Present. Television.

X-Files: The Online Community. At Livejournal.com Live Journal. 30 Oct. 2015. Web. 30 Oct. 2015.

Yancey, Kathleen Blake. "Made Not Only in Words: Composition in a New Key." College Composition and Communication. 56.2 (2004): 297-328. JSTOR. Web. 2 Feb. 2013.

Yoffe, Emily. “Bedtime Stories: Prudie Advices a Letter Writer Whose 13-year-old Daughter Reads Pornographic Fan Fiction.” Dear Prudence on Slate. The Slate Group. 8 Sep. 2014. Web. 30 Oct. 2015. 


\section{APPENDIX I}

\section{THE PARTICIPANTS AND METHODS OF GATHERING DATA}

\section{The Study - Methods:}

This study makes use of mixed qualitative methods from an ethnographic perspective. As I stated in chapter 2, what I mean to suggest by "ethnographic perspective" is doing research from an emic, or participant-based point of view. I conducted the study as a participant-observer, openly identifying as both a fan and scholar (see Figure 1 below, and an analysis of the profile document in chapter 2). I collected texts, including fanfiction stories, author notes, and posted messages stating website rules or advice for writing fanfiction. I discuss how I chose certain texts in chapter 2, but suffice it to say here, that I conducted textual analysis only on texts that were considered public by the online fanfiction communities I studied (see Figure 2 below for a specific breakdown of participant numbers).

In addition, I conducted questionnaires and interviews with 7 participants, and more in-depth case studies with 3 participants. For a copy of the questionnaire, see Appendix II. For a copy of the interview questions, see Appendix III. Note that 3 out of the 7 total participants agreed to engage in detailed case studies, which triangulated their written work, their questionnaires, and interview answers, as well as their online profiles.

\section{Figure 1 - Recruitment Profile and Recruitment Email}

\section{Profile:}

Hi! My penname is PhoenixSongFalling, and I've been a Harry Potter fan since I was 15 years old. I first discovered fanfiction during my junior year of college in 2007. I had just finished reading through the whole series (for the third time), and I was chomping at the bit for the seventh book to come out that next summer. Needless to say, I got hooked on fanfiction. I loved all kinds of pairings, but especially Harry and Draco, and, to my surprise, Hermione and Severus. I loved dystopian, "Voldemort wins" stories, and fluffy, romantic stories, and Time Turner stories. I lurked for a long time. I then started writing my own fanfiction story about Severus Snape, an original character, and a Time Turner accident - The Unfortunate Incident. I'm embarrassed to say that I haven't finished it yet, but I hope to do so soon (when I have more time for creative writing).

I also love Doctor Who, Firefly, Buffy the Vampire Slayer, and games like Dungeons and Dragons and Mansions of Madness.

So, I'm here as a fellow fan, and still developing fanwriter. 
But I'm also here as a researcher. My academic alter ego also really loves fanfiction. My name is Brittany Kelley, and I am currently working on a $\mathrm{PhD}$ in English at the University of Louisville. I am most interested in researching how people write in different kinds of spaces - school v. personal v. work v. online, etc. I'm really interested in researching fanfiction for a number of reasons. First and foremost, reading and writing fanfiction in college was what brought me back to my first love - storytelling. Really, discovering fanfiction provided me solace as I completed a degree program I realized I wasn't passionate about (Linguistics), and what inspired me to get a degree in English. But I'm also interested in it because fanfiction is, well, really fascinating to me. How I think about myself as a writer, and how I think about what good, supportive writing communities can look like, is heavily influenced by my engagement with fanwriting.

So, while I am on this website, I will be reading fics, trying to write some of my own, and I will be doing research. This research will include collecting data about fanwriters' demographics (through questionnaires), but it will also include looking closely at fanfics, reader reviews, and forum discussions. I will never quote anyone's review and discussion forum comments without gaining permission first. Eventually, I'd also really love to do interviews with some fellow fanwriters.

If you have any questions, comments, concerns, etc., feel free to email me at bnkelley86@gmail.com. You can also check out my blog, "My Textual Romance: Fanfic, Cyborgs, and Stumbling into the Digital” at bnkelley86.wordpress.com!

\section{Email: \\ Dear (participant's penname),}

My fanficcer name is PhoenixSongFalling. I've been a long-time fan and fanwriter, and I've read $a$ lot of fanfiction. I'm also a researcher. My real name is Brittany Kelley, and I am a PhD student at the University of Louisville in Louisville, Kentucky. My direct supervisor for this project is Dr. Bronwyn Williams, who is in the English Department at my university. I am currently working on a dissertation project about fanfic. I am especially interested in learning more about how fanficcers read, write, and communicate about their favorite pop-culture and fan-made stuff. I'm a writer and a writing teacher, and I am really interested in learning about how reading and writing is learned and used in places outside of school. Since I've been a fanfic fan for a long time, I think that fanfic is a great place to learn about the awesome reading and writing that happens outside of school.

I'm emailing you because I'm really interested in the fanwork that you do, and I'd like to talk to you more about it. (Here, there would likely be a specific message about wanting to use/ask the participant for the following:

- To use \& quote the fan's reader review or discussion forum comment

- To ask the fan to answer a confidential questionnaire

- To ask the fan to participate in an interview

- To ask the fan to participate in a narrowed case study) 
I have attached the official IRB consent form to this email. If you have any questions about the project, you may contact my direct supervisor, Dr. Bronwyn Williams, by emailing him at bronwyn.williams@louisville.edu or by calling his office phone number at 1-502-852-2173. And, if you have any questions about me or for me, you can visit my fan profiles at Fanfiction.net or SycophantHex.com under the name PhoenixSongFalling. To see my academic self, you can visit my Wordpress blog at bnkelley86@wordpress.com - it’s titled, My Textual Romance: Fanfic, Cyborgs, and Stumbling into the Digital. Also, feel free to email me back at bnkelley86@gmail.com, or to send me a text or call me at 1-505-270-0250. (I'm on eastern time in the United States).

Figure 2 - Participant/Community Demographics

\begin{tabular}{|c|c|c|c|}
\hline Fandom & Website & Community or “C2" & Participants \\
\hline \multirow[t]{4}{*}{ Harry Potter } & $\begin{array}{l}\text { Sycophanthex.com: A } \\
\text { small, fanfiction } \\
\text { website dedicated } \\
\text { almost solely to Harry } \\
\text { Potter fanfiction (see } \\
\text { Chapters } 3 \text { and 4) }\end{array}$ & $\begin{array}{l}\text { Ashwinder: A } \\
\text { community dedicated } \\
\text { to Hermione Granger- } \\
\text { Severus Snape pairing }\end{array}$ & $\begin{array}{l}2 \\
\text { (Chivalric and kittylefish) }\end{array}$ \\
\hline & $\begin{array}{l}\text { The Petulant Poetess: } \\
\text { Another small, } \\
\text { fanfiction website for } \\
\text { multiple universes, } \\
\text { but many of these } \\
\text { stories are Harry } \\
\text { Potter-related }\end{array}$ & N/A & $\begin{array}{l}2 \\
\text { (Chivalric and kittylefish) }\end{array}$ \\
\hline & $\begin{array}{l}\text { Fanfiction.net: A } \\
\text { large fanfiction } \\
\text { website hosting } \\
\text { multiple fandoms }\end{array}$ & $\begin{array}{l}\text { Miss Potter: A small } \\
\text { fanfiction community } \\
\text { dedicated to } \\
\text { Femme!Harry stories } \\
\text { (or stories where Harry } \\
\text { Potter is reimagined as } \\
\text { a female/woman). } \\
\text { Followers: } \mathbf{6 8 3} \\
\text { Stories: } \mathbf{1 , 4 2 8}\end{array}$ & $\begin{array}{l}1 \\
\text { (Lady Hallen) }\end{array}$ \\
\hline & & $\begin{array}{l}\text { Harry and Draco's } \\
\text { Love Shack: A small } \\
\text { fanfiction } \\
\text { communicated } \\
\text { dedicated to Harry and } \\
\text { Draco slash stories. } \\
\text { Followers: } \mathbf{1 , 9 4 3} \\
\text { Stories: } \mathbf{6 8 2}\end{array}$ & 0 \\
\hline $\begin{array}{l}\text { WWE (World } \\
\text { Wrestling } \\
\text { Entertainment) }\end{array}$ & Fanfiction.net & $\begin{array}{l}\text { WWE Fanfiction } \\
\text { World: A small } \\
\text { fanfiction community } \\
\text { dedicated to } W W E- \\
\text { related stories (mostly }\end{array}$ & $\begin{array}{l}3 \\
\text { (Liloweewoah, babyxbxgurl, and } \\
\text { LoveToTheCucumber) }\end{array}$ \\
\hline
\end{tabular}




\begin{tabular}{|c|c|c|c|}
\hline & & $\begin{array}{l}\text { heteronormative, } \\
\text { though a couple of } \\
\text { slash stories). } \\
\text { Followers: } \mathbf{6 4} \\
\text { Stories: } \mathbf{9 8}\end{array}$ & \\
\hline The X-Files & $\begin{array}{l}\text { LiveJournal.com: } \\
\text { This is actually a } \\
\text { personal blogging } \\
\text { website, but it also } \\
\text { hosts a great deal of } \\
\text { fanfiction activity. }\end{array}$ & $\begin{array}{l}\text { The X-Files: The } \\
\text { Online Community: } \\
\text { This is a smaller } \\
\text { community within Live } \\
\text { Journal that is } \\
\text { dedicated entirely not } \\
\text { only to X-Files fans, } \\
\text { but fans of David } \\
\text { Duchovny and Gillian } \\
\text { Anderson (the actors } \\
\text { who played Fox } \\
\text { Mulder and Dana } \\
\text { Scully, respectively). } \\
\text { Followers: N/A } \\
\text { Posts: N/A }\end{array}$ & $\begin{array}{l}1 \\
\text { (Madshrubbery) }\end{array}$ \\
\hline & & $\begin{array}{l}\text { The X-Files Ball of } \\
\text { Wrong Porn Battle: } \\
\text { This is a subset of the } \\
\text { porn battle community } \\
\text { at Live Journal. It } \\
\text { hosts a particular porn } \\
\text { battle that occurred in } \\
\text { 2009. It includes a } \\
\text { general call for any } \\
\text { pairing (Scully and } \\
\text { Mulder; Mulder and } \\
\text { Krycek, etc.). } \\
\text { Followers: N/A } \\
\text { Posts: } \mathbf{3 1 2}\end{array}$ & $\begin{array}{l}1 \\
\text { (Madshrubbery }\end{array}$ \\
\hline $\begin{array}{l}\text { Total } \\
\text { Fandoms: } 3\end{array}$ & Total Websites: 4 & Total C2s: 7 & Total Participants: 7 \\
\hline
\end{tabular}




\section{APPENDIX II \\ THE QUESTIONNAIRE}

The Questionnaire - Planning: In this study, I wanted to triangulate primary texts (stories, "how-to" guides, etc.) with information about fanwriters' material realities, as well as information about their personal histories of engagement with fanfiction. The questionnaire was developed in order to address elements of fanwriters' material realities, in an attempt to get a view of how class (as well as gender, sexuality, nationality, language, race, etc.) might be interacting with these writers' writerly identities, their favored fandoms, and their fan work. In addition, this questionnaire was meant to "break the research ice,” as it were. It includes 26 questions, some of which are multiple choice, and some of which are short answer. See the full questionnaire below in Figure 1. Only 6 of the 7 participants completed the questionnaire. (Note that 5 of the 7 total participants are not United States citizens. In these cases, I had to adjust my questions regarding education. I have included those adjustments in Figure 2).

\section{Figure 1: The Questionnaire}

1. What is your name?

2. What is your fanfiction penname?

3. Briefly, can you describe why you chose this penname?

4. How old are you? (Please choose one)

- Below 18

- $18-25$

- 25-39

- 30-39

- 40-49

- $50-59$

- 60-69

- $70+$

5. How do you identify in terms of gender? (Please choose one or specify)

- Man

- Woman

- Trans-man

- Trans-woman

- Other:

6. How do you identify in terms of sexuality? (Please choose one or specify)

- Straight

- Gay

- Lesbian 
- Bisexual

- Queer

- Asexual

- Other:

7. How do you identify in terms of nationality? (Please explain briefly):

8. What language(s) do you speak?:

9. Do you live in:

- A rural area?

- A suburban area?

- Urban area?

- Other:

10. Do you rent property or own property? Rent / Own

11. Please briefly describe the property in which you live:

12. Please briefly describe your neighborhood:

13. What level of education have you completed?

- Some high school

- High school diploma

- GED

- Some college

- Associate's degree

- Bachelor's degree

- Master's degree

- Terminal degree: PhD, MFA, MD, etc.

- Other:

14. What level of education has your mother completed?

- Some high school

- High school diploma

- GED

- Some college

- Associate's degree

- Bachelor's degree

- Master's degree

- Terminal degree: PhD, MFA, MD, etc.

- Other:

15. What level of education has your father completed?

- Some high school

- High school diploma

- GED

- Some college

- Associate’s degree 
- Bachelor's degree

- Master's degree

- Terminal degree: PhD, MFA, MD, etc.

- Other:

16. Are you currently in school? Y/N

17. What level of school are you in?

- Finishing high school

- College

- Professional/Graduate school

18. Do you have any student loan debt?: Yes / No

19. What is your occupation:

20. Do you work mostly in an office or from home? (If other, please specify.)

21. On average, how many hours per week do you work?

- $0-10$

- $10-20$

- 20-35

- $35-40$

- $40+$

22. On average, how often do you have to take work home (if you do not already work from home)?

- Never

- Sometimes

- Often

- Almost always

23. If so, how many hours of work do you take home per night (on average)?

- Less than one hour

- One hour

- $1-2$ hours

- 2-3 hours

- More than 3 hours

24. Do you own your own computer? Y/N

25. What kind of computer is it?

- Desktop

- Laptop

- Tablet

- Smartphone

- MAC

- PC 
26. On which device(s) do you compose the most?

27. If you do not own your own computer, how do you get access to a computer?

- Family member

- Friend

- Cyber Café

- Public library

- School computer lab

- Other:

28. How many hours per day do you spend on the computer?

- $0-1$

- $1-5$

- 5-10

- $10+$

29. How many hours a day do you spend reading/writing/participating in fanfiction?

- $0-1$

- $1-2$

- $2-5$

- 5-8

- 8-10

- $10+$

\section{Figure 2: Adjustments to Education Questions for International Participants}

1. What level of education have you completed?

- Completed education before 16 years old. Please specify:

- Completed education to 16 years old

- High school diploma (completed education to 18 years old)

- Some university

- University degree

- Advanced degree (to become a doctor, lawyer, etc.)

- Other:

2. What level of education has your mother completed?

- Completed education before 16 years old. Please specify:

- Completed education to 16 years old

- High school diploma (completed education to 18 years old)

- Some university

- University degree

- Advanced degree (to become a doctor, lawyer, etc.)

- Other: 
3. What level of education has your father completed?

- Completed education before 16 years old. Please specify:

- Completed education to 16 years old

- High school diploma (completed education to 18 years old)

- Some university

- University degree

- Advanced degree (to become a doctor, lawyer, etc.)

- Other:

4. Are you currently in school? Y/N

5. What level of school are you in?

- Finishing high school (education to 18 years old)

- University

- Professional/Graduate school

6. Do you have any student-related debt?: Yes / No 


\section{APPENDIX III: THE INTERVIEW}

Interview Methods: I did not conduct interviews with all participants. Only some were interested in engaging in the full interview (as is represented in the base set of questions below) — only 5 of the 7 participants engaged in interviews. (Only 3 of the total 7 participants agreed to participate in detailed case studies.) Only one interview took place over Skype; we conducted an audiovisual interview, and I recorded audio from this interview. It lasted 45 minutes. All other interviews (5) were conducted via email exchanges, as this is what participants preferred. Unlike the questionnaires, interviews were meant to get at participants' histories with fanfiction and their current engagement with online fanfiction activities, as well as other writing activities, as applicable. I have included only the base questions below, but note that questions were adjusted based on questionnaire responses and stories participants had written.

\section{The Interview Questions:}

1. When did you first discover fanfiction?

2. What was that experience like for you? Why?

3. When did you decide to start writing your own fics?

4. Please tell me about the first fic you wrote? What was it about? How long did it take you to write? Did you find and work with a beta reader (or more than one)? Etc.

5. How often do you take time to read fics, and what kinds of fics do you like to read? Why?

6. How often do you write a fic? Why?

7. What kinds of fics do you like to write? Why?

8. What process do you go through to write your fics? How long does it take you to complete them, on average? Why?

9. Why do you write fanfiction? 


\section{CURRICULUM VITA}

NAME: Brittany Kelley

ADDRESS: Department of English

315 Bingham Humanities

2211 S. Brook St.

Louisville, KY 40292

DOB: Terre Haute, Indiana - January 12, 1986

\section{Education}

PhD Rhetoric and Composition, University of Louisville Expected 2016

Dissertation: To My Betas, Endless Chocolate Frogs!: Exploring the Intersections of Emotion, the Body, and Literacy in Online Fanfiction Committee: Dr. Bronwyn T. Williams (Director), Dr. Mary P. Sheridan, Dr. Karen Kopelson, Dr. Susan Ryan, Dr. Dawn Heinecken

MA Rhetoric and Writing, University of New Mexico - 2011

Portfolio: These Are My Words, My Voice: Grammars, Error, and Engaged Writing

Committee: Dr. Scott Sanders (Chair), Dr. Wanda Martin, Dr. Charles Paine

BA Linguistics, Boston University - 2008

Magna cum Laude

\section{Publications}

Chocolate Frogs for My Betas!: Literacy Practices at One Online Fanfiction Website

Computers and Composition | In Press

\section{Works Under Review}

\section{Methods}

Never "Power sans Risk": Towards a Goodwill Ethics of Online Research

Journal of Literacy Research | Under Review 


\section{Conference Presentations}

PWP, Fluffy Pr0n, “Lots of Lemons!": Emotion, the Body, and the Scandalous in Online Fanfiction"

PCA/ACA | New Orleans, Louisiana | April 2015 Research

“Low” Risk / “Big” Reward?: Towards a Goodwill Ethics of Online

Conference on College Composition and Communication | Tampa, Florida | March 2015

An Ethics of Goodwill: Online Research Methodology as Responsivity

Thomas R. Watson Conference | Louisville, Kentucky | October 2014

"Flamers Not Welcome": Examining the Place of Class in Online Fanfiction Practices

Research Network Forum at CCCC | Indianapolis, Indiana | March 2014

The (Re)Legislation of Women as (Re)Productive Citizens

National Women Studies Association | Cincinnati, Ohio | November 2013

the

Hermione Granger is *my* beta: Affective Economies, Heteroglossia, and

Pedagogical Potential of Online Harry Potter Fanfiction

Conference on College Composition and Communication | Las Vegas, Nevada | March

2013

"Not mine, just borrowing": Economies of Authorship in Online Fanfiction Communities

Thomas R. Watson Conference | Louisville, Kentucky | October 2012

"Not mine, just borrowing": Language, Literacy, and Authorship in Online Fanfiction Communities

Writing the World Symposium | Albuquerque, New Mexico | April 2012

Thinking Together about the Genre-Based Approach

Working with Writers: Recognizing Diverse Discourses| Albuquerque, New Mexico | 23

March 2011

Exploring Genre through Language

Western States Rhetoric and Literacy Conference| Las Cruces, New Mexico | 22

Oct.

2010 


\section{Exploration, Play, and Codeswitching: Better Student Engagement for a Better Transfer of Skills \\ Success in the Classroom: Sharing Practices that Work | Albuquerque, New Mexico 17}

Feb. 2010

Marie de France: Loss and Innovation in her Lais

Medieval Studies Student Association Colloquium | Albuquerque, New Mexico | 13 Nov.

2009

\section{Teaching and Writing Center Experience}

Graduate Teaching Assistant (Instructor of Record)

University of Louisville | June 2012 - May 2016

Courses:

- English 101: Introduction to College Writing

- English 102: Intermediate College Writing

- English 306: Business Writing

Supervisor: Dr. James Romesburg, Acting Director of Composition | Aug. 2013-

May 2014

Dr. Brenda Brueggemann, Director of Composition | June

2014-

Present

Graduate Teaching Assistant (Instructor of Record)

University of New Mexico | Aug. 2009 - May 2011

Courses:

- English 101: Exposition

- English 101: Exposition-ESL section

- English 102: Analysis and Argument

- English 220: Expository Writing--"Writing with 'The Man"'

Supervisor: Dr. Wanda Martin, Director of Composition | Aug. 2009 - July 2010

Dr. Scott Sanders, Director of Composition | Aug. 2010 - May 2011

University Writing Center Writing Consultant

University of Louisville | May 2014, May 2015

Worked with two doctoral students on their dissertations during the week-long

Dissertation Writing Retreat, two years in row. 
Supervisor: Dr. Bronwyn T. Williams, Director of the University Writing Center

\section{Administrative Positions}

Assistant Director of Composition

University of Louisville | Aug. 2013-May 2014

Routine Duties Included:

- Mentored new GTAs

- Prepared materials for New Teacher Orientation

- Prepared materials for GTA Pedagogy Course, ENGL 602

- Addressed student and teacher complaints

- Met with publishing company representatives

Special Projects Included:

- Planned and facilitated Pedagogy Workshop series

- Assisted and facilitated annual Symposium on Student Writing

- Prepared materials for Symposium on Student Writing student presentation awards

- Prepared materials for common textbook, U of L edition of The Everyday Writer

Supervisor: Dr. Brenda Brueggemann, Director of Composition

Writing Across Communities - Working with Writers Symposium Chair University of New Mexico | Aug. 2010-May 2011

- Co-founded Graduate Student Conference to discuss Multilingual Students

- Chaired the steering committee

- Prepared marketing materials and departmental reports for the conference

- Contacted conference participants, including Keynote speakers Communities

Supervisor: Dr. Michelle Hall Kells, Faculty Advisor for Writing Across

Graduate Assistant - Multilingual Writer Mentor

University of New Mexico | Aug. 2010 - May 2011

Routine Duties Included:

- Prepared materials for the new GTA Orientation 
- Prepared materials for GTA pedagogy course

- Mentored new and returning GTAs and PTLs

Special Projects Included:

- Researched multilingual population in the Core Writing Program

- Prepared departmental report on MLW student population

- Prepared a Department Wiki for GTAs to discuss MLW questions

- Prepared resource links for multilingual students, and Department instructors

Supervisor: Dr. Scott Sanders, Director Core Writing

\section{Departmental Reports and Marketing Materials}

Recognizing Diverse Communities in Classroom Contexts and Beyond: First Annual Working with Writers Symposium

Within: Writing Communities | Writing Across Communities Newsletter, Inaugural Issue

February 2011

Supervisors: Michelle Hall Kells, Faculty Advisor of Writing Across Communities

Erin Penner Gallegos, 2010-2011 WAC Events Coordinator

Working with Writers: Recognizing Diverse Discourses--Final Report to

WAC Partners

8 April 2011

Supervisor: Michelle Hall Kells, Faculty Advisor of Writing Across Communities

Core Writing and Multilingual Writers

May 2011

Supervisor: Scott Sanders, Director of Composition | Aug. 2009 - May 2011

\section{Service}

No Dissertation without Self-Care and Self-Advocacy

University of Louisville University Writing Center Blog | 2 June 2014

Supervisor: Dr. Bronwyn T. Williams, Writing Center Director

Working with Student Veterans

University of Louisville Pedagogy Workshop Series | Louisville, Kentucky | 2 April 2014

Graduate Student Peer Mentor 
University of Louisville | Spring 2012 and Spring 2013

Mentored prospective and incoming doctoral students. Addressed students' questions about the program, teaching at the University of Louisville, and living in Louisville. Both of my mentees did decide to attend the University of Louisville.

Write On! Workshop

University of New Mexico | Dec. 2009 - May 2011

Tutored a variety of writers in preparing their final projects for core writing.

Supervisors: Dr. Michelle Hall Kells, Writing Across Communities Faculty Advisor

Rick Raab-Faber, Graduate Student Chair of WoW

\section{Awards and Honors}

University of Louisville Graduate Fellowship

Aug. 2011 - May 2012, June 2013 - May 2014

Best Emerging Instructor

University of New Mexico English Department | May 2010 